UNIVERSIDADE DE SÃO PAULO

INSTITUTO DE PSICOLOGIA

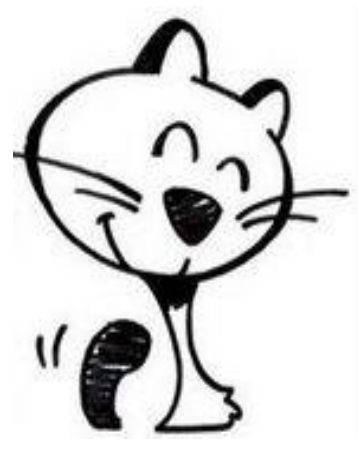

FABIANA VIEIRA GAUY

\title{
Treino de Terapeutas-Estagiários no Atendimento de Crianças Ansiosas
}




\title{
Treino de Terapeutas-Estagiários no Atendimento de Crianças Ansiosas
}

\author{
Tese apresentada ao Instituto de \\ Psicologia da Universidade de São \\ Paulo como parte dos requisitos para \\ obtenção do grau de Doutor em \\ Psicologia. \\ Área de concentração: Psicologia \\ Clínica \\ Orientadora: $\operatorname{Prof}^{\mathrm{a}} \operatorname{Dr}^{\mathrm{a}}$ Edwiges \\ Ferreira de Mattos Silvares
}


Autorizo a reprodução e divulgação total ou parcial deste trabalho, por qualquer meio convencional ou eletrônico, desde que citada a fonte.

Catalogação na publicação

Biblioteca Dante Moreira Leite

Instituto de Psicologia da Universidade de São Paulo

Gauy, Fabiana Vieira.

Treino de Terapeutas-Estagiários no Atendimento de Crianças Ansiosas / Fabiana

Vieira Gauy; orientadora Edwiges Ferreira de Mattos Silvares. -- São Paulo, 2011.

$249 \mathrm{f}$.

Tese (Doutorado - Programa de Pós-Graduação em Psicologia. Área de Concentração: Psicologia Clínica) - Instituto de Psicologia da Universidade de São Paulo.

1. Treinamento 2. Estágio 3. Terapia cognitivo-comportamental 4. Ansiedade 5.Criança I. Título.

RC569.5.E5 
Nome: Gauy, F. V.

Título: Terapeutas-Estagiários no Atendimento de Crianças Ansiosas

Tese apresentada ao Instituto de Psicologia da Universidade de São Paulo para obtenção do título de Doutor em Psicologia

Aprovado em:

\section{BANCA EXAMINADORA}

Prof $^{\mathrm{a}} \mathrm{Dr}^{\mathrm{a}}$ Edwiges Ferreira de Mattos Silvares

Universidade de São Paulo - Instituto de Psicologia

Assinatura:

Prof ${ }^{a}$ Dr $^{\mathrm{a}}$ Márcia Melo Bertolla

Universidade de São Paulo - Instituto de Psicologia

Assinatura:

Prof. Dr. Francisco Lotufo Neto

Universidade de São Paulo - Instituto de Psiquiatria

Assinatura:

Prof. Dr. Fernando Asbahr

Universidade de São Paulo - Instituto de Psiquiatria

Assinatura:

Prof. Dr. Bernard Pimentel Rangé

Universidade Federal do Rio de Janeiro - Faculdade de Psicologia

Assinatura: 
$\because$ Gafo

Corajoso

Dedico este trabalho aos alunos estagiários que estiveram comigo nesta jornada. 


\section{Agradecimentos}

Aos alunos estagiários Adriano, Clayton, Cris, Deyse, Eliane, Flávia, Gabi, Laura, Lú, Nati, Rafa, Renata e Ricardo, pela dedicação, pelas risadas e pela ansiedade e angústia compartilhadas! Fomos um grande TIME CORAJOSO!

À Profa Vivi pelo modelo de profissionalismo, por me provocar, por me incentivar, pelo carinho, pelos abraços, por me motivar a ir atrás dos meus desejos (de toda natureza), pelas preciosas orientações e dicas e por me oferecer grandes oportunidades profissionais e pessoais.

Ao Prof Bernard, que há muito tempo acompanha minha trajetória profissional, sempre que precisei me orientou para caminhos que diferenciaram o meu trabalho.

Ao Prof Fernando, que abriu de forma muito generosa $\sigma$ seu ambulatório para mim e para os alunos, que me deu dicas na composição da amostra e que compartilhou comigo o GATO CORAJOSO, essencial para este trabalho.

Ao Prof Lotufo Neto, que não sei nem como agradecer o cuidado com que sempre me tratou, desde quando nos conhecemos, por compartilhar comigo a responsabilidade deste trabalho junto ao HC e por abrir as portas para mim e para os alunos. Sua participação foi essencial para execução deste trabalho no IPQ!

Aos profissionais do AMBULANSIA, em especial à Carol, que me ajudou na seleção dos participantes deste estudo e à Lilian, Eunice e Rosa, pelo cuidado e disponibilidade em ajudar.

À Profa Márcia, que me arrebatou com sua simplicidade, dedicação e carinho e que, junto da Profa Sheila, fica me incitando a disseminar os meus conhecimentos na academia. Vocês duas são parceiras maravilhosas!

À Carol Lẽ̃o, coordenadora do NAT, que se tornou uma grande amiga e que se encorajou e se encantou pelo Projeto Gato Corajoso. Sem a sua ajuda não teria sido possivel executar o trabalho no DF. 
A equipe do NAT, principalmente a Márcia, Fatinha e Fátima, que me ajudaram na logistica do treinamento.

A minha querida amiga Marina, que foi, junto com a Márcia e a Carol, $\sigma$ maior presente que levo desta empreitada. Obrigada pelos queijos, pela comida indiana, pela cama, pelo acothimento, pelos almoços, pelas caronas, pelas longas conversas e pelos favores... grandes favores... Obrigada mesmo!

Ao Rodrigo, pela suas ajudas e pelo especial esforço em me fazer entender $\sigma$ indice de mudança confiável.

A Cláudia e Cicera, do Departamento do Instituto de Psicologia, pela incrível disponibilidade e preocupação em ajudar os alunos.

A Thais, minha estimada amiga há quase 25 anos, por dividir comigo as suas dores, que não foram poucas nem pequenas, $\sigma$ seu teto, a sua sopa $e$ os seus vinhos. Obrigada pelas conversas e pelas adoráveis teorias sobre a vida...

A minha querida familia, minha mãe, meu pai, meus irmãos e minhas lindas sobrinhas, pela compreensão da minha distância e pela torcida. Sei que às vezes vocês acharam que a distância e $\sigma$ sacrificio eram grandes, mas continuavam torcendo simplesmente por que me amam.

Ao meu amor, Leo, que está a meu lado há quase dez anos, e que me instigou a fazer $\sigma$ doutorado, apesar de saber dos riscos que estava correndo... Por me apoiar nas minhas decisões, pelos nossos sonhos, por me abraçar forte nos mens momentos de insanidade transitória, por sempre se preocupar em facilitar a minha vida, pelas leituras dedicadas do meu trabalho. O nosso amor faz a minha vida ser mais gostosa!

Aos juizes deste trabalho pela preciosa ajuda em avaliar os alunos. Sei $\sigma$ que trabalho não foi pequeno!

À Fundação de Amparo à Pesquisa do Estado de São Paulo, pela concessão da bolsa de doutorado e pelo apoio financeiro essencial para a realização desta pesquisa.

Teria sido muito menos divertido e muito mais árduo sem a ajuda de vocês... 


\section{Resumo}

Estudos em serviços-escola de psicologia questionam o quanto o modelo vigente atende adequadamente à clientela infantojuvenil, uma vez que é alta a evasão destes pacientes antes e durante o atendimento. Apesar de sugerirem propostas de mudanças no atendimento oferecido, pouco se comenta sobre a necessidade de treino de terapeutas e a baixa procura de crianças com problemas internalizantes, citados na literatura como os de maior incidência nesta população. Este trabalho teve como objetivo diminuir essa lacuna ao propor, elaborar e avaliar uma proposta de treinamento de estagiários no atendimento de crianças ansiosas, inscritas em serviços-escola, com o uso de um protocolo reconhecido internacionalmente para o atendimento dessas crianças (Gato Corajoso), adaptado para a realidade brasileira. Foram escolhidos dois serviços-escola vinculados ao serviço público de saúde, que atendem crianças ansiosas em duas capitais brasileiras, São Paulo e Brasília; treze terapeutas, alunos de graduação de psicologia, foram selecionados para receber o treinamento em duas etapas. $\mathrm{Na}$ primeira fase, foi realizado o levantamento da clientela atendida por serviços de saúde mental $(n=112)$, na segunda, foram atendidas 20 crianças com idade entre 9 e 13 anos, enquanto outras 11 crianças com características similares constituíram o grupo controle. Os resultados sugerem que as crianças dos serviços-escola estudados apresentavam características similares às das crianças atendidas pelas clínicas-escolas de psicologia tradicionais, em relação a aspectos como idade, gênero, escolaridade, renda familiar e classe social. Apresentavam, ainda, outras características similares às verificadas nos serviços-escola de saúde, como forma de encaminhamento e queixas. Os resultados também indicam que o desempenho dos terapeutas, por meio de autoavaliação, avaliação por seus pares e por juízes, foi acima da média e a percepção do protocolo pelos próprios terapeutas foi favorável a seu uso. Além disso, os resultados apontam que as crianças ansiosas que participaram da intervenção obtiveram resultados clínicos nas escalas do $\mathrm{CBCL}$ indicativos de melhora, quando as crianças foram avaliadas antes e depois da intervenção e com os dados do grupo controle, após o tempo da intervenção. Com essas informações, conclui-se que o treinamento oferecido aos alunos com base em um protocolo de atendimento para ansiedade infantil mostrou-se útil para o atendimento clínico de crianças ansiosas, para ensinar aos alunos sobre terapia cognitivo-comportamental e para orientá-los sobre o que fazer ao longo das sessões de intervenção, diminuindo o impacto da falta de experiência em atendimento infantil e em atendimento grupal. Sugere-se, assim, que o uso de protocolos em treinamentos de terapeutas pode ser uma boa forma de difundir um conhecimento clínico com base em evidências.

Palavras-chave: treinamento; estágio; terapia cognitivo-comportamental; ansiedade; criança. 


\begin{abstract}
Studies on teaching clinics question how adequately the current model provides for children and teenage clients, since the evasion of these patients is high before and during treatment. Although suggestions are made for changes in the offered treatments, little is commented about the need for training therapists and the low demand of children with internalized problems, cited in literature as the problem with the highest incidence in this population. This study has the objective of decreasing this gap by proposing, elaborating and evaluating a proposal for training interns in the treatment of anxious children, enrolled in teaching clinics, with the use of an internationally recognized protocol for the treatment of these children (Coping Cat), adapted for the Brazilian reality. Two teaching clinics linked to public health services that treat anxious children in two Brazilian capitals, São Paulo and Brasilia, were chosen; thirteen therapists, which were undergraduate psychology students, were selected to receive training in two stages. During the first stage, we conducted a survey of the clients that used the mental health services $(n=112)$; in the second stage, 20 children with ages varying between 9 and 13 were treated, while 11 other children with similar characteristics constituted the control group. The results suggest that the children from the studied teaching clinics present similar characteristics to children treated in traditional teaching psychology clinics, in aspects such as age, gender, schooling, family income and social class. They also present other similar characteristics to those verified in teaching clinics, such as the referral methods and complaints. The results also indicate that the performance of the therapists, evaluated by themselves, their colleagues and judges, was above average and that the therapists' perception of the protocol was in favor of its use. Also, results show that when the children were evaluated before and after the intervention and with the data of the control group, anxious children who participated in the intervention obtained clinical results in the $\mathrm{CBCL}$ scales that indicated improvement. Based on this information, one may conclude that the training offered to students based on a treatment protocol for children's anxiety was useful for the clinical treatment of anxious children, to teach the students about cognitive-behavioral therapy and to guide them on what they should do during the intervention, which decreased the impact of the lack of experience on children's therapy and on group therapy. It is thus suggested that the use of protocols for training therapists may be a good way of spreading evidence based clinical knowledge.
\end{abstract}

Keywords: training; cognitive/behavioral therapy; anxiety; children. 


\section{Resumé}

Des études en services scolaires de psychologie questionnent si le modèle actuel assiste proprement aux clients enfants et jeunes, une fois que ces patients abandonnent souvent le traitement avant et pendant sa réalisation. Bien qu'il existe des suggestions de changement dans le service offert, peu est dit sur le besoin d'entrainement de thérapeutes et de la faible demande pour les enfants avec des problèmes qui demandent leur hospitalisation, rapportés dans la littérature comme ceux avec l'incidence la plus élevée dans cette population. Ce travail a eu comme objectif réduire ce déficit par proposant, élaborant et évaluant une proposition d'entrainement de stagiaires dans le soin des enfants anxieux inscrits dans les services scolaires, par l'utilisation d'un protocole internationalement reconnu pour l'assistance à ces enfants (Chat Courageux) et adapté pour la situation au Brésil. Ont été choisis deux services scolaires, liés à la santé publique et qui assistent des enfants anxieux en deux capitales brésiliennes, São Paulo e Brasília; treize thérapeutes et des étudiants en psychologie ont été choisis pour recevoir la formation en deux niveaux. Au premier niveau, une enquête a été menée sur les clients assistés par des services de santé mentale $(n=112)$, au niveau suivant 20 enfants ont reçu assistance âgés entre 9 et 13 ans, pendant qu'autres 11 enfants avec des caractéristiques similaires formaient le groupe-contrôle. Les résultats suggèrent que les enfants du service scolaire étudiés présentaient des caractéristiques similaires à celles des enfants soignés par les cliniques scolaires de psychologie traditionnelle, en relation à des aspects comme l'âge, le gendre, la scolarité, le revenu de la famille et la classe sociale. Ils présentaient, encore, d'autres traits similaires à ceux observés chez les services scolaires de santé, comme la forme de procéder et les plaintes. Les résultats indiquent également que la performance des thérapeutes, par moyen d'une autoévaluation, d'une évaluation par leurs collègues et par des juges, a été au-dessus de la moyenne et la perception des thérapeutes mêmes sur le protocole a été favorable à son usage. Par ailleurs, les résultats montrent que les enfants anxieux qui ont participé de l'intervention ont obtenu des résultats cliniques favorables dans l'échelle $\mathrm{CBCL}$ qui indiquent la guérison, quand les enfants ont été évalués avant et après l'intervention et avec les données du groupe-contrôle, après la période de l'intervention. Avec ces données, on conclut que la formation offerte aux étudiants basée dans le protocole d'assistance pour enfants anxieux est utile pour l'assistance médicale d'enfants anxieux, pour enseigner aux étudiants la thérapie cognitivocomportementale et pour les diriger sur comment procéder pendant les sessions d'intervention, diminuant l'impact du manque d'expérience en assistance infantile et groupale. Il est suggéré ainsi que l'utilisation de protocoles de formation de thérapeutes peut être une bonne forme de diffuser la connaissance clinique basé en preuves.

Mots-clé : formation; thérapie cognitivo-comportementale; l'anxiété; enfant. 


\section{LISTA DE FIGURAS}

Figura 1. Resumo do modelo dos alvos de intervenção dos protocolos para problemas internalizantes (Adaptado de Barrett, e cols., 1999)

Figura 2. Descrição do protocolo Coping Cat (Fonte: Kendall, 1992).

Figura 3. Fluxograma do recrutamento dos participantes TEs.

Figura 4. Descrição da análise dos dados do perfil sociodemográfico dos CrUs coletados na primeira etapa do treinamento dos TEs $(n=112)$

Figura 5. Descrição da análise dos dados do perfil do levantamento do encaminhamento e das queixas dos CrUs coletados na primeira etapa do treinamento dos TEs.

Figura 6. Descrição da análise realizada nas questões fechadas do protocolo, por questão e por cidade.

Figura 7. Descrição da análise realizada para avaliar os ganhos terapêuticos entre $\mathrm{Grl} \times \mathrm{GrC}$ nas Fases 1 e 2 e do $\mathrm{Grl}$ nas fases de seguimento (Fase 3 e 4).

Figura 8. Porcentagens médias e desvios-padrão (dp) do desempenho dos TEs no CTS, a partir da avaliação dos próprios TEs, dos pares e dos juízes.

Figura 9. Comparação da frequência das respostas dos TEs sobre o protocolo, segundo as opções de resposta (\%), nas duas cidades $(n=13)$.

Figura 10. Porcentagem média e desvio padrão (dp) das respostas dos TEs sobre o protocolo, em cada questão fechada.

Figura 11. Comparação das variações das médias e desvios padrões das escalas do CBCL 6-18, nas fases de avaliação.

Figura 12. Comparação da variação entre as médias e desvios padrões do MASC, nas fases de avaliação

Figura 13. Representação visual da análise do IMC relativo aos dados dos participantes do Grl no

CBCL e no MASC na Fase $1 \times$ Fase 4. 


\section{LISTA DE TABELAS}

Tabela 1. Caracterização do perfil dos TEs ( $n=13)$ . .40

Tabela 2. Programação do treinamento teórico e prático dos TEs.................................................47

Tabela 3. Descrição das sessões do protocolo Gato Corajoso. ......................................................53

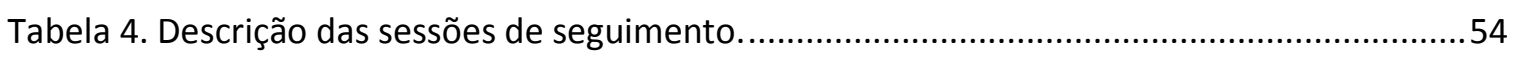

Tabela 5. Distribuição dos CrUs quanto a idade, sexo, escolaridade e procedência, por serviço $(n=112)$.

Tabela 6. Distribuição dos cuidadores quanto a idade, relação com os CrUs, escolaridade e tipo de família, por serviço $(n=112)$.

Tabela 7. Distribuição dos dados socioeconômicos quanto à ocupação do chefe da família, renda familiar e classe social, por serviço ( $n=112)$. .64

Tabela 8. Distribuição do encaminhamento e da queixa inicial segundo relato dos cuidadores, por serviço $(n=112)$.

Tabela 9. Distribuição dos escores dos instrumentos aplicados nos cuidadores e nas crianças e adolescentes.

Tabela 10. Quantificação das mudanças confiáveis de acordo com a variação dos instrumentos na Fase $1 \times 4$. 


\section{LISTA DE SIGLAS}

CBCL 6-18 Inventário dos Comportamentos para Crianças e Adolescentes entre 6 a 18 anos

CDI Inventário de Depressão Infantil

$\mathrm{Cr} \quad$ Criança selecionada para participar do grupo de intervenção ou grupo controle

Crs Crianças selecionadas para participarem do grupo de intervenção ou grupo controle

CrU Criança usuária dos serviços ambulatoriais

CrUs Crianças usuárias dos serviços ambulatoriais

CTS Lista de Verificação de Competência para Terapeutas Cognitivo-Comportamentais

DF Serviço de Saúde Mental Infanto-Juvenil (Núcleo de Apoio Terapêutico - NAT/HRAS)

GrC Grupo Controle

Grl Grupo de Intervenção

MASC Modelo Multidimensional de Ansiedade Infantil

SP Programa de Ansiedade do Serviço de Psiquiatria da Infância e Adolescência (AMBULANSIA)

TCC Terapia cognitivo-comportamental

TE Terapeuta-estagiário

TEs Terapeutas-estagiários 


\section{SUMÁRIO}

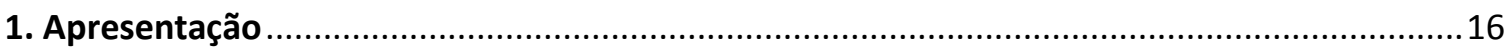

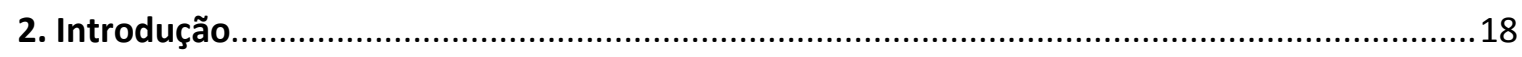

2.1. Treinamento de terapeutas para atendimento infantojuvenil ........................................20

2.1.1. Efeitos dos tratamentos psicoterápicos ................................................................. 21

2.1.2. Treinamento clínico em Terapia Cognitivo-Comportamental (TCC)........................24

2.1.3. Protocolos de atendimento em TCC para ansiedade infantojuvenil .........................29

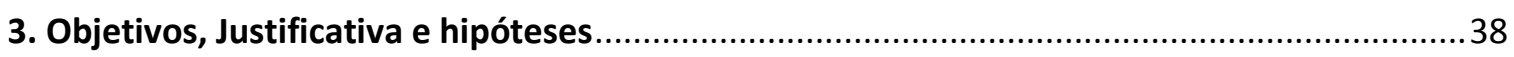

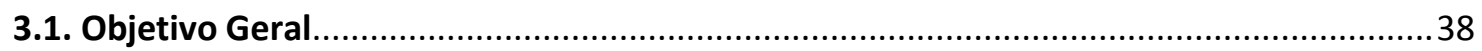

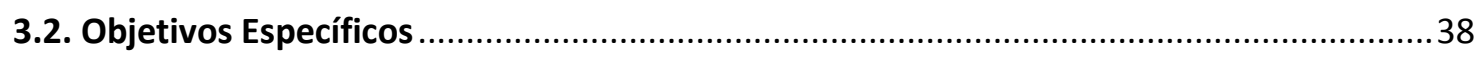

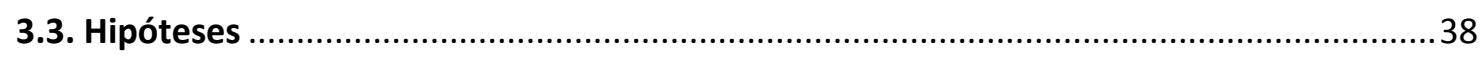

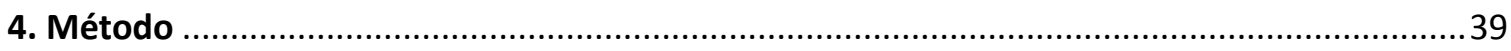

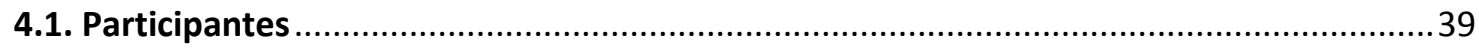

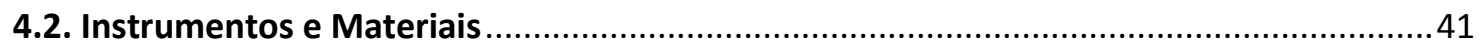

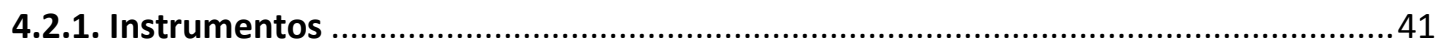

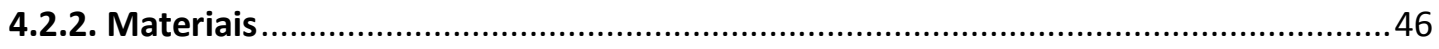

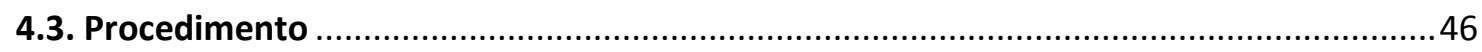

4.3.1. Etapa I - Caracterização dos serviços ……………………….................................... 47

4.3.2. Etapa II - intervenção clínica ............................................................................. 49

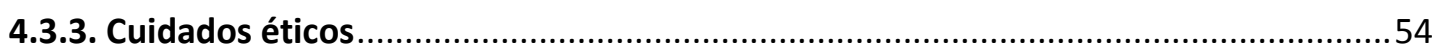

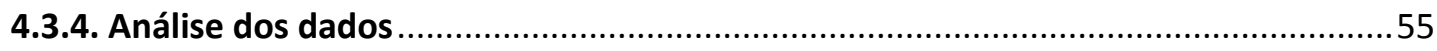

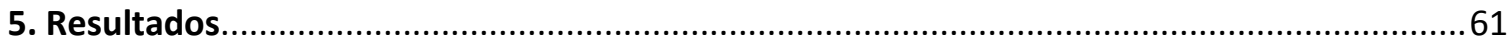

5.1. Etapa I: Descrição do perfil sociodemográfico e característica dos encaminhamentos e

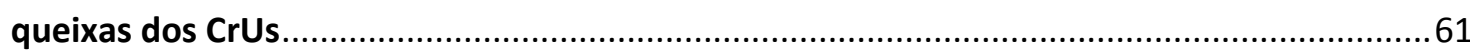

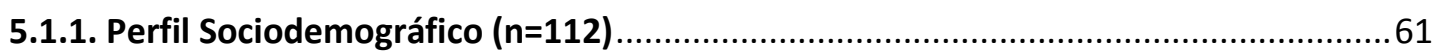

5.1.2. Características dos encaminhamentos e das queixas ...............................................65

5.2. Etapa II: Avaliação da adaptação e do uso do protocolo no treinamento dos TEs ...........70

5.2.1. Descrição das competências gerais e específicas da TCC apresentadas pelos TEs, a

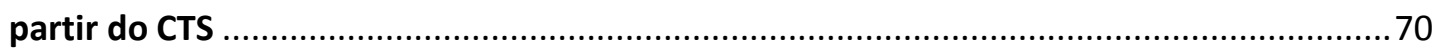

5.2.2. Avaliação dos estagiários sobre o uso do protocolo como uma ferramenta de treinamento de alunos para 0 atendimento de crianças ansiosas ......................................74

5.2.3. Comparação dos ganhos terapêuticos das crianças que participaram do Grl e do GrC

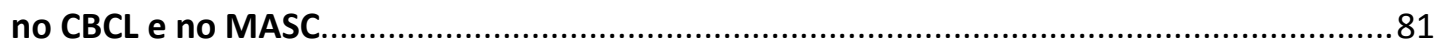

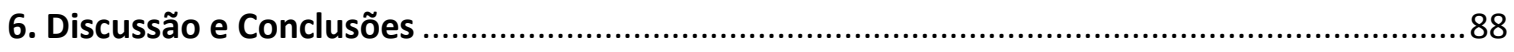


Anexo 1. Ficha de Identificação

Anexo 2. Modelo Multidimensional de Ansiedade Infantil..

Anexo 3. Inventário de Depressão Infantil (CDI)

Anexo 4. Cognitive Therapy Scale ou Lista de Verificação de Competência para Terapeutas

Cognitivo-Comportamentais (CTS)

Anexo 5. Checklist dos juízes (CTS) 116

Anexo 6. Inventário para o Estagiário. 120

Anexo 7. Termo de consentimento livre e esclarecido: TEs. 123

Anexo 8. Manual do treinamento: Etapa I 125

Anexo 9. Termo de consentimento livre e esclarecido: Cuidadores e CrUs/Crs

Anexo 10. Termômetro do Medo

Anexo 11. Painel com o acróstico 145

Anexo 12. Acróstico Imantado 146

Anexo 13. Círculo mágico 147

Anexo 14. Jogo Tô por Uma 148

Anexo 15. Agenda 149

Anexo 16. Banco de pontos e Tarefa Amigo. 150

Anexo 17. Logomarca do Protocolo 151

Anexo 18 Camiseta e botton

Anexo 19. Certificado para participantes-crianças (Exemplo)

Anexo 20. Certificado para participantes-Alunos (Exemplo) 154

Anexo 21. Manual do treinamento: Etapa II 155

Anexo 22. Aprovação do Comitê de Ética de SP 247

Anexo 23. Aprovação do Comitê de Ética do DF 249 


\section{Apresentação}

O presente trabalho de pesquisa teve o objetivo de elaborar e avaliar uma proposta de treinamento de estagiários para o atendimento de crianças ansiosas, inscritas em serviçosescola de psiquiatria, com a adaptação, para a realidade brasileira, de um atendimento americano reconhecido internacionalmente, que se apresenta sob a forma de um manual.

A pesquisa foi realizada no Laboratório de Terapia Comportamental do Instituto de Psicologia da Universidade de São Paulo, em parceria com as equipes de dois serviços-escola de psiquiatria de duas regiões brasileira: o Programa de Ansiedade do Serviço de Psiquiatria da Infância e Adolescência (AMBULANSIA), do Instituto de Psiquiatria do Hospital das Clínicas da Faculdade de Medicina, coordenado pelo psiquiatra Dr. Fernando Asbahr; e o Serviço de Saúde Mental Infanto-Juvenil (Núcleo de Apoio Terapêutico - NAT/HRAS), do Hospital Regional da Asa Sul, do Governo do Distrito Federal, coordenado pela psicóloga Carolina Coutinho Garcia Leão.

Levar os alunos a atenderem a clientela infantojuvenil com queixa de ansiedade em ambulatórios de psiquiatria, ao invés da clínica-escola da USP ou da UnB, teve pelo menos três propósitos. $\mathrm{O}$ primeiro foi de identificar as características das crianças atendidas e o quanto elas se diferenciavam da clientela dos serviços de psicologia, para o maior controle dos possíveis moderadores de impacto na intervenção. O segundo, de inverter a rota do atendimento ao proporcioná-lo no local onde o paciente já é atendido, por acreditar que seria mais fácil acessar a clientela nesses serviços e pela expectativa de que esta inversão aumentaria a adesão da clientela. E, o terceiro, complementar aos outros dois, deve-se ao interesse em se avaliar a resposta de um procedimento de pesquisa (protocolo Coping Cat) em um contexto clínico usual de atendimento, integrando pesquisa e prática.

Para alcançar o objetivo já referido deste trabalho, o treinamento de alunos da graduação foi dividido em duas partes: levantamento da clientela e, posteriormente, intervenção clínica. O levantamento da clientela teve como objetivo aproximar os alunos da clientela a ser atendida e selecionar os participantes para segunda etapa deste estudo. Com a aproximação com a clientela e a identificação de seu perfil, criaram-se condições para a adaptação do protocolo americano para a população a ser atendida. $O$ treino da intervenção clínica, com o uso de um protocolo de atendimento, justifica-se pelo auxílio que o tratamento manualizado possibilita para a orientação e supervisão de competências clínicas gerais e específicas da TCC. Ademais, sabe-se que a ansiedade patológica é a dificuldade de maior 
incidência na população infantojuvenil, e que as crianças com essa queixa são as que mais abandonam o tratamento psicológico, e que o resultado da intervenção é melhor quando realizada por profissionais mais qualificados e treinados. Desta forma, o uso de uma ferramenta que direciona o uso de estratégias avaliadas como eficazes para o atendimento de crianças ansiosas, em principio, facilita o processo terapêutico e o treino de habilidades específicas necessárias para o atendimento dessa clientela.

Ao propor a ação de incluir diferentes serviços-escola visou-se fortalecer a parceria entre diferentes serviços, unindo forças para aumentar a capacitação de profissionais da Região Centro-Oeste, e favorecer o atendimento das dificuldades de comportamento privado negligenciadas, que chegam pouco às clínicas-escolas tradicionais de psicologia.

Na primeira parte deste trabalho (seção 2), será apresentada uma revisão bibliográfica sobre questões gerais do treinamento de terapeutas-estagiários, considerando as novas diretrizes dos cursos de graduação em psicologia e a terapia cognitivo-comportamental como uma abordagem válida para treinamento clínico e atendimento de crianças e adolescentes.

Na seção 3, serão apresentados os objetivos e as hipóteses deste trabalho.

Na seção 4, será abordado o método do estudo, com a descrição dos participantes (terapeutas-estagiários, usuários do serviço e crianças que participaram do grupo de intervenção e controle), instrumentos e procedimentos utilizados, cuidados éticos tomados e descrição de como os dados foram analisados.

Na seção 5, apresentam-se os resultados considerando os objetivos específicos deste estudo, frutos da caracterização da clientela dos serviços estudados e da avaliação do protocolo escolhido para o treinamento dos alunos e o atendimento de crianças ansiosas.

Por fim, na seção 6, serão discutidas algumas conclusões realizadas com base nos dados e nas hipóteses deste trabalho, e consideradas as limitações deste estudo. 


\section{INTRODUÇÃo}

O treinamento clínico dos alunos estagiários comumente é realizado em um serviçoescola de psicologia, ambiente associado a uma instituição universitária - mas não necessariamente a uma faculdade de psicologia -, no qual o aluno exerce a prática em psicologia sob a orientação de um professor-supervisor (Löhr \& Silvares, 2006). Os serviçosescola têm o objetivo de promover ações e procedimentos que possibilitem o ensino e a pesquisa, formando o aluno no papel de psicólogo, enquanto fornecem atendimento à comunidade (Löhr \& Silvares, 2006; Silvares, 1998). Apesar de a literatura apontar que o papel do psicoterapeuta é crucial e está associado diretamente aos resultados da intervenção e na qualidade das pesquisas clínicas (James, Backburn, Milne, \& Reichfelt, 2001; Okiishi, Lambert, Nielsen, \& Oglesm, 2003; Shirk \& Phillips, 1991; Stein \& Lambert, 1995), somente há pouco tempo esse assunto passou a ser objeto de investigações.

Sabe-se que o caminho percorrido para se tornar um psicoterapeuta competente é lento, árduo e complexo, envolvendo treino de habilidades específicas e a construção da identidade profissional, que se efetiva mediante a aquisição teórica e a prática clínica supervisionada, iniciada no período de graduação. Almejando uma melhor formação dos alunos de graduação, há atualmente uma preocupação para que os cursos de psicologia diminuam o hiato entre a prática acadêmica, ainda predominantemente clínica e sob a influência do modelo psicanalítico, e a prática profissional, sob controle de um mercado crescente que solicita habilidades pouco exploradas nas universidades, como as prestadas na rede pública de saúde (Dimenstein, 2000; Paparelli \& Nogueira-Martins, 2007; Scorsolini-Comin, Souza \& Santos, 2008; Spink, Bernardes \& Menegon, 2006). Nesse sentido, o Conselho Nacional de Educação (2004) aprovou mudanças curriculares propostas nas Diretrizes Curriculares Nacionais (DCN), que constam no parecer CNE/CS 0062/2004, estabelecendo domínios de atuação profissional e dando uma maior autonomia para as instituições de ensino de psicologia, desde que seja respeitado um núcleo formador comum, que garanta uma capacitação básica para lidar com o conhecimento e a prática inerente à área.

Segundo Meire e Nunes (2005), as características teóricas dos cursos de graduação em psicologia têm um papel fundamental na formação profissional do aluno e na sua futura atuação profissional. Ressalta-se que, mesmo na área clínica dos serviços-escola, é reconhecida a necessidade de a intervenção não se restringir a espaços clínicos privados e de se articular com 
equipes multidisciplinares e com diferentes contextos (Paparelli \& Nogueira-Martins, 2007; Scorsoloni-Comin e cols., 2008; Spink e cols., 2006). Com as mudanças curriculares recentes nas universidades brasileiras, a prática clínica do aluno de graduação passou a ocorrer durante todo o curso de graduação (Löhr \& Silvares, 2006) e o termo serviço-escola passou a ser utilizado em substituição ao termo clínica-escola por caracterizar de forma mais ampla o ambiente em que a prática da psicologia ocorre (Silvares \& cols., 2006). No que se refere à formação clínica, pelo menos em princípio, tem-se como alvo a formação de competências gerais, tais como responsabilidade ética e moral, e de competências específicas associadas à abordagem clínica escolhida pelo aluno (Shirk \& Phillips, 1991; Stein \& Lambert, 1995).

Com o objetivo de investigar o perfil desses serviços-escola brasileiros de psicologia, constituiu-se uma força tarefa com o Projeto Temático de Atendimento Psicológico das Clínicasescolas, da Associação de Pós-Graduação e Pesquisa (ANPEPP), coordenada pela Prof ${ }^{a}$ Edwiges Ferreira de Mattos Silvares. Participaram desse estudo 73 gestores, 137 supervisores e 312 estagiários, de diferentes regiões brasileiras, com o preenchimento de questionários disponibilizados on-line. A despeito da baixa participação da comunidade acadêmica e da ausência de dados suficientes para caracterização da população atendida pelos referidos serviços, observou-se uma maior diversificação na formação dos alunos de psicologia, atendendo mais às necessidades regionais do que o registrado anteriormente por outros estudos (e.g. Ancona-Lopez, 1983; Silvares, 1988). Esses resultados parecem mostrar que as normas preconizadas pelas recentes diretrizes para os cursos de graduação em psicologia já têm repercussões, uma vez que se percebeu menor ênfase na prática clínica tradicional. Outro dado relevante do mesmo estudo refere-se à supervalorização da figura do supervisor e do processo de supervisão pelo estagiário. Em se tratando dos dados obtidos com os supervisores, observouse que eles compartilhavam com os alunos a mesma visão idealizada do processo da prática supervisionada (Grupo de Trabalho de Atendimento Psicológico das Clínicas-Escola, 2011).

Fortalecem as impressões apontadas acima os dados similares a estes encontrados por Fernandes (2010), em um estudo de caracterização da população atendida e do processo de supervisão de um serviço-escola de psicologia em São José do Rio Preto-SP. Em relação ao atendimento oferecido, os dados do referido estudo sugerem a necessidade de que os registros dos atendimentos sejam realizados de forma mais sistemática e que haja uma maior oferta de intervenções preventivas. Por sua vez, os dados sobre a supervisão clínica sugerem a necessidade do diálogo permanente entre supervisores e estagiários e de maior envolvimento dos supervisores em projetos de pesquisa clínica, demonstrando que os supervisores focavam 
apenas na prática clínica, não associando a ela a produção e a comunicação científica. Estes dados indicam a necessidade da formação continuada dos psicólogos que trabalham no serviçoescola, onde o estudo foi realizado.

Diante do exposto, considera-se urgente a articulação entre a formação teórica e prática oferecida na graduação, no sentido de formar o aluno, assegurando-lhe uma formação teórica consistente e atualizada, ao mesmo tempo em que se oferece treino de habilidades pertinentes e que serão exigidas posteriormente pelo mercado de trabalho. A seguir, abordaremos esta articulação considerando o atendimento infantojuvenil.

\subsection{TREINAMENTO DE TERAPEUTAS PARA ATENDIMENTO INFANTOJUVENIL}

Estima-se que de $15 \%$ a $22 \%$ da população infantojuvenil americana, em um dado momento, sofram algum comprometimento considerado clínico ou desviante em saúde mental, necessitando assim de tratamento especializado (Fleitlich \& Goodman, 2000; Harrinson, Boyle \& Farley, 1999; Kendall, 2000; Marsh \& Graham, 2001). Dados similares foram encontrados por Duarte e cols. (2003) na população latino-americana e por Fleitlich-Bilyk e Goodman (2004) e Bordin e Paula (2007) na população brasileira. Apesar da alta incidência, estima-se que de $75 \%$ a 80\% dessa população adoecida emocionalmente não receberá nenhum atendimento especializado (Harrinson \& cols., 1999; Halpern \& Figueiras, 2004; Kendall, 2000; Marsh \& Graham, 2001).

Atualmente, considera-se que esses problemas emocionais e comportamentais estão associados a diversos comportamentos de risco, como o suicídio - que já é hoje considerada a 3a causa de morte entre os adolescentes (Fleitlich \& Goodman, 2000) -, abuso de álcool e drogas, delinquência, gravidez precoce, baixo rendimento escolar, entre outros (Fleitlich \& Goodman, 2000; Halpern \& Figueiras, 2004). Com o reconhecimento do impacto dessas dificuldades emocionais e comportamentais, houve um grande interesse de diferentes pesquisadores em pesquisar e avaliar como melhor atender a essa demanda (Silvares, 1998; Silvares, 2006; Weisz, Hawley \& Doss, 2004; Weisz \& Gray, 2008). Daí se inclui a necessidade de se questionar sobre o efeito dos tratamentos psicoterápicos e o treinamento dos profissionais que melhor atendam a essas dificuldades. As pesquisas clínicas na área têm tentado responder a essas questões se utilizando de um número cada vez maior de metodologias de pesquisa, que incluem desde comparações entre grupos e intragrupos ou delineamentos de base múltipla até estudos de caso. 


\subsubsection{EFEITOS DOS TRATAMENTOS PSICOTERÁPICOS}

Weisz, Donenberg, Han e Weiss (1995a) citam que não há uma integração entre pesquisa e prática clínica, ao escreverem a frase: os "pesquisadores oferecem o banquete, mas os clínicos ficam em casa", satirizando o fato de os clínicos desconhecerem ou não fazerem uso dos dados obtidos nas pesquisas clínicas. Isso ocorre mesmo quando consideramos clínicos formadores de opinião, como é o caso dos supervisores em serviços-escola. Ao longo dos últimos 50 anos, milhares de estudos bem controlados por randomizações de amostras têm sido publicados, revisados e, mais recentemente, pelos avanços estatísticos, metanalisados, na tentativa de investigar se alguns tratamentos devem ser utilizados mais do que outros na prática clínica, e em quais condições isso deve ocorrer (e.g. Casey, \& Berman, 1985; Kazdin, Bass, Ayers \& Rodgers, 1990; Kazdin, 2008; Weisz, Weiss, Alicke \& Klotz, 1987; Weisz, Weiss, Han, Granger \& Morton, 1995b). Com interesse em responder a questão sobre a eficácia das psicoterapias, David Barlow, na década de 1990, então presidente da Divisão de Psicologia Clínica (Divisão 12), da Associação Americana de Psicologia (American Psychological Association - APA), convocou um grupo de trabalho para que se estabelecesse um conjunto de critérios que avaliassem os tratamentos psicossociais, independentemente da abordagem teórica (Albano \& Kendall, 2002; Chambless e cols, 1998; Chambless \& Ollendick, 2001).

Segundo a APA (2005), os tratamentos empiricamente baseados referem-se às intervenções ou técnicas testadas que produziram mudança terapêutica em estudos controlados. As diretrizes apresentadas para classificação dos tratamentos são, fundamentalmente, as seguintes: (a) cuidados com as características da população que recebe a intervenção; (b) randomização dos participantes nas diferentes condições de estudo; (c) uso de tratamento manualizado ou similar, que descreva os procedimentos; (d) uso de múltiplas medidas para avaliar o resultado da intervenção; (e) diferença estatisticamente relevante entre os resultados antes e depois da intervenção ou entre grupos de intervenção e grupo controle; e (f) replicação dos efeitos dos resultados, preferencialmente por pesquisadores independentes (Chambless e cols., 1998). Os critérios estabelecidos para classificar os tratamentos, que são hoje de domínio público, se diferenciam em: Critério 1 - representa aqueles nos quais a evidência é bem estabelecida; Critério 2 - aqueles em que os estudos sugerem que há uma provável eficácia; Critério 3 - possível eficácia; e Critério 4 - tratamento experimental (Chambless \& Ollendick, 2001; Kazdin \& Weisz, 2010). A partir de então, os tratamentos que passavam por esta avaliação e preenchiam um dos três primeiros critérios passaram a ser citados como "Tratamentos Baseados em Evidências" ou EBT (Empirically-Supported Treatment 
ou Empirically-Based Treatment) (Albano \& Kendall, 2002; Chambless \& Ollendick, 2001).

Na direção dos tipos de avaliação dos tratamentos psicoterápicos, merecem destaque os estudos de metanálise que avaliam a eficácia de psicoterapia, nos quais são avaliadas estatisticamente as médias do tamanho do efeito entre diferentes estudos, seguindo a designação classificatória de Cohen (1988), que define 0.20 como tamanho de efeito pequeno; 0.50, médio; e 0.80, grande. Não é demais lembrar que o tamanho de efeito reflete uma padronização da diferença de uma medida particular do tratamento em diferentes estudos, ao avaliar as fases e os grupos considerados nas pesquisas avaliadas. Dessa forma, tais estudos têm, ao longo dos últimos 26 anos, ajudado a compreender o quão bem as psicoterapias "funcionam". Ademais, guiam para uma avaliação crítica sobre os estudos publicados (Kazdin, 2002; Weisz \& Gray, 2008), bem como auxiliam na construção do conhecimento das psicoterapias para crianças e adolescentes. Interessados na avaliação crítica dos resultados desses tratamentos, focalizaremos a seguir quatro metanálises que marcaram os estudos na área infantojuvenil, a saber: Casey e Berman (1985), Weisz e cols (1987), Kazdin e cols (1990) e Weisz e cols. (1995).

Casey e Berman (1985) avaliaram 75 estudos publicados entre 1952 e 1983, com crianças a partir de 12 anos e pré-adolescentes. Os dados obtidos indicaram uma média de tamanho de efeito igual a 0.71 , demonstrando que as crianças que receberam o tratamento testado apresentavam menos dificuldades ao final da intervenção do que aquelas designadas para o grupo controle (lista de espera). Este estudo também aponta que os tratamentos comportamentais (aqui se inclui a terapia cognitivo-comportamental) foram identificados como possivelmente mais eficazes do que tratamentos não-comportamentais.

Logo em seguida, Weisz e cols (1987) avaliaram 108 estudos publicados no mesmo período considerado pelo estudo de Casey e Berman, incluindo na análise os adolescentes. Os dados indicaram uma média de tamanho de efeito igual a 0.79 . Outro dado relevante observado neste estudo foi que os terapeutas mais especializados (e.g. médicos ou psicólogos com mestrado) foram especialmente eficazes no tratamento de problemas emocionais (e.g. ansiedade, timidez), mas não se diferenciaram dos paraprofissionais (e.g. pais e professores) no tratamento de problemas comportamentais (e.g. agressividade, impulsividade), apontando uma intrigante relação entre treinamento e queixas clínicas. Novamente, os tratamentos comportamentais foram indicados como mais eficazes do que os tratamentos não comportamentais, independentemente da idade do cliente, da experiência do terapeuta ou do 
problema tratado, sustentando uma diferença entre as psicoterapias no atendimento dessa população.

Na sequência, Kazdin e cols (1990) avaliaram 223 estudos publicados entre 1970 e 1988, que incluíam crianças e adolescentes com idades entre 4 e 18 anos, e encontraram uma média de tamanho de efeito ainda maior do que os dois estudos apresentados acima (0.88). Nesse estudo, os autores discutem que as influências das variáveis moderadoras (e.g. características da criança/adolescente, dos pais, dos familiares) foram pouco abordadas nos estudos avaliados. Os referidos autores alertam que as características da população estudada e dos métodos de tratamento oferecidos se diferenciavam do que se observava nos ambientes naturais e nos tratamentos usuais da época, chamando a atenção para as dificuldades de aplicação dos tratamentos analisados no ambiente clínico tradicional, dificultando assim a generalização dos achados.

Weisz e cols. (1995) avaliaram 150 estudos publicados entre 1967 e 1993, com crianças e adolescentes de 2 a 18 anos, e encontraram uma média de tamanho de efeito igual a 0.71 . Esse estudo também observou efeitos mais positivos para as intervenções comportamentais do que para os tratamentos não comportamentais, e uma diferença entre terapeutas e queixa atendida. Nesse estudo, os autores identificaram que quando a intervenção foi realizada para clientela com dificuldades externalizantes, os resultados foram melhores quando aplicados por paraprofissionais, em que se incluem pais e professores, do que quando aplicados por profissionais e estudantes de graduação. Por sua vez, nos casos internalizantes, mais nos ansiosos do que nos deprimidos, os resultados foram melhores quando aplicados por profissionais e estudantes de graduação supervisionados. Além disso, observaram que os resultados dos estudos avaliados foram ainda melhores quando o tratamento era direcionado a uma queixa-alvo, em comparação às situações em que não havia alvo específico.

Nota-se que os quatro estudos sinalizaram um tamanho de efeito similar, indo de médio a grande. Além disso, os referidos autores de tais estudos ressaltam outros dois pontos merecedores de atenção: em primeiro lugar, o tamanho do efeito foi maior nas dificuldades alvo de intervenção; o segundo ponto observado foi que as crianças continuaram a apresentar melhoras após a finalização do atendimento (média de seguimento de 5-6 meses), sugerindo a durabilidade dos benefícios dos tratamentos analisados (Casey \& Berman, 1985; Weisz \& cols., 1987; Kazdin \& cols., 1990; Weisz \& cols., 1995). 
Ainda sobre esses estudos, observa-se que Weisz e cols. (1987) e Weisz e cols. (1995) encontraram uma intrigante associação entre queixas e resultados, ao demonstrar que, quando a queixa era de internalização, os resultados eram melhores quando a intervenção era aplicada por profissionais experientes, principalmente nos quadros ansiosos. Em outra revisão mais recente, Michael, Huelsman e Crowley (2005) relatam que os resultados dos pacientes com ansiedade e depressão foram similares quando aplicados por terapeutas experientes ou por estudantes, quando estes recebiam supervisão e utilizavam intervenção seguindo um protocolo. Em se tratando dos casos de ansiedade, Michael e cols. (2005) acrescentam que o peso da formação do terapeuta afeta tanto o resultado como a adesão ao atendimento, que no geral é baixa.

Além desses estudos analisados, ao longo dos últimos anos, diversos estudos controlados com crianças e adolescentes, ansiosos ou não, têm sugerido que intervenções comportamentais (aqui se inclui tanto as comportamentais quanto as cognitivocomportamentais) apresentam resultados mais efetivos, tanto quando comparadas com outras intervenções não comportamentais (e.g. Casey \& Berman, 1985; Cartwright-Hatton \& cols., 2004; Durlak \& Wells, 1998; Weiss \& Weiz, 1995; Weisz \& cols., 1987; Weiz \& cols., 1995b) como quando comparadas com grupos controle (e.g. Barrett, Dadds \& Rapee, 1996; Casey \& Berman,1985; Cartwright-Hatton \& cols., 2004; Flannery-Schoeder \& Kendall, 2000), em diversos quadros clínicos.

A seguir, faremos uma breve revisão dos treinamentos clínicos, sendo que aqui será abordado especificamente o treino em terapia cognitivo-comportamental, abordagem citada acima como uma das linhas de atuação clínicas mais associadas a bons resultados no atendimento infantojuvenil.

\subsubsection{TREInAMENTO Clínico EM Terapia Cognitivo-Comportamental (TCC)}

Kadzin (1991) e Weisz e cols. (1995b) propõem que psicoterapia consiste em um plano de tratamento que visa diminuir o sofrimento psicológico e o comportamento inadequado, ou que possibilite maior adaptação e o funcionamento pró-social ao enfocar a forma como o cliente pensa, o que ele sente e como ele age. A TCC constitui-se considerando estes parâmetros de psicoterapia, como será demonstrado a seguir.

Essa forma de terapia é considerada uma abordagem híbrida, por buscar a integração 
entre as posições cognitivas - processamento de informação - e comportamentais aprendizagem/aprendizagem social. Parte do princípio de que há uma interdependência entre pensamentos, emoções e comportamentos (Kendall \& Southam-Gerow, 1995, Stallard, 2009). Na TCC, as intervenções são planejadas e as técnicas são escolhidas de acordo com a avaliação clínica e o repertório do cliente. É considerada uma abordagem prática, voltada para o aqui-eagora, e baseada no treino de habilidades, em que o processo se dá em colaboração ativa entre terapeuta e paciente (empirismo colaborativo) (Beck, 1997, Stallard, 2009).

Historicamente, a TCC é uma abordagem com tradição experimental, uma vez que tem sido submetida a um considerável escrutínio empírico e goza de êxito comprovado. Pela ampla aplicabilidade, robustez teórica, técnica e flexibilidade, tem sido bastante indicada para o treinamento de psicólogos clínicos e tem indicação para diferentes problemas, como os emocionais e os comportamentais, a partir de várias modalidades clínicas, como individual, grupal e mista, com múltiplos focos de intervenção: criança/adolescente, pais e/ou escola (Beck, 1997; Friedberg, Gorman, \& Beidel, 2009; Weisz \& cols., 1995b).

Apesar do mais de meio século de existência da TCC, o uso desta nos problemas emocionais infantojuvenis ou internalizantes, entre os quais se inclui a ansiedade, começou a ser estudado de forma mais extensiva nos últimos vinte anos. Fazendo uma breve retrospectiva histórica desde os trabalhos de Eysenck e de Wolpe sobre fobias em adultos, na década de 1950, já se considerava que o medo irracional associado ao estímulo fóbico estava associado a um erro de interpretação que, se alterado, poderia desaparecer. Outros estudos, como os dos americanos Albert Ellis, no final dos anos de 1950, e os de Aaron Beck, no início da década de 1960, demonstraram que a mudança do humor e dos comportamentos desadaptativos poderia ser alcançada com o questionamento dos pensamentos disfuncionais distorcidos. Por outro lado, os estudos e pesquisas de Skinner em condicionamento operante também demonstraram ter grande aplicabilidade com crianças no modelo triádico, fosse no treino de pais, treino de professores ou de profissionais da saúde (e.g. sistema de fichas, controle de contingências). Mais recentemente, na década de 1970, Donald Meichebaum associou as ferramentas comportamentais com a ideia da influência dos pensamentos ou cognição, essencial para o desenvolvimento da Terapia Cognitiva de Aaron Beck, contribuindo para a criação da terapia cognitivo-comportamental (Vandenberghe \& Gauy, 2011; Weisz \& Gray, 2008). A partir das já citadas metanálises com psicoterapia infantojuvenil (Casey \& Berman, 1985; Weisz \& cols., 1987; Kazdin \& cols., 1990; Weisz e cols., 1995b), houve um maior interesse para o atendimento de crianças e adolescentes nesta abordagem. 
No que se referem ao treinamento clínico dos terapeutas, diferentes estudos apontam que, para ser um bom terapeuta cognitivo-comportamental, são necessárias algumas competências específicas. Calhoun e cols. (1998), por exemplo, sugerem que o treinamento deve desenvolver nos alunos: (a) a conhecimento de psicopatologia; (b) a capacidade de conceitualização de caso, identificando alvos-clínicos a serem trabalhados e a história do cliente; (c) a aquisição de habilidades terapêuticas específicas associadas às práticas baseadas em evidências (incluindo como, quando e em quem usar); (d) a aquisição de habilidades terapêuticas gerais no intuito de criar uma boa relação e aliança terapêutica, assim como um padrão de interação potencializador do processo terapêutico; e (f) a aquisição de habilidades necessárias para a avaliação da efetividade do procedimento utilizado, que incluem tanto medidas diagnósticas e clínicas válidas, como julgamento clínico acurado. Seguindo raciocínio similar de Calhoun e colaboradores (1998), Sudak, Beck e Wright (2003) sugerem dez ingredientes essenciais para um bom terapeuta em TCC: conceituar o caso clínico com diferentes transtornos; desenvolver uma aliança terapêutica forte, ativa e colaboradora; usar a conceitualização cognitiva no processo terapêutico; monitorar continuamente os progressos do paciente; estruturar as sessões para maximizar os progressos; ter como foco auxiliar o paciente a resolver ou enfrentar os problemas associados às metas terapêuticas, a partir de um conjunto de técnicas; identificar e ajudar os pacientes a modificarem as distorções cognitivas cruciais; facilitar as mudanças comportamentais; trabalhar diretamente na adesão ao tratamento; e enfatizar a prevenção de recaídas.

Especificamente no que se refere ao treino de TCC para o atendimento de crianças e adolescentes, Beidas, Benjamin, Puelo, Edmunds e Kendall (2010), Friedberg e cols. (2009) e Kendall e cols. (2008) acrescentam a importância do treino de habilidades clínicas, que vá além da cordialidade genuína e empatia, ao contemplar as dificuldades atuais do paciente, a partir de uma atitude acolhedora, aberta e flexível. Os referidos autores defendem que o treinamento baseado em elementos de manuais de suporte empírico pode auxiliar sobremaneira o terapeuta iniciante. Por sua vez, Stein e Lambert (1995) apontam a necessidade de se abordar: instruções teóricas didáticas, noções de curso do desenvolvimento e psicopatologia, modificação comportamental e teoria da aprendizagem social.

Em um estudo para avaliar questões associadas a características do terapeuta e do treino oferecido, Roth, Pilling e Turner (2010) analisaram 27 estudos controlados em TCC. Em relação às características dos terapeutas, descrevem que a maioria era alunos de mestrado ou doutorado e tinham um nível de conhecimento de TCC descrito como bom. A duração do 
treinamento e o conteúdo abordado dependiam, principalmente, da experiência e conhecimento prévio dos terapeutas, sendo que a duração do treino variou entre 1 dia e 16 meses, sendo realizado com base na discussão de exemplos clínicos filmados, manuais de intervenção e dramatização. No caso de pouco conhecimento prévio dos terapeutas, eram incluídos os conceitos básicos da TCC para familiarizá-los com o modelo cognitivo. Treze estudos identificaram a necessidade de os terapeutas terem um caso piloto ou situação clínica piloto, antes do início da intervenção. Em relação à supervisão, 14 estudos citaram que o formato de supervisão utilizado foi individual e 16 citaram que tinham frequência semanal. Em todos os estudos analisados, foi utilizado tratamento manualizado. A maior parte gravava a sessão e avaliava e monitorava os terapeutas, para avaliar competência e aderência/fidedignidade ao manual. Os autores alertam que o uso de tratamentos manualizados não determina o sucesso da intervenção, sugerindo que o treinamento dos terapeutas e a supervisão prática considerando o contexto da aplicação clínica são fundamentais para a aplicação bem-sucedida das práticas clínicas pesquisadas nos contextos naturais.

Em uma visão mais ampla, Bennett-Levy (2006), em um estudo de revisão sobre treino de terapeutas, demonstra que, nos últimos vinte anos, alguns programas de treinamento mostraram-se mais eficazes do que outros no treino de habilidades clínicas e que há uma associação entre competência do terapeuta e resultados terapêuticos obtidos. $O$ autor apresenta um modelo de três sistemas para o desenvolvimento de habilidades do terapeuta: teórico (declarative), prático (procedural) e reflexivo (reflective). O primeiro se refere ao conhecimento didático obtido com a leitura, a observação e a supervisão. $O$ segundo se refere à aplicação prática da habilidade treinada no primeiro. E o terceiro se refere à reflexão, dentro e fora da sessão, associada à prática clínica, criadora de conceitos e de teorias. Segundo este autor, os programas de treinamento devem incluir uma combinação variada de estratégias, que favoreçam o sistema reflexivo e o engajamento pessoal do terapeuta no desenvolvimento de habilidades.

Com base no modelo sugerido por Bennett-Levy (2006) para o treinamento de terapeutas cognitivo-comportamentais pediátricos, Friedberg e cols. (2009) sugerem a aplicação das três fases: (a) fase 1, de conceitos teóricos gerais, abordando os conceitos comportamentais básicos (e.g. condicionamento clássico e operante, aprendizagem vicariante) e o modelo cognitivo; (b) fase 2, de formulação de caso e habilidades clínicas com base na experiência clínica e supervisão prática, em que deve-se aplicar, no cliente e em si mesmo, os conhecimento teóricos na formulação dos casos, reforçar a capacidade de improvisar e aproveitar as situações 
que evocarem emoções para identificar e modificar os pensamentos distorcidos; e (c) fase 3, de proficiência técnica, com base na prática supervisionada e aprendizagem experiencial para aplicar procedimentos manualizados desenvolvidos em estudos clínicos controlados. Seguindo raciocínio similar, Kendall, Hayes, e Nauta. (1998) defendem que o uso de manual nas intervenções (fase 1, 2 e 3), além de desenvolver conhecimentos e habilidade clínicas, orienta os terapeutas sobre o que fazer nos atendimentos, sendo de grande auxílio para iniciantes. Beidas e cols. (2010) e Friedberg e cols. (2009) alertam que, mesmo nos tratamentos manualizados, a intervenção deve ser adaptada ao cliente, à queixa e ao contexto clínico.

Apesar dos manuais ou protocolos de tratamento já existirem desde 1960, nos últimos anos houve um grande aumento de propostas. Estes protocolos sugerem, passo a passo, o que fazer em cada sessão, conforme o problema-alvo; preconizam um trabalho focal e breve, de 12 a 16 sessões; podem ser aplicados por diferentes profissionais e alunos ou por paraprofissionais (e.g., pais e professores); são empiricamente validados; e têm valor para pesquisa e ensino (Duncan, Nicol, \& Marger, 2004). Os atendimentos manualizados têm utilidade em pesquisa clínica, uma vez que oferecem inúmeras vantagens, como: aumentar a validade interna do procedimento e a integridade do tratamento; permitir comparação de tratamentos em diferentes contextos e formatos, a partir da padronização do procedimento aplicado; facilitar o treinamento de terapeutas e a disseminação do tratamento; prover a oportunidade de replicação e comparação de resultados. Idealmente, devem ser utilizados após treinamento dos terapeutas, acompanhados de supervisão e aplicados de forma não rígida, de acordo com as necessidades e as comorbidades identificadas (Kendall \& cols., 1998; Kendall \& FlannerySchroeder, 1998).

Calhoun e cols. (1998), em uma pesquisa a respeito de treinamento de terapeutas, e Aarons (2004), em outra pesquisa sobre uso de manuais, demonstraram que os profissionais em treinamento são mais abertos às práticas manualizadas do que profissionais experientes. Isso aponta no sentido de que treinar profissionais iniciantes utilizando modelos baseados em evidências seria uma boa forma de difundir esse tipo tratamento, incentivado e reconhecido pela APA e por agências governamentais americanas, como o National Institute of Mental Health e o National Institute on Drug Abuse, e que têm gerado um elevado interesse em todo o mundo nas últimas duas décadas (Addis, 2002). No caso de terapeutas iniciantes e sem experiência na área, Kendall e cols. (1998) acrescentam que estes terapeutas devem seguir o manual de forma mais rígida do que os profissionais experientes; mas, em geral, estimula-se o uso de forma flexível e criativa, de acordo com as necessidades de cada criança. Nesses casos, os 
manuais servem para orientar os alvos e sugerir procedimentos que foram validados empiricamente. Por todas essas vantagens, considera-se que a ferramenta clínica manualizada proporcionou uma pequena revolução na psicoterapia, apesar de ainda haver resistência por parte de alguns profissionais (Kendall \& cols., 1998; Kendall \& Flannery-Schroeder, 1998).

Pretorius (2006) complementa que a supervisão dá oportunidade para os alunos aplicarem os princípios da TCC, como discutir as emoções e cognições dos pacientes, conceituar o caso, considerar o melhor tratamento e técnicas para que as metas sejam alcançadas e discutir e reconhecer as emoções e cognições do próprio terapeuta diante das situações clínicas, o que auxilia no treino de habilidades a serem utilizadas com o paciente. Para isso, indica que a discussão dos casos deve acompanhar o seguinte formato: apresentação das dificuldades do terapeuta, levantamento das hipóteses teóricas do caso e das respostas emocionais do terapeuta, para, enfim, se discutir a abordagem terapêutica a ser seguida. Recomenda o uso de gravações e medidas de competência para o treino das habilidades teóricas, práticas e reflexivas citadas por Bennett-Levy (2006).

Sabe-se hoje que o treinamento dos terapeutas tem impacto na adesão e nos resultados clínicos no atendimento de crianças e adolescentes (Michael \& cols., 2005; Weisz \& cols., 1987; Weisz \& cols., 1995b). Além disso, estudos na área apontam que a TCC é a abordagem indicada para o atendimento dessa mesma clientela (In-Albon \& Schneider, 2007; Ishikawa, Okajima, Matsuoka \& Sakano, 2007; Flannery-Shroeder \& cols., 2005; Manassis \& cols., 2002; Weisz \& cols, 1987; Weisz \& cols., 1995b). Devido a essas informações consistentemente apresentadas na literatura, houve um crescimento no uso da TCC na área infantojuvenil.

A TCC tem utilizado para o atendimento da clientela com ansiedade patológica intervenções individuais ou grupais, enfocando mudanças no pensamento, nas respostas fisiológicas e no comportamento, a partir do uso de protocolos de atendimento (Albano \& Kendall, 2002), conforme será apresentado a seguir.

\subsubsection{PRotocolos DE ATENDIMENTO EM TCC PARA ANSIEDADE INFANTOJUVENIL}

A ansiedade na infância, como em qualquer outra fase da vida, caracteriza-se por uma reação de luta-e-fuga diante da apresentação de um estímulo de perigo real ou imaginário. Quando excessiva, pode levar a intensas respostas fisiológicas devido à atividade do sistema nervoso simpático, que prepara e alerta o indivíduo para responder de forma apropriada ao perigo. Essa resposta de alerta, importante para a proteção do indivíduo, no entanto, quando 
"descalibrada" faz com que se atribua perigo a uma gama extensa de situações, experiências ou lugares, o que gera um medo intenso e uma preocupação desproporcional, chegando a ser paralisante em alguns momentos. A isso damos o nome de ansiedade patológica (Albano \& Kendall, 2002; Castillo, Recondo, Asbahr, \& Manfro, 2000; Stallard, 2009). A ativação dessa ansiedade patológica leva a uma hiperativação do sistema nervoso simpático e a uma alteração no processamento das informações, fazendo com que as crianças ansiosas supervalorizem o perigo e subvalorizem a própria capacidade de enfrentá-lo, gerando um comportamento permanente de esquiva e fuga (Albano \& Kendall, 2002; Castillo \& cols., 2000; Stallard, 2009).

A ansiedade patológica tem alta incidência na população infantojuvenil (Asbahr, 2004; Fleitlich \& Goodman, 2000; Harrinson, Boyle \& Farley, 1999; Nevo \& Manassis, 2009; Stallard, 2009). Albano e Kendall (2002) relatam que o risco individual para os transtornos de ansiedade na infância está associado a diversos fatores endógenos, como predisposição genética e temperamento; e exógenos, como estilo parental e história familiar. A prevalência de transtornos de ansiedade nesse período varia de $10 \%$ a $22 \%$, sendo considerado o transtorno mais comum em crianças (Castillo \& cols., 2000; Nevo \& Manassis, 2009; Stallard, 2009). Em se tratando de ansiedade na infância e em jovens, sabe-se que essas dificuldades são fatores de risco para outros transtornos, que, se não tratados, têm curso crônico e recaídas frequentes, de alto impacto ao longo da vida, no desempenho acadêmico e nos relacionamentos interpessoais (Barrett, Webster, \& Turner, 1999; Flannery-Schoeder \& Kendall, 2000; Flannery-Schoeder, Choudhury \& Kendall, 2005; Nevo \& Manassis, 2009).

Três tipos de intervenção para ansiedade infantojuvenil têm sido relacionados a resultados positivos e estatisticamente relevantes por replicações bem-sucedidas e devem ser consideradas no treinamento de profissionais para o atendimento dessa clientela, a saber: (a) modelagem, que consiste em observar o comportamento de enfrentamento de outra pessoa diante de situações temidas (e.g. do terapeuta, dos pares); (b) exposição reforçada (reinforced exposure), que consiste em exposição graduada a algumas situações temidas, preparadas previamente para favorecer o enfrentamento bem-sucedido que deverá ser reforçado; e (c) intervenções cognitivo-comportamental, que consiste em compreender as reações fisiológicas associadas à ansiedade e identificar e mudar os diálogos internos (inner thoughts) catastróficos e os comportamentos desadaptativos (e.g. evitação e fuga das situações temidas), que contribuem para a manutenção do problema (Weisz, Hawley \& Doss, 2004; Weisz \& Gray, 2008).

Nota-se que, diferentemente dos casos de externalização, há controvérsias em relação 
ao efeito da inclusão dos pais na intervenção para crianças/adolescentes ansiosos. Por um lado, os modelos teóricos enfatizam o papel recíproco entre diferentes comportamentos e atitudes dos pais e dos filhos no desenvolvimento e manutenção da ansiedade da criança, o que favorece a intervenção conjunta dos filhos com os pais (Bögels \& Phares, 2008; Hudson, Doyle \& Gar, 2009; McLeod, Wood \& Weisz, 2007). Por outro lado, os dados empíricos encontrados na literatura levantam algumas dúvidas ao apresentar resultados divergentes e inconsistentes ao incluirem os pais na intervenção clínica (Barrett, Dadds \& Rapee, 1996; Barrett, Duffy, Dadds, \& Rapee 2001; Barmish \& Kendall, 2005; Kendall, Hudson, Gosch, Flannery-Schroeder, \& Suveg, 2008; Silverman e cols., 1999; Wood, Piacentini, Southam-Gerow, Chu, \& Sigman, 2006).

Entre estes estudos clínicos, focalizaremos para análise os trabalhos de Barrett, Dadds e Rapee (1996) e Kendall e cols. (2008), para ilustrar a divergência existente quanto ao envolvimento parental e o seu impacto nos resultados terapêuticos. No estudo de Barrett e cols. (1996), que compara dois grupos experimentais (TCC individual para crianças ansiosas de 7-14 anos e TCC para crianças e pais) e um grupo controle (lista de espera), observa-se que $84 \%$ das crianças/adolescentes cujos pais receberam intervenção apresentaram melhoras significativas para ansiedade, enquanto resultados semelhantes foram conseguidos por $57 \%$ das crianças/adolescentes que receberam atendimento e $26 \%$ das do grupo controle, considerando o período de 12 semanas. O estudo indicou, portanto, uma supremacia de melhora com a inclusão dos pais na intervenção. Barrett e cols. (1996) e Barrett e cols. (2001) observaram um resultado superior na melhora da ansiedade quando se utiliza a intervenção combinada (criança e pais), verificada em follow-up de 12 meses, mas não em follow-up de 6 meses ou de 6 anos. Os referidos autores atribuem essa diferença de resultado avaliando que, aparentemente, a inclusão dos pais no atendimento de forma combinada tem maior impacto em crianças mais novas e meninas do que em jovens e meninos.

Por sua vez, no estudo de Kendall e cols. (2008), que comparou a eficácia de três condições de tratamento da ansiedade infantojuvenil (TCC individual para crianças/adolescentes ansiosos de 7-14 anos, combinação de TCC para crianças e pais e atenção suportiva/educacional para pais de ansiosos - Family Education/Support/Attention - FESA), observou-se que os participantes atribuídos no grupo de intervenção cognitivo-comportamental infantojuvenil e combinado obtiveram resultados superiores na melhora da ansiedade, em relação aos participantes que apenas os pais receberam orientação (FESA). No entanto, a similaridade dos resultados entre esses dois grupos (atendimento individual da criança e atendimento combinado - pais e criança) sugerem para os autores que incluir os pais na intervenção como 
clientes não é essencial, ainda mais quando se considera que no protocolo de atendimento infantil já há previsão de inclusão dos pais como colaboradores ao longo da intervenção.

Dessa forma, os protocolos existentes para este tipo de intervenção geralmente incluem a modelagem, a intervenção cognitivo-comportamental e a exposição reforçada, citadas por Weisz e cols. (2004) e Weisz e Gray (2008), e integram os pais como colaboradores e não como pacientes.

Alguns desses manuais de atendimento disponíveis na literatura foram empiricamente e extensamente avaliados e aplicados em diferentes estudos e avaliados seguindo as normas da APA com intervenção de provável eficácia (Chambless \& cols., 1998; Chambless \& Ollendick, 2001; Kazdin \& Weisz, 2010). Têm como características em comum: (a) orientarem o que fazer em cada sessão; (b) preconizarem grupos homogêneos quanto ao gênero; (c) terem aplicação, com pequenas variações, para clientela de diferentes escolaridades e situações socioeconômicas; (d) serem aplicáveis em atendimentos individuais e grupais, com no mínimo três participantes e no máximo doze; (e) levarem a melhora em longo prazo; e (f) oferecerem um modelo focal e breve, de 12 a 18 sessões (Barrett \& cols., 1996; Barrett \& cols., 1999; Kendall, 1992; Kendall \& Choudhury, 2003; Flannery-Schroeder \& cols., 2005).

Na Figura 1, apresenta-se um resumo do modelo dos alvos de intervenção dos protocolos para problemas internalizantes, que incluem alvos cognitivos, fisiológicos e comportamentais (Barrett \& cols., 1996; Hayward \& cols., 2000; Kendall \& Choudhury, 2003; Mendlowitz, \& cols., 1999). 


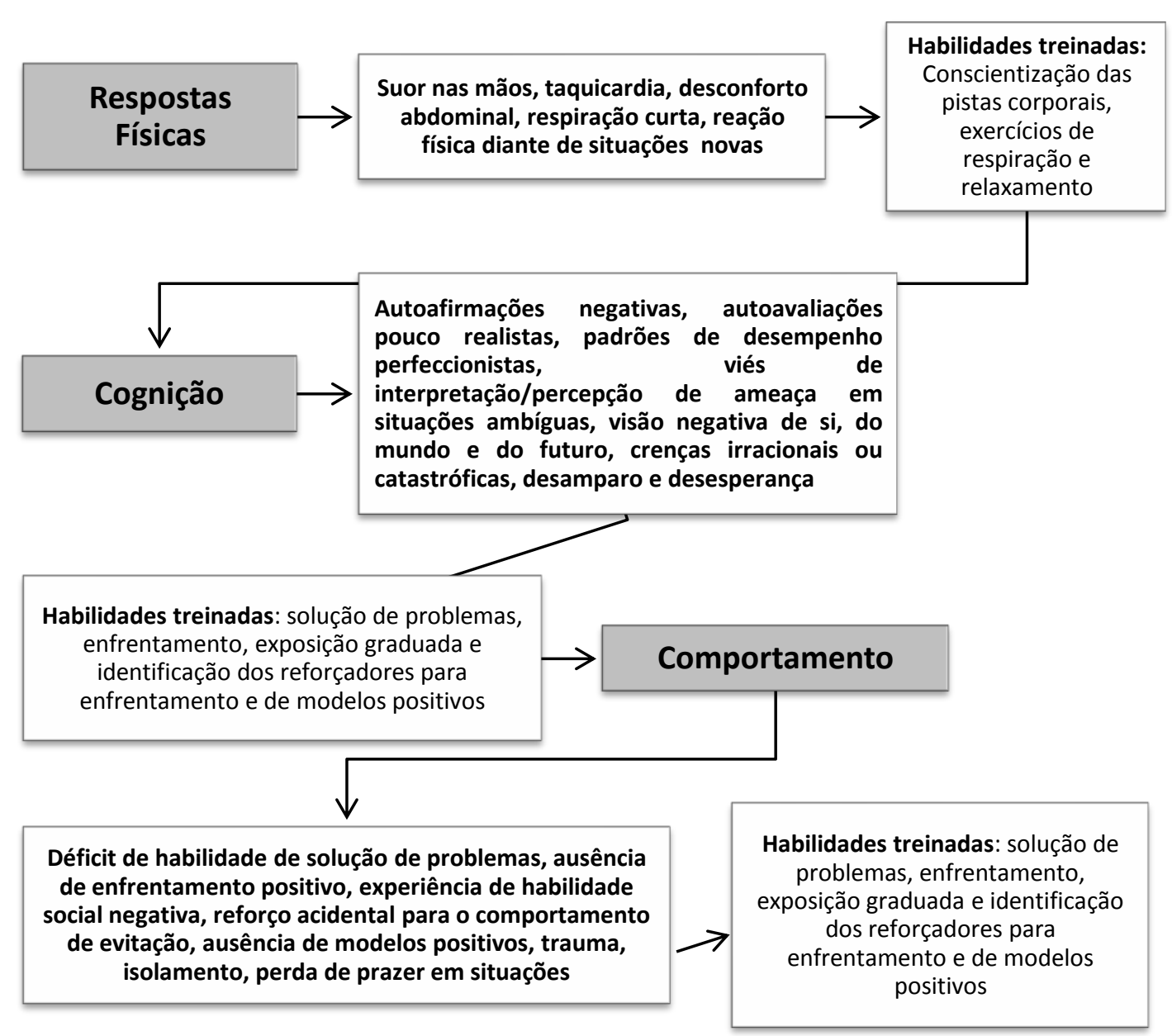

Figura 1. Resumo do modelo dos alvos de intervenção dos protocolos para problemas internalizantes (Adaptado de Barrett, e cols., 1999).

Seguindo o modelo de intervenção apresentado pela Figura 1, em 1992, foi publicado, por Philip Kendall, o protocolo mais avaliado pela literatura para atendimento individual de crianças ansiosas, denominado Coping Cat (Kendall, 1992). A descrição do modelo de intervenção de Kendall está apresentada na Figura 2. 


\section{Psicoeducativa (8 sessões)}

- Uso do acróstico da palavra MEDO

- Ensinar a reconhecer os sinais físicos associados à ansiedade, como taquicardia e respiração acelerada (M)

- Ensinar a identificar os processos cognitivos associados à ansiedade excessiva, como "se eu estou com taquicardia, logo estou em perigo!", denominados distorções cognitivas (E)

- Ensinar a manejar a ansiedade com a modificação dos pensamentos catastrósficos para pensamentos e atitudes de enfrentamento (D)

- Ensinar o autorreforço (O)

\section{Prática (8 sessões)}

- Aplicação do acróstico na prática com a exposição graduada em situações avalidas como ansiogênicas para a crianças

Figura 2. Descrição do protocolo Coping Cat (Fonte: Kendall, 1992).

Como demonstrado na Figura 2, o referido protocolo para atendimento individual consiste de 16 sessões realizadas a cada semana. A intervenção possui dois grandes objetivos divididos em duas etapas distintas e complementares, nas quais se utiliza como recurso terapêutico o acróstico da palavra MEDO, traduzido pela equipe do AMBULANSIA (IpQ-USP). Nessas 16 sessões, duas incluem os pais, com o objetivo de encorajar a responsabilidade ativa tanto da criança quanto da família no enfrentamento do problema; o treino de comunicação efetiva das emoções, exploração de crenças e expectativas em relação ao problema do filho, e o treino de solução de problemas. Nesse programa de intervenção, enfatizam-se mudanças emocionais e físicas a partir do reconhecimento das alterações dessas respostas pela ansiedade e o autocontrole; mudanças cognitivas, a partir da identificação e a alteração das autoafirmações catastróficas; e mudanças comportamentais, a partir de modelagem, exposição, role-play, treinamento de relaxamento e reforço contingente.

Em 1994, Kendall foi o primeiro a testar a eficácia de um protocolo em TCC com crianças ansiosas, ao avaliar o atendimento de 47 crianças com idade entre 9 e 13 anos, com transtornos de ansiedade, sendo que 27 foram designadas para intervenção e 20 ficaram na lista de espera. A intervenção foi realizada no formato individual, com 16 a 20 sessões em 16 semanas, com duração de 50' a 60', utilizando o programa Coping Cat. Além do atendimento das crianças, os 
pais eram atendidos em duas sessões ao longo das 16 semanas de intervenção. 0 resultado desse estudo foi encorajador, por pelo menos dois motivos principais: $42 \%$ dos participantes tratados e apenas $5 \%$ dos da lista de espera apresentaram redução da ansiedade, que foi avaliada como clinicamente significativa após a intervenção; e os ganhos foram mantidos no seguimento de 12 meses. De lá para cá, vários estudos foram publicados demonstrando provável eficácia da TCC nos quadros ansiosos. O protocolo usado por este estudo foi precursor de vários programas de atendimento de crianças ansiosas e, desde sua publicação, foi validado e adaptado para diferentes países (e.g. Coping Koala - Austrália - Barrett e cols., 1996; Coping Bear - Canadá - Mendlowitz e cols., 1999).

Devido ao número cada vez maior de profissionais da psicologia nos ambientes universitários, hospitalares e ambulatoriais, houve um aumento do interesse nos atendimentos grupais, que propiciam o atendimento de um número maior de pessoas em menor tempo, e uma adaptação desses modelos supracitados para atendimento grupal (White \& Freeman, 2000). A escolha e uso de intervenções grupais passaram a ser alvos de estudos recentes (e.g. Flannery-Shroeder \& Kendall, 2000; Flannery-Shroeder, Choudhury \& Kendall, 2005; Hudson, 2005; Mendlowitz e cols. 1999; Silverman e cols., 1999), indicando, inclusive, vantagens em relação ao atendimento individual, no que se refere ao tratamento da ansiedade, uma vez que possibilita a interação social, a mediação de pares (e.g. modelagem e reforço por pares, feedback), liderança e múltiplas exposições de medo associadas a interação ou situações sociais (Flannery-Shroeder \& Kendall, 2000; Flannery-Shroeder e cols., 2005; Mendlowitz e cols. 1999; Weisz e cols., 2004). Dando ouvidos a essa necessidade, Flannery-Schroeder e Kendall (1996) publicaram a versão grupal do Coping Cat, com 18 sessões programadas seguindo o mesmo delineamento do protocolo individual: nove sessões com foco no treino de habilidades, a partir do uso do acróstico "MEDO", e nove sessões de enfrentamento das dificuldades ansiogênicas pela exposição gradual, imaginária e ao vivo. $O$ protocolo grupal segue as mesmas diretrizes do individual e é aplicado em 18 semanas, com sessões de 90' a 120' de duração.

Mendlowitz e cols. (1999) avaliaram a aplicação do Coping Bear em 68 crianças ansiosas, de 7 a 12 anos, com 9 a 12 sessões grupais com periodicidade semanal, com duração de 1h30', sendo que cada grupo tinha no máximo 8 participantes, e eram coordenados por 2 terapeutas. Ao final da intervenção, as crianças apresentaram melhores resultados tanto para ansiedade como para depressão, do que as da lista de espera. Resultado similar ao de Barrett (1998), que avaliou a aplicação do Coping Koala, em 60 crianças e adolescentes australianas, com idade entre 6 e 17 anos, e que mostrou que o atendimento produziu significativas melhoras, mantidas 
no seguimento de 12 meses, similares às observadas no atendimento individual, apresentado no estudo de Barrrett (1996).

Flannery-Shroeder e Kendall (2000), em um estudo de comparação de intervenção em TCC grupal e individual, em uma amostra de 37 crianças e adolescentes, com idade entre 8 e 14 anos, aleatoriamente designados para atendimento com o Coping Cat, individual e grupal, e lista de espera, observaram que, após o tratamento, $73 \%$ das crianças que receberam atendimento individual e $50 \%$ das que receberam atendimento grupal deixaram de preencher os critérios para ansiedade. As medidas dos dois grupos foram similares, com exceção das medidas que avaliavam estresse infantil. Posteriormente, Flannery-Shroeder e cols. (2005) reavaliaram os participantes do estudo anterior, em seguimento de 12 meses, e observaram que as crianças continuaram a melhorar, uma vez que $81 \%$ dos que participaram do atendimento individual, e $77 \%$ das crianças que participaram do grupo deixaram de preencher os critérios de ansiedade. Estes dados do follow-up fizeram com que os autores avaliassem que ao longo do tempo não houve diferença entre os resultados das crianças que partiparam do atendimento individual e daquelas que participaram do atendimento grupal, defendendo assim a utilização do formato grupal no atendimento de crianças ansiosas, por considerar que este tipo de tratamento tem uma melhor relação custo-benefício.

Outros estudos com TCC para crianças ansiosas têm mostrado bons resultados. A intervenção grupal também levou a melhoras significativas na ansiedade, com ganhos mantidos nos seguimentos (e. g. Silverman e cols., 1999; Manassis e cols., 2002). Em outro estudo de revisão sistemática, Cartwright-Hatton e cols. (2004) avaliaram 10 estudos em TCC para o tratamento de crianças e adolescentes e encontraram, nos estudos avaliados, que $56,5 \%$ das crianças tiveram remissão dos sintomas na condição de intervenção grupal e 34,8\% na condição de lista de espera. Os autores também observaram que, ao longo do seguimento, as crianças mantiveram os ganhos e outras continuaram a melhorar.

Apesar dos benefícios encontrados no formato grupal, é importante salientar que algumas crianças se beneficiam mais com o atendimento individual (Flannery-Shroeder \& Kendall, 2000; Hudson, 2005; Manassis \& cols., 2002; Scoot \& Sembi, 2006). Nesse sentido, Hudson (2005), em um estudo de revisão, alerta que as crianças mais velhas, meninos, crianças deprimidas, crianças estressadas devido a disfunções familiares ou patologia parental, ou as crianças que se envolvem menos na intervenção, apresentam piores resultados com o formato grupal. Manassis e cols. (2002) acrescentam que observaram piores resultados no atendimento 
grupal quando a criança apresentava maior grau de ansiedade social.

Tanto Flannery-Shroeder, Choudhury e Kendall (2005) como Manassis e cols. (2002) indicam que tanto $\mathrm{o}$ atendimento grupal quanto $\mathrm{o}$ atendimento individual podem ser considerados como "provavelmente eficazes", segundo o critério 2 da APA, para crianças com ansiedade. Contudo, estudos de metanálise mais recentes sinalizam no sentido destas intervenções deixarem de ser classificadas como provavelmente eficazes e passarem a ser consideradas como de evidência bem estabelecida (Chorpita \& Southam-Gerow, 2006; In-Albon \& Schneider, 2007; Ishikawa, Okajima, Matsuoka \& Sakano, 2007; Weisz \& cols., 2006).

Diante da apresentação da existência de modelos de atendimento associados a resultados positivos de melhora na ansiedade patológica na infância e pela alta frequência da ansiedade na infância e adolescência, observa-se a necessidade de modelos de treinamento de terapeutas-estagiários para atendimento dessa clientela. Tendo o serviço-escola o papel primário de treinar competências no estagiário, observa-se a urgência de se avaliar que ações de treinamento seriam mais efetivas para aumentar as habilidades clínicas, a adesão da clientela atendida e os resultados terapêuticos.

Por todos os motivos supracitados, entende-se que o protocolo Coping Cat para atendimento grupal tem boa aplicação no treino de terapeutas de serviços-escola, ao orientar os supervisores e terapeutas iniciantes, e promover o atendimento mais breve com uma maior rotatividade da clientela, diminuindo, assim, a lista de espera para atendimento e, possivelmente, o abandono do tratamento. Ademais, não há nenhuma publicação nacional até o momento abordando o tema de treinamento de estagiários a partir de tratamento baseado em evidência para a clientela infantojuvenil, sugerindo a relevância e urgência do estudo na área. A seguir, apresentaremos os objetivos e as hipóteses que nortearam este trabalho. 


\section{OBJETIVOS, JUSTIFICATIVA E HIPÓTESES}

\subsection{OBJETIVO GERAL}

Elaborar e avaliar uma proposta de treinamento para estagiários no atendimento de crianças ansiosas, inscritas em serviços-escola ambulatoriais, a partir de um tratamento baseado em evidência e reconhecido internacionalmente para o atendimento dessas crianças - Manual Coping Cat adaptado para a realidade brasileira.

\subsection{OBJETIVOS ESPECÍficos}

3.2.1. Descrever o perfil sociodemográfico e de queixas da clientela dos serviços-escola incluídos nesta pesquisa (AMBULANSIA - SP e NAT/HRAS - DF);

3.2.2. Avaliar a adaptação e o uso do protocolo no treinamento de alunos em duas regiões brasileiras, a partir: (a) da descrição das competências gerais e específicas da TCC apresentadas pelos terapeutas-estagiários; (b) da percepção dos estagiários sobre o uso dessa ferramenta como treinamento de habilidades; e (c) da comparação dos resultados terapêuticos do grupo que recebeu intervenção $(\mathrm{Grl}) \times$ grupo controle $(\mathrm{GC})$, no pré-teste, pós-teste e nos seguimentos de três e seis meses.

\subsection{HIPÓTESES}

3.3.1. O perfil da clientela dos serviços-escola deste estudo se assemelharão com os da psicologia em relação a idade e escolaridade, mas se diferenciarão quanto a queixa.

3.3.2. O perfil da clientela de SP e DF, com queixa de ansiedade, será semelhante.

3.3.3. Os terapeutas-estagiários apresentarão ao longo do treinamento competências clínicas gerais e específicas à TCC identificadas por eles mesmos, pelos pares e pelos juízes.

3.3.4. O protocolo auxiliará os alunos a aprender a abordagem cognitivocomportamental e a atender as crianças ansiosas.

3.3.5. Ao final da aplicação do protocolo, as crianças terão menores índices de problemas emocionais e comportamentais, quando comparadas com elas mesmas no início do trabalho e com o grupo controle.

3.3.6. Os ganhos da intervenção serão mantidos ao longo de três e seis meses. 


\section{MÉTOdo}

\subsection{Participantes}

Os terapeutas-estagiários (TEs) foram recrutados em SP e no DF, por meio de anúncio verbal ou por divulgação em grupos on-line pela pesquisadora em quatro faculdades de psicologia: Instituto de Psicologia (USP-SP e UnB-DF), Faculdade Mackenzie (SP), Faculdade de Psicologia (UNICEUB-DF). Vinte e três alunos nas duas cidades se interessaram em participar do treinamento. Foram critérios de seleção dos TEs: (a) interesse em TCC com criança e adolescente; (b) estar no período de estágio curricular, preferencialmente a partir do quinto período; e (c) ter disponibilidade de horário para receber o treinamento e supervisão e para aplicar a intervenção. Treze alunos (7 de SP e 6 do DF) preencheram os referidos critérios e participaram de todo treinamento conforme demonstrado na Figura 3, que apresenta o fluxo dos alunos interessados e dos alunos que receberam o treinamento.

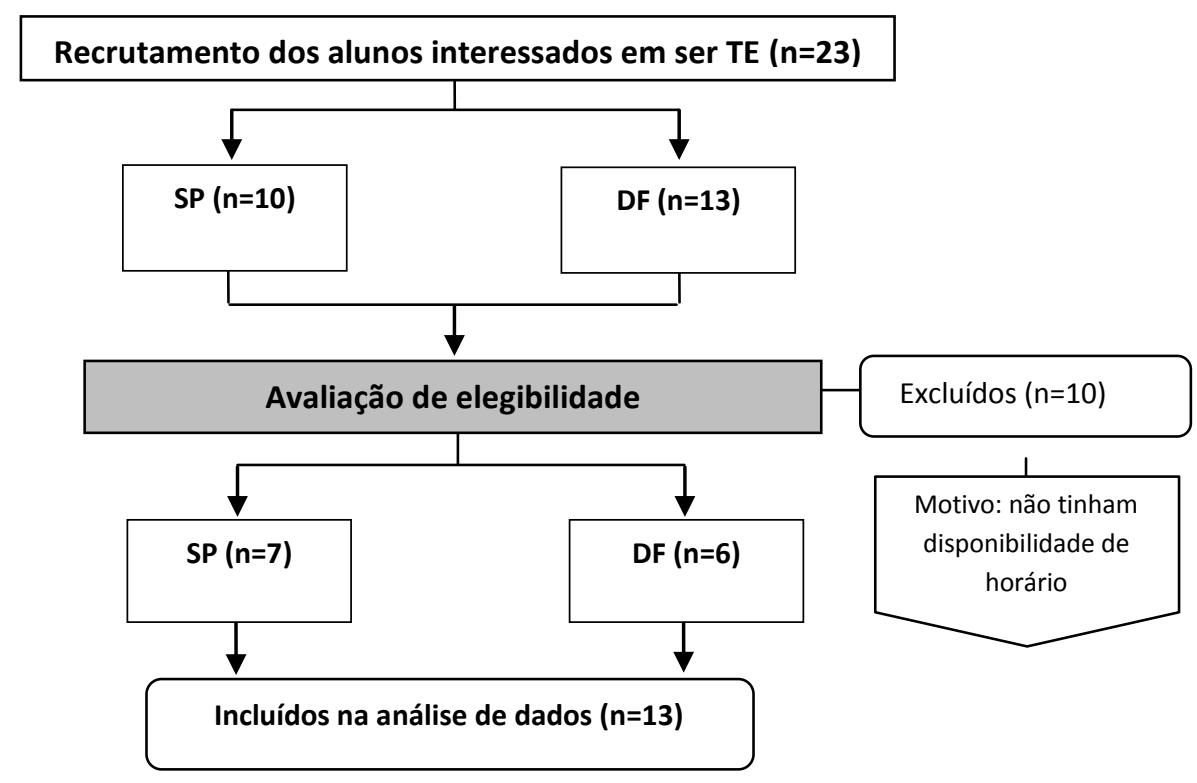

Figura 3. Fluxograma do recrutamento dos participantes TEs.

Na Tabela 1, constam os dados de caracterização pessoal e acadêmica e de experiência clínica dos TEs selecionados em SP e DF. 
Tabela 1. Caracterização do perfil dos TEs $(n=13)$

\begin{tabular}{|c|c|c|c|c|c|}
\hline & Idade & Sexo & Período & Universidade & Experiência clínica \\
\hline TE1 & 21 & Feminino & 80 & Mackenzie-SP & $\begin{array}{l}\text { Seis meses de grupo de recreação de } \\
\text { crianças, na abordagem } \\
\text { comportamental }\end{array}$ \\
\hline TE2 & 27 & Masculino & 80 & USP-SP & $\begin{array}{l}\text { Seis meses de atendimento individual } \\
\text { de adultos, na abordagem centrada na } \\
\text { pessoa. }\end{array}$ \\
\hline TE3 & 30 & Feminino & 70 & USP-SP & Nenhuma \\
\hline TE4 & 20 & Masculino & 80 & Mackenzie-SP & $\begin{array}{l}\text { Seis meses de atendimento individual } \\
\text { de adultos, na abordagem } \\
\text { fenomenológico-existencial }\end{array}$ \\
\hline TE5 & 20 & Feminino & 80 & USP-SP & $\begin{array}{l}\text { Um ano de atendimento individual de } \\
\text { adultos, na abordagem psicanalítica }\end{array}$ \\
\hline TE6 & 21 & Feminino & 80 & Mackenzie-SP & $\begin{array}{l}\text { Seis meses de atendimento individual } \\
\text { de adultos, na abordagem } \\
\text { psicodinâmica }\end{array}$ \\
\hline TE7 & 22 & Feminino & 80 & Mackenzie-SP & Nenhuma \\
\hline TE8 & 24 & Masculino & 80 & UnB -DF & $\begin{array}{l}\text { Experiência com reabilitação cognitiva } \\
\text { com adultos por } 6 \text { meses }\end{array}$ \\
\hline TE9 & 21 & Feminino & 80 & UnB -DF & $\begin{array}{l}\text { Atendimento clínico com idosos, por } 6 \\
\text { meses }\end{array}$ \\
\hline TE10 & 23 & Feminino & 90 & UnB -DF & Nenhuma \\
\hline TE11 & 22 & Feminino & $10^{\circ}$ & UnB -DF & $\begin{array}{l}\text { Experiência em Terapia de casal por } 6 \\
\text { meses }\end{array}$ \\
\hline TE12 & 22 & Feminino & 90 & UnB -DF & Nenhuma \\
\hline TE13 & 22 & Feminino & 80 & UnB -DF & $\begin{array}{l}\text { Experiência em Terapia de casal por } 6 \\
\text { meses }\end{array}$ \\
\hline
\end{tabular}

Na Tabela 1, de TE1 a TE7 correspondem aos da cidade de SP e de TE8 a TE13 aos do DF. Os dados da Tabela 1 demonstram que a idade dos TEs variou entre 20 e 30 anos, com predomínio (10/13) do sexo feminino, cursando 8o período do curso (9/13). Observa-se também que apenas TE1 tinha experiência na abordagem comportamental e com crianças, mas mesmo assim não era em intervenção clínica. Os demais ou não tinham nenhuma experiência (4/13) ou tinham experiência com atendimento em outra abordagem e com adultos (8/13). 


\subsection{INSTRUMENTOS E MATERIAIS}

\subsubsection{INSTRUMENTOS}

Os instrumentos utilizados nessa pesquisa foram diferenciados em medida de caracterização do perfil da clientela, medidas clínicas, medidas de treinamento, e medida de avaliação do protocolo.

\subsubsection{MEdida DE CARACTERIZAÇão Do PERFIL DA CLIENTELA}

Esta medida foi adaptada por meio do Inventário de Levantamento de Atividades das Clínicas-escola do Projeto Temático Clínicas-escola, do Grupo Temático da Associação Nacional de Pesquisa e Pós-Graduação em Psicologia (ANPEPP), coordenado pela professora Edwiges Silvares. O instrumento adaptado, denominado Ficha de Identificação, permitia avaliar os dados pessoais dos usuários dos serviços e dos cuidadores, nível socioeconômico da família, encaminhamento para o serviço e queixa inicial. $\mathrm{O}$ instrumento original agrupou as queixas iniciais de acordo com a categorização já utilizada nos estudos da Prof ${ }^{a}$ Maria Lúcia Tiellet Nunes, componente do grupo (ver artigo Campezatto \& Nunes, 2007) e inclui dez agrupamentos de queixas, a saber: (a) dificuldades cognitivas (de aprendizagem, de inteligência, problemas de atenção, de compreensão ou de memória); (b) dificuldades no comportamento afetivo (agressividade, ansiedade, isolamento social, depressão, choro frequente, dependência, imaturidade, temores, etc.); (c) dificuldades de relacionamento interpessoal (dificuldade com os colegas, com outras crianças, com adultos, com familiares, etc.); (d) dificuldades na vida diária (desorganização, capacidade de alimentar-se sozinho, vestir a roupa, etc.); (e) dificuldades na esfera sexual (masturbação, comportamento sexual pouco apropriado para idade - por exemplo: aborda meninos/meninas, se interessa pelo assunto excessivamente, etc.); (f) sintomas físicos (problemas médicos, como diabetes, hipertensão, alergias, cardiopatias); (g) distúrbios orgânicos (problemas neurológicos, como epilepsia, traumatismo craniano, hidrocefalia, etc.); (h) distúrbios de alimentação ou sono (tanto para mais - comer muito e dormir mais que as demais crianças na mesma idade -, quanto para menos; pesadelos; terror noturno; ingerir coisas não adequadas, como cabelo, terra, etc.); (i) dependência química; e (j) distúrbios psiquiátricos (Anexo 1).

\subsubsection{MEDIDAS CLÍNICAS}

A avaliação dos transtornos da infância envolve julgamento do desenvolvimento normal e disfuncional, tendo como referência a variação do desempenho de um grupo representativo. Esse trabalho se torna complexo, principalmente pelas dificuldades de expressão verbal e de 
conhecimento sobre as próprias emoções e ações da população infantil. Isso faz com que os pais tenham um papel crucial na identificação e comunicação das dificuldades da infância, uma vez que a convivência doméstica possibilita a observação do comportamento problema no momento e no ambiente em que ele ocorre. Considerando isso, diferentes medidas para pais e para crianças foram escolhidas por serem empiricamente validados e pela representatividade na literatura internacional, a saber:

\section{Instrumentos de Avaliação parental}

\section{O Inventário dos Comportamentos para Crianças e Adolescentes entre 6 a 18 anos} (CBCL6/18 anos), na versão preliminar de Bordin, I. A.; Silvares, E. F. M.; Rocha, M. M.; Teixeira, M. C.; e Paula, C. S., avalia, em 138 itens, a percepção parental do filho (Emerich, \& Rocha, 2010). As respostas dos pais são analisadas por um software que transforma os escores brutos em Escores T - medida estatística utilizada pelo referido sistema, que converte diferentes medidas em escalas, que avaliam competência social e problemas emocionais/comportamentais e diferencia os escores em perfil não clínico, limítrofe e clínico. Para este estudo, os escores limítrofes e clínicos foram agrupados como clínicos, considerando como ponto de corte clínico para as Escalas Individuais de Competência (em Atividade, Social e Escolar) o escore $T \leq 35$ e na Soma das Escalas de Competência o escore $T \leq 40$; para as Escalas Individuais de Problemas Emocionais/Comportamentais (Ansiedade/depressão, Retraimento/depressão, Problemas de Pensamento, Problemas Sociais, Problemas de Pensamento, Problemas de Atenção, Violação de Regras, Comportamento Agressivo), o escore $T \geq 65$ e na Soma das Escalas de Internalização, Externalização e Total de Problemas o escore $T \geq 63$. Este instrumento é considerado pela literatura um dos mais confiáveis para a avaliação de dificuldades comportamentais e emocionais para a clientela infantojuvenil de 6 a 18 anos (Holmbeck e cols., 2007). Achenbach (2004) demonstrou que o inventário original possui uma alta consistência interna, fidedignidade de teste-reteste e boa validade de construto de critérios.

SNAP-IV, elaborado para uma pesquisa multicêntrica americana, é uma escala que avalia sintomas de Transtorno de Déficit de Atenção e Hiperatividade e Transtorno Desafiador Opositivo em 26 afirmativas, agrupadas em três subescalas: (a) desatenção (TDAH/D), (b) hiperatividade/impulsividade (TDAH-H/Im), e (c) desafiador opositivo (TDO). Esse instrumento foi construído a partir dos critérios diagnósticos do DSM-IV, em que os pais e/ou professores têm que marcar entre as opções que melhor representam como o filho se comporta, entre quatro possibilidades - nem um pouco, só um pouco, bastante e demais. Para o cálculo do 
escore total de cada subescala, realiza-se a soma dos pontos atribuídos pela mãe nas questões que compõem os três agrupamentos; a seguir, esta soma é dividida pelo número de itens de cada grupo (desatenção e hiperatividade - 9 itens cada, e desafiador opositivo - 8 itens), resultando em uma média, que é avaliada como clínica a partir das seguintes notas de corte: TDAH/D: 1,8; TDAH-H/Im: 1,4; e TDO: 1,8. O instrumento original americano tem propriedades psicométricas consideradas sólidas e foi adaptado para o Brasil por Mattos, Serra-Pinheiro, Rohde e Pinto(2006).

Instrumentos de Autoavaliação

O Modelo Multidimensional de Ansiedade Infantil (Multidimensional Anxiety Scale for Children - MASC) é uma medida de autorrelato, elaborada por March e cols.(1997), está a validar no Brasil. Avalia a ansiedade em crianças e adolescentes com idades entre 8 e 19 anos, mediante a apresentação de 39 afirmativas que devem ser respondidas em uma escala de quatro pontos (0 - nunca acontece comigo, 1 - raramente acontece comigo, 2 - às vezes acontece comigo e 3 - sempre acontece comigo). Os itens são distribuídos em quatro subescalas, que avaliam sintomas físicos, evitação de perigo, ansiedade social e ansiedade de separação. Os escores brutos são transformados em escores ponderados, por gênero e idade. 0 grupo do AMBULANSIA/IPQ-USP utiliza como referência de análise os seguintes escores ponderados totais: 50, correspondendo à média; 56 a 60, discretamente acima da média; 61 a 65, acima da média; 66 a 70, muito acima da média; e acima de 70, drasticamente acima da média. Para este estudo, considerou-se escore clínico a partir de 61 . O inventário original é considerado um instrumento empiricamente bem estabelecido (Holmbeck e cols., 2007). No Brasil, foi validado por Michelle Nunes, mas ainda não foi publicado. Segundo Silva e Figueiredo (2005), o MASC está entre os 15 instrumentos mais utilizados para avaliar ansiedade infantil (Anexo 2).

O Inventário de Depressão Infantil (CDI) é uma medida de autorrelato, elaborada por Kovács em 1983 nos Estados Unidos, a partir de uma adaptação do BDI (Inventário de Depressão de Beck). Avalia sintomas de depressão em crianças e adolescentes com idade entre 7 e 14 anos, mediante a apresentação de 27 itens, para os quais existem 3 alternativas de resposta sob a forma de afirmativas que devem ser escolhidas pela criança. Cada afirmativa tem uma pontuação que varia de 0 a 2 . 0 escore total é calculado pela soma das pontuações referentes às escolhas da criança, que é transformada em um percentil estimado considerando o sexo e a idade da criança. Considera-se clinicamente significativo o percentil a partir de 85 . Na versão 
brasileira de Gouveia, Barbosa, Almeida e Gaião (1995) e na avaliação mais recente de Coutinho, Carolino e Medeiros (2008), o instrumento obteve parâmetros psicométricos aceitáveis (Anexo 3).

Raven Infantil - Matrizes Progressivas Coloridas, teste de inteligência realizado para excluir retardo mental da amostra; avalia a inteligência geral de crianças e adolescentes, por meio de 36 itens divididos em três séries. Os itens do teste são apresentados sob forma de desenho ou matriz, disposta em ordem de dificuldade crescente. A tarefa da criança consiste em escolher, entre as alternativas colocadas na metade inferior da página, a que melhor completa a parte que falta no desenho. Os totais parciais de cada série permitem determinar a consistência da pontuação, que indica a validade do resultado. O total de acertos é convertido em percentil. Pode ser aplicado individualmente ou coletivamente, em grupos de 8 a 9 crianças (Bandeira \& cols. 2004).

\subsubsection{MEDIDAS DO TREINAMENTO}

O treinamento foi avaliado mediante preenchimento de dois instrumentos similares, baseados em um inventário americano que é referência na literatura da área, conforme a orientação teórica do protocolo, que avalia habilidades e competências que devem ser demonstradas nas sessões e ao longo do atendimento. Um instrumento foi utilizado com o próprio aluno e com os pares e outro com juízes independentes.

\section{Lista de Verificação de Competência para Terapeutas Cognitivo-Comportamentais,} baseada no Cognitive Therapy Scale (CTS), desenvolvida por Young e Beck em 1980, foi adaptada para situação grupal e avaliou o desempenho do terapeuta em 18 itens, agrupado em quatro partes, a seguir descritas:

Parte I - Habilidades Terapêuticas Gerais - avalia em uma escala de 0 a 6 seis competências dos TEs, a saber: agenda, que consiste na habilidade para estabelecer com o grupo o que será trabalhado no dia; feedback, que consiste na habilidade de dar retorno verbal e não verbal durante a sessão, demonstrando compreensão e aceitação; compreensão, que consiste na capacidade de entender e escutar o paciente e de ser empático; efetividade pessoal, que consiste na habilidade de ser caloroso, genuíno e profissional, ao longo do atendimento; colaboração, que consiste na habilidade em encorajar o paciente, estabelecer bom vínculo e obter a colaboração do paciente nas atividades propostas; e ritmo e uso suficiente do tempo, que consiste na capacidade de usar o tempo eficientemente, respeitando o ritmo do grupo e 
mantendo o foco na agenda.

Parte II - Habilidades Terapêuticas Específicas - avalia, em uma escala de 0-3 ou 0-6, as seguintes competências dos TEs: descoberta guiada (0-6), que consiste na habilidade em questionar, explorar e encontrar solução para problemas juntamente com os componentes do grupo; focalizando em temas centrais ou comportamentais (0-6), refere-se à habilidade de focar nas cognições ou comportamentos mais centrais; estratégias de mudança (0-3), que consistem no uso de estratégias cognitivo-comportamentais que auxiliam na mudança de cognições e comportamentos disfuncionais; aplicações de técnicas cognitivo-comportamentais (0-6), que se referem à habilidade e perícia do terapeuta no uso e aplicação das técnicas; tarefa de casa (0-3), que consiste na capacidade de rever as tarefas previamente solicitadas e atribuir novas tarefas a partir da agenda do dia e da meta a ser alcançada.

Parte III - Considerações Adicionais - avalia se houve problemas especiais durante a sessão ou fatores não usuais que justificariam o afastamento do TE nas competências medidas no CTS e o quão bem o TE manejou a situação (0-6).

Por fim, a Parte IV - Avaliação Geral - avalia o desempenho geral do terapeuta como um terapeuta cognitivo-comportamental (0-6), qual seria a chance do TE ser selecionado pelo avaliador para participar de uma pesquisa em TCC (0-4) e o quanto o grupo de atendimento foi difícil de trabalhar (0-6). Avalia também o desempenho geral do TE (0-5). Foi utilizado pelos próprios TEs e pelos pares (Anexo 4).

Checklist de Juízes, adaptado com base nos itens da Lista de Verificação de Competência para Terapeutas Cognitivo-Comportamentais (CTS), para que juízes experts na abordagem clínica do protocolo pudessem avaliar: a fidelidade do tratamento, ou seja, o quanto os alunos seguiram os eixos do protocolo; e o desempenho dos TEs como terapeutas. Esse instrumento foi dividido em duas etapas. Na Etapa I, os juízes avaliaram a fidelidade ao protocolo; e, na Etapa II, avaliaram o desempenho do terapeuta, considerando as quatro partes consideradas pelo CTS: Parte I - Habilidades Gerais; Parte II - Habilidades Específicas; Parte III - Considerações Adicionais e Parte IV - Avaliação Geral (Anexo 5).

\subsubsection{MEDIDA DE AVALIAÇÃO DO PROTOCOLO}

A avaliação do protocolo se fez necessária para avaliar a adaptação do manual e sua aplicabilidade para a realidade brasileira e para treinar alunos em intervenções para crianças ansiosas. Foi utilizada uma medida nos estagiários, Inventário para Estagiário, para avaliar a 
percepção do aluno sobre o uso do protocolo como ferramenta para treinar terapeutas e para atender crianças ansiosas, por meio de 16 questões, nas quais o aluno avaliava, entre 5 opções apresentadas, qual melhor representava o que ele observou, e por meio de 4 perguntas abertas, a saber: (a) considerando o protocolo como uma ferramenta para atendimento de crianças ansiosas, em sua opinião, qual é o ponto forte e o ponto fraco que ele apresenta?; (b) considerando o protocolo como treino de TEs para o atendimento de crianças ansiosas, em sua opinião, qual é o ponto forte e o ponto fraco deste tipo de ferramenta para treinamento clínico?; (c) para você, o que foi mais difícil?; e (d) quais são as suas sugestões para um próximo treinamento com este protocolo? (Anexo 6).

\subsubsection{MATERIAIS}

Foram utilizados: duas filmadoras, materiais de filmagens para registro de todas as sessões de intervenção e equipamentos para edição e reprodução do material filmado; cópias dos instrumentos a serem aplicados; pastas com caneta; lápis pretos; borrachas; 11 cópias do manual do terapeuta; 66 cópias do material do protocolo, que inclui 33 cópias do livro de exercício a ser aplicado na sessão e 33 cópias do caderno de exercício com tarefas a serem realizadas em casa pelas crianças; cópias dos pontos a serem utilizados como reforçadores; livros de estórias; e material lúdico diverso para uso na sessão e como reforço.

\subsection{Procedimento}

Após a explicação rápida sobre o que se tratava a pesquisa em questão, os alunos que preencheram os critérios de seleção assinaram o Termo de Consentimento Livre e Esclarecido (Anexo 7). O procedimento do treinamento para estes alunos foi diferenciado, considerando as duas etapas do estudo: caracterização dos serviços (Etapa I) e intervenção (Etapa II). A Tabela 2 demonstra a programação do treinamento realizado com os alunos conforme a etapa do estudo. As duas etapas incluíram treinamento teórico e prático e totalizaram $250 \mathrm{~h}$ de treinamento. 
Tabela 2. Programação do treinamento teórico e prático dos TEs.

\begin{tabular}{|c|c|c|c|}
\hline & & Descrição & $\mathrm{C} / \mathrm{H}$ \\
\hline \multirow{2}{*}{ 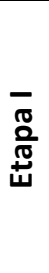 } & :. & $\begin{array}{l}\text { Explicação da pesquisa, treino nas medidas clínicas, } \\
\text { desenvolvimento normal e patológico e transtorno de } \\
\text { ansiedade }\end{array}$ & $20 \mathrm{~h}$ \\
\hline & $\frac{.0}{\frac{\pi}{2}}$ & Coleta dos dados do perfil da clientela & $96 \mathrm{~h}$ \\
\hline \multirow{3}{*}{ 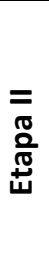 } & :.ֻ & $\begin{array}{l}\text { Treino de habilidades terapêuticas em terapia cognitivo- } \\
\text { comportamental e treino no protocolo }\end{array}$ & 44 \\
\hline & . ․․ & Prática clínica supervisionada & $80 \mathrm{~h}^{*}$ \\
\hline & $\frac{5}{2}$ & Seguimento & $10 \mathrm{~h}$ \\
\hline
\end{tabular}

Legenda: $\mathrm{C} / \mathrm{H}$. carga horária;

*cada trio realizou $20 \mathrm{~h}$ de supervisão clínica; 20h de intervenção; 40h de planejamento e organização para intervenção, correção das medidas clínicas, relatórios e reposição; e $10 \mathrm{~h}$ de avaliação pós-intervenção.

\subsubsection{ETAPA I - CARACTERIZAÇÃo DOS SERVIÇOS}

O treinamento teórico foi realizado em sete semanas e teve a duração de $20 \mathrm{~h}$, em que foram utilizadas aulas teóricas, discussão, vinhetas, artigos e textos, e uso de dramatização simulando a aplicação e correção dos instrumentos. O manual deste treinamento se encontra no Anexo 8.

Após o treinamento teórico, os alunos foram apresentados para a equipe dos serviços e iniciaram a coleta de dados, que teve a duração de $96 \mathrm{~h}$, com o objetivo de colocar em prática as informações recebidas no treino teórico. A avaliação do perfil das crianças e adolescentes usuárias do serviço, de agora em diante designadas pelas letras CrU de criança usuária, ou CrUs de crianças usuárias, foi pensada em função de se julgar importante graduar o treinamento dos alunos em avaliação clínica e a aproximação destes com a clientela a ser atendida; bem como permitir a melhor seleção das CrUs elegíveis para intervenção. Após a coleta de dados, os alunos, juntamente com a pesquisadora, discutiam os casos, avaliavam o procedimento realizado e a indicação das crianças avaliadas para a Etapa II.

Os dados foram coletados considerando a rotina dos serviços, de modo a interferir o menos possível no andamento dos atendimentos. Em SP, o AMBULANSIA é um ambulatório especializado no atendimento de ansiedade infantojuvenil até 18 anos. A equipe voluntária da psicologia clínica já atendia a clientela com o protocolo Coping Cat, traduzido pelo grupo por Gato Corajoso. A coleta dos dados de levantamento foi realizada entre junho e setembro de 2009, com os usuários e cuidadores agendados para a consulta e com os candidatos a usuários 
que tinham feito uma pré-triagem, mas ainda não tinham entrado para o serviço. A inclusão dessas crianças pré-triadas ocorreu devido aos 50 usuários avaliados inicialmente já estarem em atendimento psicológico ou terem idade maior que 13 anos, de maneira que esta primeira avaliação foi útil para o treino prático dos alunos, mas não para seleção da amostra elegível para intervenção, Etapa II do treinamento. A partir da avaliação dos pré-triados, foi estabelecido que já seriam aplicadas todas as medidas clínicas (SNAP, CDI e MASC), e não apenas a Ficha de Identificação e o CBCL, como feito inicialmente. Depois de estabelecer este novo procedimento, 24 crianças pré-triadas foram agendadas por telefone, no período de agosto a setembro de 2009. Destes, 19/24 compareceram e foram atendidos por duplas de alunos. Enquanto um aplicava a Ficha de Identificação, o CBCL e o SNAP IV no cuidador, o outro aplicava o MASC, CDI e RAVEN na criança/adolescente. Todos os pais abordados aceitaram participar da coleta.

No DF, o NAT atendia queixas múltiplas em saúde mental de crianças/adolescentes entre 0 e 14 anos. Sessenta e três crianças foram agendadas previamente pelo telefone e 53 compareceram. A coleta dos dados foi realizada com todos os pré-triados pelo serviço, entre junho e setembro de 2010, com queixa associada a quadros de ansiedade. Para esta etapa no DF, utilizou-se o mesmo procedimento utilizado com os pré-triados em SP, no qual foi aplicado nos cuidadores a Ficha de Identificação, o CBCL e o SNAP IV, e nas crianças/adolescentes, o MASC, o CDI e o Raven.

Nessa coleta, os alunos tanto de SP, como do DF, se revezavam no agendamento das crianças a serem avaliadas, na preparação do material a ser utilizado e na análise e tabulação dos dados. A digitação dos dados coletados era realizada no próprio serviço, que tinha um computador com o software ADM já instalado. O tempo médio gasto para esta etapa foi de $1 \mathrm{~h} 30$.

Nos dois serviços foram avaliadas 112 CrUs, sendo 69/112 de SP e 58/112 do DF. Dos 112 CrUs avaliados, selecionaram-se as crianças elegíveis para a intervenção, denominadas de agora em diante pelas letras $\mathrm{Crs}$ de participantes crianças, conforme os critérios estabelecidos para a intervenção, a saber: ter idade entre 9 e 13 anos, saber ler e escrever, passar pela avaliação completa pré-intervenção, obter escore clínico na Escala de Ansiedade/Depressão ( $\geq 65$ ) e na Soma das Escalas de Internalização $(\geq 63)$ do $C B C L$, aceitar participar e estar ciente e concordar com os termos da pesquisa (criança e cuidador). Além da exigência destes critérios, foram excluídos aqueles que apresentavam deficiência física ou mental, sintomas psicóticos, quadros graves de problemas externalizantes e transtorno obsessivo-compulsivo. Após esta 
seleção, 36 crianças foram indicadas para participarem da intervenção. As Crs selecionadas foram distribuídas nos grupos de intervenção $(\mathrm{Grl})$ e grupo controle $(\mathrm{GrC})$, conforme a disponibilidade de horário e ordem de inscrição.

\subsubsection{ETAPA II - INTERVENÇÃO CLÍNICA}

No primeiro semestre de 2008 , todo o material do protocolo original foi traduzido e adaptado pela pesquisadora deste trabalho, estimando um tempo para o desenvolvimento de cada atividade, por considerar que os alunos teriam dificuldade na aplicação do protocolo sem esta informação. Ao finalizar a tradução e adaptação, observaram-se outras duas necessidades. A primeira, de diminuir o número de sessões do protocolo original, devido ao receio de desistência dos CrUs. Em contato com o autor do protocolo original - Prof. Philip Kendall, da Temple University -, optou-se pela redução do protocolo para 10 sessões semanais, com 2 horas de duração, e três sessões de seguimento. Segundo Kendall, em contato pessoal, a aplicação do protocolo individual resumido (de 16 sessões para 8 sessões) levou a resultados favoráveis, similares à intervenção aplicada em 16 sessões semanais.

A segunda necessidade identificada referiu-se a tornar o material a ser utilizado mais lúdico para as crianças do que o material original americano, de modo a auxiliar os alunos na aplicação da intervenção. Para isso, foram escolhidos três livros de estória infantil, um jogo de quebra-gelo (Caixa Mágica para Crianças), e dois jogos de tabuleiro existentes no mercado para serem incluídos no protocolo (Sobre e Desce e Guerra do Stress); e construídos os seguintes materiais: (a) Termômetro do Medo - para ajudar as crianças a mensurarem a intensidade do medo, diferenciado por gênero, impresso em cores, papel sulfite 200g (Anexo 10); (b) Painel de lona impresso em cores, com as letras do acróstico do MEDO, com placas de PVC contendo as palavras que compõem cada letra do acróstico, adesivadas em preto, afixadas por velcro (Anexo 11); (c) placa de imã com o acróstico do MEDO (Anexo 12); (d) tapete redondo de lona, com 90 $\mathrm{cm}$ de circunferência, impresso em cores para auxiliar as crianças a discriminarem situação ativadora, pensamentos, emoções, respostas fisiológicas e comportamento (Anexo 13); (e) Jogo de cartas: "Tô por uma" - protótipo de um jogo de autoria da pesquisadora, com 96 cartas distribuídas em: 18 cartas especiais, 6 curingas, 9 cartas de respostas emocionais, 9 cartas de respostas fisiológicas, 15 cartas com exemplos de respostas emocionais e 15 cartas com exemplos de respostas fisiológicas, com o objetivo de ajudar as crianças a diferenciarem as respostas emocionais e fisiológicas, por meio de uma atividade lúdica (Anexo 14). 
Além destes materiais lúdicos, a pesquisadora construiu materiais que auxiliaram o treinamento dos TEs e a intervenção: (a) CD de áudio com o relaxamento para crianças, como modelo para TEs; (b) placa de PVC branco com 50 × 30, com velcro, com as palavras AGENDA DO DIA adesivadas à esquerda, com 10 plaquinhas adesivadas com figuras vinculadas ao tema da agenda de cada dia, no tamanho $8 \times 8$, com velcro, para serem afixadas no quadro maior (Anexo 15); e (c) Banco de pontos impresso em cores, adesivado em um imã, para marcar os pontos de todas as crianças pela realização da tarefa de casa descritas no protocolo como Tarefa Eu Consigo e a Tarefa Amigo. No Painel da Tarefa Amigo cada criança era representada por um imã colorido em forma de gato (Anexo 16).

A pesquisadora fez uma logomarca do programa de atendimento (Anexo 17); camisetas $100 \%$ algodão, impressas com a imagem do Gato Corajoso, que foram entregues ao final da intervenção para cada criança, TEs e juízes, e botton impresso com a imagem do Gato Corajoso, que foram entregues como brindes de participação (Anexo 18), e certificados para participantes crianças (Anexo 19) e os TEs (Anexo 20), impresso em papel couchê branco, para certificar a participação de cada um.

Preparado o material, deu-se início ao treinamento dos TEs na intervenção clínica. Esta etapa teve como objetivo treinar habilidades clínicas em TCC, para atendimentos de crianças ansiosas, com o uso de um protocolo empiricamente validado. A parte teórica, com duração de $44 \mathrm{~h}$, foi composta de aula expositiva, discussão de textos e de casos, apresentação de vinhetas filmadas de situações clínicas, e dramatização das cinco primeiras sessões do protocolo. Ao final da parte teórica, cada estagiário recebeu uma cópia do manual de treinamento da Etapa II (Anexo 21), que incluía o material do protocolo (manual do terapeuta e caderno de exercício). Na sequência, foram montadas as equipes de terapeutas compostas por três componentes por grupo de intervenção $(\mathrm{Grl})$, de acordo com a disponibilidade de tempo de cada um, combinada com a disponibilidade das crianças indicadas para a Etapa II.

Em seguida, deu-se início à parte prática de intervenção clínica grupal. Esta etapa, com duração em torno de dez semanas, teve carga horária de 80h para cada equipe de terapeutas, distribuídas em $20 \mathrm{~h}$ de atendimento clínico grupal, $20 \mathrm{~h}$ de supervisão e $40 \mathrm{~h}$ de planejamento e preparação do material clínico (material de filmagem, cópias, atividades), reposição individual das Crs que faltavam à sessão, correção dos instrumentos aplicados e lançamento nas planilhas. Além destas $80 \mathrm{~h}$, outras $10 \mathrm{~h}$ foram consideradas para a avaliação do seguimento e correção dos instrumentos aplicados. 
Antes de iniciar o atendimento, foi realizado um cronograma para determinar as funções de cada terapeuta em cada sessão, uma vez que os três TEs se revezavam nos papéis de terapeuta, coterapeuta e observador. Cabia ao terapeuta do dia a função de se preparar para aplicação do protocolo e providenciar o material necessário para a sessão do dia; o coterapeuta era encarregado de auxiliar o terapeuta do dia no que fosse necessário antes e durante a sessão; e cabia ao observador preparar a sala, a filmadora, filmar a sessão e auxiliar o terapeuta e coterapeuta, caso necessário. Todas as filmagens foram arquivadas como material de pesquisa na videoteca do Laboratório de Terapia Comportamental (USP), de responsabilidade das professoras Sônia Meyer e Edwiges Silvares, cujo acesso é controlado e restrito.

\subsubsection{SUPERVISÃO CLÍNICA}

Por se tratar de treinamento clínico, foi necessário garantir que a prática fosse supervisionada. Na supervisão clínica, tinha-se o objetivo de orientar os TEs em relação ao uso do protocolo e apresentar aos alunos a abordagem cognitivo-comportamental. Este papel foi assumido, nas duas cidades, pela pesquisadora, que possui vinte anos de experiência na área clínica tanto em TCC como no atendimento infantojuvenil. As supervisões foram realizadas semanalmente com cada equipe de trabalho, sendo duas em SP e duas no DF, e tinham a duração de $2 \mathrm{~h}$ cada. Na supervisão se discutia o que ocorreu na sessão anterior e preparava-se, juntamente com os alunos, o que fazer na sessão seguinte, tendo sempre o protocolo como norteador da intervenção. Aproveitou-se a ansiedade dos TEs como uma forma de treinar as mesmas habilidades de manejo de ansiedade infantil preconizadas pelo protocolo, de modo que em toda supervisão era utilizado o acróstico com os alunos, o termômetro do medo, e levantavam-se os possíveis problemas e as possíveis soluções. Dessa forma, cada sessão era para o terapeuta uma exposição programada, que tinha como apoio os demais pares. No momento da supervisão era identificada a necessidade de se construir algum material acessório, de acordo com a impressão e necessidade dos alunos. Os alunos eram estimulados para criar e preparar este material.

Para prevenir problemas metodológicos, pelo fato de a pesquisadora treinar e supervisionar os TEs, a avaliação do desempenho dos TEs foi realizada por eles mesmos, pelos pares e por juízes experts na área, com base no CTS. Aos TEs, foi solicitado, ao final da intervenção, que avaliassem o próprio desempenho $(n=13)$. Aos pares (coterapeuta e observador), foi atribuída a função de avaliar o desempenho do terapeuta do dia, de modo que cada terapeuta era avaliado por dois pares (coterapeuta e observador) $(n=74)$. Aos cinco juízes 
especialistas na área clínica deste estudo foram atribuídas a responsabilidade de avaliar o quanto os terapeutas seguiram o protocolo (fidelidade do tratamento) e o desempenho dos alunos ao longo da intervenção, mediante preenchimento da Checklist de Juízes, realizado pela observação do vídeo das sessões, aleatoriamente escolhidas. Cada TE teve duas sessões avaliadas por juízes $(n=26)$.

\subsubsection{Protocolo Gato Corajoso Resumido}

O protocolo utilizado foi adaptado do Coping Cat para atendimento grupal (FlannerySchroeder \& Kendal, 1996) e aplicado em grupos heterogêneos quanto a gênero e idade (9 a 13 anos). A meta principal do tratamento foi possibilitar às crianças o enfrentamento das situações ansiogênicas, a partir do reconhecimento da ansiedade e do treino de habilidades específicas, como alterar os pensamentos catastróficos, fazer um plano de ação e usar autorreforço.

O tratamento foi dividido em duas partes, cada uma com cinco sessões, totalizando 10 sessões. A primeira parte da intervenção, que ocorreu nas cinco sessões iniciais, teve como objetivo apresentar as ferramentas cognitivo-comportamentais mediante apresentação do acróstico do MEDO, trabalhar a coesão e o vínculo do grupo e montar uma hierarquia das situações temidas. A segunda parte do tratamento consistiu em aplicar as recém-adquiridas habilidades em uma variedade de exposições graduais imaginárias e ao vivo, adaptadas de acordo como os medos das crianças. Nesse momento da intervenção, os componentes do grupo foram divididos em duplas e cada dupla tinha um TE responsável por ela, de maneira que, nesse momento, os papéis dos terapeutas foram um pouco alterados, havendo maior participação do coterapeuta e do observador.

A cada sessão as crianças podiam ganhar pontos por fazerem as atividades no caderno de exercício, marcada no Banco de Pontos, com o objetivo de treinar o que foi trabalhado em cada dia; e por realizarem as "tarefas amigo", marcadas no Painel da Tarefa Amigo, que consistiam em ligar para o outro colega com o objetivo de treinar habilidades sociais e aumentar a coesão grupal. Foi estabelecido como regra ter apenas duas faltas no grupo. Quando isso acontecia, o terapeuta do dia ligava para a $\mathrm{Cr}$ para agendar um horário de reposição, preferencialmente antes do horário do grupo. Na reposição, era apresentada a atividade trabalhada com o grupo e treinada a ferramenta referente ao dia perdido. A descrição detalhada da intervenção consta na Tabela 3. 
Tabela 3. Descrição das sessões do protocolo Gato Corajoso.

\begin{tabular}{|c|c|}
\hline Sessão & Objetivos \\
\hline \multirow{3}{*}{$\begin{array}{l}\text { Sessão } 1 \text { para } \\
\text { pais }\end{array}$} & Explicar o tratamento para os pais \\
\hline & Incentivar a cooperação dos pais no tratamento \\
\hline & $\begin{array}{l}\text { Obter informações adicionais de cada criança, de forma que o terapeuta possa encaminhar melhor o } \\
\text { atendimento. }\end{array}$ \\
\hline \multirow{2}{*}{1} & Explicitar a informação básica a respeito do programa \\
\hline & Construir vínculo entre o grupo e o terapeuta, assim como entre os membros do grupo. \\
\hline \multirow{4}{*}{2} & Fortalecer o vínculo entre terapeutas e crianças, e entre as crianças \\
\hline & $\begin{array}{l}\text { Ajudar as crianças a identificarem os diferentes tipos de sentimentos e distinguirem os sentimentos de ansiedade } \\
\text { e preocupação dos outros sentimentos. }\end{array}$ \\
\hline & $\begin{array}{l}\text { Encorajar as crianças a identificarem as pistas fisiológicas (e.g., expressões faciais, postura corporal) para } \\
\text { identificarem as emoções. }\end{array}$ \\
\hline & Introduzir o Passo \#1 do acróstico - Mostrando-se ansioso e preocupado? \\
\hline \multirow{3}{*}{3} & Revisar a diferença entre ansiedade e preocupação das demais emoções. \\
\hline & $\begin{array}{l}\text { Ensinar a criança sobre as respostas somáticas da ansiedade e auxiliá-la a identificar o que cada um sente } \\
\text { (respostas somáticas) quando está ansiosa. }\end{array}$ \\
\hline & Introduzir o Passo \# 2 - Esperando que coisas ruins aconteçam? \\
\hline \multirow{3}{*}{$\begin{array}{l}\text { Sessão } 2 \text { para } \\
\text { pais }\end{array}$} & Avaliar o acompanhamento dos filhos \\
\hline & Levantar as situações de baixa, média e alta ansiedade para os filhos e para os pais \\
\hline & Ensinar os quatro passos do acróstico e o relaxamento. \\
\hline \multirow[t]{4}{*}{4} & $\begin{array}{l}\text { Começar a criar uma hierarquia de situação de ansiedade para cada membro do grupo. Introduzir o treino de } \\
\text { relaxamento e seu uso no controle da tensão associada à ansiedade. Revisar a percepção de pistas somáticas que } \\
\text { mostrem que a criança está tensa e ansiosa. Demonstrar para as crianças a relação entre as pistas somáticas e } \\
\text { exercícios de relaxamento. Introduzir o Passo \#3: Demonstrando atitudes e ações. E ajudar cada criança a } \\
\text { começar a desenvolver e usar autoinstruções que gerem menos ansiedade. }\end{array}$ \\
\hline & Desenvolver habilidade de enfrentamento e manejo da ansiedade \\
\hline & $\begin{array}{l}\text { Introduzir o Passo \#4: Oba! Resultados e Recompensas, mediante o conceito de autopremiação baseada no } \\
\text { desempenho. }\end{array}$ \\
\hline & Revisar o treino de relaxamento e os outros passos do plano de enfrentamento da ansiedade \\
\hline \multirow{4}{*}{$\begin{array}{c}\text { Sessão } 3 \text { com } \\
\text { os pais e } \\
\text { crianças } \\
\text { individual- } \\
\text { mente }\end{array}$} & Completar a avaliação intermediária do tratamento. \\
\hline & Revisar com eles o uso que fizeram do acróstico e do relaxamento e as possíveis dificuldades. \\
\hline & Revisar e resumir as habilidades dos filhos apresentadas durante a primeira metade do tratamento. \\
\hline & Explicar para os pais e para as crianças sobre a nova etapa da intervenção (exposições). \\
\hline \multirow{4}{*}{6} & Descrever as alterações no tipo de atividades, devido à mudança de tratamento para prática. \\
\hline & $\begin{array}{l}\text { Realizar um evento de coesão e confraternização do grupo para comemorar a nova etapa e as habilidades } \\
\text { aprendidas até agora. }\end{array}$ \\
\hline & $\begin{array}{l}\text { Praticar o plano de enfrentamento de } 4 \text { passos em condições de baixa ansiedade, tanto imaginárias quanto ao } \\
\text { vivo. }\end{array}$ \\
\hline & (Nota: as práticas ao vivo nesta sessão envolvem todo o grupo) \\
\hline \multirow[t]{2}{*}{7} & $\begin{array}{l}\text { Praticar a aplicação das habilidades de enfrentamento em situações individuais ao vivo que provoquem de baixo } \\
\text { a moderado níveis de ansiedade em cada participante. }\end{array}$ \\
\hline & (Nota: a partir desta sessão as exposições ao vivo desta sessão envolvem os participantes individualmente). \\
\hline \multirow{2}{*}{$\begin{array}{l}\text { Sessão } 4 \text { com } \\
\text { os pais }\end{array}$} & Avaliar com os pais as dificuldades que estão tendo com o uso do acróstico e do relaxamento. \\
\hline & $\begin{array}{l}\text { Avaliar evolução dos filhos; incentivá-los a ajudar aos filhos e a eles mesmos no enfrentamento dos medos; e } \\
\text { preparar-se para o término do programa. }\end{array}$ \\
\hline 8 & $\begin{array}{l}\text { Iniciar a prática de aplicação das habilidades de enfrentamento da ansiedade em situações ao vivo que produzam } \\
\text { altos níveis de ansiedade em cada criança }\end{array}$ \\
\hline 9 & $\begin{array}{l}\text { Continuar a prática de aplicação das habilidades de enfrentamento da ansiedade em situações ao vivo que } \\
\text { produzam altos níveis de ansiedade em cada criança. }\end{array}$ \\
\hline \multirow{2}{*}{10} & Revisar e resumir o programa de treinamento. \\
\hline & Comercial de encerramento. \\
\hline \multirow{2}{*}{$\begin{array}{l}\text { Sessão 5: } \\
\text { encontro final } \\
\text { criança e pais }\end{array}$} & Completar a avaliação final do tratamento \\
\hline & $\begin{array}{l}\text { Revisar e resumir o programa de tratamento, fazer planos com os pais para ajudar a criança a manter os ganhos } \\
\text { e a generalizar a novas habilidades adquiridas tanto de enfrentamento da ansiedade como de relacionamento } \\
\text { entre pares. }\end{array}$ \\
\hline
\end{tabular}


Ao longo do atendimento dos Crs, cinco reuniões grupais foram agendadas com os pais: uma antes do início do atendimento dos filhos e as outras respectivamente após a 3a a , 5a a $7 \underline{a}$ e 10 a sessões. As sessões 3 e 10 dos pais incluiu cada cuidador e o respectivo filho, sendo que no primeiro encontro destes dois (sessão 3) foi discutido com o cuidador e com a $\mathrm{Cr}$ a hierarquia dos medos, assim como explicada a nova fase da intervenção que poderia inclusive aumentar a ansiedade. Nesse momento, a $\mathrm{Cr}$ recebia o acróstico do MEDO imantado. No segundo encontro (sessão 10) com pais e filhos, foi realizada uma avaliação final da intervenção e aplicado o CBCL nas mães e o MASC nas Crs.

Os Grl tiveram no máximo seis componentes e no mínimo quatro. Algumas Crs tiveram dificuldades para comparecer à sessão, devido à falta de condições financeiras para pagar o deslocamento para o ambulatório. Nessas situações, era fornecido o passe de ônibus para a $\mathrm{Cr}$ e o responsável. A reserva técnica da FAPESP foi utilizada para o pagamento de todas as despesas desta pesquisa. Além das 10 sessões semanais, foram realizadas três sessões de seguimento com cada $\mathrm{Cr}$ e o respectivo cuidador (um mês, três meses e seis meses depois da intervenção). A Tabela 4 descreve o objetivo de cada uma delas.

Tabela 4. Descrição das sessões de seguimento.

\begin{tabular}{|c|c|}
\hline Sessão & Objetivos \\
\hline Seguimento de 1 mês & $\begin{array}{l}\text { Revisar as habilidades treinadas, levantar as possíveis dificuldades. } \\
\text { Prevenir recaídas. }\end{array}$ \\
\hline Seguimento de 3 meses & $\begin{array}{l}\text { Revisar as habilidades treinadas, levantar as possíveis dificuldades. } \\
\text { Prevenir recaídas. } \\
\text { Aplicar nos cuidadores o } \mathrm{CBCL} \text { e nas Crs o MASC. }\end{array}$ \\
\hline & Aplicar nos cuidadores o CBCL e nas Crs o MASC. \\
\hline Seguimento de 6 meses & Entregar os certificados e o DVD com o comercial gravado editado. \\
\hline
\end{tabular}

Ao final de todo o processo, um profissional de cada serviço entregava o Inventário do Estagiário para cada $\mathrm{TE}$, que de forma anônima avaliava o protocolo utilizado. Após o preenchimento, os inventários foram tabulados em uma planilha e só depois disto repassados para a pesquisadora.

\subsubsection{CuIdAdos Éticos}

Este projeto foi avaliado e aprovado em SP pelos Comitês de Ética do Instituto de Psicologia - USP-SP e do Hospital das Clínicas da Faculdade de São Paulo - USP-SP (Anexo 22) e no DF pela FECRS (Anexo 23). Conforme a Resolução Normativa do Conselho Nacional de Saúde 196/96, TEs, Crs e os respectivos cuidadores, nas duas instituições, foram esclarecidos sobre o 
estudo e assinaram os termos de consentimento livre e esclarecido diferenciados. Os termos de consentimento foram diferenciados de acordo com o participante e com a orientação dos comitês de ética de cada cidade.

As Crs foram distribuídas nos Grl e GrC de acordo com a entrada no serviço, evitando que ficassem por muito tempo sem atendimento. Houve o cuidado de esclarecer às $\mathrm{Crs}$ e a seus cuidadores, distribuídos no $\mathrm{GrC}$, que teriam que esperar a finalização do $\mathrm{Grl}$ em curso para que fossem atendidos. Ao finalizar o $\mathrm{Grl}$, a todas as crianças do $\mathrm{GrC}$ foi oferecida a mesma intervenção grupal.

Os estagiários receberam treinamento e assessoria contínua durante um ano e os cuidadores foram orientados sobre como lidar com as dificuldades associadas à ansiedade ao longo da intervenção e no seguimento. O treinamento e a aplicação da intervenção foram avaliados por juízes especialistas, experts na área.

\subsubsection{ANÁlise doS DADOS}

A primeira etapa do treinamento dos TEs incluiu o levantamento do perfil sociodemográfico e características do encaminhamento e das queixas dos $\mathrm{CrUs}$, diferenciadas em queixas que motivaram a procura do serviço e queixas obtidas pelo $C B C L$, SNAP, MASC e CDI. Para analisar estes dados, foram consideradas a frequência, a média e o desvio padrão das respostas obtidas; e os testes estatísticos de Igualdade de Média, que avaliaram o quanto os dados médios se diferenciaram, e o Fisher, que avaliou o quanto os dados se diferenciaram na distribuição. Nos dois testes estatísticos, foi considerado o valor de $p \leq 0,05$ como indicador de diferença estatisticamente significativa.

A Figura 4 demonstra a descrição da análise dos dados do levantamento do perfil sociodemográfico, no qual se inclui as onze variáveis utilizadas. Foram considerados, para esta análise, os dados de 112 CrUs, sendo que 62/112 são do AMBULANSIA-SP, o que equivale a 55\% da amostra, e 50/112 do NAT-DF, o que equivale a $45 \%$. 


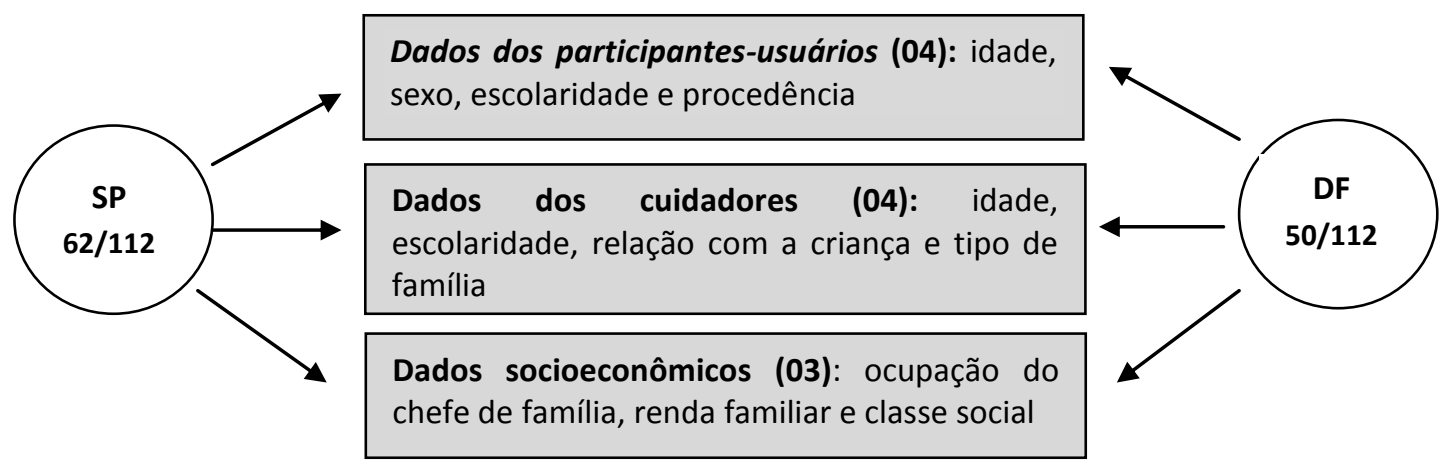

Figura 4. Descrição da análise dos dados do perfil sociodemográfico dos CrUs coletados na primeira etapa do treinamento dos TEs ( $n=112)$.

Na figura 5, descreve-se a análise realizada para caracterizar o encaminhamento e as queixas dos CrUs. Os dados do encaminhamento e das queixas iniciais foram obtidos pela Ficha de identificação ( $n=112)$ e analisadas por média e desvio padrão e pelo teste estatístico de Fisher, que avaliou a similaridade da distribuição destes dados nos dois serviços. Na análise dos dados das queixas obtidas por instrumentos aplicados no $\mathrm{CBCL}$, foram incluídos os dados de 112/112, no SNAP, MASC e CDI foram incluídos apenas 62/112, distribuídos em 19/62 do AMBULANSIA-SP, conforme explicado no procedimento (pg. 50), que equivalem a $31 \%$ da população avaliada em SP, e 50/50 do NAT-DF, que equivale a 100\% desta população. Os dados foram analisados a partir da distribuição dos escores clínicos e não clínicos das CrUs nos instrumentos, que também foi avaliada pelo Teste de Fisher.

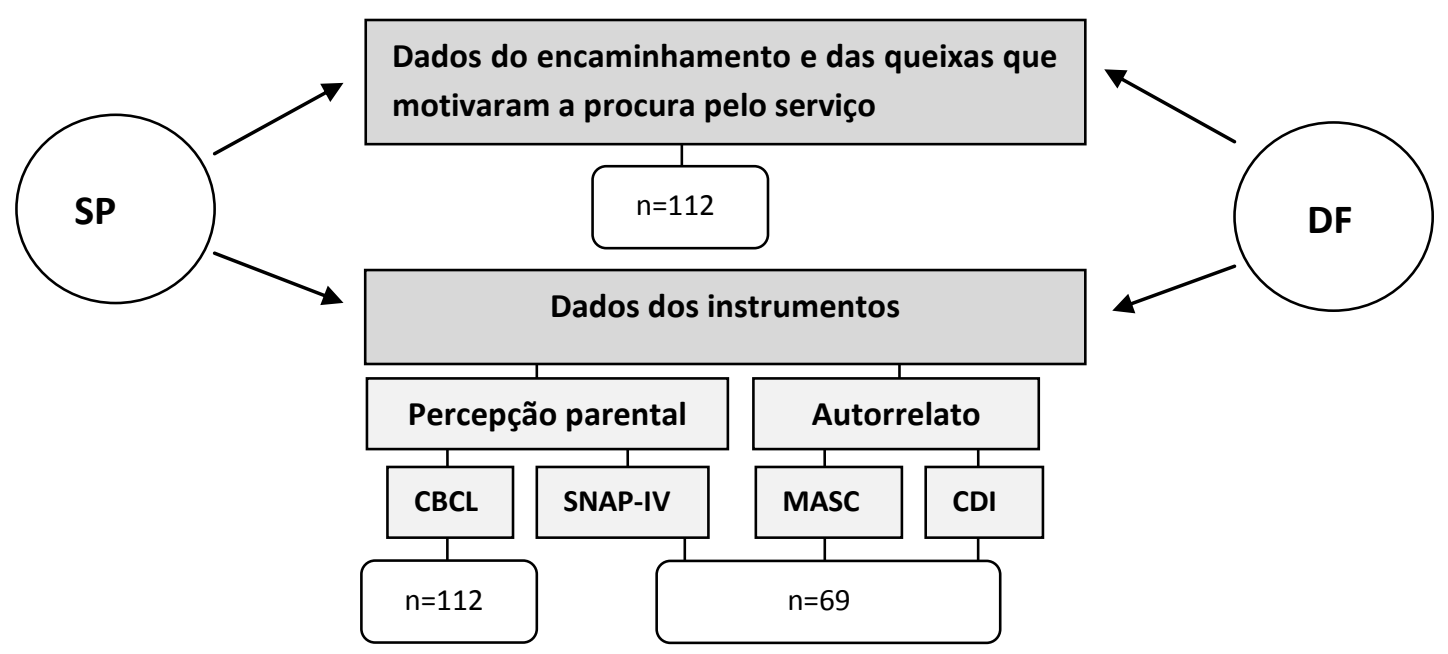

Figura 5. Descrição da análise dos dados do perfil do levantamento do encaminhamento e das queixas dos CrUs coletados na primeira etapa do treinamento dos TEs.

Na segunda etapa do treinamento do TEs, foi avaliada a adaptação e o uso do protocolo no treinamento dos alunos, considerando três análises, a saber: (a) descrição das 
competências dos TEs, por meio do CTS; (b) avaliação dos TES sobre o uso do protocolo como uma ferramenta de treinamento de alunos para o atendimento de crianças ansiosas; e (c) comparação dos ganhos terapêuticos das $\mathrm{Crs}$ que participaram do $\mathrm{Grl}$ x $\mathrm{GrC}$, no pré-teste e pósteste e das Crs do Grl nos seguimentos de três e seis meses.

Para descrição das competências dos TEs, os dados foram diferenciados em quatro partes, conforme o CTS, descritas na parte dos instrumentos (pg. 43). Para esta análise, considerou-se os dados obtidos pelas avaliações dos TEs $(n=13)$, dos pares $(n=74)$ e dos juízes $(n=26)$. O CTS utiliza uma escala variada de resposta $(0-3,0-5$ ou $0-6)$, de acordo com o desempenho avaliado, de maneira que os escores brutos atribuídos pelos informantes foram convertidos em médias (desvio padrão), em uma escala de 0-100. Foram efetuadas comparações estatísticas entre os grupos de informantes em relação a cada item do CTS, a partir do teste Kruskal-Wallis, que compara as medianas. Nos dados da Parte III do CTS, também foi realizado o teste de Fisher, que avalia a distribuição das respostas.

Além de avaliar o desempenho dos TEs, os juízes também verificaram a fidelidade ao tratamento, pela observação de $65 \%$ das filmagens selecionadas aleatoriamente. A partir dos vídeos, os juízes atribuíram uma nota de $0-4$, sendo que o zero significava que o terapeuta não seguiu o estipulado pelo protocolo e quatro indicava que seguiu totalmente. Os referidos dados foram convertidos em média (dp) e porcentagem.

Para avaliação dos estagiários sobre o uso do protocolo como uma ferramenta de treinamento de alunos para o atendimento de crianças ansiosas, foi considerada exclusivamente a percepção dos TEs, avaliada por 16 questões fechadas e 4 questões abertas. A análise dos dados das 16 questões fechadas do Inventário do Estagiário, como demonstrado na Figura 6, foi realizada a partir: (a) da distribuição (frequência) das respostas dos TEs, considerando as opções de respostas em uma escala de 0-100; e (b) da média e desvio padrão das respostas em cada questão, em uma escala de 0-100. Os dados das quatro questões abertas foram agrupados por similaridade e transcritos literalmente. 


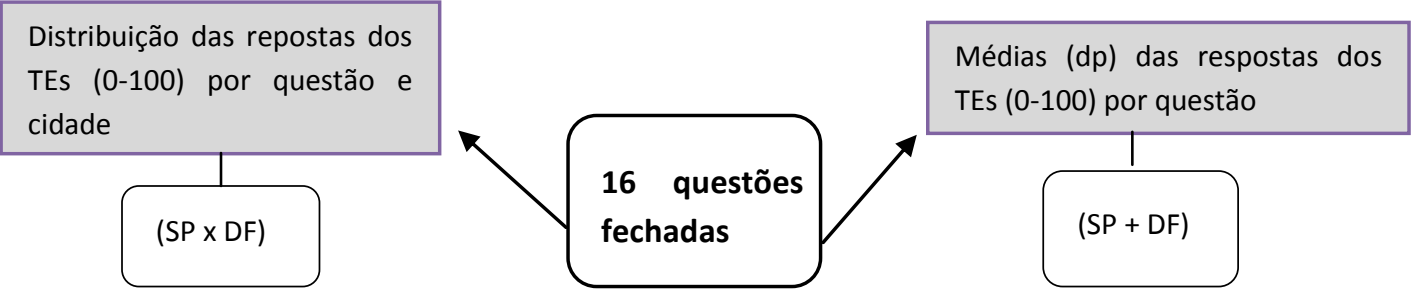

Figura 6. Descrição da análise realizada nas questões fechadas do protocolo, por questão e por cidade.

Dois testes estatísticos foram realizados: Mann-Whitney, para verificar a homogeneidade das respostas dos TEs das duas cidades; e o de Fisher, para avaliar a distribuição das respostas dos TEs nas duas cidades em cada variável.

Para comparação dos ganhos terapêuticos das crianças que participaram do Grl e do GrC, foi avaliado inicialmente o quanto as Crs de SP e do DF, indicadas para intervenção se diferenciavam. Pelos testes estatísticos Mann-Whitney, que compararam as médias dos dados sociodemográficos e da queixa obtida pelo $\mathrm{CBCL}$ e pelo MASC dos dois serviços, e de Fisher, que comparou a distribuição das frequências destes mesmos dados, não houve diferença estatisticamente relevante entre as Crs dos dois serviços em nenhuma das quatro fases de avaliação: pré-tratamento (Fase 1), pós-tratamento (Fase 2), follow-up de 3 meses (Fase 3) e follow-up de 6 meses (Fase 4). A partir deste resultado, optou-se por agrupar os dados das Crs do Grl de SP e DF. Esta mesma avaliação com os mesmo testes foi realizada para avaliar o quanto os Grl, já agrupados com os dados de SP e DF, diferenciavam-se na Fase 1 dos GrC do DF. Nesta análise estatística, os dados do Grl e GrC se diferenciaram estatisticamente pelo teste de Mann-Whitney apenas na idade média dos dois grupos, uma vez que a idade média do GrC foi um pouco mais baixa $(9,5$ anos) do que a do $\operatorname{Grl}(10,6$ anos) $(p=0,034)$. Já em relação aos demais dados sociodemográficos e os escores T médio das escalas do $\mathrm{CBCL}$ 6-18 e do MASC, os participantes dos Grl e GrC mostraram-se equivalentes. Por considerar que a diferença de idade não era de grande magnitude, acreditou-se que, apesar dos participantes do $\mathrm{GrC}$ serem do DF, seria possível a comparação dos dados deste grupo com os dados do Grl (SP+DF).

Das 21 crianças selecionadas para o $\mathrm{Grl}$, sendo $11 / 21 \mathrm{Crs}$ em SP e 10/21 no DF, uma do DF foi excluída por ter faltado mais de três vezes. E, dos 15 indicados para o GrC, 11 participaram das avaliações pré-tratamento e pós-tratamento (10 semanas depois da primeira), de maneira que foram consideradas para esta análise os dados de $20 \mathrm{Crs}$ do $\mathrm{Grl}$ e $11 \mathrm{Crs}$ do GrC. 
Posto isso, foram comparados os dados do pré-tratamento e do pós-tratamento do Grl (SP+DF) e GrC, e os dados do Grl nos seguimentos de três e seis meses. Foram considerados os escores T médios das Somas das Escalas de Competência, da Escala Individual de Ansiedade/Depressão, das Somas das Escalas de Problemas (Internalização, Externalização e de Total de Problemas), do CBCL 6-18; e os escores médios ponderados totais do MASC. O nível de significância da comparação $(p)$ foi calculado pelo uso do teste de Fischer, que avaliou a associação entre os escores de cada instrumento e os grupos ( $\mathrm{Gl}$ e $\mathrm{GrC}$ ); pelo teste de Mann Whiteney, que avaliou o quanto a média dos escores dos instrumentos se diferençou nos grupos analisados nas quatro fases de avaliação, a saber: Fase 1 - pré-tratamento, Fase 2 - póstratamento, Fase 3 - follow-up de 3 meses e Fase 4 -follow-up de 6 meses; e pelo teste de Wilcoxon, que foi usado para comparar os dados do Grl dos escores T médios do CBCL 6-18, considerando as díades: Fase 1 x Fase 2, Fase 1 x Fase 3, Fase 1 x Fase 4 e Fase 2 x Fase $4 . \mathrm{Na}$ Figura 7, descrevem-se os grupos de comparação.

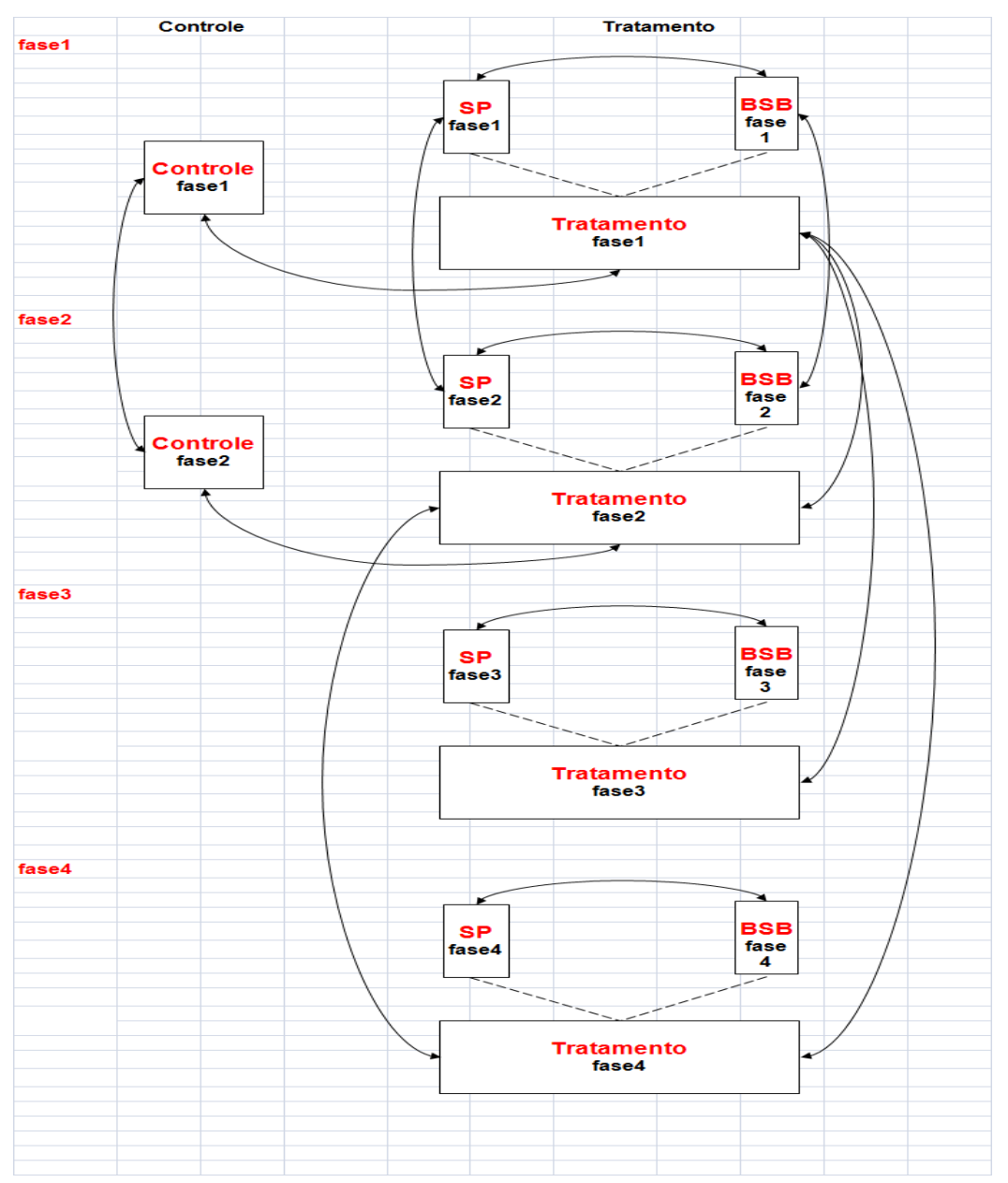

Figura 7. Descrição da análise realizada para avaliar os ganhos terapêuticos entre Grl x GrC nas Fases 1 e 2 e do $\mathrm{Grl}$ nas fases de seguimento (Fase 3 e 4). 
Além das análises estatísticas, foi realizada uma análise complementar nos dados comparativos das Fases 1 e 4, para verificar o quanto houveram mudanças confiáveis atribuíveis à intervenção. Isto foi possível com o cálculo do índice de mudança confiável, a partir do Método Jacobson e Truax (JT) (1991), que prevê uma análise comparativa entre duas medidas, sendo neste caso escolhidas as Fases 1 e 4. Este índice de mudanças confiáveis (IMC) foi calculado e representado graficamente, comparando os escores do $\mathrm{CBCL}$ e do MASC demarcando a melhora, piora ou não alteração, de cada $\mathrm{Cr}$ do Grl. Os dados do IMC também foram transformados em porcentagem de 0-100, de melhora, piora ou não alteração, e apresentados em uma tabela. 


\section{RESULTADOS}

Os resultados serão apresentados considerando os dados da Etapa I, de descrição do perfil sociodemográfico e da característica dos encaminhamentos e queixas dos CrUs; e da Etapa II, de avaliação da adaptação e do uso do protocolo no treinamento dos TEs.

\subsection{ETAPA I: DESCRIÇÃO DO PERFIL SOCIODEMOGRÁFICO E CARACTERÍSTICA DOS ENCAMINHAMENTOS E QUEIXAS DOS CRUS}

Nesta etapa, serão apresentados os dados dos CrUs, diferenciados em variáveis sociodemográficas e características do encaminhamento para os serviços, das queixas iniciais que levaram à procura do serviço e das queixas obtidas pela aplicação de instrumentos nos cuidadores ( $C B C L$ e SNAP) e nas crianças (MASC e CDI). Considerou-se para as análises estatísticas que o valor de $\mathrm{p}<0,05$ caracteriza uma diferença estatisticamente relevante, destacada em negrito nas tabelas.

\subsubsection{Perfil Sociodemográfico ( $=112)$}

As 11 variáveis que caracterizaram o perfil sociodemográfico dos CrUs foram diferenciadas em: (a) 4 variáveis dos CrUs (idade, sexo, escolaridade e procedência); (b) 4 variáveis dos cuidadores (idade, escolaridade, relação com CrUs, e tipo de família), e (c) 3 variáveis da situação socioeconômica da família (ocupação do chefe de família, renda familiar e classe social).

Na tabela 5, é apresentada a distribuição das quatro variáveis incluídas para caracterizar os dados das crianças e adolescentes, por serviço (AMBULANSIA=SP e NAT=DF). Foram utilizados os testes estatísticos de Igualdade de Média para avaliar o quanto a idade média dos CrUs das duas cidades era equivalente, e o Teste de Fisher para avaliar a similaridade da distribuição das variáveis: faixas etárias, sexo e escolaridade, nas duas cidades. 
Tabela 5. Distribuição dos CrUs quanto a idade, sexo, escolaridade e procedência, por serviço ( $n=112)$.

\begin{tabular}{|c|c|c|c|c|}
\hline Variável & Geral & SP & DF & $p$ \\
\hline \multicolumn{5}{|l|}{ Idade } \\
\hline Média (DP) & $11,3(2,71)$ & $12,5(2,93)$ & $9,9(1,40)$ & $<0,001 * *$ \\
\hline \multicolumn{5}{|l|}{ Distribuição (Frequência) } \\
\hline $6-9$ anos $(n)$ & $31,3 \%(35)$ & $16,1 \%(10)$ & $50 \%(25)$ & \multirow{3}{*}{$<0,001 * *$} \\
\hline $10-14$ anos $(n)$ & $50,0 \%(56)$ & $50 \%(31)$ & $50 \%(25)$ & \\
\hline 15 ou mais anos $(n)$ & $18,8 \%(21)$ & $33,9 \%(21)$ & $0 \%(0)$ & \\
\hline \multicolumn{5}{|l|}{ Sexo } \\
\hline Feminino $(n)$ & $36,9 \%(48)$ & $46,8 \%(29)$ & $38 \%(19)$ & \multirow{2}{*}{0,443} \\
\hline Masculino (n) & $63,1 \%(64)$ & $53,2 \%(33)$ & $62 \%(31)$ & \\
\hline \multicolumn{5}{|l|}{ Escolaridade } \\
\hline Fundamental Incompleto (n) & $82,0 \%(91)$ & $68,9 \%(42)$ & $98 \%(49)$ & \multirow{3}{*}{$<0,001 * *$} \\
\hline Ensino Médio Incompleto (n) & $16,2 \%(18)$ & $29,5 \%(18)$ & $0 \%(0)$ & \\
\hline Ensino Médio Completo ( $n$ ) & $1,8 \%(2)$ & $1,6 \%(1)$ & $2 \%(1)$ & \\
\hline \multicolumn{5}{|l|}{ Procedência } \\
\hline Cidade do serviço (n) & $53,6 \%(60)$ & $85,5 \%(53)$ & $14 \%(7)$ & \\
\hline Estado do serviço (n) & $9,8 \%(11)$ & $14,5 \%(9)$ & $4 \%(2)$ & \\
\hline Outro estado (n) & $36,6 \%(41)$ & $0 \%(0)$ & $82 \%(41)$ & \\
\hline
\end{tabular}

Conforme demonstrado na tabela 5, houve um predomínio da faixa etária de 10 a 14 anos $(50 \%)$, do gênero masculino $(63,1 \%)$ e de crianças que estavam cursando o ensino fundamental (82\%). No que se refere à procedência dos usuários, nota-se que em SP houve um predomínio de CrUs moradores da capital (85,5\%), local do serviço estudado; enquanto no DF a maioria morava em municípios do Estado de Goiás (82\%), que fazem divisa com o Distrito Federal.

O Teste de Igualdade de Média indicou uma diferença estatisticamente significativa entre serviços estudados em relação à idade média das CrUs $(p<0,001)$. Essa diferença foi também encontrada na distribuição das CrUs nas faixas etárias nos dois serviços pelo teste Fisher ( $p<0,001)$, uma vez que no DF houve uma concentração das CrUs em duas faixas etárias (6 a 9 e 10 a 14 anos), diferentemente de SP. Segundo o teste de Fisher, as CrUs dos dois serviços também se diferenciaram estatisticamente quanto à escolaridade $(p<0,001)$, já que em SP houve uma maior distribuição das CrUs entre o ensino fundamental e médio, enquanto no DF a população ficou concentrada no ensino fundamental. Considerando que a escolaridade acompanha a idade, se um número maior de CrUs de SP são mais velhas, é natural que estas apresentem maior escolaridade do que as do DF.

Além dos dados específicos das CrUs, também se avaliou o cuidador, considerando sua idade, relação com a criança, escolaridade e tipo de família. Na tabela 6, é apresentada a distribuição desses dados. Foram utilizados os mesmos testes estatísticos da análise anterior, 
sendo que nestes dados o Teste de Igualdade de Média mediu o quanto a idade média dos cuidadores das duas cidades era equivalente e o Teste de Fisher a similaridade da distribuição das variáveis dos cuidadores nas duas cidades.

Tabela 6. Distribuição dos cuidadores quanto a idade, relação com os CrUs, escolaridade e tipo de família, por serviço $(n=112)$.

\begin{tabular}{|c|c|c|c|c|}
\hline Variável & Geral & SP & DF & $P$ \\
\hline \multicolumn{5}{|l|}{ Idade } \\
\hline Média (DP) & $41,2(9,44)$ & $44,2(8,25)$ & $38,3(8,59)$ & $<0,001 * *$ \\
\hline \multicolumn{5}{|l|}{ Frequência } \\
\hline $23-34$ anos (n) & $21,4 \%(24)$ & $11,3 \%(7)$ & $34 \%(17)$ & \multirow{4}{*}{$0,001 * *$} \\
\hline $35-44$ anos (n) & $43,8 \%(49)$ & $38,7 \%(24)$ & $50 \%(25)$ & \\
\hline $45-54$ anos (n) & $25,0 \%(28)$ & $37,1 \%(23)$ & $10 \%(5)$ & \\
\hline 55 ou mais anos (n) & $9,8 \%(11)$ & $12,9 \%(8)$ & $6 \%(3)$ & \\
\hline \multicolumn{5}{|l|}{ Escolaridade } \\
\hline Não estudou (n) & $1,9 \%(3)$ & $0 \%(0)$ & $2 \%(1)$ & \multirow{8}{*}{0,354} \\
\hline Fundamental Incompleto (n) & $26,3 \%(42)$ & $16,1 \%(10)$ & $22 \%(11)$ & \\
\hline Fundamental Completo (n) & $13,8 \%(22)$ & $11,3 \%(7)$ & $8 \%(4)$ & \\
\hline Ensino Médio Incompleto (n) & $7,5 \%(12)$ & $8,1 \%(5)$ & $8 \%(4)$ & \\
\hline Ensino Médio Completo (n) & $28,1 \%(45)$ & $29 \%(18)$ & $42 \%(21)$ & \\
\hline Superior Incompleto (n) & $6,3 \%(10)$ & $11,3 \%(7)$ & $2 \%(1)$ & \\
\hline Superior Completo (n) & $12,5 \%(20)$ & $19,4 \%(12)$ & $12 \%(6)$ & \\
\hline Pós-graduação Completa (n) & $0,0 \%(0)$ & $0 \%(0)$ & $0 \%(0)$ & \\
\hline \multicolumn{5}{|l|}{ Relação com CrUs } \\
\hline Pai biológico $(n)$ & $87,5 \%(98)$ & $83,9 \%(52)$ & $92 \%(46)$ & \multirow{5}{*}{0,332} \\
\hline Pai adotivo (n) & $4,5 \%(5)$ & $6,5 \%(4)$ & $2 \%(1)$ & \\
\hline Avó/avô (n) & $4,5 \%(5)$ & $3,2 \%(2)$ & $6 \%(3)$ & \\
\hline Familiar (n) & $2,7 \%(3)$ & $4,8 \%(3)$ & $0 \%(0)$ & \\
\hline Outros (n) & $0,9 \%(1)$ & $1,6 \%(1)$ & $0 \%(0)$ & \\
\hline \multicolumn{5}{|l|}{ Tipo de Família } \\
\hline Monoparental (n) & $34,8 \%$ (39) & $37 \%(23)$ & $32 \%(16)$ & \multirow{2}{*}{0,900} \\
\hline Biparental (n) & $65,2 \%(73)$ & $62,9 \%(39)$ & $68 \%(34)$ & \\
\hline
\end{tabular}

$\mathrm{Na}$ análise dos dados dos cuidadores demonstrados na Tabela 6, observa-se um predomínio da faixa etária de 35 a 44 anos $(43,8 \%)$, de pais biológicos $(87,5 \%)$, com ensino médio $(28,1 \%)$, em união estável - família biparental $(65,2 \%)$. Um número maior de cuidadores de SP $(19,4 \%)$, mais do que os do DF (12\%), tinha curso superior completo; e um número maior de cuidadores do DF (22\%), mais do que em SP $(16,1 \%)$, tinha apenas ensino fundamental incompleto.

O Teste de Igualdade de Média e o Teste de Fisher indicam diferença estatística entre as médias de idades dos cuidadores e a distribuição dos cuidadores nas faixas etárias das duas cidades, respectivamente $p<0,001$ e $p=0,001$. Esta diferença é explicada pelo fato de os 
cuidadores de SP serem mais velhos do que os do DF, uma vez que, em SP, 75,8\% tinha idade entre 35 e 54; e no DF $84 \%$ tinha entre 23 e 44 anos (84\%). Nota-se que essa diferença de idade dos cuidadores é coerente ao dado referente à idade dos filhos, visto que as CrUs de DF eram mais novas do que as de SP, conforme os dados apresentados na Tabela 5. Observa-se que, segundo o teste de Fisher, houve uma similaridade em relação ao tipo de família biparental $(p=0,900)$ entre os dois serviços.

Na Tabela 7, são apresentados os dados socioeconômicos, caracterizados por ocupação do chefe de família, renda familiar e classe social. Nessas variáveis, utilizou-se apenas o Teste de Fisher para verificar a similaridade de distribuição dos dados dos CrUs nos dois serviços.

Tabela 7. Distribuição dos dados socioeconômicos quanto à ocupação do chefe da família, renda familiar e classe social, por serviço $(n=112)$.

\begin{tabular}{|c|c|c|c|c|}
\hline Variável & Geral & SP & DF & $\boldsymbol{P}$ \\
\hline \multicolumn{5}{|l|}{ Ocupação do chefe de família } \\
\hline Forças Armadas, Policiais e Bombeiros Militares ( $n$ ) & $0,9 \%(1)$ & $1,6 \%(1)$ & $0 \%(0)$ & \multirow{11}{*}{0,925} \\
\hline Membros superiores do poder público (n) & $0,9 \%(1)$ & $1,6 \%(1)$ & $0 \%(0)$ & \\
\hline Profissionais das ciências e das artes ( $\mathrm{n}$ ) & $4,5 \%(5)$ & $4,8 \%(3)$ & $4,1 \%(2)$ & \\
\hline Técnicos de nível médio ( $\mathrm{n}$ ) & $17,1 \%(19)$ & $17,7 \%(11)$ & $16,3 \%(8)$ & \\
\hline Trabalhadores de serviços administrativos (n) & $11,7 \%(13)$ & $11,3 \%(7)$ & $12,2 \%(6)$ & \\
\hline Trabalhadores de serviços e do comércio ( $n$ ) & $27,0 \%(30)$ & $24,2 \%(15)$ & $30,6 \%(15)$ & \\
\hline Trabalhadores agropecuários (n) & $1,8 \%(2)$ & $1,6 \%(1)$ & $2 \%(1)$ & \\
\hline Trabalhadores da produção de bens e serviços industriais ( $n$ ) & $6,3 \%(7)$ & $4,8 \%(3)$ & $8,2 \%(4)$ & \\
\hline Trabalhadores de manutenção e reparação (n) & $0,9 \%(1)$ & $1,6 \%(1)$ & $0 \%(0)$ & \\
\hline Aposentados (n) & $12,6 \%(14)$ & $14,5 \%(9)$ & $10,2 \%(5)$ & \\
\hline Desempregado (benefício) ( $\mathrm{n}$ ) & $11,7 \%(13)$ & $11,3 \%(7)$ & $12,2 \%(6)$ & \\
\hline \multicolumn{5}{|l|}{ Renda Familiar } \\
\hline Não tem (n) & $0,9 \%(1)$ & $1,6 \%(1)$ & $0 \%(0)$ & \multirow{6}{*}{$0,016^{*}$} \\
\hline 1 salário mínimo $(\mathrm{n})$ & $11,6 \%(13)$ & $3,2 \%(2)$ & $22 \%(11)$ & \\
\hline De 2 a 4 salários mínimos ( $\mathrm{n}$ ) & $58,0 \%(65)$ & $59,7 \%(37)$ & $56 \%(28)$ & \\
\hline De 5 a 8 salários mínimos ( $\mathrm{n}$ ) & $24,1 \%(27)$ & $27,4 \%(17)$ & $20 \%(10)$ & \\
\hline De 9 a 12 salários mínimos ( $\mathrm{n}$ ) & $1,8 \%(2)$ & $3,2 \%(2)$ & $0 \%(0)$ & \\
\hline >12 salários mínimos & $3,6 \%(4)$ & $4,8 \%(3)$ & $2 \%(1)$ & \\
\hline \multicolumn{5}{|l|}{ Classe Social } \\
\hline$A(n)$ & $2,7 \%(3)$ & $1,6 \%(1)$ & $4 \%(2)$ & \multirow{5}{*}{0,349} \\
\hline$B(n)$ & $41,1 \%(46)$ & $41,9 \%(26)$ & $40 \%(20)$ & \\
\hline$C(n)$ & $49,1 \%(55)$ & $53,2 \%(33)$ & $44 \%(22)$ & \\
\hline$D(n)$ & $5,4 \%(6)$ & $3,2 \%(2)$ & $8 \%(4)$ & \\
\hline$E(n)$ & $1,8 \%(2)$ & $0 \%(0)$ & $4 \%(2)$ & \\
\hline
\end{tabular}

Os dados apresentados na Tabela 7 mostram que houve um predomínio de trabalhadores de serviços e do comércio (27,5\%), renda familiar de 2 a 4 salários mínimos (58\%) e classe social " $C$ " $(49,1 \%)$. A comparação da distribuição das variáveis nas duas cidades pelo Teste de Fisher indicou uma diferença estatisticamente significativa apenas em renda familiar 
$(p=0,016)$, sendo que mais cuidadores do DF reportaram receber apenas 1 salário mínimo (22\%) em comparação com os de SP (3,2\%). Observa-se também que este mesmo teste indicou uma similaridade quanto à variável ocupação do chefe de família, pelo Teste de Fisher $(p=0,925)$.

A partir desses dados conclui-se que, no que se refere às variáveis selecionadas para caracterizar o perfil sociodemográfico, a clientela dos dois serviços não pode ser considerada equivalente em relação à idade e escolaridade das crianças/adolescentes, à idade dos cuidadores e à renda familiar. Ressalta-se que os dados da clientela dos dois serviços foram mais diferentes entre a variáveis dos CrUs, uma vez que apenas uma variável (sexo/gênero) foi similar. Todavia, nas demais variáveis do cuidador e do nível socioeconômico houve uma maior semelhança, uma vez que, de acordo com o Teste de Fisher, das quatro variáveis analisadas dos cuidadores, em três os dados foram equivalentes, e nos dados socioeconômicos, das três variáveis analisadas, em duas os dados se assemelharam estatisticamente.

Na sequência, serão abordadas as características do encaminhamento para o serviço e das queixas (inicial e atual), fechando a análise da Etapa I.

\subsubsection{CARACTERÍSTICAS DOS ENCAMINHAMENTOS E DAS QUEIXAS}

A tabela 8 dispõe variáveis de encaminhamento para o serviço e da queixa inicial obtidas com os cuidadores e as CrUs ( $n=112)$. O teste estatístico de Fisher foi utilizado para avaliar a similaridade da distribuição desses dados nos dois serviços. 
Tabela 8. Distribuição do encaminhamento e da queixa inicial segundo relato dos cuidadores, por serviço $(n=112)$.

\begin{tabular}{|c|c|c|c|c|}
\hline Variável & Geral & SP & DF & $p$ \\
\hline \multicolumn{5}{|l|}{ Encaminhamento } \\
\hline Serviços de Psicologia (n) & $8,0 \%(9)$ & $9,7 \%(6)$ & $6,0 \%(3)$ & 0,729 \\
\hline Serviço Hospitalar (n) & $9,8 \%(11)$ & $1,6 \%(1)$ & $20,0 \%(10)$ & $0,002^{*}$ \\
\hline Posto de Saúde (n) & $13,4 \%(15)$ & $6,5 \%(4)$ & $22,0 \%(11)$ & $0,024 *$ \\
\hline \multicolumn{5}{|l|}{ Médicos } \\
\hline Clínico geral (n) & $2,7 \%(3)$ & $1,6 \%(1)$ & $4,0 \%(2)$ & 0,585 \\
\hline Psiquiatra (n) & $11,6 \%(13)$ & $8,1 \%(5)$ & $16,0 \%(8)$ & 0,241 \\
\hline Neurologista (n) & $2,7 \%(3)$ & $0,0 \%(0)$ & $6,0 \%(3)$ & 0,086 \\
\hline Fonoaudióloga (n) & $0,9 \%(1)$ & $0,0 \%(0)$ & $2,0 \%(1)$ & 0,446 \\
\hline Escola (n) & $3,6 \%(4)$ & $4,8 \%(3)$ & $2,0 \%(1)$ & 0,627 \\
\hline Espontâneo (n) & $7,1 \%(8)$ & $6,5 \%(4)$ & $8,0 \%(4)$ & 1,000 \\
\hline Família (n) & $2,7 \%(3)$ & $4,8 \%(3)$ & $0,0 \%(0)$ & 0,252 \\
\hline Conhecido $(\mathrm{n})$ & $8,0 \%(9)$ & $8,1 \%(5)$ & $8,0 \%(4)$ & 1,000 \\
\hline Mídia (n) & $18,8 \%(21)$ & $33,9 \%(21)$ & $0,0 \%(0)$ & $<0,001 * *$ \\
\hline Outros (n) & $4,5 \%(5)$ & $8,1 \%(5)$ & $0,0 \%(0)$ & 0,064 \\
\hline Não consta (n) & $6,3 \%(7)$ & $6,5 \%(4)$ & $6,0 \%(3)$ & 1,000 \\
\hline \multicolumn{5}{|l|}{ Queixas Iniciais (frequência de CrUs) } \\
\hline Dificuldades cognitivas ( $\mathrm{n}$ ) & $41,1 \%(46)$ & $25,8 \%(16)$ & $61,2 \%(30)$ & $<0,001 * *$ \\
\hline Dificuldades emocionais e comportamentais ( $n$ ) & $79,5 \%(89)$ & $74,2 \%(46)$ & $87,8 \%(43)$ & 0,095 \\
\hline Dificuldades de relacionamento interpessoal (n) & $25,9 \%(29)$ & $9,7 \%(6)$ & $46,9 \%(23)$ & $<0,001 * *$ \\
\hline Dificuldades da vida diária (n) & $30,4 \%(34)$ & $6,5 \%(4)$ & $61,2 \%(30)$ & $<0,001 * *$ \\
\hline Dificuldades da esfera sexual (n) & $6,3 \%(7)$ & $1,6 \%(1)$ & $12,2 \%(6)$ & $0,043^{*}$ \\
\hline Sintomas físicos (n) & $21,4 \%(24)$ & $1,6 \%(1)$ & $46,9 \%(23)$ & $<0,001^{* *}$ \\
\hline Distúrbios orgânicos (n)s & $11,6 \%(13)$ & $1,6 \%(1)$ & $24,5 \%(12)$ & $<0,001 * *$ \\
\hline Distúrbios da alimentação e sono (n) & $27,7 \%(31)$ & $4,8 \%(3)$ & $57,1 \%(28)$ & $<0,001 * *$ \\
\hline Dependência química (n) & $3,6 \%(4)$ & $0,0 \%(0)$ & $8,2 \%(4)$ & $0,035^{*}$ \\
\hline Distúrbios psiquiátricos (n) & $24,1 \%(27)$ & $27,4 \%(17)$ & $20,4 \%(10)$ & 0,505 \\
\hline
\end{tabular}

$\mathrm{Na}$ análise dos dados dos encaminhamentos apresentados na Tabela 8, observa-se que serviços (hospital e posto de saúde) ou profissionais de saúde (médicos) foram os maiores encaminhadores $(40,2 \%)$ das CrUs para os serviços ambulatoriais. Os cuidadores relataram várias queixas motivadoras para a procura do atendimento, sendo a média geral de 2,7 queixas por criança. Os dados indicam, no entanto, que os cuidadores do DF relataram mais queixas por criança $(4,2)$ do que os de SP $(1,5)$. No entanto, houve um predomínio no relato dos cuidadores da queixa Dificuldades emocionais e comportamentais $(79,5 \%)$, definida no instrumento por agressividade, ansiedade, isolamento social, depressão, choro frequente, dependência, imaturidade, temores, entre outros.

O resultado do Teste de Fisher indicou uma diferença estaticamente relevante entre os dois serviços nas variáveis do encaminhamento: serviço hospitalar $(p=0,002)$, posto de saúde 
$(p=0,024)$ e mídia $(<0,001)$. Justifica-se esta diferença de distribuição por um número maior de usuários do DF, em relação aos de SP, terem sido encaminhados por serviços hospitalares e posto de saúde e em SP um número maior encaminhado pela mídia. Na análise do Teste Fisher, também se observa uma semelhança entre os dados das duas cidades apenas nas queixas Dificuldades emocionais e comportamentais $(p=0,095)$ e Dificuldades psiquiátricas $(p=0,505)$. 0 Teste de Fisher indica que a distribuição dos dados dos CrUs nas queixas iniciais foi a variável na qual os CrUs das duas cidades mais se diferenciaram considerando todas as variáveis analisadas na Etapa I, apesar da queixa inicial mais frequente dos dois serviços não se diferenciar.

Além dos dados apresentados sobre a queixa inicial relatada, verificaram-se também as queixas identificadas pelos cuidadores, a partir da aplicação do $\mathrm{CBCL}$ e do SNAP, e pelas crianças e adolescentes a partir da aplicação dos questionários de autorrelato - MASC e CDI. Estes dados estão apresentados na Tabela 9. Na análise foi considerada a distribuição dos escores clínico e não clínico de cada instrumento por serviço. Estes dados foram comparados pelo Teste de Fisher, que avaliou a distribuição das variáveis entre os dois serviços. Esclarece-se aqui que alguns cuidadores não preencheram todos os dados agrupados na Soma das Escalas de Competência do $\mathrm{CBCL}$, de maneira que se incluiu na tabela o número de CrUs que tiveram os dados analisados nessa escala. Nas demais escalas do $\mathrm{CBCL}$, foi considerado o número total de CrUs ( $n=112$ ), enquanto, conforme explicado na seção de Método (pg. 58), os dados do SNAP, CDI e MASC foram obtidos apenas com 69 cuidadores ou CrUs, distribuídos em 19 em SP e 50 no DF. 
Tabela 9. Distribuição dos escores dos instrumentos aplicados nos cuidadores e nas crianças e adolescentes.

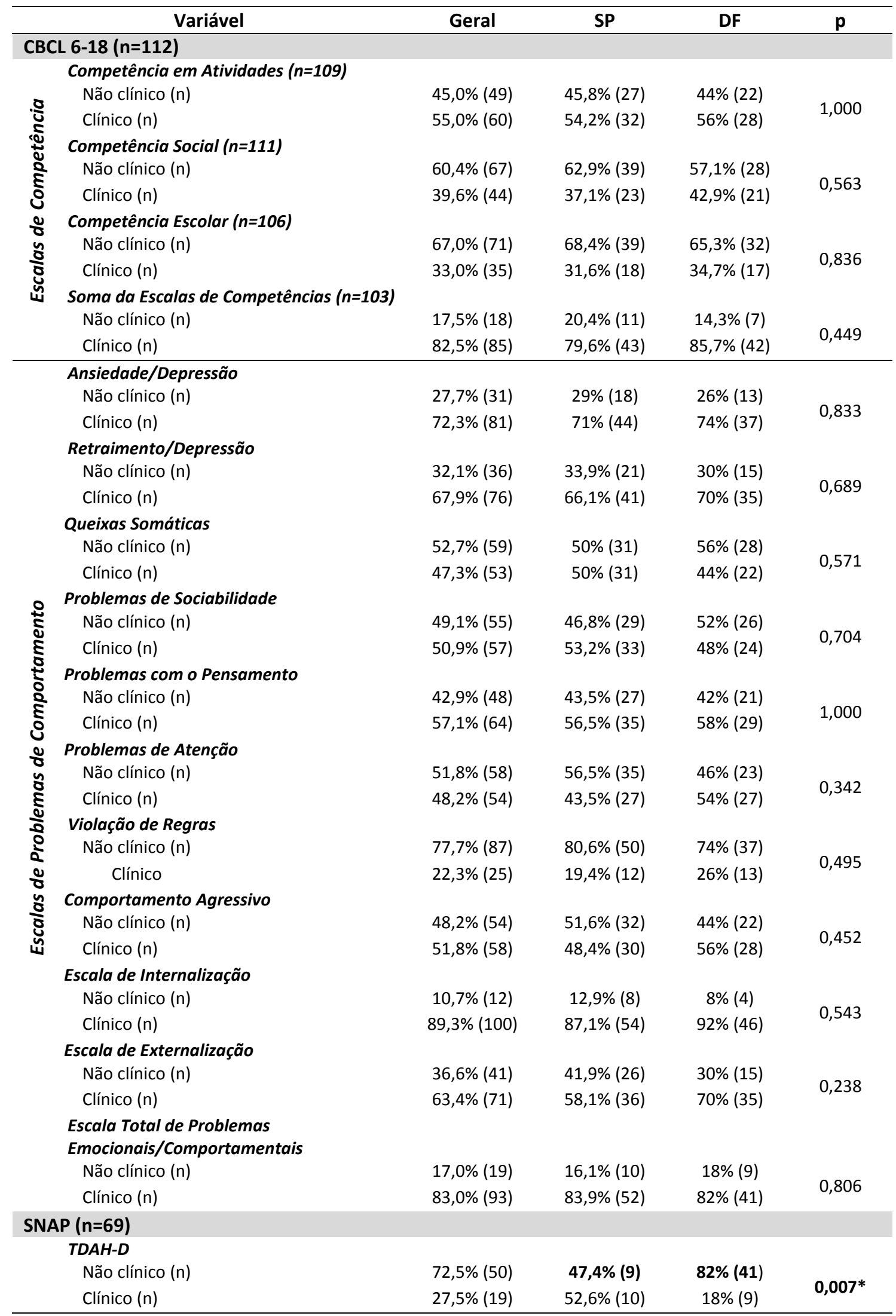




\begin{tabular}{lcccc}
\hline Cont. Tabela 9 & & & & \\
\hline TDAH-H/Im & & & & \\
Não clínico (n) & $71 \%(49)$ & $57,9 \%(11)$ & $76 \%(38)$ & 0,151 \\
Clínico (n) & $29 \%(20)$ & $42,1 \%(8)$ & $24 \%(12)$ & \\
TOD & & & & \\
Não clínico (n) & $92,8 \%(64)$ & $84,2 \%(16)$ & $96 \%(48)$ & 0,124 \\
Clínico (n) & $7,2 \%(5)$ & $15,8 \%(3)$ & $4 \%(2)$ & 0,175 \\
MASC T (n=69) & $58 \%(40)$ & $68,4 \%(13)$ & $54 \%(27)$ & \\
$\quad$ Não clínico (n) & $42 \%(29)$ & $31,6 \%(6)$ & $46 \%(23)$ & \\
Clínico (n) & & & & \\
CDI (n=69) & $68,1 \%(47)$ & $63,2 \%(12)$ & $70 \%(35)$ & $30 \%(15)$ \\
Não clínico (n) & $31,9 \%(22)$ & $36,8 \%(7)$ & & \\
Clínico (n) & & &
\end{tabular}

Como demonstra a Tabela 9, a maioria dos CrUs atingiram perfil clínico, segundo a percepção parental, em 10 das 15 escalas do CBCL analisadas, sendo que os índices clínicos foram mais frequentes nas Somas das Escalas de Competências (82,5\%), na Escala de Ansiedade/Depressão (72,3\%), na Escala de Internalização (89,3\%) e em Total de Problemas Emocionais/Comportamentais (83\%). Tanto no SNAP aplicado nos pais como nos instrumentos de autorrelato (MASC e CDI), houve um predomínio de CrUs que não atingiram escores clínicos.

Na comparação da distribuição dos escores não clínicos e clínicos dos instrumentos, pelo Teste de Fisher, observou-se uma diferença estatística significativa entre os dois serviços apenas no SNAP, no subconjunto que avalia desatenção $(p=0,007)$. Essa diferença se deve pelo fato que as respostas de 52, 6\% das CrUs atingiram escores clínicos em desatenção em SP e apenas $18 \%$ no DF.

Em relação ao Encaminhamento e Queixa Inicial, observou-se que nos dois serviços houve um baixo encaminhamento das escolas e um maior encaminhamento dos serviços e profissionais de saúde. Apesar das diferenças na distribuição das Crs nas opções previstas de queixas iniciais pelo instrumento, nota-se que a queixa predominante foi a mesma nos dois serviços. Por sua vez, na queixa obtida pelos instrumentos, o resultado do Teste Fisher indicou diferença apenas em um subconjunto do SNAP. Em algumas escalas do CBCL, os dados foram equivalentes: Competência em Atividades $(p=1,000)$ e Problemas de Pensamento $(p=1,000)$. Além disso, houve uma discordância importante, não entre os dados dos CrUs mas entre as informações relatadas pelas CrUs no MASC e dos cuidadores no $\mathrm{CBCL}$, no que se refere ao grau de ansiedade. Enquanto $72,3 \%$ dos CrUs, a partir da percepção dos cuidadores no CBCL, atingiram escore clínico para Escala de Ansiedade/Depressão, apenas $42 \%$ dos CrUs atingiram escore semelhante no MASC. 
A partir deste levantamento, as crianças de SP com indicação para a Etapa II deste estudo foram incluídas no grupo de intervenção (Grl) e as do DF foram incluídas no Grl ou no grupo controle de lista de espera $(\mathrm{GrC})$.

\subsection{Etapa II: Avaliação da Adaptação E do USO do PRotocolo no TREINAMENTO DOS TES}

A análise dos dados da Etapa II foi diferenciada em: (a) descrição das competências gerais e específicas da TCC apresentadas pelos TEs, a partir do CTS; (b) avaliação dos estagiários sobre o uso do protocolo como uma ferramenta de treinamento de alunos para o atendimento de crianças ansiosas; (c) comparação dos ganhos terapêuticos das crianças que participaram do Grl e do GrC; (d) comparação dos escores T médios do CBCL 6-18 nas quatro fases de avaliação, a partir da percepção parental e dos escores médios do MASC, a partir do autorrelato; e (e) índice de mudança confiável que calcula o quanto os resultados clínicos podem ser atribuídos a intervenção.

\subsubsection{DESCRIÇÃO DAS COMPETÊNCIAS GERAIS E ESPECÍfICAS DA TCC APRESENTADAS PELOS TES, A PARTIR DO CTS}

Os dados obtidos pelo CTS foram analisados considerando: (a) as porcentagens médias e desvio padrão do desempenho do TEs, pelas respostas dos próprios TEs, dos pares e dos juízes; (b) o resultado do teste estatístico Kruskal-Wallis, que avaliou o quanto os dados dos três informantes foram equivalentes estatisticamente nas quatro partes do instrumento; e (c) o resultado do teste de Fisher, que foi utilizado na Parte III do instrumento, para avaliar se houve diferença entre os informantes no que se refere aos itens que analisaram problemas especiais na sessão e fatores não usuais.

Na Figura 8, estão apresentados os dados das porcentagens médias e desvios padrões das respostas dos informantes nas quatro partes do CTS: Parte I - Habilidades Gerais, Parte II Habilidades Específicas, Parte III - Considerações Adicionais e Parte IV - Avaliações Gerais. 


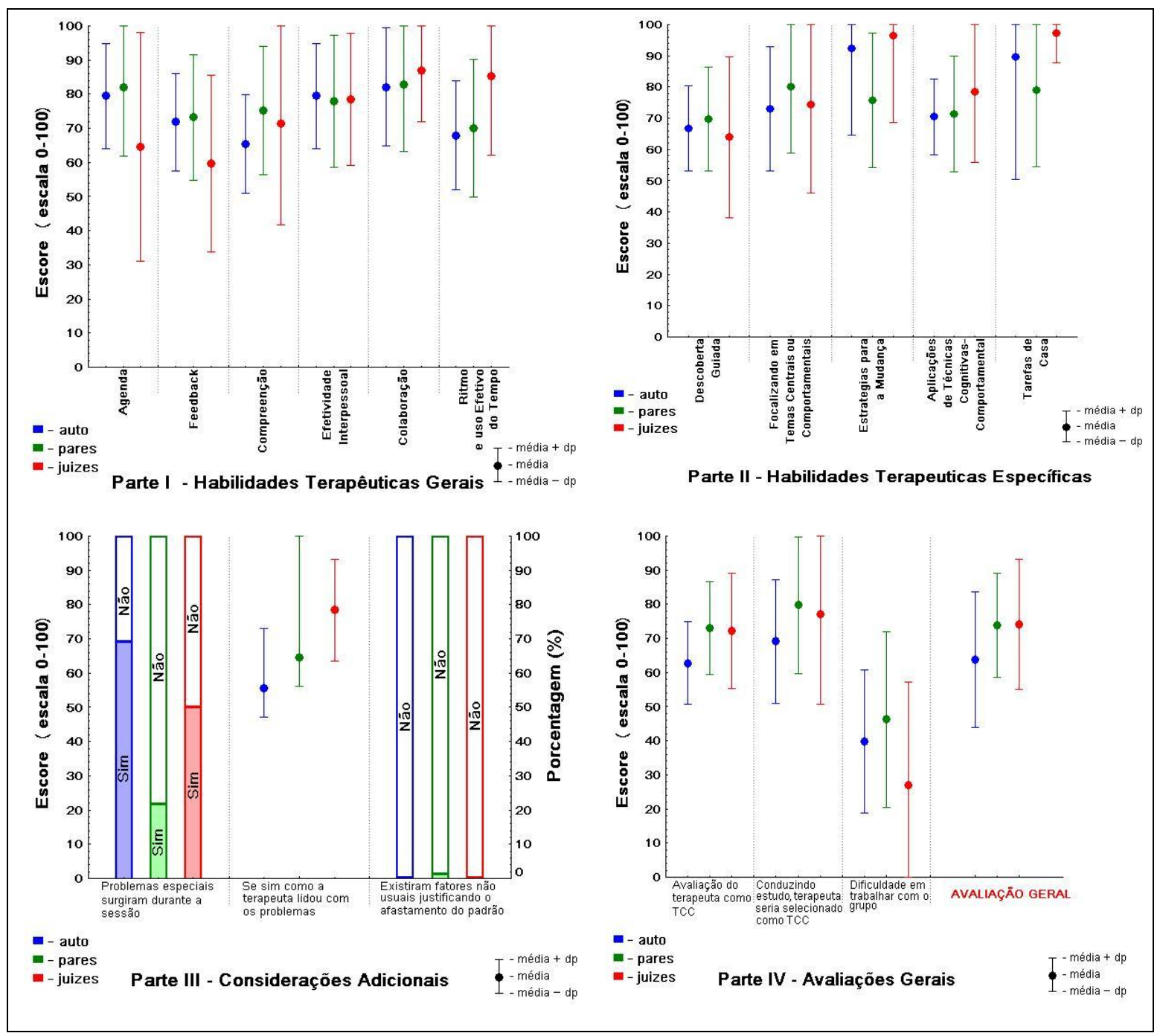

Figura 8. Porcentagens médias e desvios-padrão (dp) do desempenho dos TEs no CTS, a partir da avaliação dos próprios TEs, dos pares e dos juízes.

Conforme apresentado na Figura 8, observa-se que em Habilidades Terapêuticas Gerais (Parte I), o desempenho médio dos TEs ficou acima de $59 \%$ em todas as habilidades avaliadas. Na Parte I do CTS, os pares avaliaram os TEs como mais competentes do que os demais informantes em Agenda (média=82,2\%; $d p=20,04$ ), em Feedback (média=73,2\%; $d p=18,47$ ) e em Compreensão (média=75,2\%; $d p=18,76$ ); já os juízes, em Colaboração (média=86,8\%; $d p=14,73$ ) e em Ritmo e uso eficiente do tempo (média=85,4\%; $d p=23,22$ ); enquanto os alunos se avaliaram como mais competentes apenas em Efetividade Interpessoal (média=79,5\%; $d p=15,45)$. Houve uma concordância entre informantes em relação ao melhor desempenho avaliado na Parte I, sendo a habilidade Colaboração mais bem avaliada por todos (média geral $=83,5 \% ; p=0,656)$. Em relação ao pior desempenho demonstrado pelo $\mathrm{TE}$, houve uma divergência entre os informantes. Os TEs avaliaram Compreensão como a habilidade em que 
mais tiveram dificuldade (média=67,9\%; $d p=14,37$ ), enquanto os pares elegeram Ritmo e uso eficiente do tempo (média=70,0\%; $d p=20,27$ ) e os juízes, Feedback (média=59,7\%; $d p=25,97$ ).

No teste de Kruskal-Wallis, identificaram-se duas diferenças estatisticamente significativas entre juízes e TEs e entre juízes e pares. A primeira delas foi em relação a Agenda, respectivamente $p=0,050$ e $p<0,001$, devido aos juízes avaliarem o desempenho dos TEs pior do que os demais. E a segunda, em Ritmo e uso eficiente do tempo $(p=0,010$ e $p=0,002)$, por motivo inverso, pois os juízes avaliaram o desempenho dos TEs mais positivamente do que os demais. A diferença de avaliação entre os informantes pares e juízes em Agenda pode ser explicado por um fator não associado à intervenção nem ao treinamento. Diferentemente dos pares e dos TEs, que avaliaram o desempenho dos terapeutas pela observação ao vivo, o juiz o fez pela observação da sessão em vídeo. Como em várias sessões, a filmadora foi ligada após o estabelecimento do que seria tratado na sessão, isto justificaria a diferença nessa categoria. teste Kruskal-Wallis também indica que houve uma semelhança estatística alta entre os informantes em relação à habilidade Efetividade Pessoal $(p=0,985)$.

Ainda na Figura 8, nota-se que, com relação aos dados avaliados em Habilidades Terapêuticas Específicas à TCC (Parte II), a média de desempenho dos TEs ficou um pouco mais alta que na Parte I - acima de 63\%, independentemente do informante, apesar de ter havido uma maior discordância entre eles. Na Parte II, diferentemente da Parte I, os juízes avaliaram mais positivamente os TES, do que os pares e os próprios TEs. Das cinco habilidades avaliadas, em três os juízes avaliaram os TEs mais competentes do que os demais informantes: Estratégias para mudança (média=96,5\%; dp=27,79), Aplicações das técnicas cognitivo-comportamentais (média=78,5\%; dp=22,78) e Tarefa de casa (média=97,2\%; dp=9,41). O desempenho dos TEs nas duas habilidades restantes foi mais bem avaliado pelos pares: Descoberta Guiada (média=69,8\%; dp=16,71) e Focalizando em temas centrais ou comportamentos (média=80,0\%; $d p=21,01$ ). Houve uma menor concordância entre os informantes no que diz respeito ao melhor desempenho dos TEs. Segundo os próprios TEs, o melhor desempenho foi na competência Estratégias para mudança (média=92,3, $d p=19,88$ ), enquanto para os pares foi em Focalizando em temas centrais ou comportamentos (média $=80,0, d p=21,01$ ) e para os juízes Tarefa de casa (média=97,2, dp=9,41). Contudo, todos concordaram que os TEs tiveram dificuldades no uso da Descoberta Guiada. A discordância entre os pares e autoavaliação/juízes em relação à competência Estratégia para mudanças foi indicada pelo teste estatístico de Kruskal-Wallis como estatisticamente significante (valor $p=0,001$ ), devido aos pares avaliarem de forma mais negativa este desempenho nos TEs do que os outros informantes. 
Na Parte III, que avalia o quanto houve problemas especiais no atendimento e o quanto estes problemas não são usuais na TCC, observa-se na Figura 8 que houve uma diferença entre avaliadores tanto em relação a quanto os pacientes eram difíceis quanto na habilidade dos TEs para lidar com os problemas. Os TEs consideraram os pacientes atendidos como mais difíceis e se perceberam menos hábeis para resolver os problemas ocorridos na sessão, em relação à avaliação dos pares e dos juízes. Em uma escala crescente de 0 a 6, utilizada para aferir o grau de habilidade com que o terapeuta lidou com os problemas especiais, a autoavaliação apontou uma nota média de 3,3, que corresponde a $55,6 \%$ da pontuação máxima possível; enquanto os pares relataram 3,9 , que corresponde a $64,6 \%$. Os juízes avaliaram que os TEs foram mais habilidosos no manejo destas dificuldades do que os próprios TEs e do que os pares, uma vez que a nota média atribuída por eles foi de 5,6, que corresponde a 93,3\% da nota máxima. Estas diferenças entre avaliadores foram consideradas estatisticamente relevantes tanto no teste de Fisher, em relação aos problemas especiais no atendimento (valor $p=0,001$ ), quanto no teste de Kruskal-Wallis, que avaliou o quão habilmente o terapeuta manejou estes problemas, entre a avaliação dos próprios TEs $x$ pares $(p=0,032)$ e TEs $x$ juízes (valor $p<0,001)$ e entre pares $x$ juízes $(p<0,001)$. Nenhum dos informantes considerou os problemas identificados como não usuais no processo psicoterápico.

Por fim, na Parte IV, de avaliação geral das competências, em uma escala crescente de 0 a 6 utilizada para aferir o grau do desempenho do TE como terapeuta cognitivocomportamental, a autoavaliação apontou uma nota média de 3,8, que corresponde a $62,8 \%$ da pontuação máxima possível, que foi menor do que a nota média aferida pelos pares $(4,4)$ e pelos juízes $(4,3)$, que correspondem respectivamente a $73 \%$ e 72,2\%. Essa diferença de avaliação dos TEs em relação aos demais avaliadores foi considerada pelo teste de Kruskal-Wallis como estatisticamente relevante $(p=0,014)$. Na questão "se você estivesse conduzindo um estudo de resultados em terapia cognitivo-comportamental, você acha que deveria selecionar o TEs avaliado para participar deste estudo", utilizando uma escala crescente de 0 a 4 , novamente os TEs se avaliaram com menos chances de serem selecionados do que os demais informantes, apesar de não haver uma diferença estatística $(p=0,151)$. A autoavaliação apontou uma nota média de 2,8, que corresponde a $69,2 \%$ da pontuação máxima possível, a dos pares foi de 3,2, que corresponde a $79,7 \%$ e dos juízes, de 3,1, que corresponde a 77,1\%. Em se tratando do quanto foi difícil trabalhar com o Grl, houve uma diferença entre os avaliadores ao utilizar uma escala crescente de 0 a 6, uma vez que os pares indicaram como média 2,8 de dificuldade, que corresponde a $46,2 \%$ da pontuação máxima possível, enquanto os TEs avaliaram como média de 
2,4, que corresponde a 39,7\% e os juízes, uma média ainda menor de 1,6, que corresponde a 27,1\%. De acordo com o teste Kruskal-Wallis, esta diferença foi ainda mais significante entre pares e juízes $(p=0,002)$. No entanto, na avaliação do desempenho geral dos TEs, houve semelhança entre os avaliadores, de modo que em uma escala crescente de 0 a 5 , a autoavaliação apontou uma nota média de 3,2 , que corresponde a $63,8 \%$ da nota máxima; a dos pares, 3,7 , que corresponde a $73,8 \%$ da nota máxima; e dos juízes, 3,7 , que corresponde a 74,2 da nota máxima $(\mathrm{p}=0,058)$.

Aos juízes também foi solicitado que avaliassem a fidelidade dos TEs ao manual. $\mathrm{Na}$ avaliação média dos juízes, a fidelidade ao protocolo por parte dos TEs foi de 3,7, que corresponde a $93,6 \%$ de adesão ao tratamento preconizado. Isso aumenta a chance do resultado do tratamento estar associado ao protocolo utilizado e não a outras variáveis.

Além da avaliação do desempenho a partir do CTS, também foi questionada a adaptação do protocolo para uso no treinamento de terapeutas e atendimento de crianças ansiosas com os TEs a partir da aplicação de um questionário. A seguir, apresentaremos estes dados.

\subsubsection{Avaliação dos estagiários sobre o uso do Protocolo Como uma FERRAMENTA DE TREINAMENTO DE ALUNOS PARA O ATENDIMENTO DE CRIANÇAS ANSIOSAS}

Para avaliar os dados sobre o protocolo foram realizadas três análises dos dados obtidos do Inventário do Estagiário. As duas primeiras abordam os dados das questões objetivas. A primeira análise compara a frequência das respostas em uma escala de 0-100, dos TEs das duas cidades, considerando as opções possíveis, conforme a escala utilizada para cada uma das questões fechadas. Além da análise da frequência, estes mesmos dados foram testados pelo teste de Fisher, para avaliar o quanto as respostas dos TEs nas duas cidades foram estatisticamente semelhantes $(p>0,05)$ ou diferentes $(p<0,05)$, considerando a opções de resposta do instrumento. Estes dados são demonstrados na Figura 9. A segunda análise foi realizada por meio da porcentagem média e do desvio padrão das respostas dos TEs, sem diferenciar a cidade. Estes dados serão apresentados na Figura 10. Nestes dados, também foi realizado o teste estatístico Mann-Whitney, que indica se houve uma diferença estatística nas médias das respostas dos TEs em cada questão fechada. Finalmente, a terceira análise descreve os dados relatados pelos TEs nas questões abertas, considerando o conteúdo de cada uma. 


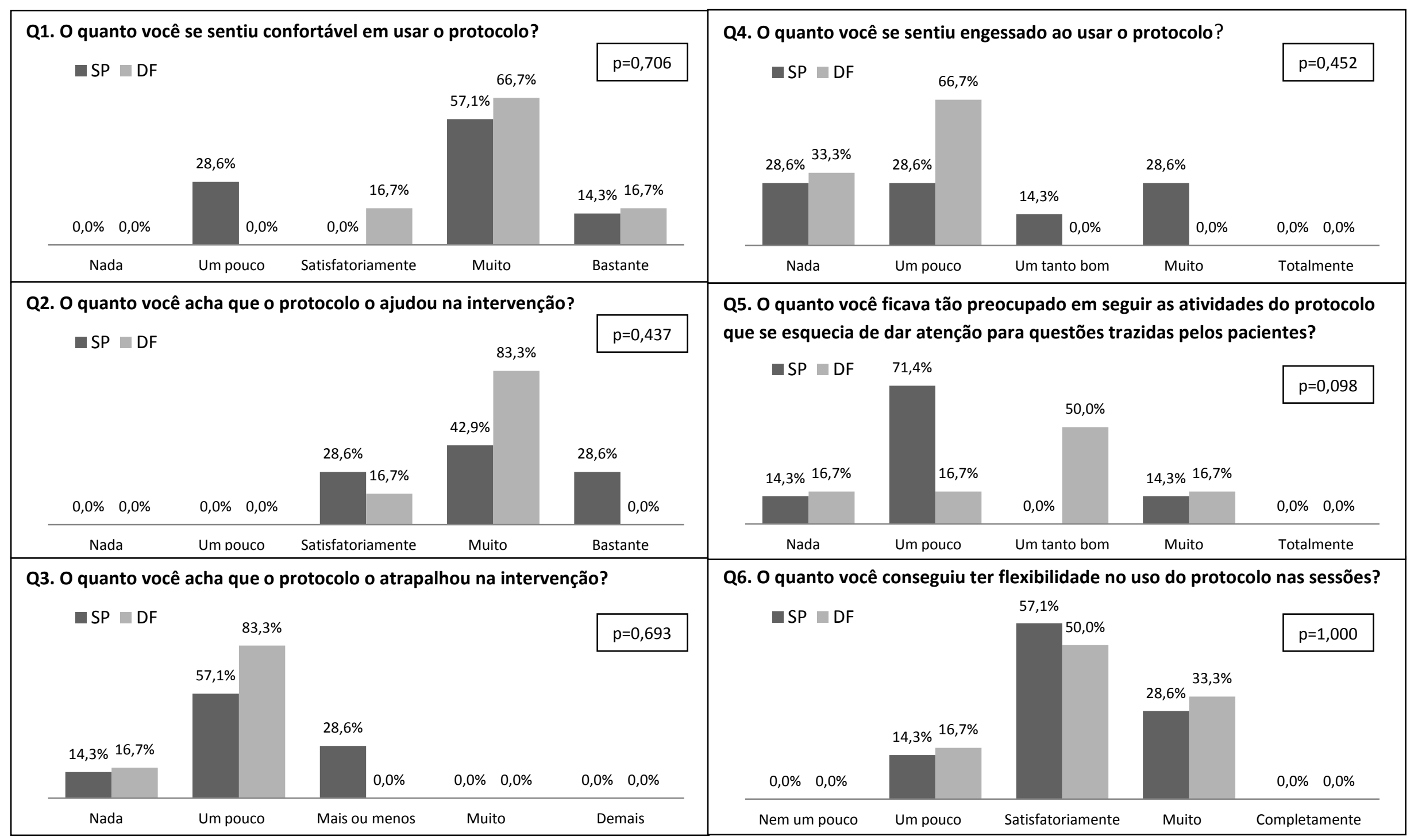

Figura 9. Comparação da frequência das respostas dos TEs sobre o protocolo, segundo as opções de resposta (\%), nas duas cidades ( $\mathrm{n}=13$ ). 


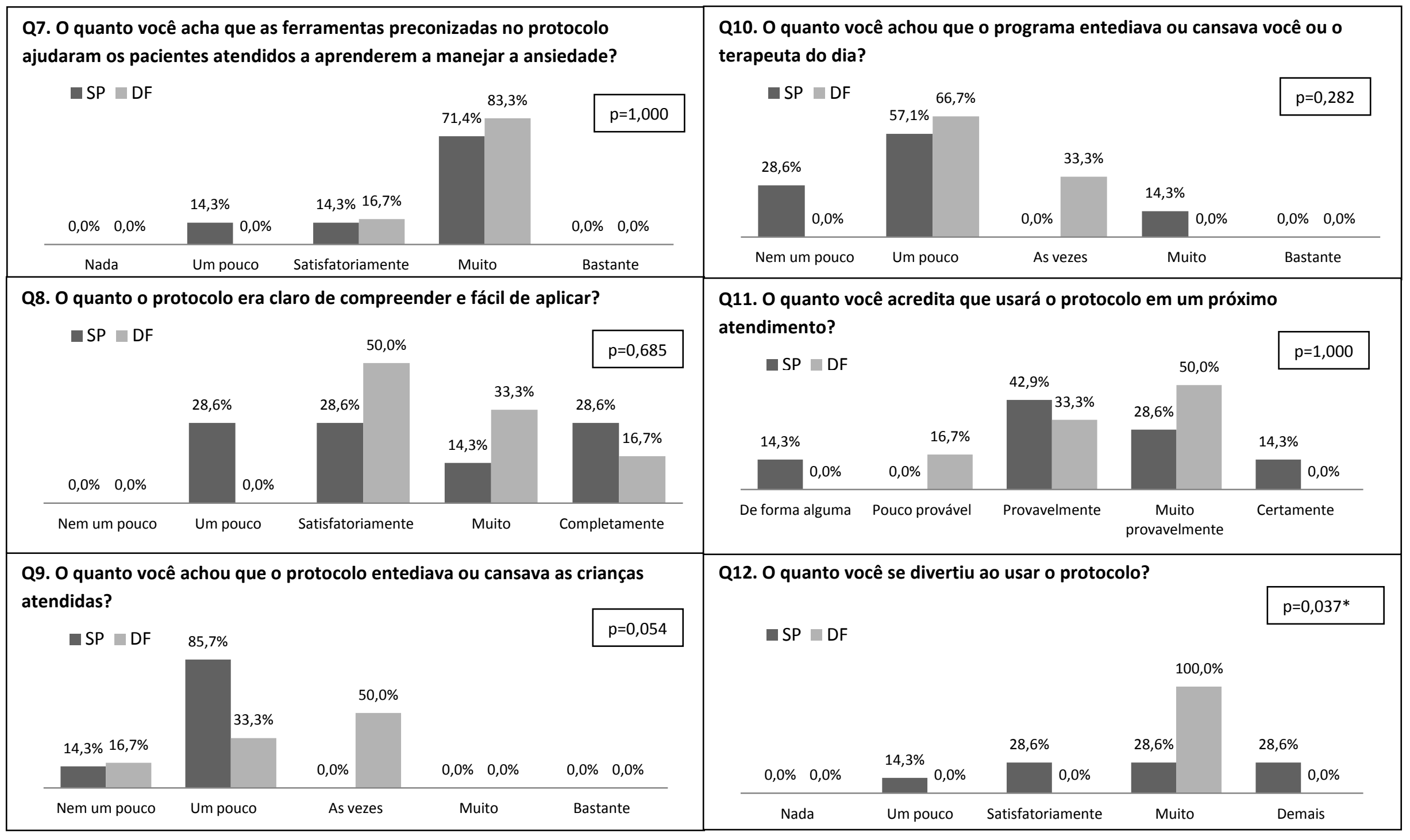

Cont. Figura 9 


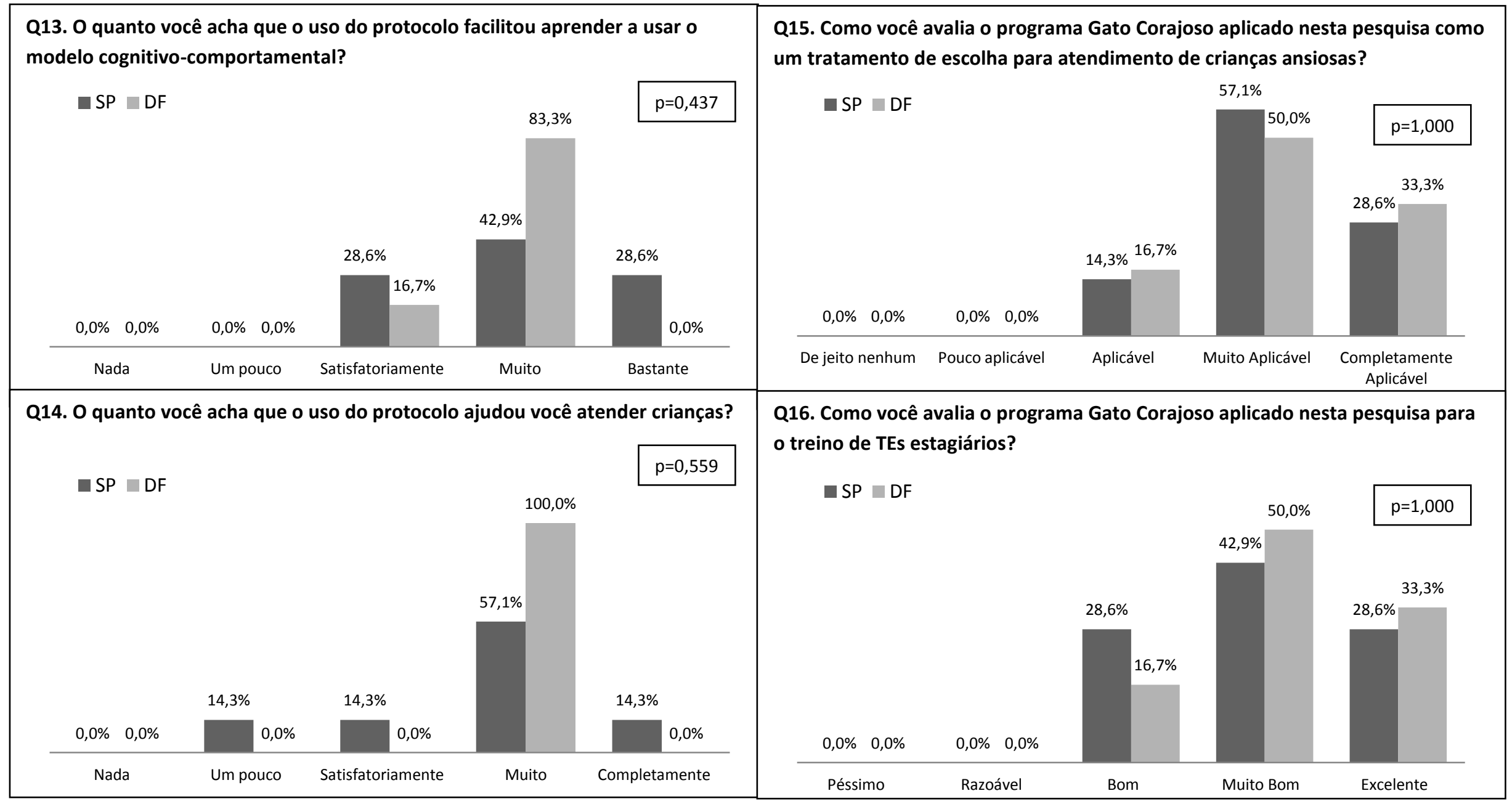

Cont. Figura 9 
Conforme consta na Figura 9, a maioria dos TEs avaliou que se sentiu "muito" ou "bastante" confortável com o uso do protocolo (Q1: SP-71,4\%; DF-83,4\%); e que o uso deste os ajudou "muito" ou "bastante" na aplicação da intervenção (Q2: SP-71,5\%; DF-83,3\%), na compreensão do modelo da TCC (Q13: SP - 71,5\%; DF-83,3\%) e no atendimento infantojuvenil (Q14: SP- 71,4\%; DF- 100\%). Houve, também, uma percepção predominante de que as ferramentas preconizadas no protocolo ajudaram os pacientes atendidos a aprenderem a manejar a ansiedade (Q7: SP - 71,4\%; DF- 83,3\%), de que o protocolo era "satisfatoriamente" ou "muito" claro de entender e de aplicar (Q8: SP - 42,9\%; DF- 83,3\%) e que houve flexibilidade "satisfatória" na aplicação da intervenção (Q6: SP - 57,1\%; DF- 50\%). Apesar da avaliação positiva em relação ao uso deste tipo de intervenção manualizada, a maioria dos TEs relatou que esta ferramenta atrapalhou "um pouco" a intervenção (Q3: SP - 57,1\%; DF- 83,3\%). Os TEs do DF se sentiram, mais do que os de SP, um pouco engessados com o uso do protocolo (Q4: 66,7\%), provavelmente porque ficaram preocupados em seguir as atividades do protocolo e se esqueciam de dar atenção para questões trazidas pelos pacientes (Q5: 50\%), e por acharem que o protocolo entediava ou cansava um pouco as crianças atendidas (Q9: 50\%).

Em síntese, pode-se afirmar que, na opinião dos TEs, o protocolo auxiliou no atendimento realizado com as crianças ansiosas, embora alguns tenham se sentido mais confortáveis com o formato padronizado do que outros. Nas questões que investigaram o grau de aplicabilidade do protocolo para o atendimento de crianças ansiosas e para o treino de TEs, no geral (SP+DF) a maioria avaliou o instrumento como, respectivamente, muito aplicável (54\%) e excelente ou muito bom (77\%). O teste de Fisher indicou uma diferença estatisticamente significativa apenas na Q12, que avaliou o quanto os TEs se divertiram ao usar o protocolo (valor $p=0,037$ ). Todos os TEs do DF citaram que se divertiram "muito" na aplicação do protocolo, enquanto os de SP relataram que se divertiram "satisfatoriamente" $(28,6 \%)$, "muito" $(28,6 \%)$ ou "demais" $(28,6 \%)$.

A avaliação das médias das respostas dos dois serviços (SP+DF), em uma escala de 0-100, às mesmas questões é demonstrada na Figura 10. É importante ressaltar que na figura, pelo conteúdo das questões, é desejável que o resultado seja mais alto nas apresentadas em azul e que seja mais baixo nas demonstradas em vermelho. 


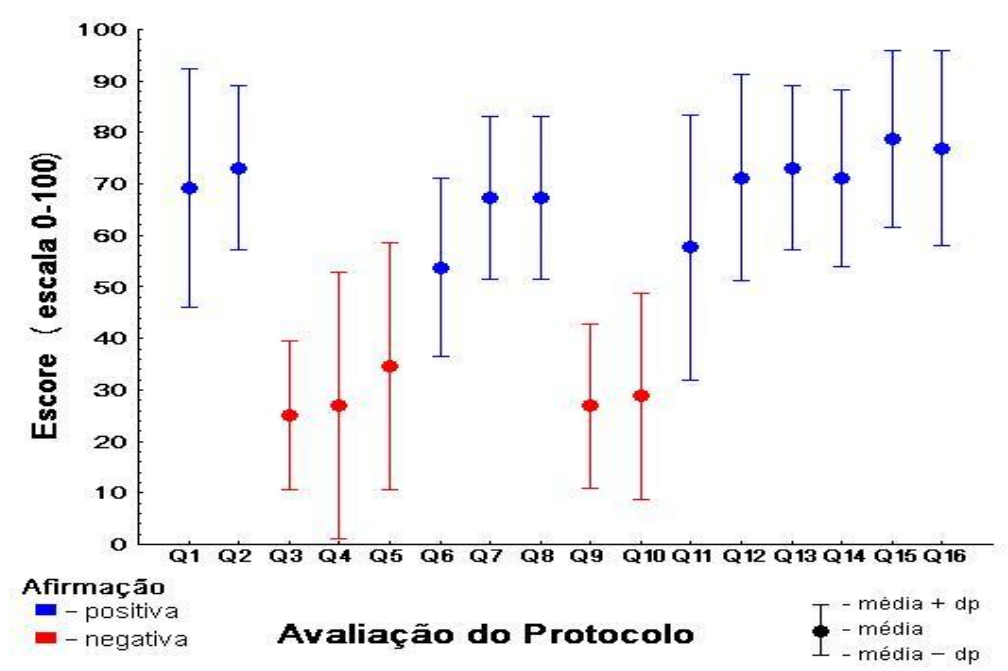

Figura 10. Porcentagem média e desvio padrão (dp) das respostas dos TEs sobre o protocolo, em cada questão fechada.

Observa-se, na Figura 10, que os TEs avaliam que o protocolo tem utilidade no treinamento de terapeutas (Q15: média=78,8\%; $d p=17,22$ ) e para o atendimento de crianças ansiosas (Q16 : média=76,9\%; $d p=18,99$ ). Ademais, o protocolo foi identificado pela maioria como um facilitador para intervenção (Q2: média=73,1; $d p=16,01$ ) e para o aprendizado da TCC (Q13: média=73,1\%; $d p=16,01$ ), e ajudou a atender crianças (Q14: média=71,2\%; $d p=17,22$ ). Os TEs citaram que se divertiram na aplicação do protocolo nas crianças (Q12: média=71,2\%; $d p=20,02$ ).

Entre as questões que avaliaram aspectos negativos do protocolo (Q3, Q4, Q5, Q9 e Q10), em média os TEs acharam que o maior prejuízo foi em relação a Q5 (média=34,6\%; $d p=24,02$ ), pela preocupação em seguir o protocolo e, com isso, não perceber informações importantes na sessão.

O teste de Mann-Whitney não indicou nenhuma diferença estatística, considerando a média entre as respostas dos TEs das diferentes cidades. A maior semelhança estatística nesta análise foi quanto ao uso do protocolo em um próximo atendimento demonstrada tanto no teste de Mann Whiteney como no teste de Fisher $(p=1,000)$, uma vez que $84,7 \%$ dos TEs afirmou que usaria novamente o protocolo (provavelmente ou certamente).

Além das perguntas fechadas, foram avaliadas quatro perguntas abertas. No que se refere ao uso do protocolo para atendimentos de crianças, os TEs listaram como pontos fortes: trazer estratégias claras para ensinar as crianças a identificarem e lidarem melhor com as suas dificuldades; ser sistematizado e organizado, facilitando a atuação do terapeuta; propiciar uma 
excelente compreensão do que seria a ansiedade e quais estratégias para manejá-la, passo a passo; as atividades de caráter lúdico que auxiliaram na aprendizagem dos conceitos propostos; proporcionar a integração e troca grupal; ensinar as estratégias para crianças de forma lúdica; a adesão das crianças ao atendimento; e o fato de, apesar de ser estruturado, ter flexibilidade. Além disso, mencionaram como pontos fracos: deixar pouco espaço para o que emerge da criança, sendo necessário escolher ouvir o que elas trazem ou seguir com as atividades do protocolo; o risco de algumas crianças ficarem de lado se o terapeuta não estiver atento; o número reduzido de sessões; a baixa adesão das crianças às tarefas de casa; e ser muito complexo e com muitos detalhes, o que atrapalhava às vezes o rendimento e a organização do grupo.

No que se refere ao uso do protocolo para treinamento de TEs, foram considerados pontos fortes: oferecer um modelo a ser seguido que proporciona segurança para quem tem pouca experiência; ensinar novas técnicas ao terapeuta e formas para ajudar a criança a entender seu comportamento diante de situações de ansiedade; além de discutir os casos na supervisão. Além disso, os TEs mencionaram como pontos fracos: a possibilidade de deixar o terapeuta dependente das regras definidas; não favorecer a criação e adaptação com aquilo que o paciente traz; ser focal demais; não abrir espaço para problemas que podem aparecer em outra área; e exigir muito trabalho e organização dos TEs.

Os TEs citaram as seguintes dificuldades na aplicação do protocolo: adequar as atividades ao tempo, principalmente quando as crianças queriam continuar uma atividade mas o tempo não permitia; obter a atenção do grupo, uma vez que em alguns momentos as crianças ficavam dispersas; lidar com as questões pessoais das crianças e das mães; não saber o que dizer diante de algumas perguntas ou comentários das crianças ou mães; e a organização dos TEs e supervisora na preparação do material antes da sessão.

Como sugestão para próximos treinamentos, apontaram: diminuir o número de atividades por sessão e aumentar o número de sessões do protocolo, para que o estagiário possa trabalhar melhor as atividades, sem se preocupar tanto com a tarefa seguinte e o tempo; e organizar melhor os prêmios sociais e o material impresso a ser trabalhado com as crianças em cada sessão no início do treinamento.

A avaliação do uso do protocolo e das competências adquiridas pelos TEs também foi verificada com o resultado da intervenção, realizada pela comparação dos dados dos instrumentos intragrupos (grupos de intervenção e grupo controle) e do intergrupo (grupo com ele mesmo). A seguir, discutiremos a comparação dos dados dos instrumentos dos $\mathrm{Cr}$, alocados no 
Grl e GrC nas Fases 1 e 2 e os dados dos $\mathrm{Cr}$ do Grl nas Fases 3 e 4.

\subsubsection{COMPARAÇ̃̃o DOS GANHOS TERAPÊUTICOS DAS CRIANÇAS QUE PARTICIPARAM DO GRI E DO GRC NO CBCL E NO MASC}

Além das competências avaliadas pelo CTS e da avaliação dos alunos sobre o protocolo, outra forma de avaliar o treino dos terapeutas é por meio dos resultados clínicos dos que receberam a intervenção. A seguir, será apresentada a comparação dos dados clínicos das Crs do Grl e do GrC. Esta análise foi realizada mediante a distribuição dos escores médios e desvios padrões e mediante testes estatísticos (Mann-Whitney, Fisher e Wilcoxon), considerando: os dados do CBCL 6-18 apenas na Soma das Escalas de Competência, da Escala Individual de Ansiedade/Depressão, e as Somas das Escalas de Problemas (Internalização, Externalização e Total de Problemas); e os dados do MASC.

\subsubsection{Dados do CBCL 6-18: PERCEPÇ̃̃o PARENTAL}

O escore $\mathrm{T}$ médios e desvio padrão do $\mathrm{CBCL}$ 6-18 dos $\mathrm{Cr}$ do $\mathrm{Grl}$ nas quatro fases de avaliação, e do $\mathrm{GrC}$, nas duas primeiras fases avaliadas está apresentado na Figura 11, na qual no eixo Y o número em vermelho representa o ponto de corte do escore T clínico considerado para cada escala do CBCL 6-18. Lembrando que, na Soma das Escalas de Competência, o escore $T \geq 41$ indica perfil menos clínico e, na escala de Ansiedade/Depressão, escore $T \leq 66$ e, na Somas das Escalas de Problemas (Internalização, Externalização e Total de Problemas), escore $T \leq 64$ indicam perfis menos clínicos. 


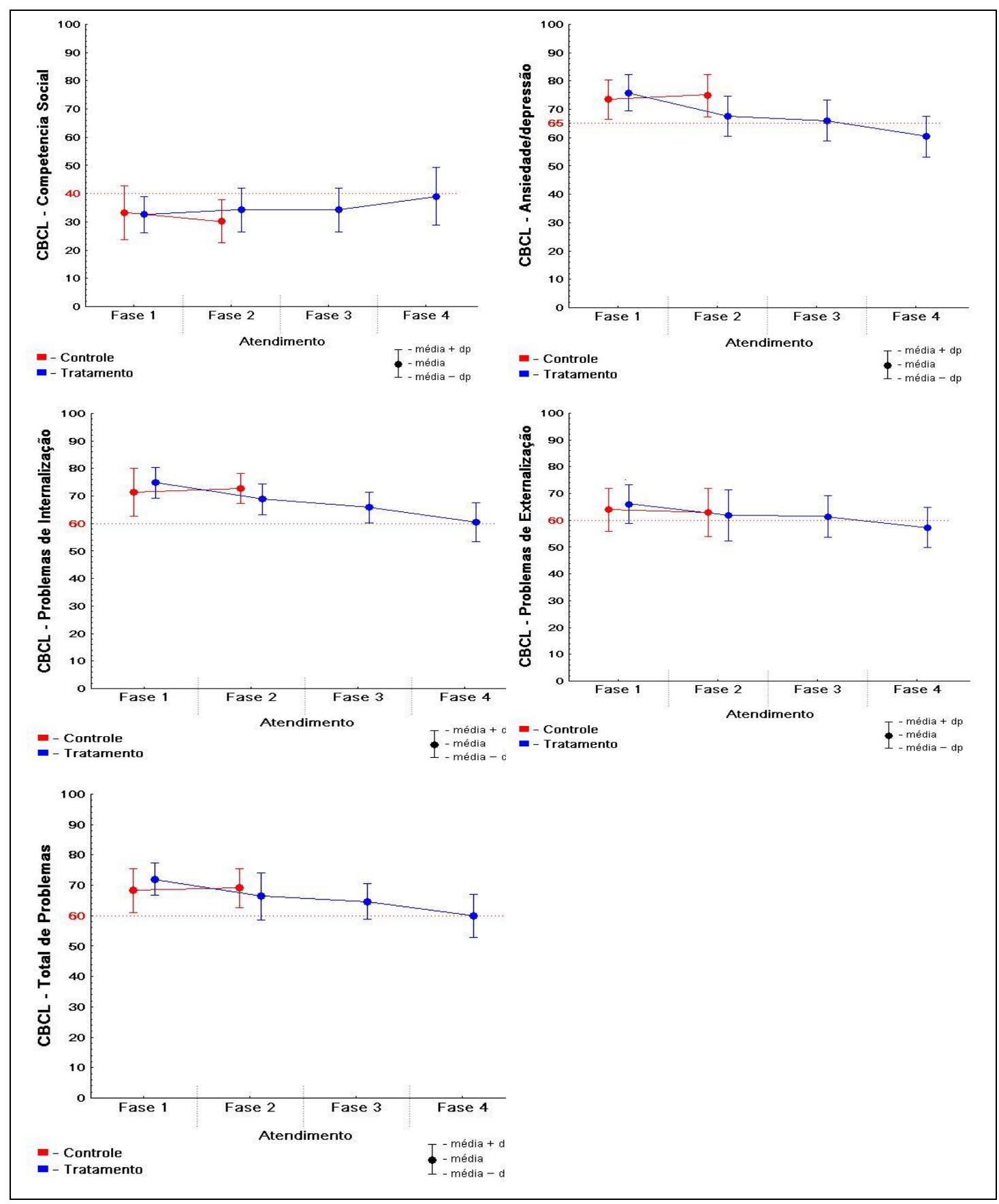

Figura 11. Comparação das variações das médias e desvios padrões das escalas do $C B C L$ 6-18, nas fases de avaliação.

Na Figura 11, observa-se que entre as Fases 1 e 2 já houve uma diferença entre os dados do Grl e do Grl x GrC. Na comparação dos dados das Fases 1 e 2, houve uma maior variação estatisticamente relevante entre as médias das Crs do Grl, do que das do GrC, nas Escalas de Ansiedade/Depressão (Grl: escore médio= -10,5\%; $d p=9,77$ x GrC: média=2,3; $d p=10,31$ ), de Internalização (Grl: média= -7,8\%; $d p=7,02 \times \mathrm{GrC}$ : média=2,7\%; $\mathrm{dp}=8,24$ ), e de Total de 
Problemas (Grl: média $=-7,7 \%$; dp=9,16 x GrC: média=1,6\%; dp=8,11). Essas diferenças foram consideradas no teste de Mann Whiteney como estatisticamente significativas pelo valor do $\mathrm{p}$ ser menor do que 0,05 na Escala Individual de Ansiedade/Depressão $(p=0,001)$, na Escala de Internalização $(p=0,001)$ e na Escala de Total de Problemas $(p=0,003)$. Isso indica que as $\mathrm{Cr}$ do $\mathrm{GrI}$ apresentavam diferenças estatisticamente relevantes sugestivas de melhora clínica, quando comparadas com elas mesmas nas Fases 1 e 2 e quando comparadas com as $\mathrm{Cr}$ do $\mathrm{GrC}$.

Na comparação entre os dados do Grl x GrC, já na Fase 2, foi atribuído escore T não clínico na Escala Individual de Ansiedade/Depressão para 6 crianças das 20 que participaram do Grl e para 1 criança das 11 do $\mathrm{GrC}$, e na Escala de Internalização para 2/20 crianças do Grl e 0/11 do GrC.

Na comparação das médias dos participantes do Grl no CBCL 6-18 nas Fases 1, 2, 3 e 4, demonstrada na Figura 11, observa-se que houve uma melhora crescente entre as fases, em todas as escalas do CBCL avaliadas. No entanto, apenas no follow-up de 6 meses (Fase 4), nota-se que o escore T médio dos participantes do Grl atingiu escore não clínico na Escala de Ansiedade/Depressão (escore T médio: 60,4; dp:7,23), na Escala de Externalização (escore T médio: 57,3; dp:7,47) e na Escala de Total de Problemas (escore T médio: 59,9; dp:7,14). Os escores T médios das Escalas de Competência (escore T médio: 39,1; dp:10,16) e de Internalização (escore T médio: 60,6; dp:7,05) ficaram bem próximos da linha que demarcou o corte clínico nessa mesma fase. $\mathrm{Na}$ avaliação dos dados na Fase 4, foi atribuído escore T não clínico na Escala Individual de Ansiedade/Depressão para 7 das $20 \mathrm{Crs}$ do $\mathrm{Grl}$, que equivale a 35\% dos participantes; e na Escala de Internalização para $10 / 20$ Crs, que equivale a 50\% dos participantes.

Os resultados do teste de Wilcoxon demonstram que estas diferenças entre as fases de avaliação foram estatisticamente significantes. Essa afirmativa só não vale no $\mathrm{CBCL}$ para os dados da Soma das Escalas de Competência $(p=0,500)$, quando comparadas as variações entre as Fases 1 e 2 e Fases 1 e 3. Este teste também confirma que a diferença entre os dados das Fases 1 x Fase 4 foi a mais estatisticamente significativa em todas as escalas do $\mathrm{CBCL}$, inclusive na Soma das Escalas de Competência $(p=0,011)$.

\subsubsection{Dados do MASC: AUtorrelato}

A distribuição das médias e dos desvios padrões do MASC, nas quatro fases de avaliação, é apresentada na Figura 12, seguindo a análise semelhante a descrita no tópico anterior. 


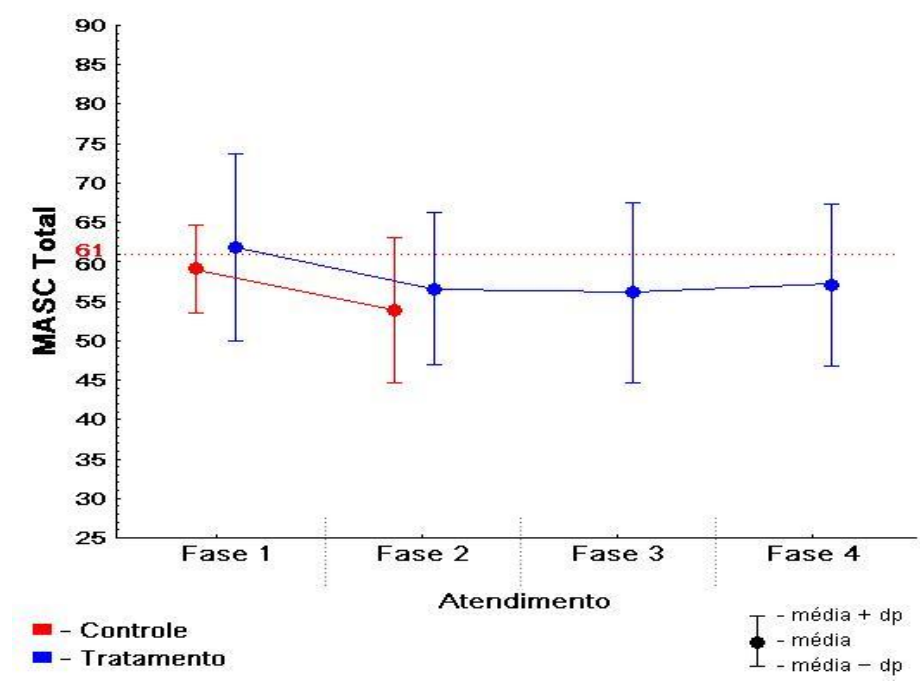

Figura 12. Comparação da variação entre as médias e desvios padrões do MASC, nas fases de avaliação.

Na figura 12, observa-se que nas Fases 1 e 2 não houve uma variação estatisticamente significante das médias entre as Crs do Grl (média= -6,9\%; $d p=15,51$ ) e do $\operatorname{GrC}$ (média=-8,6\%; $d p=$ 13,79), uma vez que todas as Crs atingiram escores não clínicos na Fase 2.

Na Fase 1 do Grl, foi atribuído escore clínico no MASC para 60\% das Crs e no GrC para $54,5 \%$. Estes dados foram analisados pelo teste de Fisher, que indicou equivalência entre os dois grupos ( $p=1,000$ ). Na Fase 2, 55\% das Crs do Grl atingiram escore não clínico para o MASC e 72,7\% das do $\mathrm{GrC}$ apresentaram o mesmo resultado. Novamente o teste de Fisher não indicou que essa diferença era relevante $(p=0,452)$. O teste Mann-Whiteney confirma essa informação ao indicar que não houve diferença nas médias entre os $\mathrm{Cr}$ do $\mathrm{Grl}$ e do $\mathrm{GrC}$ nos dados do MASC entre as Fases 1 e $4(p=0,396)$. Estes dados indicam que, diferentemente do observado no $C B C L$, quando comparadas as Fase 1 e 2, os dados das Crs do Grl e GrC não se diferenciaram.

Na comparação das médias e desvios padrões dos dados do MASC, nas quatro fases de avaliação apresentadas na Figura 12, observa-se que os dados do Grl, nas Fases 2, 3 e 4, os escores médios dos participantes do Grl no MASC mantiveram-se na faixa não clínica ao longo do tempo. O resultado do teste Wilcoxon mostra que variação da média do Crs no MASC foi estatisticamente significativa apenas entre as Fases $1 \times 3(p<0,001)$.

Além dos indicadores quantitativos já apresentados, os dados também foram avaliados considerando o índice de mudança confiável (IMC), para determinar o quanto a mudança dos participantes do Grl foi relevante clinicamente e o quanto ela pode ser atribuída à intervenção realizada. 


\subsubsection{3. ÍNDICE DE MUDANÇA CONFIÁVEL}

Há diversas formas de se avaliar a efetividade de um tratamento. O método mais usualmente empregado, com o propósito de avaliar se o tratamento produz melhoras nos pacientes, é a análise estatística baseada na comparação das medidas grupais obtidas antes e depois do tratamento, assim como entre as medidas dos pacientes que receberam a intervenção e os dados relativos àqueles que não receberam o mesmo tratamento, seja por terem permanecido na lista de espera ou por terem recebido um tratamento alternativo. Este método apresenta limitações nos estudos clínicos, pois os "bons resultados" não significam que a melhora verificada decorra necessariamente da intervenção (Kazdin, 2008b).

Em outras palavras, o método descrito não é suficiente para assegurar a validade interna da intervenção sob análise, uma vez que não permite demonstrar de forma conclusiva que os resultados obtidos podem ser atribuídos aos procedimentos e técnicas utilizadas. Dessa forma, é útil recorrer a uma análise de dados que considere o nível de confiabilidade das alterações ocorridas entre as medidas pré e pós-intervenção, caso a caso, como propiciado pelo denominado Índice de Mudança Confiável (IMC).

Assim, para complementar a análise estatística apresentada, incluiu-se a análise desse índice, para comparar os resultados individuais dos participantes do $\mathrm{Grl}(\mathrm{n}=20)$, entre a Fases 1 e a Fase 4. A Figura 13 é a representação gráfica desta análise, na qual são retratadas seis figuras, cada uma representando os dados das cinco escalas do CBCL e uma escala do MASC. Cada ponto nas figuras representa um determinado $\mathrm{Cr}$ do $\mathrm{Grl}$, posicionada no gráfico de acordo com os escores obtidos nas duas fases comparadas, representadas pelos eixos x (Fase 1) e y (Fase 4). Os pontos que sobrepõem a linha vermelha indicam os $\mathrm{Cr}$ para os quais não houve alteração nas duas fases consideradas, ou seja, situações em que as medidas da Fase 4 se equivaleram às medidas da Fase 1.

No caso da Escala de Competência, os pontos posicionados acima da linha vermelha indicam um aumento do escore e, consequentemente, uma melhora na competência social; ao contrário, os pontos abaixo da linha vermelha indicam uma redução do escore, ou seja, uma piora na competência social. Nas demais escalas do $\mathrm{CBCL}$ e do MASC, a análise gráfica segue lógica inversa à descrita. Assim, os pontos posicionados abaixo da linha vermelha indicam redução do escore e, portanto, melhora dos pacientes; por sua vez, os pontos situados acima da linha vermelha indicam aumento do escore, e piora da condição clínica dos indivíduos. 
Além disso, há em cada figura uma faixa cinza que abrange a linha vermelha central. Essa faixa delimita a área de confiança, de tal forma que, em todos os casos, uma mudança (melhora ou piora) somente será considerada confiável caso o ponto esteja fora da faixa. Portanto, em termos gráficos, é esta localização que irá indicar se a melhora verificada pode ser realmente atribuída à intervenção, permitindo uma avaliação da efetividade do tratamento.

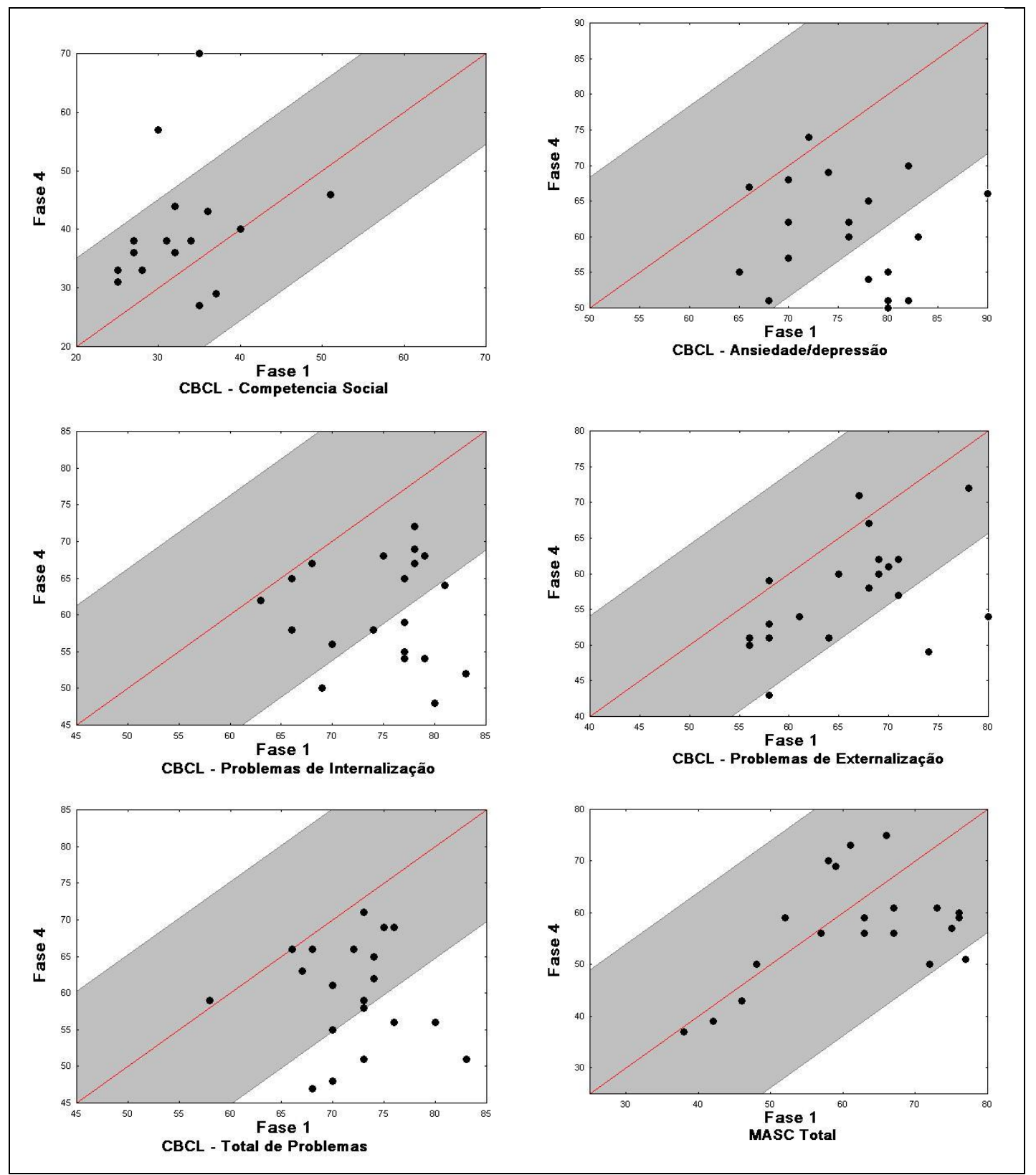

Figura 13. Representação visual da análise do IMC relativo aos dados dos participantes do GrI no $\mathrm{CBCL}$ e no MASC na Fase 1 x Fase 4.

Conforme demonstra a Figura 13, nas escalas do CBCL e no MASC, os Crs atingiramescores indicativos de melhora clínica na comparação da Fase 4 com a Fase 1, resultado concordante com a análise estatística apresentada ao longo deste trabalho. Observa-se, também, que um número 
maior de Crs aparece fora da faixa cinza nas escalas do CBCL, indicando mudança confiável, embora o mesmo fato não seja observado na figura que representa visualmente os dados do MASC.

Para aumentar a precisão desta análise, os dados do IMC foram transformados em porcentagem de melhora, de não alteração e de piora, conforme se apresenta na Tabela 10, a seguir.

Tabela 10. Quantificação das mudanças confiáveis de acordo com a variação dos instrumentos na Fase 1 × 4 .

\begin{tabular}{llccc}
\hline & Instrumentos & \multicolumn{3}{c}{ Índice de Mudança Confiável ${ }^{(\mathbf{1})}$} \\
\cline { 3 - 5 } & Competência Social & melhora & não altera & piora \\
\hline \multirow{3}{*}{ CBCL } & Ansiedade/Depressão & $\mathbf{3 5 , 0 \% ( 7 )}$ & $\mathbf{8 8 , 2 \% ( 1 5 )}$ & $11,8 \%(2)$ \\
& Problemas de Internalização & $\mathbf{4 0 , 0 \% ( 8 )}$ & $60,0 \%(12)$ & $0,0 \%(0)$ \\
& Problemas de Externalização & $15,0 \%(3)$ & $85,0 \%(17)$ & $0,0 \%(0)$ \\
& Total de Problemas & $\mathbf{3 0 , 0 \% ( 6 )}$ & $70,0 \%(14)$ & $0,0 \%(0)$ \\
\hline MASC & & $5,0 \%(1)$ & $95,0 \%(19)$ & $0,0 \%(0)$ \\
\hline
\end{tabular}

${ }^{(1)}$ definido por Jacobson, N.S.e alli 1984, 1986, 1988

No caso da análise sobre os dados apresentados na Tabela 10, observa-se que houve uma maior mudança confiável nas escalas do CBCL que avaliavam o foco da intervenção. Na Escala Individual de Ansiedade/Depressão, em que se observa que 35\% dos Crs apresentaram melhoras confiáveis, assim como $40 \%$ dos Crs na Escala de Internalização. A mudança nestas duas escalas também refletiu em melhora de $30 \%$ dos Crs na Escala de Total de Problemas. 


\section{Discussão E Conclusões}

Este estudo teve o objetivo de elaborar e avaliar uma proposta de treinamento de TEs no atendimento de crianças com ansiedade excessiva, inscritas em serviços-escola ambulatoriais, com um tratamento baseado em evidência e reconhecido internacionalmente para o atendimento desta queixa clínica - Manual Coping Cat, adaptado para a realidade brasileira.

O treino dos TEs foi estabelecido considerando práticas de treinamento e intervenção baseada em evidências. O modelo de treinamento utilizado foi o apresentado por Bennett-Levy (2006) e consiste de três fases para o desenvolvimento de habilidades do terapeuta, adaptado por Friedberg e cols. (2009) para o treino de TCC no atendimento infantojuvenil. Tanto na primeira Fase Teórica como na segunda Fase Prática, foi utilizado, principalmente, o protocolo Coping Cat para o treino de habilidades da abordagem em TCC e para o treino de habilidades clínicas para o atendimento de crianças ansiosas. Para o treino teórico, a terceira etapa - Fase Reflexiva consistiu da exposição das crianças a situações ansiogênicas previstas no protocolo, etapa na qual os alunos tinham que criar situações ou atividades para o enfrentamento de cada criança, considerando a lista de situações ansiogênicas (0-5).

A seguir discutiremos as conclusões destes estudos considerando as seis hipóteses iniciais colocadas na pg. 39.

\subsection{O perfil da clientela dos serviços-escola deste estudo se assemelhará com os da psicologia em relação aos dados sociodemográficos e socioeconômicos, mas se diferenciará quanto a queixa?}

Os alunos de graduação, ao longo do curso, têm contato com a clientela infantojuvenil, que busca atendimento nas clínicas-escola de psicologia e, em princípio, diferencia-se um pouco dos que buscam atendimento nos serviços de saúde. Nesse processo de conhecer a clientela, que caracterizou a Etapa I do treinamento, como já esperado, observaram-se nos dados coletados uma predominância do gênero masculino, já conhecida pelos alunos estagiários por seguir a mesma tendência dos dados obtidos em serviços-escola de psicologia (e.g. Ancona-Lopez, 1983; Campezatto \& Nunes, 2007; Cunha \& Benetti, 2009; Melo \& Perfeito, 2006; Romaro \& Capitão, 2003; Silvares, 1998). O mesmo pode ser dito em relação à faixa etária de maior predominância encontrada, que foi de 6 a 14 anos (e.g. Romaro \& Capitão, 2003; Santos \& Alonso, 2004; Cunha \& Benetti, 2009). 
Como os estudos em serviço-escola de psicologia já apontaram (e.g. Ancona-Lopez, 1983; Campezatto \& Nunes, 2007; Silvares, 1998), a grande maioria dos usuários dos serviços de SP e DF morava distante do ambulatório onde recebiam o atendimento. Este fato contraria a orientação do Ministério da Saúde, que estabelece que o município ofereça cuidados em saúde mental o mais próximo possível do local de moradia dos cidadãos. Esta prestação de serviço em nível local, de fato, favorece a intervenção precoce e contribui para aumentar a adesão ao tratamento (OMS, 2002); contudo, há poucos serviços especializados para esta clientela, o que torna esta proposta ainda pouco factível. Diante do exposto, atender a clientela no serviço onde já é usuária, como feito neste estudo, pode ser uma alternativa a ser considerada para aumentar a adesão ao atendimento psicoterápico.

Uma contribuição deste estudo foi a de avaliar o perfil do cuidador, pouco investigado em outros estudos. Os dados obtidos indicaram que a maioria da clientela morava com os cuidadores biológicos em união estável, com idade entre 34 a 44 anos, escolaridade de ensino médio, trabalhadores de serviços, renda familiar de 2 a 4 salários mínimos, pertencentes à classe C. Estes dados foram similares aos encontrados no estudo em serviço-escola de psicologia, de Cunha e Benetti (2009) e de Melo e Perfeito (2006). A escolaridade, situação conjugal e renda salarial parental têm sido identificadas como fatores de proteção ou de risco para o curso normal do desenvolvimento na população infantojuvenil (Poletto e cols., 2004; Marsh \& Graham, 2005). Sabe-se que família monoparental, com baixa escolaridade e renda utiliza mais práticas disciplinares punitivas, apresentam com maior frequência história de transtornos psiquiátricos nos pais e estão mais expostas a situações estressoras do que as biparentais com perfil semelhante, família predominante neste estudo (Poletto e cols., 2004). Segundo Kazdin e Wassel (1999) e Kazdin (2000), a baixa aderência dos pais no tratamento, devido a fatores como baixa escolaridade, psicopatologia e estresse familiar, pode neutralizar ou atenuar os resultados terapêuticos. Por isso, essas informações são relevantes para o mapeamento da intervenção, que pode inclusive definir o tipo de participação dos pais, que podem ser incluídos como colaboradores, coterapeutas, ou como pacientes passíveis de intervenção individual ou treino de pais (Kendall e cols., 1995).

Entre os dados dessa clientela que se diferenciaram da clientela padrão da psicologia, cita-se o encaminhador para o serviço e a queixa, conforme previsto inicialmente. Enquanto nos serviços tradicionais de psicologia o maior encaminhador é a escola, devido a queixas externalizantes (Ancona-Lopez, 1983; Romaro \& Capitão, 2003; Santos \& Alonso, 2004; Silvares, 1998), neste estudo o maior encaminhador foi outros serviços ou profissional de saúde, devido a 
queixas emocionais e comportamentais. Dados semelhantes a estes foram encontrados por Fernandes (2010) em um serviço-escola hospitalar em Rio Preto-SP. No CBCL, 89,3\% das CrUs atingiram escore clínico na Escala de Internalização, enquanto 63,4\% para Escala de Externalização.

Outros estudos atuais têm demonstrado o aumento do encaminhamento por parte de outros serviços de saúde, principalmente nos casos do serviço de atendimento fazer parte de um serviço de saúde, como é o caso dos serviços estudados, que estavam inseridos em um ambiente hospitalar (e.g., Delvan \& cols., 2010; Louzada, 2003). O fato de 34\% dos CrUs de SP buscarem o serviço devido a divulgação na mídia não surpreendeu, uma vez que as crianças pré-triadas do AMBULANSIA foram convocadas por uma chamada pública. Ademais, este serviço está mais envolvido com pesquisas do que os de psicologia e do que o DF, sendo a chamada pública um recurso para recrutamento bastante útil de divulgação e recrutamento de participantes.

\subsection{O perfil da clientela de SP e DF, com queixa de ansiedade, será semelhante?}

A clientela dos dois serviços incluídos neste estudo se assemelhou estatisticamente em relação ao gênero, no encaminhamento para o serviço por serviços de hospitalares e postos de saúde na queixa motivadora para a busca do atendimento. Houve uma maior semelhança entre as Crs nas queixas obtidas pelos instrumentos aplicados, que indicaram o predomínio de baixa competência social e problemas internalizantes. Os cuidadores se assemelharam quanto a escolaridade (ensino médio completo), relação com a criança (pais biológicos), em união estável, trabalhadores de serviço e do comércio, renda familiar de 2 a 4 salários mínimos e provenientes da classe social C.

Os dados que fizeram com que as crianças usuárias e os cuidadores mais se diferenciassem foram: idade e escolaridade. As Crs de SP eram mais velhas do que as do DF e consequentemente tinham maior escolaridade e pais mais velhos. O que já era esperado, uma vez que SP atende até 18 anos, e do DF até 14 anos. Além desses diferenciadores principais, notou-se que mais CrUs do DF do que de SP tinham renda familiar de um salário mínimo, o que poderia ser justificado por sua menor escolaridade, e em SP um número maior de Crs chegou até o serviço via divulgação na mídia. Os cuidadores do DF também relataram ter procurado o serviço de atendimento por mais queixas iniciais do que os de SP. Esta diferença talvez possa ser atribuída à características do serviço, uma vez que o serviço do DF atende queixas diversas, enquanto o de SP é especializado no atendimento de crianças ansiosas. 


\subsection{Os terapeutas-estagiários apresentarão ao longo do treinamento competências clínicas gerais e específicas a TCC identificadas por eles mesmos, pelos pares e pelos juízes?}

Em relação às habilidades clínicas dos TEs apresentadas ao longo da intervenção, observou-se, com a percepção dos próprios terapeutas, pares e juízes independentes, que os TEs apresentaram competências médias gerais e específicas acima da média, sendo que os pares avaliaram os TEs mais positivamente nas Habilidades Gerais e os juízes, nas Habilidades Específicas.

Houve uma concordância entre os avaliadores, TEs, pares e juízes, quanto ao bom desempenho dos TEs em Colaboração, avaliada na Parte I do CTS, e um pior desempenho em relação à habilidade Descoberta Guiada, na Parte II do instrumento. Ressalta-se, porém, que os TEs se avaliaram também com dificuldade no Ritmo e uso eficiente do tempo. Essa dificuldade também foi citada na avaliação do protocolo, demonstrado que os alunos tiveram dificuldade de administrar o tempo e as atividades previstas na sessão.

Apesar de os três grupos de avaliadores terem identificados que ocorreram alguns problemas especiais no decorrer dos atendimentos, estes problemas não foram considerados como não usuais por nenhum dos informantes. Novamente aqui, os juízes avaliaram melhor o desempenho dos TEs no manejo das dificuldades que ocorreram na sessão, do que os demais avaliadores. Na avaliação geral, os juízes avaliaram os TEs de forma mais positiva do que os pares e eles mesmos. Considerando que a TCC não é definida pela aplicação de um conjunto de técnicas, e sim pela integração de habilidades que incluem avaliação, base teórica sobre os princípios básico da abordagem, e prática adaptada aos alvos terapêuticos e as características da clientela atendida, especula-se que o treinamento dos TEs possibilitou aos alunos uma maior compreensão da abordagem clínica utilizada neste estudo.

\subsection{0 protocolo auxiliará os alunos a aprender a abordagem cognitivo- comportamental e a atender as crianças ansiosas?}

Segundo Trinidad (2007), a imersão do aluno na prática clínica é a melhor forma de se ensinar TCC, uma vez que é esperado que os terapeutas da TCC apresentem habilidades melhor compreendidas quando se está vivenciando a situação. No caso do atendimento de criança ansiosa, isso incluiu avaliar cada caso para verificar o que poderia estar gerando a ansiedade; fazer uma hierarquia dos medos com a criança e o cuidador; ensinar as crianças a identificarem as alterações físicas, diferenciarem os pensamentos catastróficos dos de enfrentamento, para 
aumentarem os comportamentos de enfrentamento; preparar o material a ser utilizado na sessão; discussão com o paciente sobre o que seria trabalhado na sessão; e preparar e acompanhar as crianças nas exposições.

$\mathrm{Na}$ avaliação do protocolo, os alunos confirmam a afirmação de Trinidad (2007) citada acima. O uso do tratamento manualizado na prática clínica foi considerado pelos alunos como útil para o treinamento clínico em TCC, para aprender a usar o modelo da TCC e para o atendimento de crianças ansiosas. A maioria dos TEs citou ter se sentido confortável com o uso do manual e sugeriu o aumento do número das sessões para a aplicação da intervenção, para facilitar a adequação das atividades ao tempo.

Os pontos fortes do programa de atendimento para crianças ansiosas mais citados pelos alunos também são concordantes aos citados na literatura (Barrett, Dadds \& Rapee, 1996; Barrett, Webster \& Turner, 1999; Kendall, 1992; Kendall \& Choudhury, 2003; Flannery-Schroeder, Chondhury, \& Kendall, 2005), a saber: (a) protocolo traz estratégias claras, descritas passo a passo, do que trabalhar com as crianças; e (b) sistematiza e organiza a intervenção, facilitando, assim, a atuação do terapeuta. Kendall e cols. (1998) indicam que os terapeutas inexperientes devem usar o manual de forma mais rígida. Neste caso, mais do que terapeutas experientes, os manuais servem para orientar os alvos e sugerir procedimentos que foram validados empiricamente, fazendo com que os alunos consigam resultados clínicos semelhantes aos profissionais experientes. No entanto, Friedberg e cols. (2009) e Kendal e cols. (2008) alertam que o uso do protocolo deve ser de forma criativa e flexível, sugerindo que a intervenção deve sofrer adaptações sempre que seja necessário para que se alcance a melhor compreensão da criança sobre o seu problema e como manejá-lo.

\subsection{Ao final da aplicação do protocolo as crianças terão menores índices de problemas emocionais e comportamentais, quando comparadas com elas mesmas no início do trabalho e com o grupo controle?}

Além da avaliação do desempenho do terapeuta e a percepção do protocolo, o treinamento oferecido aos alunos foi avaliado pelos resultados clínicos das Crs que participaram do $\mathrm{Grl}$ e do GrC. A literatura aponta que utilizar os resultados clínicos dos participantes da intervenção é a forma mais objetiva de se avaliar o impacto do treinamento de terapeutas (Michael, \& cols., 2005; Weisz, \& cols., 1987; Weisz, \& cols ,1995).

Conforme as metanálises em psicologia clínica infantojuvenil, as Crs melhoraram mais na dificuldade-alvo trabalhada, que, neste caso, foi a ansiedade (Kazdin, 1990; Weisz, \& cols.,1987, 
Weisz, \& cols., 1995). Na comparação dos dados pré-tratamento e o pós-tratamento das Crs que participaram da intervenção, observou-se que na escala do $\mathrm{CBCL}$ de Ansiedade/Depressão seis crianças que atingiram perfil clínico no pré-tratamento passaram a atingir perfil não clínico póstratamento. O mesmo ocorreu com duas crianças na Escala de Internalização. Contudo, nenhuma que atingiu escore clínico para Externalização apresentou perfil clínico diferente no póstratamento.

Os resultados clínicos das Crs apontam que as que participaram do Grl apresentaram perfis clínicos diferentes delas mesmas e do grupo controle, na comparação pré-tratamento e pós-teste. Na avaliação pós-teste, houve diferença apenas nos dados do $\mathrm{CBCL}$ em todas as escalas analisadas houve uma melhora nas $\mathrm{Crs}$ que participaram do $\mathrm{Grl}$, enquanto no $\mathrm{GrC}$ ou não houve alteração, ou houve piora, a saber: na Escala de Competência enquanto 15\% das Crs do Grl deixaram de atingir escore clínico, não houve diferença entre as Crs do GrC; para Escala de Ansiedade/Depressão, 30\% das do Grl deixaram de atingir escore clínico, e apenas 9,1\% obtiveram a mesma diferença no grupo controle; na Escala de Internalização, 10\% das crianças do Grl deixarem de atingir escore clínico, e nenhuma do GrC; na Escala de Total de Problemas, 10\% das $\mathrm{Crs}$ do $\mathrm{Grl}$ deixarem de atingir escore clínico, enquanto as $\mathrm{Crs}$ do $\mathrm{GrC}$ pioraram, uma vez que 10\% a mais passou a atingir escore clínico. Apesar de menos Crs terem atingindo escore clínico no pós-tratamento no MASC, não houve diferença entre os dados do Grl e GrC.

\subsection{Os ganhos da intervenção serão mantidos ao longo de três e seis meses?}

Conforme observado por Flannery-Shroeder e cols.(2005), a crianças continuaram a melhorar ao longo do tempo. Os resultados clínicos das Crs do Grl entre as fases de prétratamento e pós-tratamento com as de follow-up de 3 e 6 meses foram ainda mais promissores, principalmente quando comparados os dados da Fase 1 (pré-tratamento) e da Fase 4 (follow-up de 6 meses).

Na avaliação do CBCL do follow-up de 6 meses, na Escala de Competência Social, 20\% das crianças deixaram de atingir escore clínico; na Escala de Ansiedade/Depressão, 65\% ; na Escala de Internalização, 50\%; e na Escala de Externalização, 27\%. Novamente é demonstrado que apesar das queixas externalizantes também terem diminuído, os cuidadores relatam maior mudança na dificuldade trabalhada na intervenção, medidas pelas Escalas de Ansiedade/depressão e de Internalização. O resultado do IMC indica que este resultado foi confiável e pode ser atribuível à 
intervenção.

\subsection{Conclusões finais}

Os dados do CTS, a satisfação dos TEs com o uso do protocolo e a melhora dos pacientes atendidos, tanto na comparação com eles mesmos antes da intervenção e no follow-up de 6 meses, como com os dados do $\mathrm{GrC}$, sugerem que:

1. O treinamento oferecido aos alunos por meio de um protocolo de atendimento para ansiedade infantil foi útil para atendimento clínico de crianças ansiosas, por deixar os alunos mais seguros do que fazer na sessão, ao orientá-los o que fazer, diminuindo o impacto da falta de experiência dos TEs em atendimento infantil e em atendimento grupal.

2. O treinamento de profissionais iniciantes em intervenções manualizadas pode ser uma boa forma de difundir um conhecimento clínico baseado em evidência, de impacto na melhora clínica do paciente atendido. Os alunos tiveram uma boa aceitação do modelo de intervenção manualizada e relataram que provavelmente o utilizarão em um próximo atendimento.

3. O treinamento clínico para atendimento grupal em TCC de crianças ansiosas, ao invés do atendimento individual, pode ter uma boa relação custo-benefício, ao permitir o atendimento efetivo de um maior número pacientes e ao favorecer a formação dos alunos de psicologia que considere as demandas do mercado de trabalho, onde o atual maior empregador é o serviço de saúde público, que possuem uma alta demanda.

4. A melhora das Crs atendidas pode indicar a adequação do treinamento e do modelo de atendimento utilizado no contexto ambulatorial, tanto pelos resultados clínicos póstratamento como pela a consistência da melhora ao longo do tempo. Considerando a ansiedade patológica uma das dificuldades mais comuns na infância e adolescência, adaptar ou oferecer um tipo de atendimento psicológico, passível de ser utilizado no contexto da clínica usual de atendimento, pode ser de grande utilidade na clínica e na formação dos alunos.

5. Os resultados clínicos obtidos pelo $C B C L$ não foram confirmados pelo MASC, o que nos leva a questionar se esta diferença pode ser atribuída à sensibilidade do respondente do instrumento (pais $x$ crianças) ou a sensibilidade do instrumento (CBCL x MASC).

Acrescenta-se que este trabalho ofereceu a oportunidade de se criar uma ponte entre a pesquisa clínica e a prática, ao apontar a possibilidade do uso flexível de um protocolo manualizado utilizado em pesquisa clínica para o contexto natural. Esta integração entre pesquisa e prática e a disseminação dos dados promissores desta ponte têm sido cada vez mais citadas e 
incitadas entre os pesquisadores clínicos, como Addis (2002), Kazdin (2008a, b) por diminuir o hiato entre pesquisa clínica e prática clínica em saúde mental infantojuvenil. Há ainda hoje poucos serviços investigando a eficácia dos tratamentos usuais e a aplicação dos procedimentos de pesquisa, associados a melhora clínica no contexto acadêmico, nos ambulatórios ou serviço de saúde mental.

Além do uso do protocolo, notou-se que incluir três terapeutas no atendimento grupal foi de grande auxílio no treinamento ao possibilitar que: (a) dois observadores avaliassem o desempenho do terapeuta em cada sessão e dessem valorosos feedbacks; e (b) o maior preparo prévio das sessões, seja das atividades clínicas como separar o material da sessão e a criação criativa compartilhada das atividades de exposição, ou o preparo das gravações das sessões.

\section{8. Limitações deste estudo}

Devido ao número reduzido de terapeutas treinados $(n=13)$ e de crianças atendidas $(n=20)$, não se pode generalizar os dados obtidos neste estudo para outros contextos, nem para outras clientelas, mesmo este estudo tendo sido realizado em diferentes cidades. Os dados são apenas sugestivos de que o treinamento realizado foi efetivo para que os alunos de graduação apresentassem competências clínicas associadas a resultados clínicos nas crianças ansiosas; e de que o protocolo utilizado tem aplicabilidade efetiva nas crianças ansiosas brasileiras.

Contudo, apesar da inexperiência clínica relatada pelos TEs, tanto em TCC como no atendimento de crianças; e do uso de uma medida de habilidades clínicas dos TEs aplicadas ao longo da intervenção (CTS), não foi possível aplicar uma medida de pré-treinamento. De maneira que não há como afirmar que os alunos passaram a apresentar as habilidades aferidas apenas devido ao treinamento recebido. Uma alternativa passível de ser utilizada em outros estudos é de comparar as competências dos TEs obtidas por este estudo com o treino usual que os alunos recebem na graduação, ou até mesmo comparar o treinamento com uma variação na parte de prática clínica, como atender as crianças com o protocolo x sem o protocolo. Com um número maior de TEs, provavelmente seria possível verificar se de fato o atendimento manualizado neutraliza os fatores intrínsecos dos TEs que podem gerar melhora do cliente, citados como moderadores do tratamento e não pesquisados neste estudo de forma específica.

Diferentemente dos estudos de pesquisa clínica realizados em contexto acadêmico, as $\mathrm{Cr}$ foram selecionadas e avaliadas nas quatros fases, principalmente a partir do $\mathrm{CBCL}$, e não por uma avaliação diagnóstica aplicada por profissionais cegos quanto ao objetivo do estudo. 
Considerando isso, não é possível dizer que os participantes destes estudos apresentavam transtornos de ansiedade antes da intervenção e, consequentemente, não é possível dizer que, após a intervenção ou com a intervenção, eles deixaram de apresentar um quadro de Eixo I. Outra limitação deste estudo é que não foi possível randomizar as Crs para as duas condições deste estudo: Grl e GrC. Também não foi possível uso de outros informantes, como o professor, ou outras medidas de autorrelato, que poderia esclarecer ou até indicar outros resultados do que os obtidos. Apesar de estas duas limitações poderem ser explicadas pela aplicação desta pesquisa no contexto natural, não acadêmico, no qual a disponibilidade de tempo dos profissionais para contribuir com atividades extratrabalho; o uso de múltiplos informantes, como professor, não ser fácil; e a espera dos pacientes levar a uma maior desistência; esclarece-se de que o uso destes recursos, não possíveis neste estudo, enfraquece a magnitude dos dados obtidos de melhora clínica associada ao treinamento. 


\section{REFERENCIAS}

Aarons, G. A. (2004). Mental health provider attitudes toward adoption of evidence-based practice: The Evidence-Based Practice Attitude Scale (EBPAS). Mental Health Services Research, 6(2), 61-74.

Achenbach, T.M. (2004). Manual of the Child Behavior Checklist. Burlington: Department of Psychiatry, University of Vermont.

Addis, M. E. (2002). Methods for disseminating research products and increasing evidence based practice: Promises, obstacles, and future directions. Clinical Psychology: Science and Practice, 9, 381-392.

Albano, A. M. \& Kendall, P. C. (2002). Cognitive behavioural therapy for children and adolescent with anxiety disorders: Clinical research advances. International Review of Psychiatry, 14, 129-134.

Ancona-Lopez, M. A. (1983). Características da clientela de clínicas-escola de Psicologia em São Paulo. Arquivos Brasileiros de Psicologia, 35(1), 78-92.

American Psychological Association. American psychological association policy statement on evidencebased practice in psychology. 2005 Aug. Retrieved March 6, 2006, from http://www.apa.org/practice/ebpreport.pdf

Asbahr, F. R. (2004). Anxiety disorders in childhood and adolescence: clinical and neurobiological aspects. Jornal de Pediatria, 80(2), S28-34.

Barmish, A.J., \& Kendall, P.C. (2005). Should parents be co-clients in Cognitive-Behavioral Therapy for anxious youth? Journal of Clinical Child and Adolescent Psychology, 34, 569-581.

Barrett, P., Dadds, M. R. \& Rapee, R. M. (1996). Family treatment of childhood anxiety: A controlled trial. Journal of Consulting Clinical Psychology, 64, 333-342.

Barrett, P, Webster, H. L. \& Turner, C. (1999). Friends for children. Australian Academic Press.

Barrett, P. M., Duffy, A. L., Dadds, M. R. \& Rapee, R. M. (2001). Cognitive-behavioral treatment of anxiety disorders in children: Long-term (6-year) follow-up. Journal of Consulting \& Clinical Psychology, 69(1), 135-141.

Bandeira, D. R., Alves, I. C. B., Giacomel, A. E. \& Lorenzatto, L. (2004). Matrizes progressivas coloridas de Raven - escala especial: normas para Porto Alegre. Psicologia em Estudo, 9(3), 479-486.

Beck, J.S. (1997). Terapia cognitiva: Teoria e prática. Porto Alegre: Artmed.

Beidas, R, Benjamin, C. L., Puelo, C. M., Edmunds, J. M. \& Kendall, P. C. (2010). Flexible Applications of the Coping Cat Program for Anxious Youth. Cognitive and Behavioral Practice, 17(2),142-153. 
Bennett-Levy, J. (2006). Therapist skills: A cognitive models of their acquisition and refinement. Behavioural and Cognitive Psychoterapy, 34, 57-78.

Bordin, I. A. S. \& Paula, C. S. (2007). Estudos populacionais sobre saúde mental de crianças e adolescentes brasileiros. Em Mello, M.F.de, Mello, A.A.F.de, \& Kohn, R. (Orgs.). Epidemiologia da saúde mental no Brasil (pp.101-117). Porto Alegre: Artmed.

Casey, R. J., \& Berman, J. S. (1985). The outcome of psychotherapy with children. Psychological Bulletin, 98, 388-400.

Calhoun, K. S.,Moras, K., Pilkonis, P. A., Rehm, L. P. (1998) Empirically supported treatments: Implications for training. Journal of Consulting and Clinical Psychology, 66(1), 151-162.

Campezatto, P. v. M. \& Nunes, M. L. T. (2007). Caracterização da clientela das clínicas-escola de cursos de Psicologia da região metropolitana de Porto Alegre. Psicologia Reflexão e Crítica, 20(3), 376-388.

Castillo, A. R. G. L., Recondo, R., Asbahr, F. R., \& Manfro, G. C. (2000) Transtorno de ansiedade. Revista Brasileira de Psiquiatria, 22, 20-23.

Cartwright-Hatton, S. Roberts, C., Chitsabesan, P., Fothergill' \& Harrington, R. (2004). Systematic review of the efficacy of cognitive behaviour therapies for childhood and adolescent anxiety disorders. British Journal of Clinical Psychology, 43(4), 421-436.

Chorpita, B. F. \& Southam-Gerow, M. (2006). Fears and anxieties. In E. J. Mash and R. A. Barkley (Eds.), Treatment of child disorders (3rd ed.) (pp. 271-335). New York: Guilford.

Chambless D.L., Baker M.J., Baucom D.H., Beutler L.E., Calhoun K.S., Crits-Cristoph P., Daiuto A., DeRubeis R.J., Detweiler J., Haaga D.A., Bennett Johnson S., McCurry S, Mueser K.T., Pope K.S., Sanderson W.C., Shoham V., Stickle T., Williams D.A. \& Woody S.R. (1998). Update on empirically validated therapies, II. The Clinical Psychologist, 51, 1: 3-16

Chambless, D. R. \& Ollendick, T. H. (2001). Empirically supported psychological interventions: Controversies and evidence. Annual Reviews Psychology, 52:685-716

Cohen, J. (1988). Statistical power analysis for the behavioral sciences (2nd ed.). Hillsdale, NJ: Lawrence Erbaum.

Conselho Nacional de Educação (2004). Notícia: Diretrizes Curriculares Nacionais para os cursos de graduação em Psicologia. Psicologia: Pesquisa e Prática, 20 (2), 205-208.

Coutinho, M. P. L., Carolino, Z. C. G. \& Medeiros, E. D.( 2008). Inventário de Depressão Infantil (CDI): evidências de validade de constructo e consistência interna. Avaliação Psicológica, 7(3), 291-300.

Cunha, T. R. S. \& Benetti, S. P. C. (2009). Caracterização da clientela infantil numa clínica-escola de Psicologia. Arquivos Brasileiros de Psicologia,59(130), 117-127. 
Delvan, J. S., Portes, J. R. M., Cunha, M. P., Menezes, M., Legal, E. J. (2010). Crianças que utilizam os serviços de saúde mental: caracterização da população em uma cidade do sul do Brasil. Revista Brasileira de Crescimento e Desenvolvimento Humano, 20(2), 228-237.

Dimenstein, M. (2000). A cultura profissional do psicólogo e o ideário individualista: Implicações para a prática no campo da assistência pública à saúde. Estudo em Psicologia, 5 (1) 95121.

Duarte, C.; Hoven, C.; Berganza, C.; Bordin, I.; Bird, H., \& Miranda, C. T. (2003). Child mental health in Latin America: present and future epidemiologic research. International Journal of Psychiatry in Medicine, 33, 203-222.

Ducan, E. A. S., Nicol, M. N. \& Marge, A. (2004). Factors that constitute a good cognitive behavioural treatment manual: Delphi study. Behavioural and Cognitive Psychoterapy, 32, 199-213.

Durlak, J. A. \& Wells, A. M. (1998). Evaluation of indicated preventive intervention (secondary prevention) mental health programs for children and adolescents. American Journal of Community Psychology, 26(5), 775-802.

Emerich. D. R., \& Rocha, M. M. (2010). Estudo de validação preliminar do "Inventário dos Comportamentos de Crianças e Adolescentes de 6 a 18 anos" (CBCL/6-18), versão brasileira do Child Behavior Checklist. Projeto de Pesquisa elaborado sob orientação da Profa. Dra. Edwiges Ferreira de Mattos Silvares.

Ehrenreich-May, J., Southam-Gerow, M. A., Hourigan, S. E., Wright, L. R., Pincus, D. B., \& Weisz, J. R. (2010). Characteristics of anxious and depressed youth seen in two different clinical contexts. Administration and Policy in Mental Health and Mental Health Services Research, 38 (5), 398-411.

Fernandes, L. F. B. (2010). Caracterização da população atendida e do processo de supervisão do Serviço de Psicologia do Hospital de Base de São José do Rio Preto/SP. Dissertação de Mestrado, Universidade de São Paulo, São Paulo.

Flannery-Schoeder, E. C., \& Kendall, P. C. (2000). Group and individual cognitive-behavioral treatments for youth with anxiety disorders: A randomized clinical trial. Cognitive Therapy and Research, 24(3), 251-278.

Flannery-Schoeder, E., Choudhury, M, S., \& Kendall, P.C. (2005). Group and individual cognitivebehavioral treatments for youth with anxiety disorders: 1-year follow-up. Cognitive Therapy and Research, 29(2) 253-259.

Fleitlich, B. W., \& Goodman, R. (2000). Epidemiologia. Revista Brasileira de Psiquiatria, 22, 2-6.

Flannery-Schroeder, E., \& Kendall, P. C. (1996). Cognitive-behavioral therapy for anxious children: Therapist manual for group treatment. Ardmore, PA: Workbook. 
Friedberg, R. D., Gorman, A. A., \& Beidel, D. C. (2009). Training Psychologists for CognitiveBehavioral Therapy in the Raw World: A Rubric for Supervisors. Behavior Modification, $33(1), 104-123$

Gouveia, V. V., Barbosa, G. A., Almeida, J. H. \& Gaião, A. (1995). Inventário de depressão infantil CDI: estudo de adaptação com escolares de João Pessoa . Jornal Brasileuiro de Psiquiatria, 44(7), 345-349.

Grupo de Trabalho de Atendimento Psicológico nas Clínicas-Escola (2011). Relatório Técnico do Projeto: Serviços-Escola de Psicologia. São Paulo: ANPEPP.

Halpern, R. \& Figueiras, A. C. M. (2004). Influências ambientais na saúde mental da criança. Jornal de Pediatria, 80(2)Supl., S104-S110.

Harrinson, R. S., Boyle, S. W., \& Farley, O. W. (1999). Evaluating the outcomes of family-based intervention for troubled children: A pretest-posttest study. Research on Social Work Practice, 9(6), 640-655.

Hayward, C., Varady, S., Anne, M., Thienemann, M., Herderson, L. \& Schatzberg, A. (2000). Cognitive-behavioral group therapy for social phobia in female adolescent: Result of a pilot study. Journal of the American Academy of Child \& Adolescent Psychiatric, 39(9), 721-726.

Herschell,A. D., Mcneil, C. B. \& Mcneil, D. W. (2004). Clinical child psychology's progress in disseminating empirically supported treatments. Clinical Psychology: Science and Practice, 11(3), 267-288.

Higa, C. K., \& Chorpita, B. F. (2008). Evidence-based therapies: Translating research into practice. In R. G. Steele, T. D. Elkin \& M. C. Roberts (Org.), Handbook of evidence-based therapies for children and adolescents (pp.45-61). Springer.

Holmbeck, G. N., Thill. A. W., Bachanas, P., Garber, J., Miller, K. B, Abad, M., Bruno, E. F., Carter, J. S., David-Ferdon, C., Jandasek, B., Mennuti-Washburn, J. E., O'Mahar, K., \& Zukerman, J. (2007). Evidence-Based Assessment in Pediatric Psychology: Measures of Psychosocial Adjustment and Psychopathology. Journal of Pediatric Psychology Advance Access, 1-23.

Hudson, J. (2005). Efficacy of Cognitive-Behavioural Therapy for Children and Adolescents With Anxiety Disorders. Behaviour Change, 22(2), 55-70.

In-Albon, T. \& Schneiderb, S. (2007). Psychotherapy of Childhood Anxiety Disorders: A MetaAnalysis. Psychotherapy and Psychosomatics, 76, 15-24.

Ishikawa, S. I., Okajima, I., Matsuoka, H. \& Sakano, Y. (2007). Cognitive Behavioural Therapy for Anxiety Disorders in Children and Adolescents: A Meta-Analysis. Child and Adolescent Mental Health, 12(4), 164-172. 
James, I. A., Backburn, I. M., Milne, D. L. \& Reichfelt, F. K. (2001). Moderators of trainee therapist' competence in cognitive therapy. British Journal of Clinical Psychology, 40, 131-141.

Kazdin, A. E. (1991). Effectiveness of psychotherapy with children and adolescents. Journal of Consulting and Clinical Psychology, 59(6), 785-798.

Kazdin, A. E. (2003). Psychoterapy for children and adolescent. Annual Review of Psychology, 54, 253-276.

Kazdin A. E., Bass D, Ayers, W. A., \& Rodgers A. (1990). Empirical and clinical focus of child and adolescent psychotherapy research. Journal of Consulting \& Clinical Psychology, 58(6):729- 40. Psychology, 54(1), 32-39.

Kazdin, A. E. \& Weisz, J. R. (2010). Evidence-based psychotherapies for children and adolescents. New York: Guilford Press.

Kazdin, A. E. (2008a). Evidence-based treatment and practice: New opportunities to bridge clinical research and practice, enhance the knowledge base, and improve patient care. American Psychologist, 63, 146-159.

Kazdin, A. E. (2008b). Evidence-based treatment and delivery of psychological services: Shifting our emphases to increase impact. Psychological Services, 5(3) 201-215.

Kendall, P. C. (2000). Childhood Disorders. Psychology Press.

Kendall, P. C. (1992). Cognitive-Behavioral Therapy for anxious children: Therapist manual. Workbook Publising.

Kendall, P. C. (1994). Treating anxiety disorders in children: Results of a randomized clinical trial. Journal of Consulting and Clinical Psychology, 62(1), 100-110.

Kendall, P. C. \& Flannery-Schroeder, E. C. (1998). Methodological issues in treatment research for anxiety disorders in youth. Journal of Abnormal Child Pscychology, 26(1), 27-38.

Kendall, P. C., Hudson, J., Gosch, E., Flannery-Schroeder, E., \& Suveg, C. (2008). Child and family therapy for anxiety-disordered youth: results of a randomized clinical trial. Journal of Consulting and Clinical Psychology, 76, 282-297.

Kendall, P. C. \& Southam-Gerow, M. A. (1995). Issues in the transportability of treatment: The case of anxiety disorders in youths. Journal of Consulting and Clinical Psychology, 63(5), 702-708.

Kendall, P. C., Hayes, C. \& Nauta, M. (1998). Breathing life into a manual: Flexibility and creativity with manual-based treatments. Cognitive and Behavioral Practice, 5, 177-198.

Kendall, P. C. \& Choundhury, M. S. (2003). Children and adolescents in cognitive-behavioral therapy: some past efforts and current advances, and the challenges in our future. Cognitive Therapy and Research, 27(1), 89-114. 
Kendall, P.C., Hudson, J. L., Gosch, E., Flannery-Schroeder, E. \& Suveg, C. (2008a). Cognitivebehavioral therapy for anxiety disordered youth: A randomized clinical trial evaluating child and family modalities. Journal of Consulting and Clinical Psychology, 76(2), 282-297.

Kendall, P. C., Gosch, E., Furr, J. M. \& Sood, E. (2008b). Flexibility with fidelity. Journal American Academy Child and Adolescent Psychiatry, 47(9), 987-993.

Löhr, S. S., \& Silvares, E. F. M. (2006). Clínica-escola: Integração da formação acadêmica com as necessidades da comunidade. Em E. F. M. Silvares (Org.), Atendimento psicológico em clínicas-escola (pg. 11-22). Campinas: Átomo/Alínea Editora.

Louzada, R. C. R. (2003). Caracterização da clientela atendida no Núcleo de Psicologia Aplicada da Universidade Federal do Espírito Santo. Estudos em Psicologia, 8(3), 451-457.

Manassis, K., Mendlowitz, S., Scapillato, D. C.Y. W., Avery, D. C. Y. W., Fiksenbaum, L. M. A., Freire, M. M. D., Monga, S. M.D . \& Owens, M. (2002). Group and Individual Cognitive-Behavioral Therapy for Childhood Anxiety Disorders: A Randomized Trial. Journal of the American Academy of Child \& Adolescent Psychiatry, 41(12), 1423-1430.

Marsh, E. J., \& Graham, S. A. (2001) Classificación y tratamiento de la psicopatología infantil. Em V. E. Caballo, \& M. A Simon.(Eds.), Manual de psicología clínica infantil y del adolescente (pp. 29-58). Madri: Pirámides.

Mattos, P., Serra-Pinheiro, M. A., Rohde, L. A. \& Pinto, D. (2006). Apresentação de uma versão em português para uso no Brasil do instrumento MTA-SNAP-IV de avaliação de sintomas de transtorno do déficit de atenção/hiperatividade e sintomas de transtorno desafiador e de oposição. Revista de Psiquiatria do Rio Grande do Sul, 28(3), 290-297.

Meire, C. H. M. \& Nunes, M. L. T. (2005). Psicologia clínica, psicoterapia e o estudante de psicologia. Paidéia, 15(32), 339-343

Melo, S.A. \& Perfeito, H.C.C.S. (2006). Características da população infantil atendida em triagem no período de 2000 a 2002 numa clínica-escola. Estudos de Psicologia - Campinas, 23, 239-249.

Mendlowitz, S. D., Manassis, K., Bradley, S., Scapillato, D. C.C.W., Miezitis, S. \& Shaw, B.E. (1999). Cognitive-Behavioral Group Treatments in Childhood Anxiety Disorders: The Role of Parental Involvement. Journal of the American Academy of Child \& Adolescent Psychiatry,38(10), 1223-1229

Michael, K. D., Huelsman, T. J., \& Crowley, S. L. (2005). Interventions for child and adolescent depression: Do professional therapist produce better results? Journal of Child and Family Studies, 14(2) 233-236.

Nevo, G. A., Manassis, K.. (2009). Outcomes for treated anxious children: a critical review of LongTerm-Follow-Up studies. Depression and Anxiety, 26(7),650-60. 
Paparelli, R. B. \& Nogueira-Martins, M. C. F. (2007). Psicólogos em formação: vivências e demandas em plantão psicológico. Psicologia: Ciência e Profissão, 27 (1), 64-79.

Poletto, M., Wagner, T. M. C. \& Koller, S. H. (2004). Resiliência e desenvolvimento infantil de crianças que cuidam de crianças: uma visão em perspectiva. Psicologia: Teoria e Pesquisa, 20(3), 241-250.

Pretorius, W. M. (2006). Cognitive behavioural therapy supervision: Recommended practice. Behavioural and Cognitive Psychoterapy, 34, 413-420.

OMS (2002). XXIV Relatório Mundial da Saúde: Saúde mental: nova concepção, nova esperança. http://www.who.int/whr/2001/en/whr01_djmessage_po.pdf

Okiishi, J. Lambert, M. J., Nielsen, S. L. \& Ogles, B. M. (2003). Waiting for Supershrink: An empirical analysis of therapist effects. Clinical Psychology and Psychotherapy, 10, 361-373.

Romaro, R. A. \& Capitão, C. G. (2003). Caracterização da clientela da Clínica-Escola de Psicologia da Universidade São Francisco. Psicologia: Teoria e Prática, 5, 111-121.

Roth, A. D., Pilling, S. \& Turner, J. (2010). Therapist Training and Supervision in Clinical Trials: Implications for Clinical Practice. Behavioural and Cognitive Psychotherapy, 38, 291-302.

Santos, W. P. \& Alonso, M. Z. (2004). Caracterização da demanda infantil de um serviço de Psicologia. Revista do Ministério de Saúde Pública, 3, 35-42.

Stallard, P. (2009). Ansiedade: Terapia cognitivo-comportamental para crianças e jovens. Porto Alegre: ARTMED.

Scoot, M. J. \& Sembi, S. (2006). Cognitive-behavior therapy treatment failures in practice: The neglected role of diagnostic inaccuracy. Behavioural and Cognitive Psychotherapy, 34, 491-495.

Scorsolini-Comin, F., Souza, L. V., \& Santos, M. A. dos. (2008). Tornar-se psicólogo: experiência de estágio de psico-oncologia em equipe multiprofissional. Revista Brasileira de Orientação Profissional, 9 (2), 113-126.

Shirk, S. R. Phillips, J. S. (1991). Child therapy training: Closing gaps with research and practice. Journal of Consulting and Clinical Psychology, 59(6), 766-776.

Silva, W. V. \& Figueiredo, V. L. M. (2005). Ansiedade infantil e instrumento de ansiedade: uma revisão sistemática. Revista Brasileira de Psiquiatria, 27(4), 329-335.

Silvares, E. F. M. (1998). Clínicas-escola: novas formas de atendimento psicológico. Tese de Livre Docência, Universidade de São Paulo, São Paulo.

Silvares, E. F. M (2006). Atendimento psicológico em clínicas-escola. Campinas: Átomo/Alínea Editora. 
Silvares, E. F. M., Meyer, S. B., Santos, E. O. L \& Gerencer, T. T. (2006). Um estudo em cinco clínicas-escola brasileira com a lista de verificação comportamental para crianças (CBCL). Em E. F. M. Silvares (Org.), Atendimento psicológico em clínicas-escola (pg.59-72). Campinas: Átomo/Alínea Editora.

Silverman, W. K., Kurtines ,W. M., Ginsburg, G. S., Weems, C. F., Lumpkin, P. W., \& Carmichael, D. H. (1999). Treating anxiety disorders in children with group cognitive-behaviorial therapy: a randomized clinical trial. Journal of Consulting Clinical Psychology, 67(6), 995-1003.

Spink, M. J. P., Bernardes, J. S. \& Menegon, V. S. M. (2006). A Psicologia em diálogo com o SUS: prática profissional e produção acadêmica (Projeto Coletivo de Cooperação Técnica da Associação Brasileira de Ensino de Psicologia - Mudança na Formação em Psicologia e Pesquisa e Sistematização de Experiências). Recuperado em 1 de fevereiro de 2011, de http://www.abepsi.org.br/abep/Relatorio_pesquisa_ABEP.pdf.

Southam-Gerow, M. A., Weisz, J. R., \& Kendall, P. C. (2003). Youth with anxiety disorders in research and service clinics: Examining client differences and similarities. Journal of Clinical Child and Adolescent Psychology, 32. 375-385.

Sudak, D. M. Beck, J. S., \& Wright, J. (2003).Cognitive behavioural therapy: A blueprint for attaining and assessing psychiatric resident competence. Academic Psychiatry, 27(3), 154159.

Stein, D. M. \& Lambert, M. J. (1995). Graduate training: Are therapy outcomes enhanced. Journal of Consulting and Clinical Psychology, 63(2), 182-196.

Trinidad, A. C. (2007). How not to learn cognitive-behavioral therapy (CBT). American Journal of Psychotherapy, 61(4), 395-403.

Vandenberghe, L. \& Gauy, F. V. (2011). Terapias cognitivas e comportamentais. Em L. Becker, Psicologia para Concursos e Graduação. São Paulo: Campus.

Weiss, B. \& Weiz, J. R. (1995). Relative efecctiveness of behavioral versus nonbehavioral child psychoterapy. Journal of Consulting and Clinical Psychology, 63(2), 317-320.

Weisz, J. R., Weiss, B., Alicke, M. D., \& Klotz, M. L. (1987). Effectiveness of psychotherapy with children and adolescents: a meta-analysis for clinicians. Journal of Consulting and Clinical Psychology, 55(4):542-9.

Weisz, J.R., Donenberg, G.R., Han, S.S., \& Weiss, B. (1995a). Bridging the gap between lab and clinic in child and adolescent psychotherapy. Journal of Consulting and Clinical Psychology, 63, 688-701.

Weisz, J. R., Weiss, B., Han, S. S., Granger, D. A., \& Morton, T. (1995b). EffeCTS of psychotherapy with children and adolescents revisited: a meta-analysis of treatment outcome studies. Psychological Bulletin, 117(3):450-68. 
Wesiz, J. R. \& Gray, J. S. (2008). Evidence-based psychotherapy for children and adolescents: Data from the present and model for the future. Child and Adolescent Mental Health, 13(2), 5465.

Weisz, J.R., Doss, A.J., \& Hawley, K.M. (2006). Evidence-based youth psychotherapies versus usual clinical care: A meta-analysis of direct comparisons. American Psychologist, 61, 671-689.

Weisz, J. R., Hawley, K. M. \& Doss, A. J. (2004). Empirically tested psychotherapies for youth internalizing and externalizing problems and disorders. Child Adolescent Psychiatric Clinics of North America, 13, 729-815.

White, J. R. \& Freeman, A. S. (2000). Cognitive-behavioral Group Therapy. Washington: American Psychology Association.

Wood, J. J., Piacentini, J. C., Southan-Gerow, M., Chu,, B. C., \& Sigman, M. (2006). Family cognitive behavioral therapy for child anxiety disorders. Journal of the American Academy of Child \& Adolescent Psychiatry, 45, 314-321. 
$\because$ Gata 


\section{ANEXo 1. Ficha de IDENTIFICAÇÃo}

\section{Serviço:}

$\square$ AMBULANSIA - USP

$\square N A T-D F$

Encaminhamento para o serviço: $1 . \square$ serviços de psicologia $\quad 2 . \square$ hospitais $\quad 3 . \square$ postos de saúde $\quad$ 4. $\square$ médico clínico geral $5 . \square$ médico psiquiatra 6. $\square$ médico neurologista 7. $\square$ assistente social $\quad \mathbf{8 .} \square$ fonoaudiólogo $9 . \square$ instituições escolares 10. $\square$ demanda espontânea 11. $\square$ familiares 12. $\square$ conhecidos 13. $\square$ paciente/cliente do serviço-escola $14 . \square$ rádio/jornal/TV $15 . \square$ outra(s) fonte(s)

\section{Dados de identificação}

PROT.:

$$
\text { ID: }
$$

\section{Dados do cliente:}

Nome:

Data de Nascimento: $\_l / l \_$Idade: $\quad$ Sexo: 1. $\square$ Feminino 2. $\square$ Masculino

Escola: $1 . \square$ Particular 2. $\square$ Conveniada 3. $\square$ Pública 3.1. $\square$ municipal 3.2. $\square$ estadual $3.3 \square$ federal Nome

Escola:

\section{Escolaridade}

1. $\square$ não estuda 2. $\square$ Escola Especial $\quad 3 . \square$ Escola Infantil $\quad 4 . \square$ Ensino Fundamental incompleto $5 . \square$ Ensino Fundamental completo (da 2 a 9 ano) $\quad 6 . \square$ Ensino Médio incompleto $\quad 7 . \square$ Ensino Médio completo (da $1^{\text {a a }}$ a $3^{\mathrm{a}}$ série)

Endereço:

Cidade: Estado: Telefones $\mathrm{p} /$ contato:

\section{Queixa:}

1. $\square$ dificuldades em processos cognitivos (de aprendizagem, de atenção, de compreensão ou de memória)

2. $\square$ dificuldades no comportamento afetivo (agressividade, ansiedade, isolamento social, depressão, choro frequente, dependência, imaturidade, temores etc.)

3. $\square$ dificuldades de relacionamento interpessoal

4. $\square$ dificuldades na vida diária (desorganização etc.)

5. $\square$ dificuldades na esfera sexual

6. $\square$ apresenta sintomas físicos

7. $\square$ apresentam distúrbios orgânicos

8. $\square$ distúrbios de alimentação ou sono

9. $\square$ apresenta dependência química

10. $\square$ apresenta distúrbios psiquiátricos. Qual?

11. $\square$ apresentam problemas no trabalho

Queixa relatado pelo: 1. $\square$ próprio paciente $\quad 2 . \square$ cuidador/cônjuge $\quad 3 . \square$ tutor $\quad 4 . \square$ Outro. Quem?

\section{Dados do Cuidador:}

Nome:

Relação com o cliente: $1 . \square$ pai/mãe biológica $\quad$ 2. $\square$ pai/mãe adotivos $3 . \square$ avó/avô $4 . \square$ tia/tio $\quad 5 . \square$ vizinho $6 . \square$ professor

7. $\square$ tutor 6. $\square$ outro.Qual?

Data de Nascimento: $1 / 1+$ Idade:__ Sexo: 1. $\square$ Feminino 2. $\square$ Masculino

Escolaridade: $1 . \square$ analfabeto 2. $\square$ Escola Especial 3. $\square$ Escola Infantil 4. $\square$ Ensino Fundamental incompleto $5 . \square$ Ensino Fundamental completo (da 2 a 9 ano) 6. Ensino Médio incompleto 7. $\square$ Ensino Médio completo (da 1를 a $3^{\underline{a}}$ série) 8. $\square$ Ensino Superior incompleto $\quad 9 . \square$ Ensino Superior completo 10. $\square$ Pós-Graduação incompleto 11. $\square$ PósGraduação completo

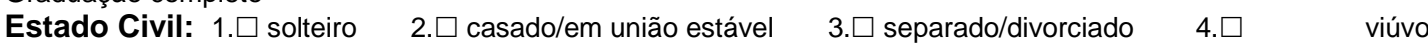

\section{Dados socioeconômicos}

\section{Renda familiar:}

1. $\square$ possuem nenhuma renda 5. $\square$ de 8 a 12 SM

6. $\square$ acima de 12 SM

\section{2. $\square$ até $1 \mathrm{SM} \quad 3 . \square$ de 2 a 4 SM}

4. $\square$ de 4 a 8 SM

7. $\square$ dado não disponível

II. Critério Brasil 2008: Sistema de Pontos: O sistema de pontuação é baseado na posse de bens de consumo duráveis, instrução do chefe da família e outros fatores, como a presença de empregados domésticos.

1. Responder sobre a quantidade dos itens:

Quantos televisores em cores $=$

Quantos videocassetes e/ou aparelhos de DVD =

Quantos rádios =

geladeira) $=$

Quantos banheiros $=$
Quantas máquinas de lavar =

Quantas geladeiras =

Quantos freezers (independente ou $2^{a}$ porta da

Quantos automóveis = 
Quantas empregadas mensalistas $=$

Pontuar cada item: Na tabela abaixo, verifique quantos pontos vale a quantidade de cada um dos itens e assinale quantos pontos você alcançou em cada item. Veja que a quantidade de cada item está indicada no alto da tabela e a pontuação para cada quantidade está indicada no corpo da tabela (parte sombreada) Por exemplo, ter 01 aparelho de TV em cores vale 01 ponto, ter 02 aparelhos vale 02 pontos e assim por diante.

\begin{tabular}{|l|c|c|c|c|c|}
\hline \multirow{2}{*}{ Posse de Itens } & \multirow{2}{*}{ Não tem } & \multicolumn{4}{|c|}{ T E M (Quantidade) } \\
\cline { 3 - 6 } & & 1 & 2 & 3 & 4 ou + \\
\hline Televisores em cores & $\mathbf{0}$ & $\mathbf{1}$ & $\mathbf{2}$ & $\mathbf{3}$ & $\mathbf{4}$ \\
\hline Videocassete/ DVD & $\mathbf{0}$ & $\mathbf{2}$ & $\mathbf{2}$ & $\mathbf{2}$ & $\mathbf{2}$ \\
\hline Rádios & $\mathbf{0}$ & $\mathbf{1}$ & $\mathbf{2}$ & $\mathbf{3}$ & $\mathbf{4}$ \\
\hline Banheiros & $\mathbf{0}$ & $\mathbf{4}$ & $\mathbf{5}$ & $\mathbf{6}$ & $\mathbf{7}$ \\
\hline Automóveis & $\mathbf{0}$ & $\mathbf{4}$ & $\mathbf{7}$ & $\mathbf{9}$ & $\mathbf{9}$ \\
\hline Empregadas mensalistas & $\mathbf{0}$ & $\mathbf{3}$ & $\mathbf{4}$ & $\mathbf{4}$ & $\mathbf{4}$ \\
\hline Máquinas de lavar & $\mathbf{0}$ & $\mathbf{2}$ & $\mathbf{2}$ & $\mathbf{2}$ & $\mathbf{2}$ \\
\hline Geladeira & $\mathbf{0}$ & $\mathbf{4}$ & $\mathbf{4}$ & $\mathbf{4}$ & $\mathbf{4}$ \\
\hline Freezer $\left(^{*}\right)$ & $\mathbf{0}$ & $\mathbf{2}$ & $\mathbf{2}$ & $\mathbf{2}$ & $\mathbf{2}$ \\
\hline
\end{tabular}

$\left(^{*}\right)$ Independente ou $2^{\underline{a}}$ porta da geladeira

2. Responder sobre o grau de instrução

\begin{tabular}{lcl}
\hline \multicolumn{1}{c}{ GRAU DE INSTRUÇÃO DO CHEFE DE FAMILIA } & PONTOS & \multicolumn{1}{c}{ NOMENCLATURA ATUAL } \\
\hline Analfabeto/Primário incompleto & 0 & Analfabeto / até 3 $3^{\text {a Série Fundamental }}$ \\
\hline Primário completo/Ginasial incompleto & 1 & $4^{\text {a }}$ Série Fundamental \\
\hline Ginasial completo/Colegial incompleto & 2 & Fundamental Completo \\
\hline Colegial completo/Superior incompleto & 4 & Médio Completo \\
\hline Superior completo & 8 & Superior Completo \\
\hline
\end{tabular}

\section{Ocupação}

3.1. Forças Armadas, Policiais e Bombeiros Militares, Membros das Forças Armadas; Policiais militares; Bombeiros militares.

3.2. Membros superiores do poder público, dirigentes de organizações de interesse público e de empresas e gerentes, Membros superiores e dirigentes do poder público; Dirigentes de empresas e organizações (exceto de interesse público); Dirigentes e Gerentes em empresas de serviços de saúde, Dirigentes e Gerentes em empresas de educação, Dirigentes e Gerentes em empresas de serviços culturais, sociais e pessoais; Gerentes.

3.3.Profissionais das ciências e das artes, Pesquisadores e profissionais policientíficos; Profissionais das ciências exatas, físicas e da engenharia; Profissionais das ciências biológicas, da saúde e afins; Profissionais do ensino; Profissionais das ciências jurídicas; Profissionais das ciências sociais e humanas; Comunicadores, artistas e religiosos.

3.4. Técnicos de nível médio,Técnicos polivalentes; Técnicos de nível médio das ciências físicas, químicas, engenharia e afins;Técnicos de nível médio das ciências biológicas, bioquímicas, da saúde e afins; Professores leigos e de nível médio; Técnicos de nível médio em serviços de transportes; Técnicos de nível médio nas ciências administrativas; Técnicos de nível médio dos serviços culturais, das comunicações e dos desportos

3.5. Trabalhadores de serviços administrativos, Escriturários; Trabalhadores de atendimento ao público

3.6. Trabalhadores dos serviços, vendedores do comércio em lojas e mercados, Trabalhadores dos serviços; Vendedores; Prestadores de serviços do comércio.

3.7. Trabalhadores agropecuários, florestais, da caça e pesca, Produtores na exploração agropecuária; Trabalhadores na exploração agropecuária; Pescadores e extrativistas florestais; Trabalhadores da mecanização agropecuária e florestal.

3.8. Trabalhadores da produção de bens e serviços industriais, Trabalhadores da indústria extrativa e da construção civil; Trabalhadores da transformação de metais e compósitos; Trabalhadores da fabricação e instalação eletroeletrônica; Montadores de aparelhos e instrumentos de precisão e musicais; Joalheiros, vidreiros, ceramistas e afins; Trabalhadores das indústrias têxteis, do curtimento, do vestuário e das artes gráficas; Trabalhadores das indústrias de madeira e do mobiliário;

Trabalhadores de funções transversais.

3.9. Trabalhadores da produção de bens e serviços industriais, Trabalhadores em indústrias de processos contínuos e outras indústrias, Trabalhadores de instalações siderúrgicas e de materiais de construção; Trabalhadores de instalações e máquinas de fabricação de celulose e papel; Trabalhadores da fabricação de alimentos, bebidas e fumo; Operadores de produção, captação, tratamento e distribuição (energia, água e utilidades).

3.10. Trabalhadores de manutenção e reparação, Operadores de outras instalações industriais; Trabalhadores em serviços de reparação e manutenção mecânica;Polimantenedores.

Não tem ocupação: ( )Benefício ( ) Aposentado

TOTAL: Classe: 1. $\square$ A1 2. $\square$ A2 3. $\square$ B1 4. $\square$ B2 $5 . \square$ C1 6. $\square$ C2 7. $\square$ D 8. $\square$ E 
Anexo 2. Modelo Multidimensional de Ansiedade Infantil

\begin{tabular}{|c|c|c|c|c|}
\hline & $\begin{array}{l}\text { Nunca é } \\
\text { verdade } \\
\text { sobre me }\end{array}$ & $\begin{array}{c}\text { Raramente } \\
\text { acontece } \\
\text { comigo }\end{array}$ & $\begin{array}{c}\text { Às vezes } \\
\text { acontece } \\
\text { comigo }\end{array}$ & $\begin{array}{c}\text { Sempre } \\
\text { acontece } \\
\text { comigo }\end{array}$ \\
\hline 1. Eu me sinto tenso ou nervoso & 0 & 1 & 2 & 3 \\
\hline 2. Eu costumo pedir permissão para fazer as coisas & 0 & 1 & 2 & 3 \\
\hline $\begin{array}{l}\text { 3. Eu me preocupo que as outras pessoas dêem } \\
\text { risada de mim }\end{array}$ & 0 & 1 & 2 & 3 \\
\hline 4. Eu fico com medo quando os meus pais saem & 0 & 1 & 2 & 3 \\
\hline 5. Sinto falta de ar & 0 & 1 & 2 & 3 \\
\hline 6. Eu fico atento se há algum perigo & 0 & 1 & 2 & 3 \\
\hline 7. A idéia de ficar longe de casa me assusta & 0 & 1 & 2 & 3 \\
\hline 8. Eu fico tremendo ou inquieto & 0 & 1 & 2 & 3 \\
\hline $\begin{array}{l}\text { 9. Eu me esforço para obedecer meus pais e } \\
\text { professores }\end{array}$ & 0 & 1 & 2 & 3 \\
\hline 10. Eu tenho medo que os outros gozem de mim & 0 & 1 & 2 & 3 \\
\hline 11. Eu tento ficar perto da minha mãe ou meu pai & 0 & 1 & 2 & 3 \\
\hline 12. Eu tenho tontura ou sensação de desmaio & 0 & 1 & 2 & 3 \\
\hline 13. Eu verifico as coisas antes de fazê-las & 0 & 1 & 2 & 3 \\
\hline 14. Eu me preocupo em ser chamado na classe & 0 & 1 & 2 & 3 \\
\hline 15. Eu me sinto desassossegado (sobressaltado) & 0 & 1 & 2 & 3 \\
\hline $\begin{array}{l}\text { 16. Eu tenho medo que os outros achem que eu sou } \\
\text { bobo }\end{array}$ & 0 & 1 & 2 & 3 \\
\hline $\begin{array}{l}\text { 17. Eu deixo as luzes acesas à noite porque tenho } \\
\text { medo }\end{array}$ & 0 & 1 & 2 & 3 \\
\hline 18. Eu sinto dores no peito & 0 & 1 & 2 & 3 \\
\hline 19. Eu evito sair sem minha família & 0 & 1 & 2 & 3 \\
\hline $\begin{array}{l}\text { 20. Eu me sinto estranho, esquisito, ou fora da } \\
\text { realidade }\end{array}$ & 0 & 1 & 2 & 3 \\
\hline 21. Eu tento fazer coisas que vão agradar os outros & 0 & 1 & 2 & 3 \\
\hline $\begin{array}{l}\text { 22. Eu me preocupo com o que os outros pensam de } \\
\text { mim }\end{array}$ & 0 & 1 & 2 & 3 \\
\hline $\begin{array}{l}\text { 23. Eu evito assistir filmes ou programas de TV que } \\
\text { assustam }\end{array}$ & 0 & 1 & 2 & 3 \\
\hline 24. Meu coração dispara ou "falha" & 0 & 1 & 2 & 3 \\
\hline 25. Eu evito as coisas que me aborrecem & 0 & 1 & 2 & 3 \\
\hline $\begin{array}{l}\text { 26. Eu durmo junto de alguém da minha família } \\
\text { porque tenho medo }\end{array}$ & 0 & 1 & 2 & 3 \\
\hline 27. Eu me sinto inquieto e nervoso & 0 & 1 & 2 & 3 \\
\hline 28. Eu tento fazer tudo exatamente do jeito certo & 0 & 1 & 2 & 3 \\
\hline $\begin{array}{l}\text { 29. Eu me preocupo em não fazer coisa boba ou que } \\
\text { me envergonhe }\end{array}$ & 0 & 1 & 2 & 3 \\
\hline $\begin{array}{l}\text { 30. Eu fico com medo quando ando de carro ou de } \\
\text { ônibus }\end{array}$ & 0 & 1 & 2 & 3 \\
\hline 31. Eu sinto mal estar no estômago & 0 & 1 & 2 & 3 \\
\hline $\begin{array}{l}\text { 32. Se eu fico aborrecido ou com medo, eu conto logo } \\
\text { para alguém }\end{array}$ & 0 & 1 & 2 & 3 \\
\hline $\begin{array}{l}\text { 33. Eu fico nervoso se eu tenho que fazer alguma } \\
\text { coisa em público }\end{array}$ & 0 & 1 & 2 & 3 \\
\hline $\begin{array}{l}\text { 34. Tenho medo de tempo ruim, escuridão, altura, } \\
\text { animais ou insetos }\end{array}$ & 0 & 1 & 2 & 3 \\
\hline 35. Minhas mãos tremem & 0 & 1 & 2 & 3 \\
\hline $\begin{array}{l}\text { 36. Eu preciso ter certeza que as coisas estão } \\
\text { seguras }\end{array}$ & 0 & 1 & 2 & 3 \\
\hline $\begin{array}{l}\text { 37. Eu tenho dificuldade em chamar outras crianças } \\
\text { para brincar comigo }\end{array}$ & 0 & 1 & 2 & 3 \\
\hline 38. Minhas mãos ficam suadas ou frias & 0 & 1 & 2 & 3 \\
\hline 39. Eu sinto vergonha & 0 & 1 & 2 & 3 \\
\hline
\end{tabular}




\section{Anexo 3. Inventário de Depressão Infantil (CDI)}

Por favor, marque com um " $\mathrm{X}$ " as alternativas abaixo de alguns pensamentos ou comportamentos seus durante as duas últimas semanas.

1.

Eu fico triste de vez em quando.

- Eu fico triste muitas vezes.

- Eu fico triste o tempo todo.

2.

Nunca nada vai dar certo para mim.

- Eu não tenho certeza se as coisas vão dar certo para mim.

口 Val dar tudo certo para mim. 3.

- Eu faço quase tudo certo.

- Muitas coisas eu faço errado.

- Eu faço tudo errado.

4.

- Eu me divirto com muitas coisas.

- Eu me divirto com algumas coisas.

Não me divirto com nada.

5.

- Eu sou ruim o tempo todo.

․ Muitas vezes eu sou ruim.

Eu sou ruim uma vez ou outra.

6.

- Eu penso que coisas ruins podem acontecer para mim, de vez em quando.

- Eu me preocupo que coisas ruins aconteçam comigo.

- Eu tenho certeza que coisas horríveis vão acontecer comigo.

7.

․ Eu me detesto.

G Eu não gosto de mim.

․ Eu gosto de mim.

8.

- Todas as coisas ruins acontecem por minha culpa.

- Muitas coisas ruins acontecem por minha culpa.

a As coisas ruins geralmente não acontecem por minha culpa.

9.

․ Eu não penso em me matar.

- Eu penso em me matar mas eu não faria isso.

- Eu quero me matar.

10.

a Tenho vontade de chorar todos os dias.
12.

Eu gosto de estar com outras pessoas.

- Muitas vezes eu não gosto de estar com outras pessoas.

口 Eu não tenho vontade de estar com ninguém.

13.

[ Eu não consigo me decidir sobre nada.

口 É difícil tomar decisões.

- Eu me decido sobre as coisas facilmente.

14.

- Minha aparência é legal.

- Tem umas coisas que eu não gosto na minha aparência.

a Eu sou feio(a).

15.

- Eu tenho sempre que me forçar para fazer minhas lições escolares.

- Muitas vezes eu tenho que me forçar a fazer minhas tarefas escolares.

Não tenho problemas para fazer as tarefas escolares.

16.

- Eu tenho problemas para dormir todas as noites.

- Muitas vezes tenho problemas para dormir.

- Eu durmo bem.

17.

․ Eu me canso de vez em quando.

- Muitos dias eu fico cansado.

- Estou sempre cansado.

18.

ㅁ Eu não estou a fim de comer na maioria dos dias.

a Muitos dias eu não tenho vontade de comer.

․ Eu como bem.

19.

Não me preocupo com dores.

a Muitas vezes eu me preocupo com dores.

- Eu sempre me preocupo com dores.

20.

․ Eu não me sinto sozinho.

a Muitas vezes eu me sinto sozinho.

a Eu sempre me sinto sozinho. 
21

a Nunca me divirto na escola.

- Só me divirto na escola uma vez ou outra.

- Muitas vezes me divirto na escola.

22.

u tenho muitos amigos (amigas).

- Eu tenho amigos (amigas), mas queria ter mais.

․ Eu não tenho amigos (amiga).

23.

- Minhas notas na escola estão boas.

- Minhas notas na escola não estão tão boas como antes.

- Estou indo mal em matérias que antes eu ia bem.

24.

a Nunca vou ser tão bom quanto os outros.

- Se eu quiser posso ser tão bom quanto os outros.

[ Eu sou tão bom quanto os outros.

25.

- Ninguém me ama de verdade.

- Não tenho certeza se alguém me ama.

- Nunca me divirto na escola.

a Só me divirto na escola uma vez ou outra.

a Muitas vezes me divirto na escola.

22.

․ Eu tenho muitos amigos (amigas).

- Eu tenho amigos (amigas), mas queria ter mais.

․ Eu não tenho amigos (amiga).

23.

[ Minhas notas na escola estão boas.

- Minhas notas na escola não estão tão boas como antes.

- Estou indo mal em matérias que antes eu ia bem.

24

- Nunca vou ser tão bom quanto os outros.

- Se eu quiser posso ser tão bom quanto os outros.

- Eu sou tão bom quanto os outros.

25.

a Ninguém me ama de verdade.

- Não tenho certeza se alguém me ama.

- Tenho certeza que alguém me ama.

- Nunca vou ser tão bom quanto os outros.
26.

E Eu geralmente faço o que me mandam fazer.

E Eu geralmente não faço o que me mandam fazer.

口 Eu nunca faço o que me mandam fazer.

27.

Eu me dou bem com as pessoas.

- Muitas vezes eu me meto em brigas.

- Eu me meto em brigas o tempo todo.

- Tenho certeza que alguém me ama.

Obs.: 


\section{Anexo 4. Cognitive Therapy Scale ou lista de VERIFICAÇÃo de CoMpetÊnCIA PARA TERAPEutas COGNITIVO-COMPORTAMENTAIS (CTS)}

Terapeuta:

Data da sessão:

Avaliador: Data da avaliação:

Sessão \# :

Instruções: Para cada vez, avalie o terapeuta numa escala de 0 a 6 e registre o número na linha próxima ao número do item. São apresentadas descrições para pontos de escala igualados. Se você acreditar que o terapeuta estiver situado entre duas descrições, selecione o número intermediário $(1,3,5)$. Por exemplo, se o terapeuta tiver estabelecido uma boa agenda, mas não estabeleceu prioridades, atribua um grau 5 mais do que 4 ou 6 . Se as descrições para um dado item ocasionalmente não parecerem se aplicar à sessão que você está avaliando, sinta-se livre para desconsiderá-las e usar a escala mais geral abaixo:

$\begin{array}{ccccccc}0 & 1 & 2 & 3 & 4 & 5 & 6 \\ \text { Pobre } & \text { Medíocre } & \begin{array}{c}\text { Minimamente } \\ \text { adequado }\end{array} & \text { Bom } & \text { Satisfatório } & \begin{array}{c}\text { Muito } \\ \text { bom }\end{array} & \begin{array}{c}\text { Excelente } \\ \text { bom }\end{array}\end{array}$

Instruções: Para cada vez, avalie o terapeuta numa escala de 0 a 6 e registre o número na linha próxima ao número do item. São apresentadas descrições para pontos de escala igualados. Se você acreditar que o terapeuta estiver situado entre duas descriç̃os, selecione o número intermediário $(1,3,5)$. Por exemplo, se o terapeuta tiver estabelecido uma boa agenda, mas não estabeleceu prioridades, atribua um grau 5 mais do que 4 ou 6 . Se as descrições para um dado item ocasionalmente não parecerem se aplicar à sessão que você está avaliando, sinta-se livre para desconsiderá-las e usar a escala mais geral abaixo:

\begin{tabular}{|c|c|c|c|c|c|c|}
\hline 0 & 1 & 2 & 3 & 4 & 5 & 6 \\
\hline Pobre & Medíocre & $\begin{array}{l}\text { Minimamente } \\
\text { adequado }\end{array}$ & Bom & Satisfatório & $\begin{array}{c}\text { Muito } \\
\text { bom }\end{array}$ & Excelente \\
\hline
\end{tabular}

Por favor não deixe nenhum item em branco. Em todos os itens, enfoque a habilidade do terapeuta, levando em consideração quão difícil o paciente parece ser.

\section{Parte I. HABILIDADES TERAPÊUTICAS GERAIS}

1. AGENDA

0 O terapeuta não estabeleceu uma agenda

2 A agenda estava vaga ou incompleta

4 O terapeuta trabalhou com o grupo para estabelecer uma agenda mutuamente satisfatória que incluía problemas alvo, específicos (p.ex., ansiedade na escola).

6 O terapeuta trabalhou com o grupo para estabelecer uma agenda apropriada com metas específicas, adequada para o tempo disponível. Estabeleceu prioridades e seguiu a agenda

\section{FEEDBACK}

0 O terapeuta não pediu feedback para determinar a compreensão ou a resposta do grupo à sessão.

2 O terapeuta eliciou algum feedback do grupo mas não perguntou o suficiente para se assegurar de que os componentes do grupo tenha compreendido a linha de raciocínio durante a sessão ou para se certificar se o grupo estava satisfeito com a sessão.

4 O terapeuta fez perguntas suficientes para se certificar de que o grupo compreendeu a linha de raciocínio durante a sessão e para determinar as reações do grupo à sessão. $O$ terapeuta ajustou o próprio comportamento em resposta ao feedback, quando apropriado.

6 O terapeuta foi especialmente ajustado em eliciar e responder ao feedback verbal e não-verbal durante a sessão (p.ex., eliciou reações à sessão, verificou regularmente a compreensão, ajudou a sumariar os tópicos principais ao fim da sessão).

\section{COMPREENSÃO}

0 O terapeuta falhou repetidamente em compreender o que os componentes do grupo disseram explicitamente e assim errou o alvo. Habilidades empáticas pobres 
2 O terapeuta foi usualmente hábil em refletir ou refrasear o que os componentes do grupo disseram explicitamente, mas falhou em responder em comunicações mais sutis. Habilidade limitada para escutar e empatizar.

4 O terapeuta pareceu compreender geralmente a "realidade interna" dos componentes do grupo como refletida seja pelo que eles explicitamente disseram e por comunicações mais sutis. Boa habilidade para escutar e empatizar.

6 O terapeuta pareceu compreender a "realidade interna" dos componentes do grupo de modo completo e foi capaz de comunicar essa compreensão o grupo através de respostas verbais e não-verbais apropriadas (p.ex., o tom da resposta do terapeuta indicava uma compreensão simpática da "mensagem" do grupo). Habilidades excelentes de escuta e empatia

\section{EFETIVIDADE INTERPESSOAL}

O O terapeuta teve habilidades interpessoais pobres. Pareceu hostil, rebaixado ou de algum outro modo destrutivo para o grupo.

2 O terapeuta não pareceu destrutivo, mas teve problemas interpessoais significativos. Por vezes, o terapeuta pareceu desnecessariamente inseguro, indiferente, insincero ou teve dificuldade em transmitir confiança e competência.

4 O terapeuta manifestou um grau satisfatório de calor, interesse, confiança, genuinidade e profissionalismo. Nenhum problema interpessoal significativo.

6 O terapeuta demonstrou níveis ótimos de calor, interesse, genuinidade e profissionalismo, apropriados para este grupo em particular nessa sessão.

\section{COLABORAÇÃO}

0 O terapeuta não tentou estabelecer uma colaboração com o grupo.

2 O terapeuta tentou colaborar com o grupo, mas teve dificuldades ou em definir um problema que o grupo considerasse importante ou em estabelecer rapport.

4 O terapeuta foi capaz de colaborar com o grupo, focalizar num problema em que consideraram em conjunto importante e estabeleceram rapport.

6 A colaboração pareceu excelente; o terapeuta encorajou os componentes do grupo tanto quanto possível para assumirem um papel ativo durante a sessão (p.ex., oferecendo escolhas) de modo que funcionassem como uma equipe.

\section{RITMO E USO EFICIENTE DO TEMPO}

O O terapeuta não fez nenhuma tentativa

2 A sessão teve alguma direção, mas o terapeuta teve problemas significantes com estruturação e ritmo (p.ex., muito pouca estrutura, inflexibilidade sobre a estrutura, ritmo lento rápido demais)

4 O terapeuta teve sucesso razoável em usar o tempo de forma eficiente. O terapeuta manteve um controle apropriado sobre o fluxo da discussão e o ritmo.

6 O terapeuta usou o tempo eficientemente por conseguir afastar com tato discussões periféricas e improdutivas e por dar um ritmo à sessão tão rapidamente quanto apropriado o grupo

\section{PARTE II. CONCEITUAÇÃO, ESTRATÉGIA E TÉCNICA}

\section{DESCOBERTA GUIADA}

0 O terapeuta apoiou-se principalmente em discussão, persuasão ou "ensino". O terapeuta pareceu "interrogar" o grupo, colocando-o na defensiva ou forçando o próprio ponto de vista sobre grupo.

2 O terapeuta se apoiou fortemente em persuasão e discussão mais do que numa descoberta guiada. Entretanto, o estilo do terapeuta foi suficientemente apoiador para o grupo não parecer se sentir atacado ou defensivo

4 O terapeuta, na maioria das vezes, ajudou o grupo a ver novas perspectivas através da descoberta guiada (p.ex., examinando evidências, considerando alternativas, pesando vantagens e desvantagens) mais do que por discussão. Usou questionamento apropriadamente

6 O terapeuta foi especialmente habilidoso em usar a descoberta guiada durante a sessão para explorar problemas e ajudar o grupo a chegar às suas próprias conclusões. Alcançou um equilíbrio excelente entre questionamento habilidoso e outros modos de intervenção

\section{FOCALIZANDO EM TEMAS CENTRAIS OU COMPORTAMENTOS}

0 O terapeuta não tentou eliciar pensamentos específicos, suposições, imagens significados ou comportamentos.

2 O terapeuta usou técnicas apropriadas para eliciar cognições ou comportamentos; entretanto, o terapeuta teve dificuldades em encontrar um foco ou enfocou 
cognições/comportamentos que eram irrelevantes para os problemas centrais do grupo

4 O terapeuta focalizou cognições ou comportamentos específicos e relevantes para os problemas visados. Entretanto, o terapeuta poderia ter focalizado cognições ou comportamentos mais centrais que prometessem mais progresso

6 O terapeuta focalizou muito habilmente pensamentos-chave, suposições, comportamentos etc. que eram os mais relevantes para a área problemática e que ofereciam considerável promessas de progresso

9. ESTRATÉGIAS PARA A MUDANÇA (Nota: Para este item, focalizar a qualidade da estratégia do terapeuta para a mudança, não em quão efetivamente a estratégia fo implementada ou se mudanças reais ocorreram).

0 O terapeuta não selecionou técnicas cognitivo-comportamental-comportamentais.

1 O terapeuta selecionou técnicas cognitivo-comportamentais; entretanto, ou a estratégia geral para produzir a mudança pareceu vaga ou não pareceu promissora em ajudar o grupo.

2 O terapeuta pareceu ter uma estratégia geralmente coerente para a mudança que mostrou-se uma promessa razoável e incorporou estratégias cognitivocomportamentais.

3 O terapeuta seguiu uma estratégia para mudança consistente que pareceu muito promissora e incorporou as técnicas cognitivo- comportamentais mais apropriadas.

10. APLICAÇÕES DE TÉCNICAS COGNITIVO-COMPORTAMENTAL-COMPORTAMENTAIS (Nota: Para este item, focalizar em quão habilidosamente as técnicas foram aplicadas, não em quão apropriadas eram para o problema visado ou se a mudança realmente ocorreu).

0 O terapeuta não aplicou técnicas cognitivo-comportamental-comportamentais.

2 O terapeuta usou técnicas cognitivo-comportamental-comportamentais mas aconteceram falhas significativas no modo em que foram aplicadas.

4 O terapeuta aplicou técnicas cognitivo-comportamental-comportamentais com perícia moderada

6 O terapeuta empregou técnicas cognitivo-comportamental-comportamentais muito habilmente e com perícia.

\section{TAREFAS DE CASA}

0 O terapeuta não tentou incorporar tarefas de casa relevantes para a terapia cognitivo-comportamental.

1 O terapeuta teve dificuldades significativas em incorporar tarefas de casa (p.ex., não reviu tarefas de casa prévias, não explicou as tarefas de casa em detalhes suficientes, atribuiu tarefas de casa inapropriadas).

2 O terapeuta reviu tarefas de casa prévias a atribuiu tarefas de casa "padrão" em terapia cognitivo-comportamental relevantes para temas enfrentados na sessão. As tarefas de casa foram explicadas com detalhe suficiente.

3 O terapeuta reviu as tarefas de casa prévias e cuidadosamente atribuiu tarefas de casa retiradas da terapia cognitivo-comportamental para a semana seguinte. A atribuição pareceu "costurada" para ajudar o grupo a incorporar novas perspectivas, testar hipóteses, experimentar os novos comportamentos discutidos durante a sessão.

\section{PARTE III.}

12. (a) (a)

\section{CONSIDERAÇÕES ADICIONAIS}

Problemas especiais surgiram durante a sessão (p.ex., nãodesesperança em continuar a terapia, recaída?).

Se sim:

0 O terapeuta não lidou adequadamente com problemas especiais que surgiram.

2 O terapeuta lidou com problemas especiais adequadamente, mas usou estratégias e conceituações inconsistentes com a terapia cognitivo-comportamental.

4 O terapeuta tentou lidar com problemas especiais usando uma perspectiva cognitiva e foi moderadamente habilidoso em usar as técnicas.

6 O terapeuta foi muito habilidoso em manejar problemas especiais usando uma perspectiva da terapia cognitivo-comportamental.

13. Existiram fatores não usuais nessa sessão que você sentiu justificado o afastamento do terapeuta de um ponto de vista padrão medido por esta escala? SIM (por favor explique abaixo) 


\section{PARTE IV.AVALIAÇÕES GERAIS E COMENTÁRIOS}

14. Como você avaliaria o terapeuta dessa sessão como um terapeuta cognitivocomportamental?

\section{$0 \quad 1$}

Pobre Medíocre

2
Minimamente
adequado

3

adequado

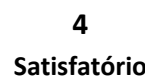

Satisfatório

\section{5}

Muito

bom

Quão difícil você sentiu este grupo para trabalhar?

$\begin{array}{ccccccc}0 & 1 & 2 & 3 & 4 & 5 & 6 \\ \begin{array}{c}\text { Nada } \\ \text { difícil }\end{array} & & \begin{array}{c}\text { Moderadamente } \\ \text { difícil }\end{array} & & \begin{array}{c}\text { Muito } \\ \text { receptivo }\end{array} & & \begin{array}{c}\text { Extremamente } \\ \text { receptivo }\end{array}\end{array}$

17.COMENTÁRIOS E SUGESTÕES PARA O DESENVOLVIMENTO DO TERAPEUTA

AVALIAÇÃO GERAL:

Escala de avaliação: comportamental, você acha que você deveria selecionar esse terapeuta para participar nesse momento (assumindo que essa sessão seja típica?)

$\begin{array}{ccccc}0 & 1 & 2 & 3 & 4 \\ \text { Definitivamente } & \text { Provavelmente } & \text { Incerto } & \text { Provavelmente } & \text { Definitivamente } \\ \text { não } & \text { não } & \text { Limítrofe } & \operatorname{sim} & \text { sim }\end{array}$




\section{Anexo 5. Checklist dos juízes (CTS)}

Terapeuta:

Juiz:

Data da sessão:

Sessão \# 8

Favor avaliar o quanto o terapeuta seguiu o objetivo da sessão de acordo com o protocolo (ETAPA I) e o desempenho na sessão considerando a abordagem cognitivocomportamental (ETAPA II)

\section{ETAPA I:}

Avalie o quanto o terapeuta seguiu o protocolo de 0 a 4 :

Nada

1

2

3

4

Nesta sessão o terapeuta deveria:

Revisar a Tarefa eu consigo e Tarefa amigo

Fortalecer o vínculo

Ajudar as crianças a identificarem os diferentes tipos de sentimentos e distinguirem os sentimentos de ansiedade e preocupação dos outros sentimentos.

Encorajar as crianças a identificarem as pistas fisiológicas (e.g., expressões faciais, postura corporal) para identificarem as emoções. (Passo 1: Mostrando-se ansioso e preocupado?)

Estabelecer a Tarefa Eu Consigo e Tarefa Amigo da semana

\section{AVALIAÇÃO GERAL:}

Circule o número que representa na sua opinião o quanto o protocolo foi seguido nesta sessão:

$\begin{array}{ccccc}\mathbf{0} & \mathbf{1} & \mathbf{2} & \mathbf{3} & \mathbf{4} \\ \text { Nada } & \text { Um pouco } & \text { satisfatoriamente } & \text { Muito } & \text { Completamente }\end{array}$

Observações:

\section{ETAPA II:}

Instruções: Para cada vez, avalie o terapeuta numa escala de 0 a 6 e registre o número na linha próxima ao número do item. São apresentadas descrições para pontos de escala igualados. Se você acreditar que o terapeuta estiver situado entre duas descrições, selecione o número intermediário $(1,3,5)$. Por exemplo, se o terapeuta tiver estabelecido uma boa agenda, mas não estabeleceu prioridades, atribua um grau 5 mais do que 4 ou 6 . Se as descrições para um dado item ocasionalmente não parecerem se aplicar à sessão que você está avaliando, sinta-se livre para desconsiderá-las e usar a escala mais geral abaixo:

$\begin{array}{ccccccc}0 & 1 & 2 & 3 & 4 & 5 & 6 \\ \text { Pobre } & \text { Medíocre } & \begin{array}{c}\text { Minimamente } \\ \text { adequado }\end{array} & \text { Bom } & \text { Satisfatório } & \begin{array}{c}\text { Muito } \\ \text { bom }\end{array} & \begin{array}{c}\text { Excelente } \\ \text { bom }\end{array}\end{array}$

Por favor não deixe nenhum item em branco. Em todos os itens, enfoque a habilidade do terapeuta, levando em consideração quão difícil o paciente parece ser.

\section{Parte I. HABILIDADES TERAPÊUTICAS GERAIS}

1. AGENDA

0 O terapeuta não estabeleceu uma agenda

2 A agenda estava vaga ou incompleta

4 O terapeuta trabalhou com o grupo para estabelecer uma agenda mutuamente satisfatória que incluía problemas alvo, específicos (p.ex., ansiedade na escola).

6 O terapeuta trabalhou com o grupo para estabelecer uma agenda apropriada com metas específicas, adequada para o tempo disponível. Estabeleceu prioridades e seguiu a agenda 
2. FEEDBACK

0 O terapeuta não pediu feedback para determinar a compreensão ou a resposta do grupo à sessão.

2 O terapeuta eliciou algum feedback do grupo mas não perguntou o suficiente para se assegurar de que os componentes do grupo tenha compreendido a linha de raciocínio durante a sessão ou para se certificar se o grupo estava satisfeito com a sessão.

4 O terapeuta fez perguntas suficientes para se certificar de que o grupo compreendeu a linha de raciocínio durante a sessão e para determinar as reações do grupo à sessão. $\mathrm{O}$ terapeuta ajustou o próprio comportamento em resposta ao feedback, quando apropriado.

6 O terapeuta foi especialmente ajustado em eliciar e responder ao feedback verbal e não-verbal durante a sessão (p.ex., eliciou reações à sessão, verificou regularmente a compreensão, ajudou a sumariar os tópicos principais ao fim da sessão).

\section{COMPREENSÃO}

0 O terapeuta falhou repetidamente em compreender o que os componentes do grupo disseram explicitamente e assim errou o alvo. Habilidades empáticas pobres

2 O terapeuta foi usualmente hábil em refletir ou refrasear o que os componentes do grupo disseram explicitamente, mas falhou em responder em comunicações mais sutis. Habilidade limitada para escutar e empatizar.

4 O terapeuta pareceu compreender geralmente a "realidade interna" dos componentes do grupo como refletida seja pelo que eles explicitamente disseram e por comunicações mais sutis. Boa habilidade para escutar e empatizar.

6 O terapeuta pareceu compreender a "realidade interna" dos componentes do grupo de modo completo e foi capaz de comunicar essa compreensão o grupo através de respostas verbais e não-verbais apropriadas (p.ex., o tom da resposta do terapeuta indicava uma compreensão simpática da "mensagem" do grupo). Habilidades excelentes de escuta e empatia

\section{EFETIVIDADE INTERPESSOAL}

0 O terapeuta teve habilidades interpessoais pobres. Pareceu hostil, rebaixado ou de algum outro modo destrutivo para o grupo.

2 O terapeuta não pareceu destrutivo, mas teve problemas interpessoais significativos. Por vezes, o terapeuta pareceu desnecessariamente inseguro, indiferente, insincero ou teve dificuldade em transmitir confiança e competência.

4 O terapeuta manifestou um grau satisfatório de calor, interesse, confiança, genuinidade e profissionalismo. Nenhum problema interpessoal significativo.

6 O terapeuta demonstrou níveis ótimos de calor, interesse, genuinidade e profissionalismo, apropriados para este grupo em particular nessa sessão.

\section{COLABORAÇÃO}

0 O terapeuta não tentou estabelecer uma colaboração com o grupo.

2 O terapeuta tentou colaborar com o grupo, mas teve dificuldades ou em definir um problema que o grupo considerasse importante ou em estabelecer rapport.

4 O terapeuta foi capaz de colaborar com o grupo, focalizar num problema em que consideraram em conjunto importante e estabeleceram rapport.

6 A colaboração pareceu excelente; o terapeuta encorajou os componentes do grupo tanto quanto possível para assumirem um papel ativo durante a sessão (p.ex. oferecendo escolhas) de modo que funcionassem como uma equipe.

\section{RITMO E USO EFICIENTE DO TEMPO}

O O terapeuta não fez nenhuma tentativa

2 A sessão teve alguma direção, mas o terapeuta teve problemas significantes com estruturação e ritmo (p.ex., muito pouca estrutura, inflexibilidade sobre a estrutura, ritmo lento rápido demais)

4 O terapeuta teve sucesso razoável em usar o tempo de forma eficiente. O terapeuta manteve um controle apropriado sobre o fluxo da discussão e o ritmo.

6 O terapeuta usou o tempo eficientemente por conseguir afastar com tato discussões periféricas e improdutivas e por dar um ritmo à sessão tão rapidamente quanto apropriado o grupo 
PARTE II.

\section{CONCEITUAÇÃO, ESTRATÉGIA E TÉCNICA}

\section{DESCOBERTA GUIADA}

0 O terapeuta apoiou-se principalmente em discussão, persuasão ou "ensino". O terapeuta pareceu "interrogar" o grupo, colocando-o na defensiva ou forçando o próprio ponto de vista sobre grupo.

2 O terapeuta se apoiou fortemente em persuasão e discussão mais do que numa descoberta guiada. Entretanto, o estilo do terapeuta foi suficientemente apoiador para o grupo não parecer se sentir atacado ou defensivo

$4 \quad$ O terapeuta, na maioria das vezes, ajudou o grupo a ver novas perspectivas através da descoberta guiada (p.ex., examinando evidências, considerando alternativas, pesando vantagens e desvantagens) mais do que por discussão. Usou questionamento apropriadamente

6 O terapeuta foi especialmente habilidoso em usar a descoberta guiada durante a sessão para explorar problemas e ajudar o grupo a chegar às suas próprias conclusões. Alcançou um equilíbrio excelente entre questionamento habilidoso e outros modos de intervenção

\section{FOCALIZANDO EM TEMAS CENTRAIS OU COMPORTAMENTOS}

0 O terapeuta não tentou eliciar pensamentos específicos, suposições, imagens significados ou comportamentos.

2 O terapeuta usou técnicas apropriadas para eliciar cognições ou comportamentos; entretanto, o terapeuta teve dificuldades em encontrar um foco ou enfocou cognições/comportamentos que eram irrelevantes para os problemas centrais do grupo

4 O terapeuta focalizou cognições ou comportamentos específicos e relevantes para os problemas visados. Entretanto, o terapeuta poderia ter focalizado cognições ou comportamentos mais centrais que prometessem mais progresso

6 O terapeuta focalizou muito habilmente pensamentos-chave, suposições, comportamentos etc. que eram os mais relevantes para a área problemática e que ofereciam considerável promessas de progresso

9. ESTRATÉGIAS PARA A MUDANÇA (Nota: Para este item, focalizar a qualidade da estratégia do terapeuta para a mudança, não em quão efetivamente a estratégia foi implementada ou se mudanças reais ocorreram).
0 O terapeuta não selecionou técnicas cognitivo-comportamental-comportamentais.

1 O terapeuta selecionou técnicas cognitivo-comportamentais; entretanto, ou a estratégia geral para produzir a mudança pareceu vaga ou não pareceu promissora em ajudar o grupo.

2 O terapeuta pareceu ter uma estratégia geralmente coerente para a mudança que mostrou-se uma promessa razoável e incorporou estratégias cognitivocomportamentais.

3 O terapeuta seguiu uma estratégia para mudança consistente que pareceu muito promissora e incorporou as técnicas cognitivo- comportamentais mais apropriadas.

10. APLICAÇÕES DE TÉCNICAS COGNITIVO-COMPORTAMENTAL-COMPORTAMENTAIS (Nota: Para este item, focalizar em quão habilidosamente as técnicas foram aplicadas, não em quão apropriadas eram para o problema visado ou se a mudança realmente ocorreu).

0 O terapeuta não aplicou técnicas cognitivo-comportamental-comportamentais.

2 O terapeuta usou técnicas cognitivo-comportamental-comportamentais mas aconteceram falhas significativas no modo em que foram aplicadas.

4 O terapeuta aplicou técnicas cognitivo-comportamental-comportamentais com perícia moderada

6 O terapeuta empregou técnicas cognitivo-comportamental-comportamentais muito habilmente e com perícia.

\section{TAREFAS DE CASA}

0 O terapeuta não tentou incorporar tarefas de casa relevantes para a terapia cognitivo-comportamental.

1 O terapeuta teve dificuldades significativas em incorporar tarefas de casa (p.ex., não reviu tarefas de casa prévias, não explicou as tarefas de casa em detalhes suficientes, atribuiu tarefas de casa inapropriadas).

2 O terapeuta reviu tarefas de casa prévias a atribuiu tarefas de casa "padrão" em terapia cognitivo-comportamental relevantes para temas enfrentados na sessão. As tarefas de casa foram explicadas com detalhe suficiente.

3 O terapeuta reviu as tarefas de casa prévias e cuidadosamente atribuiu tarefas de casa retiradas da terapia cognitivo-comportamental para a semana seguinte. A atribuição pareceu "costurada" para ajudar o grupo a incorporar novas perspectivas, testar hipóteses, experimentar os novos comportamentos discutidos durante a sessão. 


\section{PARTE III.}

12. (a)

\section{CONSIDERAÇÕES ADICIONAIS} entre o terapeuta e o paciente, desesperança em continuar a terapia, recaída?).

SIM

Se sim:

1 O terapeuta não lidou adequadamente com problemas especiais que surgiram.

3 O terapeuta lidou com problemas especiais adequadamente, mas usou estratégias e conceituações inconsistentes com a terapia cognitivo-comportamental.

5 O terapeuta tentou lidar com problemas especiais usando uma perspectiva cognitiva e foi moderadamente habilidoso em usar as técnicas.

7 O terapeuta foi muito habilidoso em manejar problemas especiais usando uma perspectiva da terapia cognitivo-comportamental.

13. Existiram fatores não usuais nessa sessão que você sentiu justificado o afastamento do terapeuta de um ponto de vista padrão medido por esta escala?

SIM (por favor explique abaixo)

NÃO

\section{PARTE IV.AVALIAÇÕES GERAIS E COMENTÁRIOS}

14. Como você avaliaria o terapeuta dessa sessão como um terapeuta cognitivocomportamental?

$\begin{array}{ccccccc}0 & 1 & 2 & 3 & 4 & 5 & 6 \\ \text { Pobre } & \text { Medíocre } & \begin{array}{c}\text { Minimamente } \\ \text { adequado }\end{array} & \text { Bom } & \text { Satisfatório } & \begin{array}{c}\text { Muito } \\ \text { bom }\end{array} & \begin{array}{c}\text { Excelente } \\ \text { nom }\end{array}\end{array}$

15. Se você estivesse conduzindo um estudo de resultados em terapia cognitivocomportamental, você acha que você deveria selecionar esse terapeuta para participar nesse momento (assumindo que essa sessão seja típica?)

$\begin{array}{ccccc}0 & 1 & 2 & 3 & 4 \\ \text { finitivamente } & \text { Provavelmente } & \text { Incerto } & \text { Provavelmente } & \text { Definitivamente } \\ \text { não } & \text { não } & \text { Limítrofe } & \text { sim } & \text { sim }\end{array}$

16. Quão difícil você sentiu este grupo para trabalhar?

$\begin{array}{ccccccc}0 & 1 & 2 & 3 & 4 & 5 & 6 \\ \begin{array}{c}\text { Nada } \\ \text { difícil }\end{array} & & \begin{array}{c}\text { Moderadamente } \\ \text { difícil }\end{array} & & \begin{array}{c}\text { Muito } \\ \text { receptivo }\end{array} & & \begin{array}{c}\text { Extremamente } \\ \text { receptivo }\end{array}\end{array}$

17.COMENTÁRIOS E SUGESTÕES PARA O DESENVOLVIMENTO DO TERAPEUTA

AVALIAÇÃO GERAL:

Escala de avaliação:

$\begin{array}{cccccc}0 & 1 & 2 & 3 & 4 & 5 \\ \text { Inadequado } & \text { Medíocre } & \text { Satisfatório } & \text { Bom } & \begin{array}{c}\text { Muito } \\ \text { bom }\end{array} & \text { excelente }\end{array}$




\section{ANEXO 6. INVENTÁRIO PARA O ESTAGIÁRIO}

\section{Dados do Estagiário : Gato Corajoso}

( ) SP: Grupo: ( )। ( ) II

( ) BSB: Grupo:（）III （ ）IV

Data da avaliação:

Avaliador:

Hoje iremos avaliar a supervisão recebida por você durante estas 12 semanas e o protocolo no qual você foi treinado e supervisionado para utilizar no atendimento das crianças. Este inventário é anônimo. Após o preenchimento deste eu irei lacrá-lo na sua frente e encaminharei para Profa. Edwiges Silvares, que entregará para outra pessoa lançar os dados. A coordenadora deste projeto só terá acesso deste material após a análise total dos dados. Não tendo em suas mãos em nenhum momento este inventário com ela. Todos estes cuidados foram tomados para você ficar o mais confortável possível, para responder de forma honesta o que você realmente achou da supervisão recebida e do protocolo utilizado. 
AVALIAÇÃO GERAL:

1. O quanto você se sentiu confortável em usar o protocolo?

$\begin{array}{lllll}0 & 1 & 2 & 3 & 4 \\ \text { Nada } & \text { Um pouco } & \text { Satisfatoriamente } & \begin{array}{l}\text { Muito } \\ \text { bem }\end{array} & \text { Completamente }\end{array}$

2. O quanto você acha que o protocolo o ajudou na intervenção?

$\begin{array}{lllll}0 & 1 & 2 & 3 & 4 \\ \text { Nada } & \text { Um pouco } & \text { Satisfatoriamente } & \begin{array}{l}\text { Muito } \\ \text { bem }\end{array} & \text { Completamente }\end{array}$

3. O quanto você acha que o protocolo o atrapalhou na intervenção?

$\begin{array}{lllll}0 & 1 & 2 & 3 & 4 \\ \text { Nada } & \text { Um pouco } & \text { Suficientemente } & \text { Muito } & \text { Completamente }\end{array}$

4. O quanto você se sentiu engessado ao usar o protocolo?

$\begin{array}{lllll}0 & 1 & 2 & 3 & 4 \\ \text { Nada } & \text { Um pouco } & \text { Suficientemente } & \text { Muito } & \text { Completamente }\end{array}$

5. O quanto você ficava tão preocupado em seguir as atividades do protocolo que esquecia-se de dar atenção para questões trazidas pelos pacientes?

$\begin{array}{lllll}0 & 1 & 2 & 3 & 4 \\ \text { Nada } & \text { Um pouco } & \text { Suficientemente } & \text { Muito } & \text { Completamente }\end{array}$

6. O quanto você conseguiu ter flexibilidade no uso do protocolo nas sessões?

$\begin{array}{lllll}0 & 1 & 2 & 3 & 4 \\ \text { Nada } & \text { Um pouco } & \text { Satisfatoriamente } & \begin{array}{l}\text { Muito } \\ \text { bem }\end{array} & \text { Completamente }\end{array}$

7. O quanto você acha que as ferramentas preconizadas no protocolo ajudaram os pacientes atendidos a aprenderem a manejar a ansiedade?

$\begin{array}{lllll}0 & 1 & 2 & 3 & 4 \\ \text { Nada } & \text { Um pouco } & \text { Suficientemente } & \text { Muito } & \text { Completamente }\end{array}$

8.0 quanto o protocolo era claro de compreender e fácil de aplicar?

$\begin{array}{lllll}0 & 1 & 2 & 3 & 4 \\ \text { Nada } & \text { Um pouco } & \text { Suficientemente } & \text { Muito } & \text { Completamente }\end{array}$

9. O quanto você achou que o protocolo entediava ou cansava as crianças atendidas?

$\begin{array}{lllll}0 & 1 & 2 & 3 & 4 \\ \text { Nada } & \text { Um pouco } & \text { Suficientemente } & \text { Muito } & \text { Completamente }\end{array}$

10. O quanto você achou que o programa entediava ou cansava você ou o terapeuta do dia?

$\begin{array}{lllll}0 & 1 & 2 & 3 & 4 \\ \text { Nada } & \text { Um pouco } & \text { Suficientemente } & \text { Muito } & \text { Completamente }\end{array}$

11. O quanto você acredita que usará o protocolo em um próximo atendimento?

$\begin{array}{lllll}0 & 1 & 2 & 3 & 4 \\ \begin{array}{l}\text { De forma } \\ \text { alguma }\end{array} & \begin{array}{l}\text { Pouco } \\ \text { provável }\end{array} & \text { Provavelmente } & \begin{array}{l}\text { Muito } \\ \text { provavelmente }\end{array} & \text { Certamente }\end{array}$

12. O quanto você se divertiu ao usar o protocolo?

$\begin{array}{lllll}0 & 1 & 2 & 3 & 4 \\ \text { Nada } & \text { Um pouco } & \text { Suficientemente } & \text { Muito } & \text { Completamente }\end{array}$

13. O quanto você acha que o uso do protocolo facilitou aprender a usar o modelo cognitivo-comportamental? 


$\begin{array}{lllll}0 & 1 & 2 & 3 & 4 \\ \text { Nada } & \text { Um pouco } & \text { Satisfatoriamente } & \text { Muito } & \text { Completamente }\end{array}$

14. O quanto você acha que o uso do protocolo ajudou você atender crianças?

$\begin{array}{lllll}\mathbf{0} & \mathbf{1} & \mathbf{2} & \mathbf{3} & \mathbf{4} \\ \text { Nada } & \text { Um pouco } & \text { Satisfatoriamente } & \text { Muito } & \text { Completamente }\end{array}$

15. Como você avalia o programa Gato Corajoso aplicado nesta pesquisa como um tratamento de escolha para atendimento de crianças ansiosas

$\begin{array}{lllll}0 & 1 & 2 & 3 & 4 \\ \text { De jeito } & \text { Pouco } & \text { Aplicável } & \text { Muito } & \text { Completamente } \\ \text { nenhum } & \text { aplicável } & & \text { Aplicável } & \text { Aplicável }\end{array}$

16. Como você avalia o programa Gato Corajoso aplicado nesta pesquisa para o treino de terapeutas estagiários

$\begin{array}{lllll}0 & 1 & 2 & 3 & 4 \\ \text { Péssimo } & \text { Razoável } & \text { Bom } & \begin{array}{l}\text { Muito } \\ \text { Bom }\end{array} & \text { Excelente }\end{array}$

17. Considerando o protocolo como uma ferramenta para atendimento de crianças ansiosas, na sua opinião qual é o ponto forte dele:

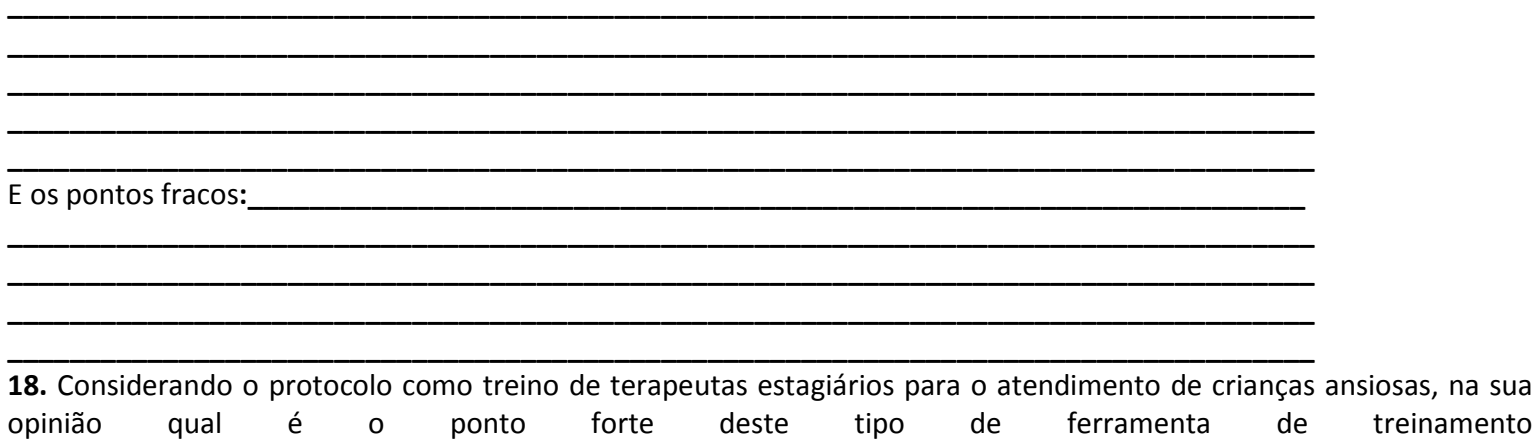
clínico:

$\overline{ } \overline{ } \overline{\text { E os pontos fracos: }}$

19. Para você o que foi mais difícil?

20. Profissionalmente o que você vai levar desta experiência?

21. Quais são as suas sugestões para um próximo treinamento com este protocolo? 


\section{Anexo 7. TERMO de CONSENTIMENTO LIVRE E ESCLARECIDO: TES}

Você está sendo convidado a participar do projeto: Treino de Terapeutas-Estagiários no Atendimento de Crianças Ansiosas. O nosso objetivo com este trabalho é elaborar e avaliar uma proposta de treinamento de estagiários no atendimento de crianças ansiosas, inscritas em clínicas-escola, a partir de uma ferramenta reconhecida internacionalmente para o atendimento destas crianças - Manual Coping Cat, adaptado para a realidade brasileira, a partir do levantamento da clientela do serviço e da aplicação da intervenção.

Você receberá todos os esclarecimentos necessários antes e no decorrer da pesquisa e lhe asseguramos que seu nome não aparecerá, sendo mantido o mais rigoroso sigilo através da omissão total de quaisquer informações que permitam identificá-lo(a)

A sua participação poderá ser apenas pela aplicação de alguns questionários, a saber CBCL, SNAP IV, CDI, MASC e Raven Infantil, nos pacientes encaminhados pelo setor de saúde mental do NAT/HRAS, com o tempo estimado de preenchimento de cinquenta minutos; ou também pela aplicação da intervenção psicológica na abordagem cognitivo-comportamental, aplicada em grupo em crianças ansiosas de 9 a 13 anos ou nos pais.

O resultado deste trabalho irá contribuir para o atendimento do serviço e a capacitação de outros profissionais da psicologia no atendimento da ansiedade infantil. O tratamento não oferecerá desconforto, nem risco à saúde as crianças, nem a você. O atendimento será aplicado a partir da adaptação de um manual reconhecido internacionalmente, realizado em 10 sessões semanais e em grupo. Além disso, os atendimentos serão filmados, gravados e avaliados por experts na área clínica, para que possamos analisar os dados e avaliar o seu desempenho ao longo do atendimento. Você receberá supervisão semanal, com duração de $2 \mathrm{~h}$ cada para realizar o referido atendimento. Após o tratamento, estas filmagens serão arquivadas como material de pesquisa pela pesquisadora. Tanto as filmagens como os dados observados sobre o seu desempenho só poderão ser usados para ensino e pesquisa.

Você não terá nenhum gasto por participar desta pesquisa. Os resultados da pesquisa serão divulgados no Setor de Saúde Mental do HRAS, e para cada um de vocês, podendo ser publicados posteriormente. Os dados e materiais utilizados na pesquisa ficarão sobre a guarda do pesquisador.

A sua participação não é obrigatória e a qualquer momento você poderá interromper a sua participação, se assim achar conveniente. Caso tenha qualquer dúvida em relação à pesquisa, por favor telefone para:Dr(a) Fabiana Gauy, no telefone: (61) 82032393, no horário: das 8h as 18h. Antes de começar este trabalho com você, este projeto foi Aprovado pelo Comitê de Ética em Pesquisa da SES/DF. As dúvidas com relação à assinatura do Termo de consentimento livre e esclarecido ou os direitos do sujeito da pesquisa podem ser obtidos através do telefone: (61) 3325-4955.

Caso esteja de acordo em participar, favor assinar abaixo. Uma cópia deste termo que tem duas folhas ficará com você.

Muito obrigada!

Brasília, de de 
Acredito ter sido suficientemente informado a respeito das informações que li ou foram lidas para mim descrevendo o estudo "Treino de Terapeutas-Estagiários no Atendimento de Crianças Ansiosas". Discuti com o presente responsável pelo projeto sobre a decisão de participar nesse estudo. Ficaram claros para mim quais os propósitos do estudo, os procedimentos a serem realizados, seus desconfortos e riscos, as garantias de confidencialidade e os esclarecimentos permanentes. Ficou claro também que minha participação será isenta de despesas. Concordo voluntariamente em participar deste estudo e poderei retirar o consentimento a qualquer momento, antes ou durante o mesmo, sem penalidades ou prejuízo ou perda de qualquer benefício que eu possa ter adquirido.

Data

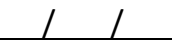

Assinatura do estagiário

(Somente para o responsável do projeto)

Declaro que obtive de forma apropriada e voluntária o Consentimento Livre e Esclarecido deste estagiário para a participação neste estudo.

Fabiana Vieira Gauy - Responsável pelo estudo 
Anexo 8. Manual do treinamento: Etapa I

\section{Projeto Ansiedade}

\section{Manual de Treinamentos ETAPA I}

\section{Fabiana Gauy}

Orinetagẽos Edwiges Slluares 
Caros Alunos,

O treinamento da Etapa I será dividido em:

- Levantamento do perfil da clientela do HRAS, onde aplicaremos o questionário de levantamento adaptado do Inventário de Levantamento de Atividades das Clínicas-escola e o CBCL. A partir destes dados iremos selecionar a amostra para Fase 2;

- Seleção dos participantes, onde aplicaremos o CBCL, MASC, SNAP, CDI e Raven Infantil.

A apresentação deste manual foi dividida em 2 partes:

SEÇÃO 1: Breve introdução sobre o tema clínica-escola e descrição da pesquisa.

SEÇÃO 2: Descrição de como coletar os dados e corrigir os instrumentos (Ficha de Identificação, SNAP-IV, MASC e CDI).

Fabiana Gauy 


\section{SEÇÃO 1: BREVE INTRODUÇÃO SOBRE SERVIÇOS-ESCOLA E DESCRIÇÃO DA PESQUISA}

Nos últimos 60 anos, resultados de pesquisas já demonstraram contundentemente os efeitos de significância estatística e clínica da psicoterapia para uma variedade de pacientes e queixas (e.g. Kazdin, 1991; Kazdin, 2003; Stein \& Lambert, 1995; Weiss, \& Weiz, 1995). Pesquisas nesta área também demonstram que o papel do terapeuta é crucial e está associado diretamente nos resultados da intervenção (Shirk \& Phillips, 1991; Stein \& Lambert, 1995).

O caminho percorrido para se tornar um terapeuta competente é lento, árduo e complexo e envolve treino de habilidades específicas e a construção da identidade profissional, que se efetiva, comumente, mediante a aquisição teórica e a prática clínica supervisionada (Shirk \& Phillips, 1991; Stein \& Lambert, 1995). N Nas universidades brasileiras a prática clínica do aluno de graduação se dá ordinariamente no último ano de graduação, momento em que se entende que o aluno já possui um conteúdo teórico mínimo. A partir deste momento ele inicia o atendimento de forma livre em um serviço-escola de psicologia, geralmente no ambiente da Faculdade, e recebe supervisão de um professor expert. Este modelo circunscrito à clínica-escola da Faculdade gera críticas não apenas no Brasil como em outros países. Segundo Charous (1996), em uma revisão sobre o treinamento do século 21 em saúde mental e em assistência a saúde, cita que os alunos de graduação têm pouca experiência nas áreas de saúde. 0 que para a autora é uma falha na formação acadêmica e clínica, e a leva a criticar o grau de adequação (goodness of fit) dos treinamentos clínicos tradicionais para alunos de graduação. Sugere a necessidade dos treinos de alunos de graduação envolver o trabalho clínico em serviços de saúde utilizando um modelo prático-científico para: (a) maior efetividade no treinamento para futuro trabalho em saúde, (b) expansão das contribuições especializadas do profissional da psicologia nos tratamento de saúde mental, e (c) aplicação da metodologia de pesquisa clínica para avaliar a eficácia e o resultado dos tratamentos psicológicos nestes ambientes de saúde.

Ademais, os estudos na área infanto-juvenil apontaram que as intervenções comportamentais (aqui se inclui tanto as comportamentais quanto as cognitivo-comportamentais) parecem apresentar resultados mais efetivos tanto quando comparadas com outras intervenções não comportamentais (e.g., Durlak \& Wells, 1998; Weiss \& Weiz, 1995), como quando comparadas com grupo de espera (e.g., Barrett, Dadds \& Rapee, 1996; Flannery-Schoeder \& Kendall, 2000; Flannery-Schoeder, Choudhury \& Kendall, 2005), em diversos quadros clínicos, incluindo ansiedade. No entanto, poucos são os professores supervisores clínicos nesta abordagem.

Outro aspecto citado por Michael e cols (2005), em um estudo de revisão, refere-se a interação intrigante entre treino profissional e tipo de problema. Os dados obtidos por eles apontaram que, quando a intervenção foi realizada para clientela de externalizantes, os resultados foram melhores quando aplicados por paraprofissionais, aqui se incluem pais e professores, do que quando aplicados por profissionais e estudantes de graduação. Já nos casos internalizantes, mais nos ansiosos do que nos deprimidos, os resultados foram melhores quando aplicados por profissionais e estudantes de graduação. Notou-se neste estudo pouca diferença entre profissionais e estudantes. Os referidos autores sugerem que, o fato dos estudantes receberem supervisão e da intervenção seguir um protocolo de atendimento, pode levar uma homogeneização da intervenção entre profissionais e estudantes. Tanto o uso de manuais de intervenção, quanto o treinamento considerando queixas específicas, também tem sido, recorrentemente, negligenciado na formação do aluno.

Na última década, os estudos em serviços-escola brasileiros apresentaram propostas de mudanças, a saber: mapeamento do perfil da clientela (Silvares e cols., 2006); atendimentos clínicos predominantemente grupais (Löhr \& Silvares, 2006); inversão do fluxo atual do atendimento ao realizar a intervenção em ambientes naturais (e.g., escolas, ambulatórios), como uma estratégia para facilitar o acesso à intervenção e aumentar a adesão (Silvares, 1998); e implantação de intervenções preventivas (Silvares e cols, 2006). No entanto, não há nenhuma proposta específica referente ao treinamento de terapeutas-estagiários. Tendo a serviço-escola o papel primário de treinar competências no estagiário, observa-se a urgência de se avaliar que ações de treinamento seriam mais efetivas para aumentar as habilidades clínicas do estagiário, a adesão da clientela atendida e os resultados terapêuticos.

Este projeto abordará este tema considerando o treinamento do estagiário para o atendimento de crianças ansiosas, uma vez que a ansiedade tem alta incidência na população infanto-juvenil (Asbahr, 2004; Castillo, e cols., 2000; Fleitlich \& Goodman, 2000; Harrinson, Boyle \& Farley, 1999); tem alto impacto no desempenho acadêmico e nos relacionamentos interpessoais (Barrett, Webster, \& Turner, 1999; Flannery-Schoeder \& Kendall, 2000; Flannery- 


\section{$\because$ Gafo \\ Corajoso}

Schoeder, Choudhury \& Kendall, 2005); é fator de risco para outros transtornos, que, se não tratados, tem curso crônico e recaídas frequentes, de alto impacto ao longo da vida (Barrett, Webster, \& Turner, 1999); e está associada ao abandono prematuro do tratamento (Michael, Huelsman, \& Crowley, 2005).

Bennett-Levy (2006) demonstra que, nos últimos vinte anos, alguns programas de treinamento mostraram-se mais eficazes do que outros, e de que há uma associação entre competência do terapeuta e resultados terapêuticos obtidos. O autor apresenta um modelo de três sistemas para o desenvolvimento de habilidades do terapeuta: teórico (declarative), prático (procedural) e reflexivo (reflective). O primeiro se refere ao conhecimento didático obtido a partir da leitura, da observação e da supervisão. $\mathrm{O}$ segundo se refere à aplicação prática da habilidade treinada no primeiro. $\mathrm{E}$ o terceiro se refere à reflexão, dentro e fora da sessão, associada à prática clínica, que é fomentadora e criadora de conceitos e de teorias. Segundo este autor, os programas de treinamento devem incluir uma combinação variada de estratégias, que favoreçam o sistema reflexivo e o engajamento pessoal do terapeuta no desenvolvimento de habilidades.

Stein e Lambert (1995) em um estudo de meta-análise examinaram a relação entre experiência do terapeuta, treinamento e resultado terapêutico. Relatam que grande parte dos estudos nesta área pesquisa separadamente os efeitos da terapia e os efeitos do tratamento, não associados os dois temas. Posto esta consideração, identificam as seguintes limitações, a saber: a maioria dos estudos não avalia em medidas o comportamento treinado dentro de um contexto processual, alguns sugerem que o efeito do treinamento diminui nos contextos clínicos naturais, e programas de treinamento curto não permitem que o aluno de fato internalize ou incorpore as novas habilidades treinadas. Os autores encontraram um modesto tamanho de efeito associado treinamento de terapeutas, e maior treinamento relacionado a menor abandono; e apontam o uso de manual ou protocolo de atendimento como associado ao aumento a habilidade dos terapeutas, uma vez que esta ferramenta torna o caminho psicoterápico mais concreto ao oferecer um guia aos alunos do que fazer.

Os manuais de tratamento cognitivo-comportamental existem desde 1960, contudo, nos últimos 25 anos houve um grande aumento de propostas. Os manuais, ou protocolos, sugerem passo-a-passo o que fazer em cada sessão, conforme o problema-alvo; podem ser aplicados por diferentes profissionais e alunos, ou por paraprofissionais; são empiricamente validados; e têm valor para pesquisa e ensino (Duncan, Nicol, \& Anger, 2004). O uso de protocolos em pesquisa clínica, segundo Kendall e Flanenry-Schroeder (1998), oferece inúmeras vantagens, como aumentar a validade interna do procedimento e a integridade do tratamento, permitir comparação de tratamentos em diferentes contextos e formatos a partir da padronização do procedimento aplicado, facilitar o treinamento de terapeutas, e dar a oportunidade de replicação e comparação de resultados. Devem ser utilizados após treinamento dos terapeutas, acompanhados de supervisão, e aplicados de forma não rígida, de acordo com as necessidades e as comorbidades identificadas.

Os protocolos existentes para intervenção em crianças ansiosas: (a) orientam o que fazer em cada sessão; (b) foram empiricamente e extensamente avaliados e aplicados em diferentes estudos; (c) preconizam grupos homogêneos quanto à idade e/ou ao gênero; (d) podem ser aplicados, com pequenas variações, para clientela de diferentes escolaridades e situações socioeconômicas; (e) podem ser aplicados em atendimento individual e grupal, com no mínimo três participantes e no máximo doze; (f) levam a melhora a longo prazo; (g) incluem os pais na intervenção; e (h) preconizam um trabalho focal e breve, de 12 a 16 sessões (Barrett, Dadds \& Rapee, 1996; Barrett, Webster \& Turner, 1999; Kendall, 1992; Kendall \& Choudhury, 2003; Flannery-Schroeder, Chondhury, \& Kendall, 2005).

Cita-se o protocolo Coping Cat, publicado por Philip Kendall em 1992, como o precursor para o atendimento de crianças ansiosas. Desde a sua publicação, este protocolo foi validado e adaptado para diferentes países. 0 atendimento para crianças ansiosas consiste em 16 sessões, no caso de atendimento individual, e 18 sessões, de atendimento grupal, com frequência semanal, e dois grandes objetivos divididos em duas etapas: (a) ensinar a reconhecer os sinais físicos associados à ansiedade, como taquicardia e respiração acelerada, e a identificar os processos cognitivos associados à ansiedade excessiva, como "se eu estou com taquicardia, logo estou em perigo!", denominados distorções cognitivas; e (b) treinar estratégias cognitivas para manejo de ansiedade, relaxamento e habilidades de enfrentamento. Destas sessões, três incluem os pais com o objetivo de encorajar a responsabilidade ativa tanto da criança quanto da família no enfrentamento do problema, e o treino de comunicação efetiva das emoções, exploração de crenças e expectativas em relação ao problema do filho e negociação de problemas. 


\section{Gało \\ Corajoso}

Por todos os motivos supracitados, entende-se que esta ferramenta tem boa aplicação no treino de terapeutas de clínicas-escola, ao orientar os supervisores e terapeutas iniciantes, ter aplicabilidade em contexto natural (e.g. ambulatórios de saúde mental), e promover o atendimento mais breve e uma maior rotatividade da clientela, diminuindo, assim, a lista de espera para atendimento e, possivelmente, o abandono do tratamento. Ademais, não há nenhuma publicação nacional até o momento abordando este tema de tamanha relevância no que se refere ao atendimento em saúde mental infanto-juvenil, sugerindo a relevância e urgência do estudo na área.

\section{Programa de treinamento}

Um programa de atendimento deve abordar não somente as necessidades dos pacientes e das famílias, mas também o treinamento dos terapeutas, supervisores e corpo clínico envolvido. Todas as partes devem estar cientes do projeto e preparadas para assegurar para em conjunto oferecer o melhor atendimento possível.

Há um consenso, a partir de evidencias clínicas, de que a terapia cognitivo-comportamental é um tratamento psicológico eficaz para a ansiedade. Diferentes estudos apontam que, para ser um bom terapeuta cognitivocomportamental, são necessárias algumas competências específicas. Sudak, Beck e Wright (2003) sugerem dez ingredientes essenciais: conceituar o caso clínico com diferentes transtornos; desenvolver uma aliança terapêutica forte, ativa e colaboradora; usar a conceitualização cognitiva no processo terapêutico; monitorar continuamente os progressos do paciente; estruturar as sessões para maximizar os progressos; ter como foco auxiliar o paciente a resolver ou enfrentar os problemas associados às metas terapêuticas, a partir de um conjunto de técnicas; identificar e ajudar os pacientes a modificarem as distorções cognitivas cruciais; facilitar as mudanças comportamentais; trabalhar diretamente na adesão ao tratamento; e enfatizar a prevenção de recaídas.

Pretorius (2006) cita que, a supervisão dá oportunidade de discutir as emoções e cognições dos pacientes, de conceituar o caso, de considerar o melhor tratamento e técnicas para que as metas sejam alcançadas; e de discutir e reconhecer as emoções e cognições do próprio terapeuta diante das situações clínicas, e que isso auxilia no treino de habilidades a serem utilizadas com o paciente. Para isso, indica que a discussão dos casos deve seguir o seguinte formato: apresentação das dificuldades do terapeuta, levantamento das hipóteses teóricas do caso e das respostas emocionais do terapeuta, para, enfim, se discutir a abordagem terapêutica a ser seguida. Recomenda o uso de gravações e medidas de competência, como Cognitive Therapy Scale e Revised Version of the Cognitive Therapy Scale, para o treino das habilidades teóricas, práticas e reflexivas citadas por Bennett-Levy (2006).

Stein e Lambert (1995) no que se refere ao treinamento apontam a necessidade de se abordar: instruções teóricas didáticas, noções de curso do desenvolvimento e psicopatologia, modificação comportamental, e teoria da aprendizagem social. Sugerem que as teorias e técnicas de intervenção e avaliação devem ocorrer antes da prática clínica.

\subsection{Objetivos do treinamento}

A psicoterapia para crianças, segundo Kazdin (2003), desafia os profissionais devido a seis características intrínsecas a esta população:

1. Grande parte dos problemas emocionais ou comportamentais passíveis de serem tratados em psicoterapia são maximizações de dificuldades normais do desenvolvimento. Em princípio, devem ser alvo de tratamento psicoterápico aquelas dificuldades extremas, que fazem partem de um conjunto de problemas de alto impacto na vida diária e não atenuadas pela maturidade. Identificar estas dificuldades e diferenciá-las das demais dificuldades transitórias ou do desenvolvimento intriga os profissionais da área.

2. A criança raramente identifica sofrimento ou sintomas psicológicos em si mesma, o que faz com que a maioria seja encaminhada apenas quando há problemas identificáveis por adultos - normalmente, naqueles casos que há perturbação do ambiente, como nos problemas externalizantes (e.g., agressividade). Desta forma, os problemas tidos como emocionais ou internalizantes (e.g., isolamento, ansiedade) são negligenciados pelos pais e professores. Pela dificuldade da criança em identificar em si mesma o problema, muitas vezes o desafio é envolvê-la no tratamento e demonstrar a necessidade de mudanças.

3. A dependência da criança em relação ao adulto a torna vulnerável a múltiplos fatores que não estão sob seu próprio controle, como discórdia conjugal, saúde mental dos pais, estresse familiar, dificuldades socioeconômicas. Estes fatores tanto podem expor a criança a adversidades ao longo do desenvolvimento, como podem interferir no sucesso 
da psicoterapia. Assim, a psicoterapia é apenas uma parte da intervenção, sendo necessário despender esforços junto aos pais e às disfunções familiares que podem estar mantendo ou contribuindo para a dificuldade da criança.

4. Atender criança foge do protótipo da terapia tradicional (cliente é atendido individualmente pelo terapeuta), uma vez que exige que o terapeuta inclua na intervenção pais, professores, irmãos e pares, de forma individual ou combinada. $O$ desafio aqui é envolver estas pessoas na mudança da criança.

5. Reter crianças e os familiares na terapia é o maior desafio. Em torno de 40 a $60 \%$ das crianças, adolescentes e adultos abandonam o tratamento. Uma vez que a criança muitas vezes não se percebe com problema e depende de outros para ser levada para a terapia, é fácil perceber dois problemas que podem contribuir para a desistência: a resistência da criança e a dificuldade dos pais pelo esforço e custo exigido semanalmente para a manutenção da criança no tratamento.

Posto isso, observa-se que quando se atende crianças é importante o terapeuta ter uma noção sobre: (a) desenvolvimento normal e psicopatologia desenvolvimental, (b) psicopatologia infanto-juvenil, e (c) terapia cognitivocomportamental, que serão o foco do treinamento teórico, que posteriormente serão praticadas a partir da avaliação dos casos, da aplicação da intervenção manualizada e da supervisão clínica.

Assim, este trabalho terá como objetivo treinar terapeutas para o atendimento grupal de crianças ansiosas em um serviço-escola de saúde metal em São Paulo, e faz parte de um projeto da aluna de doutorado Fabiana Gauy, do Instituto de Psicologia, que tem a orientação da Profa. Edwiges Silvares. Posto isso, este programa foi delineado com uma perspectiva de uma investigação de pesquisa, no qual inclui-se critérios específicos de seleção dos alunos que passarão pelo treinamento que terá duas etapas: teórica e prática. A primeira parte consiste em 20h de curso com aulas expositivas. A segunda parte, $\mathbf{9 6} \mathrm{h}$ de levantamento da clientela totalizando $\mathbf{1 1 6}$ horas de treinamento.

\subsubsection{Parte teórica}

A parte teórica deste treinamento incluirá $5 \mathrm{~h}$ de treinamento com o foco nas informações gerais do projeto de pesquisa e treinamento nas medidas de levantamento da clientela atendida e na aplicação do CBCL6-18 (Achenbach, 2004) (Fase 1) e $17 \mathrm{~h}$ de treinamento com o foco em abordar o desenvolvimento normal e patológico, transtornos de ansiedade e comorbidades.

\subsubsection{Parte prática}

A parte prática será realizada a partir do levantamento da clientela atendida no serviço e da seleção dos participantes para intervenção e grupo controle. A seleção dos participantes será iniciada em julho e finalizada em setembro.

\section{Seleção dos alunos}

Serão selecionados 10 terapeutas-estagiários. Foram critérios de seleção dos TEs: (a) interesse em TCC com criança e adolescente; (b) estar no período de estágio curricular, preferencialmente a partir do quinto período; e (c) ter disponibilidade de horário para receber o treinamento e supervisão, e para aplicar a intervenção.

\section{Medidas de avaliação}

\subsection{Medidas de levantamento ${ }^{1}$}

Estas medidas fazem parte do Projeto Temático já referido e consistem em inventários on-lines a ser aplicados no coordenador da clínica-escola, nos supervisores e nos estagiários, conforme descrito abaixo, no intuito de mapear os serviços-escola brasileiros.

1. Ficha de Identifiação, que consiste em um questionário dividido em três partes: a primeira, de identificação da clínica-escola; a segunda, com 11 itens, avalia o funcionamento; e a terceira, com 21 itens, avalia o perfil da clientela, diferenciando aspectos sociodemográficos e aspectos clínicos;

\subsection{Medidas clínicas}

\footnotetext{
${ }^{1}$ Estas medidas fazem parte do Projeto Temático Clínicas-escolas de Psicologia no Brasil.
} 


\section{$\because$ Gafo \\ Corajoso}

A avaliação dos transtornos da infância envolve julgamento do desenvolvimento normal e patológico, tendo como referência a variação do desempenho de um grupo representativo. Esse trabalho se torna complexo, principalmente pelas dificuldades de expressão verbal e de conhecimento sobre as próprias emoções e ações da população infantil. Isso faz com que os pais tenham um papel crucial na identificação e comunicação das dificuldades da infância, uma vez que a convivência doméstica possibilita a observação do comportamento problema no momento e no ambiente em que ele ocorre. Considerando isso, diferentes medidas a serem aplicadas nos pais e crianças foram escolhidas por serem empiricamente validada e pela representatividade na literatura internacional.

1. Inventário dos Comportamentos de Crianças e Adolescentes entre 6 a 18 anos (Child Behavior Checklist, CBCL6/18 anos), traduzido e validado parcialmente no Brasil por Bordin, Mari e Caeiro (1995), que avalia, em 138 itens, a percepção parental da competência social, diferenciada em participação e desempenho em atividades recreativas, sociais e acadêmicas; e dos problemas, diferenciados em internalizantes, externalizantes e total de problemas. Os dados são analisados em escores clínico, limítrofe e não clínico. Este instrumento é considerado pela literatura um dos mais confiáveis para a avaliação de dificuldades comportamentais e emocionais para a clientela infanto-juvenil de 6 a 18 anos. Achenbach (2004) demonstrou que o inventário original possui uma alta consistência interna, fidedignidade de teste-reteste e boa validade de construto de critérios;

2. Modelo Multidimensional de Ansiedade Infantil (Multidimensional Anxiety Scale for Children - MASC) é uma escala que avalia ansiedade infanto-juvenil com 39 afirmativas nas quais a criança tem que marcar a opção que melhor representa como ela teme entre as quatro possibilidades - nunca, raramente, às vezes e frequentemente. Os referidos itens avaliam ansiedade de separação, ansiedade social, sintomas físicos e medo específicos (March e cols., 1997). Foi validada por Michelle Nunes e aguarda publicação;

3. Inventário de Depressão Infantil (CDI), elaborado por Kovács em 1983 nos Estados Unidos, a partir de uma adaptação do BDI (Inventário de Depressão de Beck) para identificar alterações afetivas, de humor, da capacidade de sentir prazer, das funções vegetativas, de auto-avaliação e de outras condutas interpessoais em crianças e adolescentes em 20 itens, no qual a criança ou adolescentes tem que escolher uma entre as três opções de respostas oferecidas. Na versão brasileira de Gouveia e cols. (1995) e na avaliação mais recente de Coutinho, Carolino e Medeiros (2008) o instrumento obteve parâmetros psicométricos aceitáveis;

4. MTA-SNAP-IV (SNAP-IV), elaborada para uma pesquisa multicêntrica americana, é uma escala que avalia TDAH e TOD em 26 afirmativas, construídas a partir dos critérios diagnósticos do DSM-IV, nas quais a criança tem que marcar a opção que melhor representa como ela se comporta entre as quatro possibilidades - nem um pouco, só um pouco, bastante e demais, o instrumento original americano tem propriedades psicométricas consideradas sólidas e foi adaptado para o Brasil por Mattos e cols. em 2006.

5. Raven Infantil - Matrizes Progressivas Coloridas, avalia a inteligência geral de crianças de 5 anos a 11 anos e meio, a partir de 36 itens divididos em três séries. Os itens do teste são apresentados sob a forma de um desenho ou matriz, disposta em ordem de dificuldade crescente. A tarefa da criança consiste em escolher, entre as alternativas colocadas na metade inferior da página, a que melhor completa a parte que falta no desenho Os totais parciais de cada série permitem determinar a consistência da pontuação, que indica a validade do resultado. $O$ total de acertos é convertido em percentil. Pode ser aplicado individualmente ou coletivamente, em grupos de 8 a 9 crianças (Angelini, Alves, Custódio, Duarte, \& Duarte, 1999).

\section{Materiais}

Serão utilizados: 01 filmadora e material de filmagens para registro de todas as sessões de intervenção e equipamentos para edição e reprodução do material filmado; cópias dos instrumentos a serem aplicados; 34 pastas com caneta; 40 lápis preto; 10 borrachas; 12 cópias do manual do terapeuta; 34 cópias do material do protocolo, que inclui 34 cópias do livro de exercício a ser aplicado na sessão e 34 cópias do caderno de exercício com tarefas a serem realizadas em casa pelas crianças; cópias dos pontos a serem utilizados como reforçadores; e material lúdico diverso para uso na sessão e como reforço. 
Achenbach, T.M. (2004). Manual of the Child Behavior Checklist. Burlington: Department of Psychiatry, University of Vermont.

Asbahr, F. R. (2004). Anxiety disorders in childhood and adolescence: clinical and neurobiological aspects. Jornal de Pediatria, 80(2), S28-34.

Barrett, P., Dadds, M. R. \& Rapee, R. M. (1996). Family treatment of childhood anxiety: A controlled trial. Journal of Consulting Clinical Psychology, 64, 333-342.

Barrett, P, Webster, H. L. \& Turner, C. (1999). Friends for children. Australian Academic Press.

Bennett-Levy, J. (2006). Therapist skills: A cognitive models of their acquisition and refinement. Behavioural and Cognitive Psychoterapy, 34, 57-78.

Castillo, A. R. G. L., Recondo, R., Asbahr, F. R., \& Manfro, G. C. (2000) Transtorno de ansiedade. Revista Brasileira de Psiquiatria, 22, 20-23.

Charous, M. A. (1996). Mental health and managed care: Training for the 21st century. Psychotherapy, 33(4), 628-635.

Ducan, E. A. S., Nicol, M. N. \& Marge, A. (2004). Factors that constitute a good cognitive behavioural treatment manual: Delphi study. Behavioural and Cognitive Psychoterapy, 32, 199-213.

Durlak, J. A. \& Wells, A. M. (1998). Evaluation of indicated preventive intervention (secondary prevention) mental health programs for children and adolescents. American Journal of Community Psychology, 26(5), 775-802.

Flannery-Schoeder, E. C., \& Kendall, P. C. (2000). Group and individual cognitive-behavioral treatments for youth with anxiety disorders: A randomized clinical trial. Cognitive Therapy and Research, 24(3), 251-278.

Flannery-Schoeder, E., Choudhury, M, S., \& Kendall, P.C. (2005). Group and individual cognitive-behavioral treatments for youth with anxiety disorders: 1-year follow-up. Cognitive Therapy and Research, 29(2) 253-259.

Fleitlich, B. W., \& Goodman, R. (2000). Epidemiologia. Revista Brasileira de Psiquiatria, 22, 2-6.

Harrinson, R. S., Boyle, S. W., \& Farley, O. W. (1999). Evaluating the outcomes of family-based intervention for troubled children: A pretest-posttest study. Research on Social Work Practice, 9(6), 640-655

Kazdin, A. E. (1991). Effectiveness of psychotherapy with children and adolescents. Journal of Consulting and Clinical Psychology, 59(6), 785-798.

Kazdin, A. E. (2003). Psychoterapy for children and adolescent. Annual Review of Psychology, 54, 253-276.

Kendall, P. C. (1992). Cognitive-Behavioral Therapy for anxious children: Therapist manual. Workbook Publising.

Kendall, P. C. \& Flannery-Schroeder, E. C. (1998). Methodological issues in treatment research for anxiety disorders in youth. Journal of Abnormal Child Pscychology, 26(1), 27-38.

Kendall, P. C. \& Choundhury, M. S. (2003). Children and adolescents in cognitive-behavioral therapy: some past efforts and current advances, and the challenges in our future. Cognitive Therapy and Research, 27(1), 89-114.

Löhr, S. S., \& Silvares, E. F. M. (2006). Clínica-escola: Integração da formação acadêmica com as necessidades da comunidade. Em E. F. M. Silvares (Org.), Atendimento psicológico em clínicas-escola (pg. 11-22). Campinas: Átomo/Alínea Editora.

Michael, K. D., Huelsman, T. J., \& Crowley, S. L. (2005). Interventions for child and adolescent depression: Do professional therapist produce better results? Journal of Child and Family Studies, 14(2) 233-236.

Pretorius, W. M. (2006). Cognitive behavioural therapy supervision: Recommended practice. Behavioural and Cognitive Psychoterapy, 34, 413-420.

Silvares, E. F. M. (1998). Clínicas-escola: novas formas de atendimento psicológico. Tese de Livre Docência, Universidade de São Paulo, São Paulo.

Silvares, E. F. M., Meyer, S. B., Santos, E. O. L \& Gerencer, T. T. (2006). Um estudo em cinco clínicas-escola brasileira com a lista de verificação comportamental para crianças ( $\mathrm{CBCL}$ ). Em E. F. M. Silvares (Org.), Atendimento psicológico em clínicas-escola (pg.59-72). Campinas: Átomo/Alínea Editora.

Shirk, S. R. \& Phillips, J. S. (1991). Child therapy training: Closing gaps with research and practice. Journal of Consulting and Clinical Psychology, 59(6), 766-776.

Stein, D. M. \& Lambert, M. J. (1995). Graduate training: Are therapy outcomes enhanced. Journal of Consulting and Clinical Psychology, 63(2), 182-196.

Sudak, D. M. Beck, J. S., \& Wright, J. (2003). Cognitive behavioural therapy: A blueprint for attaining and assessing psychiatric resident competence. Academic Psychiatry, 27(3), 154-159.

Weiss, B. \& Weiz, J. R. (1995). Relative efecctiveness of behavioral versus nonbehavioral child psychoterapy. Journal of Consulting and Clinical Psychology, 63(2), 317-320. 


\section{SEÇÃO 2. CORREÇÃO DOS DADOS COLETADOS NO LEVANTAMENTO}

\section{Para Começar:}

Um dia antes: selecionem quem vai imprimir o material que será ser usado (Ficha de Identificação, $\mathrm{CBCL}$, SNAP-IV, MASC e CDI (imprimir frente-verso)

No dia de coleta: chegue no horário combinado, no primeiro dia você receberá o material permanente e de uso para esta fase (crachá, prancheta, pasta e caneta). Vocês devem ir de jaleco e serão responsáveis pelo material recebido.

Chequem com o pessoal do local quantos pacientes serão atendidas naquele dia e anotem o nome do cuidador e do filho. Distribuam os pacientes. Em seguida, abordem os cuidadores da sua responsabilidade. Os dois instrumentos serão aplicados neles. Para abordarem se apresentem.

Script : "Boa tarde! Meu nome é $X$, eu sou estudante de psicologia e faço parte do Projeto Ansiedade. Estaremos nos próximos meses tentando conhecer quem é atendido pelo ambulatório. Para isso é importante sabermos alguns dados de seu filho, outros seus, e os principais problemas dele. Faremos este levantamento com todos cuidadores dos pacientes. Para isso eu vou as questões desse formulário para você e vou escrever suas respostas Se o médico chamar para o atendimento enquanto estivermos conversando, não tem problema. Podemos interromper e continuar depois da consulta. Eu fiquei responsável de aplicar o questionário em algumas pessoas, por isso gostaria que se o médico a chamasse o Sr. (a) me esperasse. Caso não seja possível podemos agendar para próxima vez que você retornar. Obrigada(o) por participar. Será muito importante sabermos deste dados.".

Quando os respondentes lêem bem o suficiente geralmente começam a responder às questões sem esperar que cada uma seja lida. Pergunte se eles preferem responder sozinhos. Quando eles entregarem o material. Dê uma conferida! No entanto, para aqueles que não conseguem ler bem, esse procedimento evita constrangimentos e informações imprecisas, enquanto mantém a padronização para os informantes que preenchem o inventário de maneira independente.

Em dupla convidem o cuidador e seu filho para se sentarem um pouco afastados do grupo, caso isso seja possível. Um aluno ficará com o cuidador e outro com a criança. Dêem a eles uma cópia dos instrumentos para ele seguir a leitura. Comece aplicando a Ficha de Identificação e depois o $\mathrm{CBCL}$, conforme a ordem das folhas grampeadas. No filho aplique o CDI e depois o MASC. Ao terminar, passe para o próximo paciente.

Importante: Na aplicação da Ficha de identificação certifique-se que não deixou nada em branco. No item queixa avise o cuidador que ser refere a aquela dificuldade que o levou a procurar o serviço. Os pais podem responder mais de uma queixa. Caso você tenha alguma dúvida, é mais comum neste item queixa e no item ocupação, anote a resposta do cuidador para conversarmos depois. Na sequência passe para o $\mathrm{CBCL}$.

Após coleta: complete suas anotações, avalie a classe social pela tabela do critério Brasil. Entregue o material para o responsável pela digitação e correção do material. 


\section{Como corrigir}

\section{Ficha de Identificação}

Referente à situação socioeconômica da família: são duas categorias, a saber (a) renda familiar; e (b) classe social. Marcar com 1 a categoria que representar o dado coletado, e com 0 nas demais (Tabela 8). A seguir detalharemos cada uma destas categorias.

(a) O item Renda familiar foi dividido em salários mínimos em 7 colunas: NT- não tem renda; até 1 SM ( R\$ 465,00); de 2 SM a 4 SM (R\$930,00 a R\$ 1860,00); de 5 SM a 8 SM (R\$2325,00 a R\$ 3720,00); de 9 SM a 12 SM (R\$ 4185,00 a R\$ 5580,00); > 12 SM - mais do que R\$5580,00; e Não sabe - quando o relator não tem o dado.

(b) O item Critério Brasil (2008) foi dividido em 8 colunas indicativas do IBGE. Estas oito classes sociais são caracterizadas a partir do levantamento dos bens da família e da escolaridade do chefe de família (Quadro 1 e 2).

\section{Quadro 1. Sistema de pontos do Critério Brasil (2008)}

O sistema de pontuação é baseado na posse de bens de consumo duráveis, instrução do chefe da família e outros fatores, como a presença de empregados domésticos.

\section{Responder sobre a quantidade dos itens:}
Quantos televisores em cores $=$
Quantas máquinas de lavar $=$
Quantos videocassetes e/ou aparelhos de DVD = Quantas geladeiras $=$

Quantos rádios $=$

Quantos freezers (independente ou 2 2 porta da geladeira) $=$

Quantos banheiros =

Quantos automóveis =

Quantas empregadas mensalistas $=$

2. Responder sobre o grau de instrucão

Analfabeto / até 3a Série Fundamental

4a Série Fundamental

Fundamental Completo

Médio Completo

Superior Completo 


\section{Quadro 4. Pontuação do Critério Brasil (2008)}

Pontuar cada item: Na tabela abaixo, verifique quantos pontos vale a quantidade de cada um dos itens e assinale quantos pontos você alcançou em cada item. Veja que a quantidade de cada item está indicada no alto da tabela e a pontuação para cada quantidade está indicada no corpo da tabela (parte sombreada) Por exemplo, ter 01 aparelho de TV em cores vale 01 ponto, ter 02 aparelhos vale 02 pontos e assim por diante.

\begin{tabular}{|c|c|c|c|c|c|c|c|c|c|}
\hline \multirow[b]{2}{*}{ Posse de Itens } & \multirow[t]{2}{*}{ Não tem } & \multicolumn{4}{|c|}{ T E M (Quantidade) } & & & & \\
\hline & & 1 & 2 & 3 & $\begin{array}{l}4 \text { ou } \\
+\end{array}$ & & & & \\
\hline $\begin{array}{l}\text { Televisores em } \\
\text { cores }\end{array}$ & 0 & 1 & 2 & 3 & 4 & $\begin{array}{c}\text { GRAU DE } \\
\text { INSTRUÇÃO DO } \\
\text { CHEFE DE } \\
\text { FAMÍLIA } \\
\end{array}$ & $\begin{array}{c}\text { PONTO } \\
\text { S }\end{array}$ & $\begin{array}{l}\text { NOMENCLAT } \\
\text { URA ATUAL }\end{array}$ & \\
\hline $\begin{array}{l}\text { Videocassete/ } \\
\text { DVD }\end{array}$ & 0 & 2 & 2 & 2 & 2 & $\begin{array}{l}\text { Analfabeto/Primário } \\
\text { incompleto }\end{array}$ & 0 & $\begin{array}{l}\text { Analfabeto } \quad / \\
\text { até } 3^{\mathrm{a}} \quad \text { Série } \\
\text { Fundamental }\end{array}$ & \\
\hline Rádios & 0 & 1 & 2 & 3 & 4 & $\begin{array}{l}\text { Primário } \\
\text { completo/Ginasial } \\
\text { incompleto }\end{array}$ & 1 & $\begin{array}{l}4^{\text {a }} \quad \text { Série } \\
\text { Fundamental }\end{array}$ & \\
\hline Banheiros & 0 & 4 & 5 & 6 & 7 & $\begin{array}{l}\text { Ginasial } \\
\text { completo/Colegial } \\
\text { incompleto }\end{array}$ & 2 & $\begin{array}{l}\text { Fundamental } \\
\text { Completo }\end{array}$ & \\
\hline Automóveis & 0 & 4 & 7 & 9 & 9 & $\begin{array}{l}\text { Colegial } \\
\text { completo/Superior } \\
\text { incompleto }\end{array}$ & 4 & $\begin{array}{l}\text { Médio } \\
\text { Completo }\end{array}$ & \\
\hline $\begin{array}{l}\text { Empregadas } \\
\text { mensalistas }\end{array}$ & 0 & 3 & 4 & 4 & 4 & Superior completo & 8 & $\begin{array}{l}\text { Superior } \\
\text { Completo }\end{array}$ & \\
\hline Máquinas de & 0 & 2 & 2 & 2 & 2 & & & & \\
\hline lavar & & & & & & POTUAÇÃO & & & \\
\hline Geladeira & 0 & 4 & 4 & 4 & 4 & Classe A1 42 a & 6 pontos & Classe C1 18 & a 22 \\
\hline Freezer $\left(^{*}\right)$ & 0 & 2 & 2 & 2 & 2 & pontos & 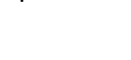 & & \\
\hline$\left({ }^{*}\right)$ Independent & ou $2^{\mathrm{a}}$ porta & $\overline{\mathrm{lage}}$ & idei & & & $\begin{array}{l}\text { Classe A2 } 35 \text { a } \\
\text { pontos }\end{array}$ & 1 pontos & Classe C2 14 & a 17 \\
\hline & & & & & & $\begin{array}{l}\text { Classe B1 } 29 \text { a } \\
\text { pontos }\end{array}$ & 4 pontos & Classe D 8 & a 13 \\
\hline & & & & & & & 8 pontos & & \\
\hline
\end{tabular}




\section{Cálculo:}

\begin{tabular}{|c|c|c|c|c|c|c|c|c|}
\hline \multirow{2}{*}{$\begin{array}{|ll|}\text { (A) } & \begin{array}{l}\text { Posse de } \\
\text { Itens }\end{array} \\
\end{array}$} & \multirow[t]{2}{*}{$\begin{array}{l}\text { Não } \\
\text { tem }\end{array}$} & \multicolumn{4}{|c|}{$\begin{array}{c}\text { T E M } \\
\text { (Quantidade) }\end{array}$} & & & \\
\hline & & 1 & 2 & 3 & $\begin{array}{c}4 \\
\text { ou } \\
+\end{array}$ & & & \\
\hline Televisores em cores & 0 & 1 & 2 & 3 & 4 & $\begin{array}{l}\text { (B) GRAU DE } \\
\text { INSTRUÇÃO } \\
\text { DO CHEFE } \\
\text { DE FAMÍLIA }\end{array}$ & PONTOS & $\begin{array}{l}\text { NOMENCLATURA } \\
\text { ATUAL }\end{array}$ \\
\hline Videocassete/ DVD & 0 & 2 & 2 & 2 & 2 & $\begin{array}{l}\text { Analfabeto/Primário } \\
\text { incompleto }\end{array}$ & 0 & $\begin{array}{l}\text { Analfabeto / até } 3^{\text {a }} \\
\text { Série Fundamental }\end{array}$ \\
\hline Rádios & 0 & 1 & 2 & 3 & 4 & $\begin{array}{l}\text { Primário } \\
\text { completo/Ginasial } \\
\text { incompleto }\end{array}$ & 1 & 4aㅗ Série Fundamental \\
\hline Banheiros & 0 & 4 & 5 & 6 & 7 & $\begin{array}{l}\text { Ginasial } \\
\text { completo/Colegial } \\
\text { incompleto }\end{array}$ & 2 & $\begin{array}{l}\text { Fundamental } \\
\text { Completo }\end{array}$ \\
\hline Automóveis & 0 & 4 & 7 & 9 & 9 & $\begin{array}{l}\text { Colegial } \\
\text { completo/Superior } \\
\text { incompleto }\end{array}$ & 4 & Médio Completo \\
\hline $\begin{array}{l}\text { Empregadas } \\
\text { mensalistas }\end{array}$ & 0 & 3 & 4 & 4 & 4 & Superior completo & 8 & Superior Completo \\
\hline Máquinas de lavar & 0 & 2 & 2 & 2 & 2 & \multirow{2}{*}{\multicolumn{3}{|c|}{ Soma A: $(1+0+2+4+0+0+2+4+0)=13$ pontos }} \\
\hline Geladeira & 0 & 4 & 4 & 4 & 4 & & & \\
\hline Freezer $\left(^{*}\right)$ & 0 & 2 & 2 & 2 & 2 & \multicolumn{3}{|c|}{ Soma $A+B:(13+1)=14$ pontos } \\
\hline & & & & & & CLASSE C2 & & \\
\hline
\end{tabular}




\section{Instruções para pontuação na escala de avaliação SNAP-IV}

A escala de avaliação SNAP-IV é uma revisão de Swanson, Nolan e Pelham (SNAP) Questionário (Swanson et al, 1983). Os itens do DSM-IV (1994) critérios para TDAH são incluídos para os dois subconjuntos de sintomas: desatenção (artigos \#1-\#9) e hiperatividade /impulsividade (artigos \#11-\#19). Também, são incluídos os critérios do DSM-IV para transtorno desafiador opositivo (TDO) (artigos \#21-\#28) uma vez que ele Frequentemente está presente nas crianças com TDAH. Foram somados itens para resumir o domínio da desatenção (\#10) e o domínio da hiperatividade/impulsividade (\#20) do TDAH. Dois outros itens foram somados: um item do DSM-III-R (\#29) que não foi incluído na lista do DSM-IV para o TDO, e um artigo para resumir o domínio TDO (\#30).

A SNAP-IV é baseada em uma taxa de avaliação de 0 a $3:$ nem um pouco $=0$, um pouco $=1$, bastante $=2$ e demais $=3$. Os escores das subescalas da SNAP-IV são calculados pela soma dos escores dos itens dos subconjuntos e dividido pelo número de itens dos subconjuntos. O escore para cada subconjunto é expresso dentro de uma média de avaliação para cada item, como mostrado para avaliação do TDAH do tipo desatento (subconjunto TDAH-D) no exemplo abaixo:

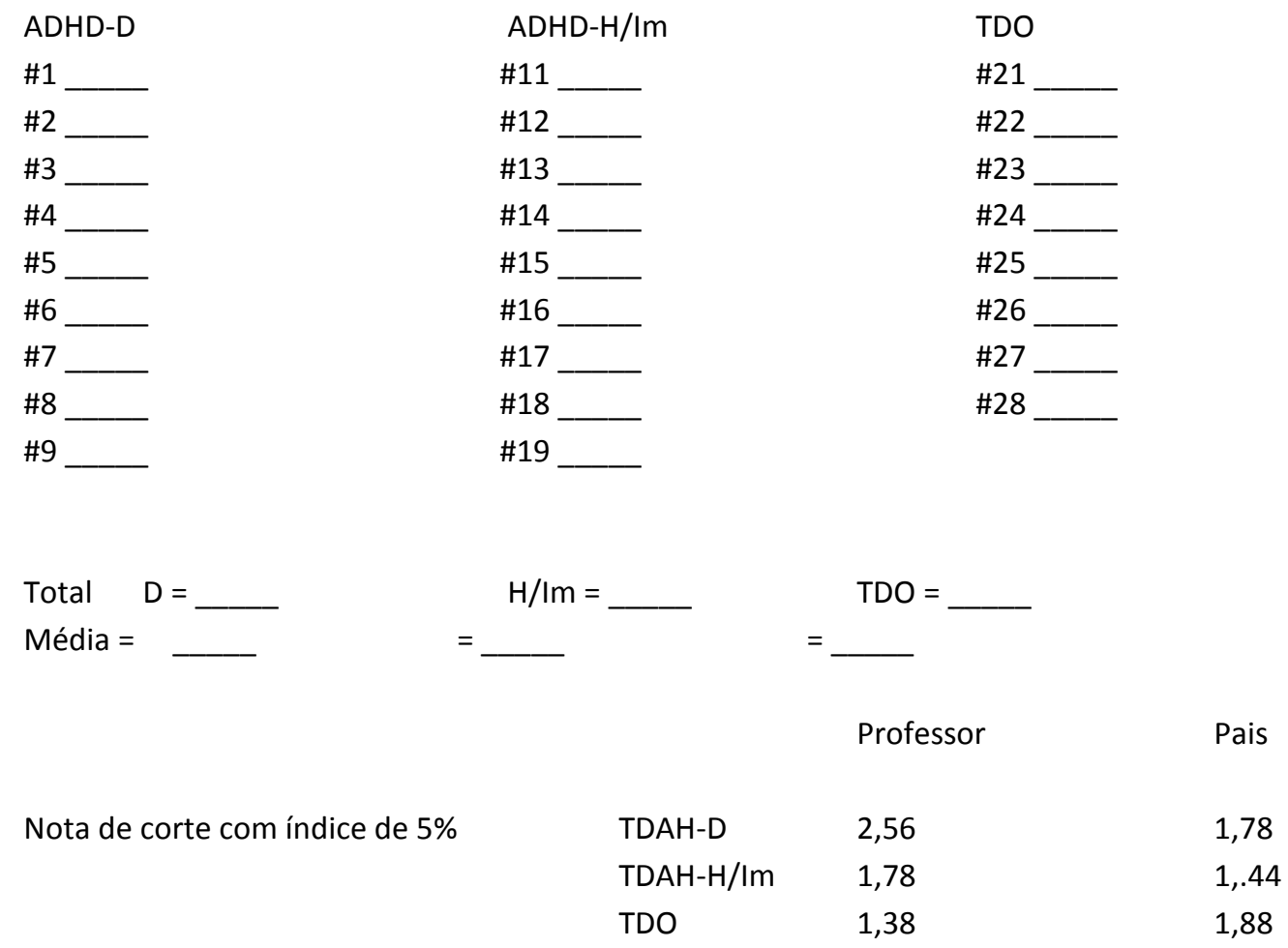




\begin{tabular}{|c|c|c|c|c|c|c|c|c|c|c|c|c|}
\hline \multirow{3}{*}{$e^{0}:$} & \multicolumn{6}{|c|}{ Meninos } & \multicolumn{6}{|c|}{ Meninas } \\
\hline & \multicolumn{3}{|c|}{$7-12$ anos } & \multicolumn{3}{|c|}{ 13-17 anos } & \multicolumn{3}{|c|}{$7-12$ anos } & \multicolumn{3}{|c|}{ 13-17 anos } \\
\hline & F1 & F 2 & F 3 & F 1 & F 2 & F 3 & F 1 & F2 & F3 & F 1 & F2 & F3 \\
\hline 1 & 0 & 0 & 0 & 0 & 0 & 0 & 0 & 0 & 0 & 0 & 0 & 0 \\
\hline 5 & 0 & 0 & 0 & 0 & 0 & 0 & 0 & 0 & 0 & 0 & 0 & 0 \\
\hline 10 & 0 & 0 & 0 & 0 & 1 & 1 & 0 & 1 & 0 & 1 & 1 & 1 \\
\hline 15 & 0 & 1 & 1 & 0 & 1 & 1 & 0 & 1 & 1 & 1 & 2 & 1 \\
\hline 20 & 0 & 1 & 1 & 1 & 1 & 2 & 0 & 2 & 1 & 1 & 2 & 2 \\
\hline 25 & 0 & 1 & 1 & 1 & 1 & 2 & 0 & 2 & 1 & 2 & 2 & 2 \\
\hline 30 & 1 & 2 & 1 & 1 & 2 & 2 & 1 & 2 & 2 & 2 & 3 & 3 \\
\hline 35 & 1 & 2 & 2 & 1 & 2 & 2 & 1 & 3 & 2 & 2 & 3 & 3 \\
\hline 40 & 1 & 2 & 2 & 1 & 2 & 3 & 1 & 3 & 2 & 3 & 3 & 3 \\
\hline 45 & 2 & 3 & 2 & 1 & 2 & 3 & 2 & 3 & 3 & 3 & 4 & 3 \\
\hline 50 & 2 & 3 & 3 & 2 & 3 & 4 & 2 & 4 & 3 & 3 & 4 & 4 \\
\hline 55 & 2 & 3 & 3 & 2 & 3 & 4 & 2 & 4 & 3 & 3 & 4 & 4 \\
\hline 60 & 3 & 3 & 3 & 2 & 3 & 4 & 3 & 4 & 4 & 4 & 5 & 4 \\
\hline 65 & 3 & 4 & 4 & 2 & 4 & 4 & 3 & 5 & 4 & 4 & 5 & 5 \\
\hline 70 & 3 & 4 & 4 & 3 & 4 & 5 & 4 & 5 & 4 & 5 & 5 & 5 \\
\hline 75 & 4 & 5 & 5 & 3 & 4 & 5 & 4 & 5 & 5 & 5 & 6 & 5 \\
\hline 80 & 5 & 5 & 6 & 4 & 5 & 6 & 5 & 6 & 6 & 6 & 6 & 6 \\
\hline 85 & 5 & 6 & 6 & 4 & 5 & 7 & 6 & 7 & 6 & 6 & 7 & 7 \\
\hline 90 & 6 & 6 & 7 & 6 & 7 & 7 & 7 & 7 & 8 & 8 & 8 & 8 \\
\hline 95 & 9 & 8 & 9 & 9 & 9 & 8 & 9 & 9 & 9 & 9 & 9 & 9 \\
\hline 99 & 13 & 12 & 11 & 12 & 11 & 9 & 15 & 11 & 11 & 11 & 11 & 11 \\
\hline 100 & 15 & 15 & 12 & 12 & 11 & 9 & 16 & 14 & 11 & 12 & 11 & 11 \\
\hline
\end{tabular}

* Fator 1: Afetivo-somático; Fator 2: - Relação com o outro; Fator 3: Desempenho.

Fonte: Walthier, Dell'Aglio, \& Bandeira (2008). Análise fatorial do Inventário de Depressão Infantil (CDI) em amostra de jovens brasilieros. Avaliação Psicológica, 7(1) 75-84. 


\section{MASG Proflle Aor Females}

For age groups: Columin 1 is sor 8 - 1l year olds, Colwm 2 is for $12-15$ year olds, and Column 3 is for 16 - 19 year olds.

\begin{tabular}{|c|c|c|c|c|c|c|c|c|c|c|c|c|c|c|c|c|c|c|c|c|c|c|c|c|c|}
\hline & 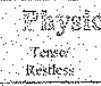 & & 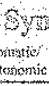 & & & & Perfecta & Exist & & 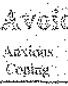 & & rosi & & 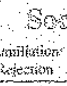 & & & & Tital & 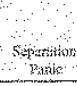 & & & & & 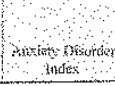 & \\
\hline $\mathrm{T}$ & 123 & 1 & 23 & & 12 & & 12 & 3 & $i$ & 23 & 7 & 23 & & 2.3 & i & 2 & 3 & 1.23 & 12 & & 3 & - & 3 & 123 & \\
\hline 90. & $\because \quad \therefore$ & . & . . & & $\therefore \quad \cdots$ & & . . & . . & & $\because \because$ & $\cdot$ & . . & & $\therefore \because$ & & 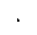 & 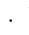 & $\therefore \quad \therefore$ & $\therefore 19 \div 2$ & & 12 & 103 & $10 \%$ & .3030 & 90 \\
\hline 89 & & & & & $\therefore \quad \therefore$ & & & & & & & & & & & & & & & & 11-12 & $100-10 !$ & 100 & .2929 & 89 \\
\hline 8 & & . & & & $\therefore$ & & . . & - . & & & & . & & 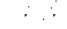 & & . & & & & & 310 & igg & 61 & & 88 \\
\hline 87 & & & & & & & & & & & & & & & & & & & & & $108-109$ & 9748 & gon tol & .2828 & 87 \\
\hline 86 & & & & & & & & & & & & & & & & 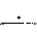 & & $\cdots$ & $26 \cdot 1$ & & 14 & 96 & 28 & & 86 \\
\hline $85:$ & & . & . . & & 36 & & . & . & & & & & & & & & & & $\therefore 18$ & & $105-106$ & 55 & $.96,9 \%$ & & 85 \\
\hline$\$ s$ & $\because$ & . & 18. & . & 35 & & . & . & & : & . & . & . & : & & . & & & 25 & & 103 & 0394 & 8 & $29 \geq 727$ & 84 \\
\hline 83 & \% & & & 3 & 5 & & & & & & & , & : & & & & & & & & $16 z$ & 92 & is & & 83 \\
\hline 82. & 18, & & & & 434 & & . . & . & & $\therefore$ & 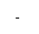 & . . & . & $\therefore$ & & . & . & $\therefore$ & 2417 & & 800 & 90.91 & $92-93$ & 282626 & 82 \\
\hline 81 & 18 & & 1718 & & 33 & & & & & & & & & & & & & & & & i & 89 & 91 & & 1 \\
\hline 80 & $17 \%$ & 18 & . & 3 & 3 & & . & . & & . & - & 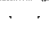 & & $\cdots$ & & & 12 & 27 & 23 & & 97.984 & $37-38$ & 85490. & $27 \cdot 25$ & 8 \\
\hline 39. & $\square 18$ & & .17 & & 232 & & . & . & & & - & . & & & & 12 & & 272626 & -16 & & 5 & $\therefore 86$ & & .25 & 79 \\
\hline 78 & $17 \ldots$ & & 16 & & $\therefore 1$ & & . & 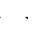 & & . & & . & & 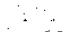 & & & & & $22 \cdot 1$ & & 9 & 8485 & & & 78 \\
\hline 77 & $16 \therefore 17$ & 17 & & & 30 & & . & . & & 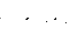 & & . & & & & $\cdot$ & & 262525 & & & $92-93$ & 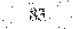 & 55 & .2424 & 77 \\
\hline $76:$ & 16 & & 1516 & 3 & 6 & i. & & . & & $\therefore \cdots$ & & & & 15. & & & 11 & $35 \quad 24$ & 2115 & & 83 & 82 & $8-8$ & & 76 \\
\hline $75:$ & & 16 & 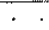 & met & 29 & &. & $\cdot$ & & $\therefore$ & & .27 & & & & 11 & & $2 \pi$ & & 15 & 89.9 & $80-8 \$$ & 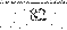 & 252323 & 75 \\
\hline 74 & $16 \quad 16$ & & $\therefore \therefore$ & & 923 & & & . . & & $\therefore \quad \therefore$ & 3 & 27 & & . 14 & & & & $24 \therefore 23$ & 2014 & & $67-83$ & 79 & $80-41$ & & 76 \\
\hline 73 & $1+1$ & & 145 & & 88 & & & - & & $\therefore 15$ & . & .26 & & 14 & . & & & 23 & & 14 & 86 & $77-48$ & & & 73 \\
\hline $72:$ & $44 \quad \square$ & 15 & & & 727 & & & . . & & 15 & & & & $4 \ldots$ & 11 & & 10 & 23,22 & & & 48 & 76 & 77.78 & .2222 & 72 \\
\hline 71 & +215 & & & & 26 & & & & & 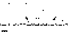 & 273 & & & & & 10 & & 23 & 13 & & 82 & 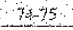 & 6 & & 31 \\
\hline 70 & $\alpha-$ & M & 13 . & 3 & $6 \ldots 2$ & & & ${ }^{\circ}$ & & $\xi \ldots$ & & 25 & & 13 & . & & $\cdot$ & 229121 & 18 & & $3 !$ & 73 & $=$ & $.212 !$ & 70 \\
\hline . & 13 & & & & 525 & & & . 12 & & 14 & 262 & & & & 10 & & & & & & $n$ & 712 & 73.74 & 22 & 69 \\
\hline 68 & 13 & & 1213 & & $24:$ & & & & & 14 & & & & $12:$ & - & . & 9 & $\therefore 2020$ & 1712 & & 78 & 78. & 7 & 20 & 68 \\
\hline 67 & $\because$ & 13 & & & 232 & & -12 & & & a & & & & & & 9 & . & 2019 & & & $76-77$ & 69 & $x(x+1)$ & 21,20 & 67 \\
\hline & 12123 & & & & 3 & & & & & & 253 & & & 11 & & & & 19 & & & $74-45$ & 6768 & iji & & 66 \\
\hline 65 & & & 1112 & & 22 & & & & & $\because 13$ & & & & $11 \ldots$ & 9 & . & & $19 \therefore 13$ & 111 & & 73 & $=$ & 6768 & 1019 & 65 \\
\hline 64 & $11 \quad 12$ & & & & 2212 & & . & 11 & & $13:$ & 242 & & & & 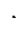 & & 8 & $\therefore 8$ & & & $7 \mathrm{t}$ & 6.65 & & & $6 d$ \\
\hline 63 & $f\}$ & & 11 & & $1:$ & & & & & & & & & 10 & & 8 & & $18 \quad 17$ & 10 & & 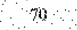 & 63 & 245 & 13 & 63 \\
\hline$\therefore$ & 101011 & 111 & & & 20 & & & & & 1212 & 232 & $22^{22}$ & & 10 & 8 & . & . & 171716 & & & $68+5 \%$ & 60 & 62 & 19.18 & $\begin{array}{l}62 \\
61\end{array}$ \\
\hline 609 & 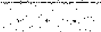 & & 10 & 1 & 9 & & & & & $2: \cdots$ & 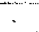 & . & & & . & 7 & 7 & 16 & 9 & & 6 & 5855 & 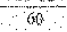 & 181717 & 60 \\
\hline & & & 9. & & 86 & & & 10 & & & 222 & 2121 & & 9 & & . & . & 15 & & & 63 & & & & 59 \\
\hline 53 & 9010 & & . 9 & & $\because 17$ & & 11. & . & & $\therefore \ldots$ & - & . . & $\therefore$ & 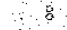 & 7 & 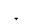 & & $15 \quad 16$ & & & 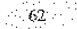 & & $5: 5:$ & 1716 & 58 \\
\hline 5 & 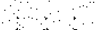 & 9 & 8. & & $7 x$ & & .10 & & & 111 & & & & 8 & . & 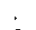 & & 14 & 1288 & & 60 & & 5 & 16 & 57 \\
\hline & 8.9 & & & & 6 & & & & & $1 \quad \therefore$ & 212 & & $: 3$ & & & 6 & 6 & 14 & & & 5 & & 54 & 1615 & 56 \\
\hline & $\cdots$ & & 8 & & 15 & & & & & $\cdots$ & & & & 7 & 6 & 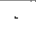 & . & 13.13 & & & & & & 15 & 55 \\
\hline & 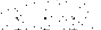 & 8 & 7 & & 1 & 6 & & 9 & & 10 & 201 & 9919 & & $\pi$ & 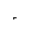 & . & , & $12+2$ & 77 & & 5 & & & & 54 \\
\hline & 788 & & . & 1 & 4 & & .9 & & & 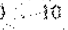 & & & & & 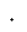 & & & 3 & & & $s$ & 45 & & 1514. & 5.3 \\
\hline & $2 \quad 0 \quad$ & 7 & .7 & & 13 & & . . & . & & $w_{n}$ & 19 & .19 & & & & 5 & 5 & 111 & .6 & & $y$ & $n$ & 46 & . . 14 & 52 \\
\hline & $6 \quad 7$ & & & & 312 & & & & & $\therefore$ & & 18 & & 6 & 5 & & & 1 & & & 30 & $43+6$ & & 14,3 & \\
\hline 50 & 6 & . & 6 & 1 & 2 & 3 & 9 & & & 9 & & & & & & & & 101010 & & & 49 & 4 & 5 & 13 & 50 \\
\hline 48 & $\cdots \cdots$ & 6 & 5 & & 1.11 & & & 8 & & $\because 9$ & 1 & 1717 & & 5.5 & & & & & 855 & & 325 & & & & 49 \\
\hline 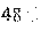 & 556 & & . & & $10 \%$ & & .8 & . & & $\therefore$ & & & & $\therefore$ & 4 & 4 & \& & 99 & & & 4 & $4\{-4 ?$ & 4.2 & 12 & 48 \\
\hline & $\cdots$ & 5 & . \$ & 11 & 09 & & & & & $8 \%$ & 17 & & & & . & 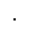 & . & an 8 & & & & & & 12.12 & 47 \\
\hline 4 & $\therefore \quad \square$ &. & 4 & 9 & & 0 & . & . & & $\therefore \quad \therefore$ & .1 & 1616 & & 4 & . & . & . & 8 & 44 & 4 & 6 & 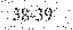 & 4 & 11. & 46 \\
\hline & 46 & & & & 8 & & 8 & & 8 & $\therefore$ & & & & & & & & $7 \quad 7$ & & & & & & $11 \ldots 11$ & \\
\hline $34-3$ & & 4 & 4 & 8 & 37 & 9 & . & 7 & & $\therefore \theta$ & 161 & 1515 & & 3. & 3 & 3 & 3 & 7 & & & 39 & $55-36$ & 37 & 10 & 34 \\
\hline 4 & $3-4$ & & 3 & 7 & & & .7 & . & & $7 \quad$ & & & & 3 & 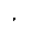 & 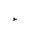 & . & $6 \% \Leftrightarrow$ & 533 & & & & & & \\
\hline $42-2$ & $\checkmark \quad \square$ & 3 & . 3 & & 6 & & . & . & 7 & 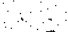 & 15 & & & & & . & . & $\because$ & & & 3637 & $32-33$ & & . .10 & 4 \\
\hline 4 & 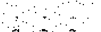 & . & 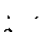 & 6 & 5 & & 7 & . & & $\because 7$ & $i$ & 4 & & 22 & 2 & & & 355 & 422 & 2. & & & & 9 & 41 \\
\hline 40 & 2,23 & & 2 & 5 & : & & & & & & 14 & & & & & 2 & $z$ & & & & 3 & & & 9 & \\
\hline 4 & $\gamma$ & 2 & 2 & & $\cdots$ & & & 6 & & 6 & 1 & & & & & & & 44 & & & & & & 8 & \\
\hline & 12 & & 1 & & 3 & & 6 & . & ?. & & . & .13 & & 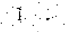 & & . & & $\therefore$ & $1 i$ & & 36 & & & & $3 i$ \\
\hline & $1 \%$ & 1 & . 1 & & 2 & & 6 & . & & 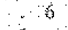 & 13 & & & . & 1 & & & 33 & & & & & & 78 & \\
\hline 3 & $\cdots$ & 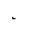 & . . & & & & 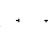 & . & & $\therefore 5$ & & 212 & & & 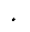 & 1 & I & 232 & & & $26 \times 2$ & & 2 & & \\
\hline & $00 \quad 1$ & & 0 & & & & & & & & 12 & & & 0 & & & & & 100 & & & & & 7 & \\
\hline 3. & & 0 & .0 & i & 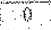 & & & 5 & & & .1 & 11 & & & 0 & & & 111 &. & & 23. & $2 \mathrm{~F}$ & 23 & 66 & 34 \\
\hline 3. & $\cdots$ & . & . . & 6 & & & 5 & 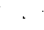 & & & & . 11 & & & . & & & $\ldots$ & 0 & & & & & & \\
\hline 3 & 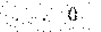 & . & . & & 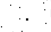 & & 5. & . & & 4 & 1.1 & & & & . & 0 & a & 4000 & . & & 26 & f & 10020 & 556 & 32 \\
\hline & $-\quad \alpha$ & . & . & & 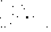 & & s. & . & & $\therefore$ & 1 & 10 & & & . & . & - & 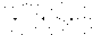 & . & & $i s-1$ & & & . & \\
\hline 3 & & & & & & & & & & & & 10 & & & & & & & & & 13 & 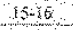 & $46, E 7$ & 5 & 31 \\
\hline 2. & & . & . & & & & & $A$ & & 34 &. & 9 & & & & + & & & & & 15. & & & $4 \frac{4}{n}$ & \\
\hline 2 & & & & & & & 44 & & 3 & & & & & & & - & & & . & & $13+10$ & $12+33$ & $13-14$ & & 28 \\
\hline 2 & $\therefore$ & . & . & & & & & & & & 9 & & & & & ${ }^{*}$ & & & & & 4 & & 12 & 324 & \\
\hline 2 & & & & & & & & & & & & & & & & 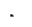 & & & & & & 210 & 16 & & \\
\hline 25 & $\because$ & & & & & & $4<<4$ & $4<4$ & & 34 & 9 & 88.9 & & & & & & & & & 10 & 0 & .3 & $<34$ & 25 \\
\hline
\end{tabular}

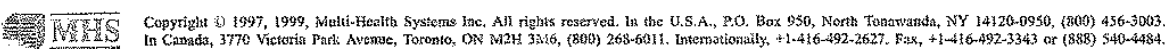




\section{MASC Profile Por Males}

For age groups: Column 1 is for 8 - 1 year olds, Columan 2 is for $12-15$ year olds, and Colum 3 is 6 ar $16-19$ year olds.

\begin{tabular}{|c|c|c|c|c|c|c|c|c|c|c|c|c|c|c|c|c|c|c|c|}
\hline & \multicolumn{3}{|c|}{ 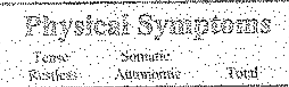 } & \multicolumn{3}{|c|}{ 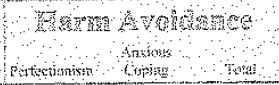 } & \multicolumn{5}{|c|}{ 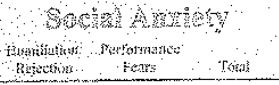 } & & \multicolumn{2}{|c|}{ 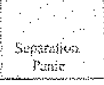 } & \multicolumn{3}{|c|}{ MASC TOUSL } & 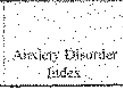 & \\
\hline 1 & 1.20 & 123 & 123 & 133 & 123 & 123 & 873 & 12 & $23^{3}+4$ & & 17 & & 12 & & $\mathrm{i}$ & $=$ & 3 & 123 & \\
\hline & $\because 18$ & . is & $36-3336$ & 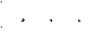 & $\therefore \quad \cdots$ & & & & & & & & $\ldots 17$ & & & 93 & st & $30>27>27$ & 90 \\
\hline & 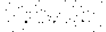 & . 18 & 33.35 & & & . . & & & & & & & 23 & & 10. & 09.43 & & .27 & 89 \\
\hline & $\because \because$ & .17 & 353234 & & & . . & & . & . & & & & & & & 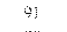 & 4 & 29 & 38 \\
\hline & 817 &.$\quad 17$ & & . & & & & & & & & & 2217 & & 191 & $\therefore$ & 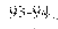 & $\therefore 2627$ & 87 \\
\hline & & & & & & & & & & & & & & & $97.9 \mathrm{k}$ & 8 & 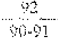 & $\frac{28}{2}$ & $\frac{86}{83}$ \\
\hline & 71 & 1816.16 & $\begin{array}{l}333 \\
35\end{array}$ & & & $\cdot$ & & . & . & & 37 & & & & 46 & 85.56 & $\therefore \%$ & $27^{2526}$ & $\begin{array}{l}83 \\
84\end{array}$ \\
\hline & 7 i & 16 & 2931 & . & $\cdots$ & . & & . & $:$ & & 26. & & & 16 & & $\Leftrightarrow$ & & 25 & 83 \\
\hline & & 1715. & 31 & 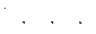 &. & . & & & & & & & 2015 & & & 2 & tis & 2624. & 82 \\
\hline & & & & & & & 15 & & & & 2725 & & & 15 & & & 5 & & 81 \\
\hline & 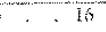 & & 30 & Fin & & & & . & 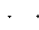 & & & & & & & & 3 & 2324 & 80 \\
\hline & 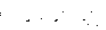 & 1614 & & . . . & $\cdots$ & & & . & & & 2624 & & $\cdot 14$ & & & & & 25 . & 79 \\
\hline & 1514 & $\therefore .14$ & 2628 & . . . . & $\ldots \ldots$. & 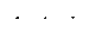 & .41 & . & & & & & & 14 & & & & & 3 \\
\hline & 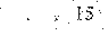 & & 27 & . & $\cdots \therefore$ & & $\therefore \quad \therefore 3$ & & 11 & & 23 & & & & & & & 2422 & 77 \\
\hline & & -1 & 2725 & . . & & & & 12 & & & & & & & & 3 & $=$ & 22 & 76 \\
\hline & 14.13 & & 26 & $\cdot \cdot$ & $\because$ & 27 & 13 & . & & & 22 & & 17 & 13 & & $3=73$ & $7 \leqslant \frac{16}{4}$ & 2321 & 75 \\
\hline & $\therefore$ & & $26 \quad 25$ & $\cdots$ & 15 & & 13 & .1 & 101 & 0 & 2331 & & & & & & 4 & 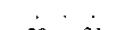 & 74 \\
\hline & & . & 25 & . . . & $\because \quad 15$ & $\therefore 26$ & & & . & . & & ? & 1612 & & $8 \%$ & ;i) & 3 & $22 \cdot 21$ & 7.3 \\
\hline & 13 & & 24 & . . . & 15 & $27 \cdot 26$ & 1212 & 11 & & & 22.20 & & & $1:$ & & & & 20 & 72 \\
\hline & & & & & 14 & .25 & 13 & & & & & & 15 & & 7 & & & 20 & 71 \\
\hline & 12 & .11 & 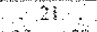 & $\cdot$ & $\therefore \cdots$ & & $\because$ & & 9 & & 21.19 & & & 1 & & & & .19. & 70 \\
\hline & .11 & $\therefore 11$ & 22 & . . 12 & $14 \quad 4$ & 26 & $\therefore 1011$ & 10 & & & $30 \quad$ & & & & & & & & 69 \\
\hline & & & 0 & . . . & 13 & . 2424 & & & & & $\mathrm{~s}$ & & 14 & & & & & 19 & 68 \\
\hline & & 10 & & .12. & $\because \because$ & 25 & & & & & $y$ & & & 10 & & & & 18 & 67 \\
\hline & $=10$ & 10 & & & $3-13$ & & 1010 & 9 & 8 & & & & 13 & & & & & & 66 \\
\hline & an & 11 & 20 & & $\therefore \quad \therefore$ & 2,4 & 10 & . & . & . & 18 & & & & 66 & & & 17 . & 65 \\
\hline & $16:$ & 0 & 19 & $12 \cdot 11$ & $\because 2$. & .22 & $\cdots$ & . & 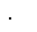 & & 1716 & & 129 & 9 & & & & $18 \cdot 17$ & 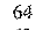 \\
\hline & $\cdots$ & 10 & 7 18 & . 11. & $12 \quad$ & $23 \cdot 22$ & $\therefore 9 \div 9$ & & & : & & & & & 6 & 5 & & & 63 \\
\hline & $\therefore$ & & & . . . & 12 & 21 & & 8 & 7 & 7 & 1615 & & $11 \%$ & & & & & 1716 & 62 \\
\hline & 9 & .8 & 37 & & 11 & $22 \cdot 21$ & $\therefore 8$ & & & & 14 & & & 8 & 58 & & & 16 & . \\
\hline & $\because \therefore$ & 9.8 & & $\therefore 10$ & 11 & & & & 15 & & & & & & & & & 1615 & 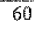 \\
\hline & $\therefore \therefore$ & . . . & 16 & 110 & $\therefore=11$ & 21 & & 7 & & & 1413 & & 107 & i & & & & 15 & \\
\hline & $\$$ & $\therefore 7$ & $\mathrm{ss}$ & $\therefore$. & $\because 10$ & & $\because 77$ & . & 6 & 6 & & & & 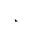 & & 3 & & 14. & 8 \\
\hline & $\therefore 7$ & 7 & Is & ( & 10 & 19 & & . & 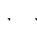 & & 1312 & & 9 & & & & & 5 & $77>-2>$ \\
\hline & & & & 9 & -10 & & & & & & & & & 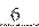 & & & & 14 & \\
\hline & 7 & 6 & 33 & 10 & & 18 & 65 & 6 & & & 1 & & 3 & & & & & $\therefore$ & \\
\hline & $\therefore$. & 7.6 & 13 & .9 & $\$ 9$ & & $f \quad$ & . & $s$ & & & & & & & & & 13 & 344 \\
\hline & (1) & . & 12 & 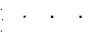 & & 1817 & $\cdots$ & & . & & 10 & & 75 & $x^{5}+5$ & & & & 312 & 33 \\
\hline & & . 5 & 911 & . & $\therefore \quad \therefore 9$ & & 53 & 5 & & & 6 & & 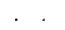 & & & & & .12 & 32 \\
\hline & 5 & $6 \cdot 5$ & & 8 & $8 x$ & 1716 & & & 2 & & & & & & & & 46 & & $5 i$ \\
\hline & 5 & & 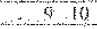 & $\therefore 8$ & 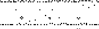 & 16 & & & 3 & & 9 & 8 & 64 & 3 & & & & $\mathrm{II}^{2}$ & 5 \\
\hline & $\because$ & 54 & 6. & 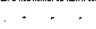 & $\because \because 8$ & & & 4 & (2) & & & & & & & & & & 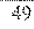 \\
\hline & 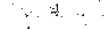 & 4 & 9 & . & 47 & ts & & . & . & & 8 & & 5 & 3 & & & & 10 & 48 \\
\hline & & 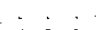 & $\ldots$ & 7 & $\therefore \quad \cdots$ & 15 & & . & & & & & .3 & & & & & 10 & 47 \\
\hline & $\therefore$ & 433 & $\ldots: 6$ & 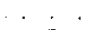 & & & $\because 3 \cdot 3$ & & 3 & & & & 4 & & & & & & 46 \\
\hline & $\because 3$ & & & 7 & 6.8 & 1 & & 3 & & & & & & & & & & 99 & \\
\hline & 3 & 2 & 7.56 & . & & .13 & & . & . & & & & 3 & & & & & 9 & $4: 44$ \\
\hline & $\therefore \quad \therefore$ & $3 \cdot 2$ & & .6 & & & & . & & & 5 & & & & & & & 8 & \\
\hline & 2 & . & 4 5 & 7. & $5 \quad 6$ & 2 & & 2 & 2 & & 4 & & .1 & 1 & & & & 8.8 & 42 \\
\hline & 2 & 1 & $5: 3 \ldots 4$ & .6. & & & & & & & & & & & & & & & 4 \\
\hline & 1 & 2 & A & & & $=1$ & 11 & & & & 3.3 & & & & & & & $7 i z$ & \\
\hline & & & $\because 2$ & . & $4 \therefore 5$ & & & & & & & & 10 & & & & & & \\
\hline & & $\theta$ & 3 & 6 & $\therefore 4$ & 11 & $\therefore \quad \therefore$ & 1 & 1 & & 22 & & & & & . & 20 & 66 & 38 \\
\hline & $\therefore 8$ & 1. & 2,3 & & & 1010 & $\begin{array}{lll}0 & 0\end{array}$ & & & & & & 0 & & & & & - & \\
\hline & $\hat{B}$ & . . . & $\therefore 0 \%$ & .5 & $\because \quad \therefore \quad$ & 10 & $\therefore$ & & 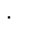 & & 11 & & & & & 7 & 1 & 5 & 36 \\
\hline & & 0 & & & 34 & & & 0 & & & 00 & & & & & & & & \\
\hline & & 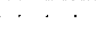 & $\theta$ & $5 \cdot 4$ & $\therefore$ & 9 & & . & 0 & & & & & & 7 & & & & 34 \\
\hline & & & & & & & & & & & & & & & & & & 444 & \\
\hline & & . & $\therefore \quad$ & $\cdot 4$ & $2 \div 3$ & 8 & & . & & & & & & & $11 \%$ & $\cdots$ & 11 & 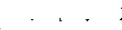 & 32 \\
\hline & & 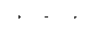 & 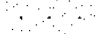 & . . & $\cdots 2 \cdots$ & $\therefore 7$ & $\because$ & - & & & & & & & & & & 33 & \\
\hline & & & & & & 7 & & & & & & & & & 16 & & 78 & & iv \\
\hline & & & & $4:$ & $1 \ldots 2$ & $\therefore 6$ & $\therefore$ & 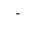 & & & & & & & $\theta$ & w & & & \\
\hline & & & $\therefore \because c^{\prime}$ & 3 & $\therefore \cdots$ & 6 & & & & & & & & & 78 & 5 & 34 & .22 & 25 \\
\hline & & & & & $\cdots$ & & & & & & & & & & s- & 4 & & & \\
\hline & & & $\therefore$. & $\therefore 2$ & $a$ & 5 & & & & & & & & & . & $\pi$ & 12 & . \& 1 & \\
\hline & & & & 2432 & 2 & 5 & & & & & & & & & 4 & & & $1<1$ & \\
\hline
\end{tabular}

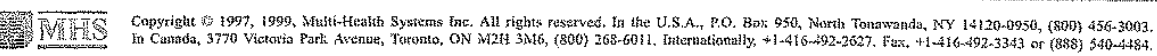




\section{MASC Scoring Grid}

by John March, M.D., M.P.H

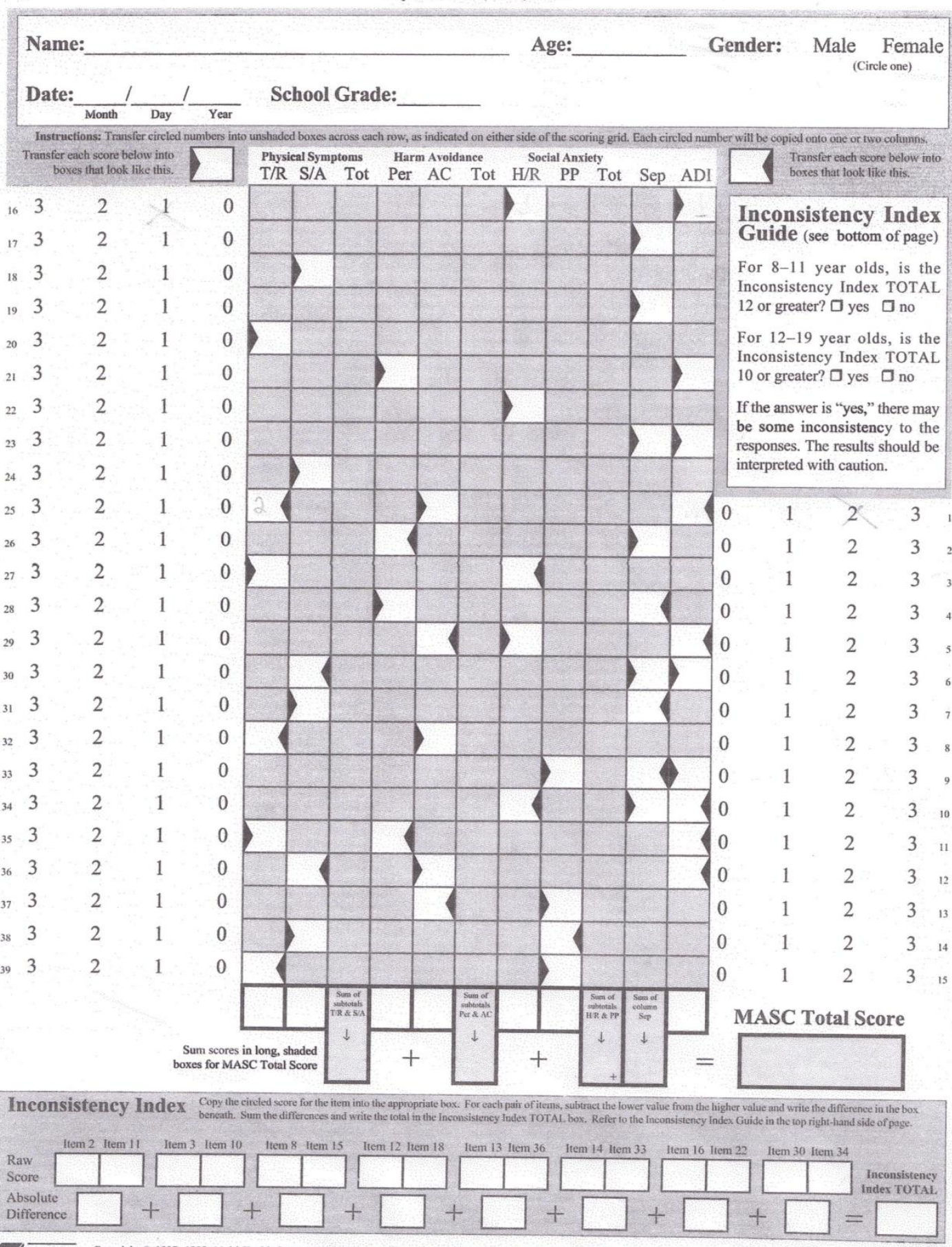

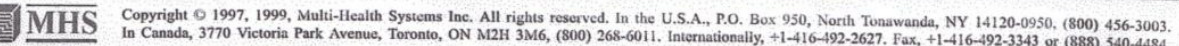




\section{Anexo 9. Termo de consentimento livre e esclarecido: Cuidadores e CRUS/CRS}

$\mathrm{O}(\mathrm{a})$ senhor(a) e seu filho estão sendo convidados a participar do projeto: Treino de TerapeutasEstagiários no Atendimento de Crianças Ansiosas, que faz parte do trabalho de doutorado da pesquisadora, aluna do Instituto de Psicologia da Universidade de São Paulo, sob a orientação da Profa. Edwiges Silvares.

O nosso objetivo com este trabalho é elaborar e avaliar uma proposta de treinamento de estagiários no atendimento de crianças ansiosas, inscritas em clínicas-escola, a partir de uma ferramenta reconhecida internacionalmente para o atendimento de crianças - Manual Coping Cat-, adaptado para a realidade brasileira, a partir do levantamento da clientela do serviço e da aplicação da intervenção.

A sua participação poderá ser apenas mediante o preenchimento de alguns questionários, que você responderá no setor de saúde mental do NAT/HRAS, com o tempo estimado de preenchimento de cinquenta minutos; ou também através da intervenção psicológica na abordagem cognitivocomportamental, aplicada no seu filho. Quando for aplicado os questionários não existe obrigatoriamente, ou um tempo pré-determinado, para responder o questionário. Informamos que a Senhor(a) pode se recusar a responder qualquer questão que lhe traga constrangimento. $O$ resultado deste trabalho irá contribuir para o atendimento do serviço e a capacitação de profissionais da psicologia no atendimento da ansiedade infantil.

Caso o seu filho seja encaminhado para o atendimento psicológico, saiba que o tratamento não oferecerá desconforto, nem risco à saúde do(a) seu filho(a). O atendimento será aplicado a partir da adaptação de um manual reconhecido internacionalmente, realizado em 10 sessões semanais e em grupo. Além disso, os atendimentos serão filmados e gravados para que possamos analisar os dados. Após o tratamento e a análise dos dados, as filmagens serão arquivadas como material de pesquisa pela pesquisadora, no laboratório de terapia comportamental do Instituto de Psicologia-USP/SP. Tanto as filmagens como os dados observados sobre o seu filho só poderão ser usados para ensino e pesquisa. Você não terá nenhum gasto por participar desta pesquisa. Os resultados da pesquisa serão divulgados aqui no Setor de Saúde Mental e no HRAS, podendo ser publicados posteriormente. Os dados e materiais utilizados na pesquisa ficarão sobre a guarda e responsabilidade da pesquisadora.

O(a) senhor(a) receberá todos os esclarecimentos necessários antes e no decorrer da pesquisa e lhe asseguramos que seu nome e o do seu filho não aparecerá, sendo mantido o mais rigoroso sigilo através da omissão total de quaisquer informações que permitam identificá-lo(a). Além disso, a sua participação não é obrigatória e nem irá interferir no atendimento que seu filho receberá no serviço. A qualquer momento você poderá interromper a sua participação ou do seu filho, se assim achar conveniente. Caso tenha qualquer dúvida em relação à pesquisa, por favor telefone para:Dr(a) Fabiana Gauy, no telefone: (61) 82032393, no horário: das 8h as 18h, ou no e-mail fabianagauy@usp.br. Antes de começar este trabalho com vocês, este projeto foi encaminhado para o Comitê de Ética em Pesquisa da SES/DF. As dúvidas com relação à assinatura do TCLE ou os direitos do sujeito da pesquisa podem ser obtidos através do telefone: (61) 3325-4955.

Caso esteja de acordo em participar, favor assinar abaixo. Uma cópia deste termo ficará com você. Muito obrigada!

Brasília, 09 de outubro de 2010. 
Acredito ter sido suficientemente informado a respeito das informações que li ou foram lidas para mim descrevendo o estudo "Treino de Terapeutas-Estagiários no Atendimento de Crianças Ansiosas". Discuti com o presente responsável pelo projeto sobre a decisão de participar nesse estudo. Ficaram claros para mim quais os propósitos do estudo, os procedimentos a serem realizados, seus desconfortos e riscos, as garantias de confidencialidade e os esclarecimentos permanentes. Ficou claro também que minha participação será isenta de despesas e que terei garantia do acesso a tratamento psicológico caso seja necessário. Concordo voluntariamente em participar deste estudo e poderei retirar o consentimento a qualquer momento, antes ou durante o mesmo, sem penalidades ou prejuízo ou perda de qualquer benefício que eu possa ter adquirido.

Data

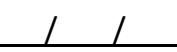

Nome/Assinatura

\section{(Somente para o responsável do projeto}

Declaro que obtive de forma apropriada e voluntária o Consentimento Livre e Esclarecido deste cuidador e seu filho para a participação neste estudo.

Fabiana Vieira Gauy - Responsável pelo estudo

Data

11


Anexo 10. Termômetro do Medo

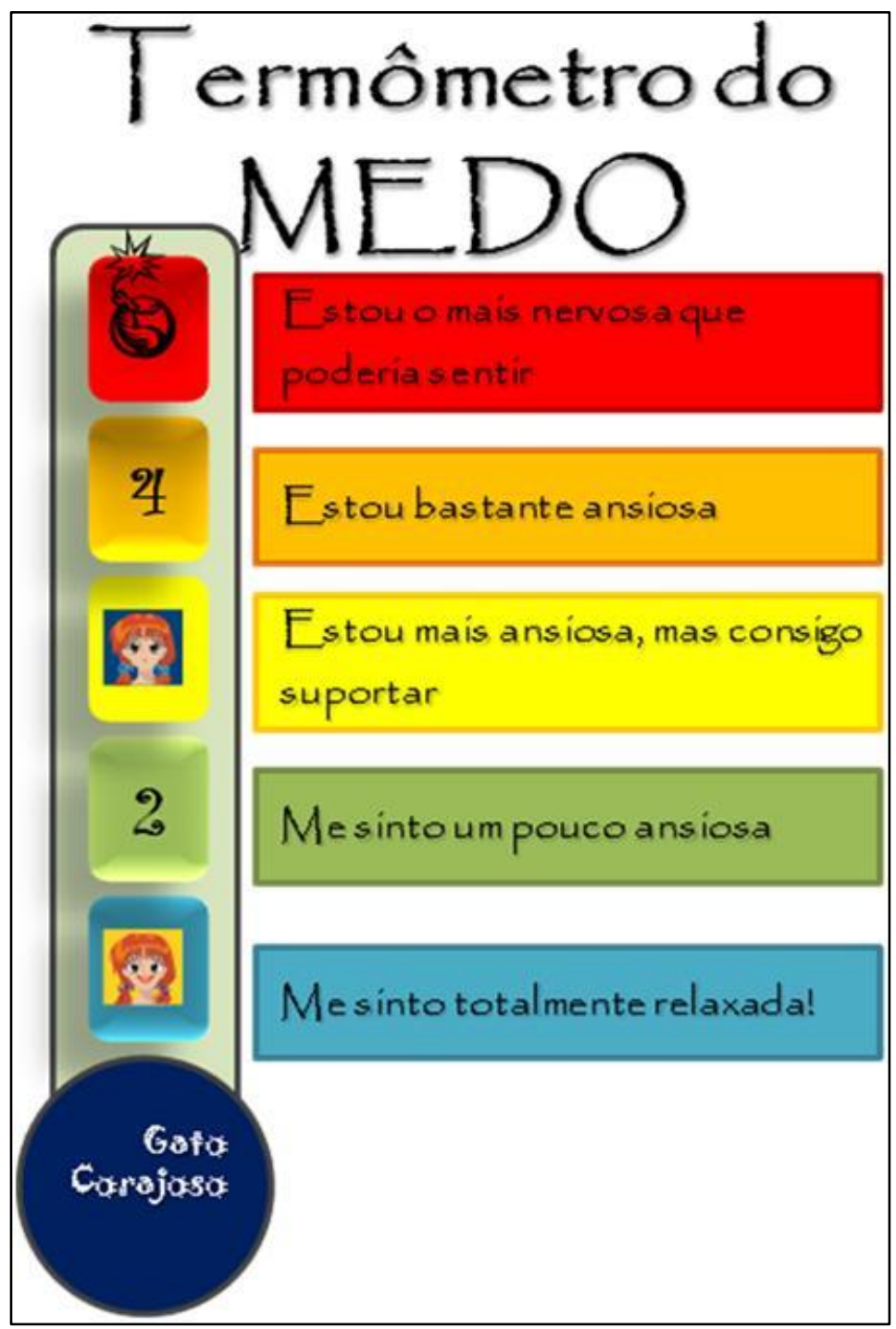




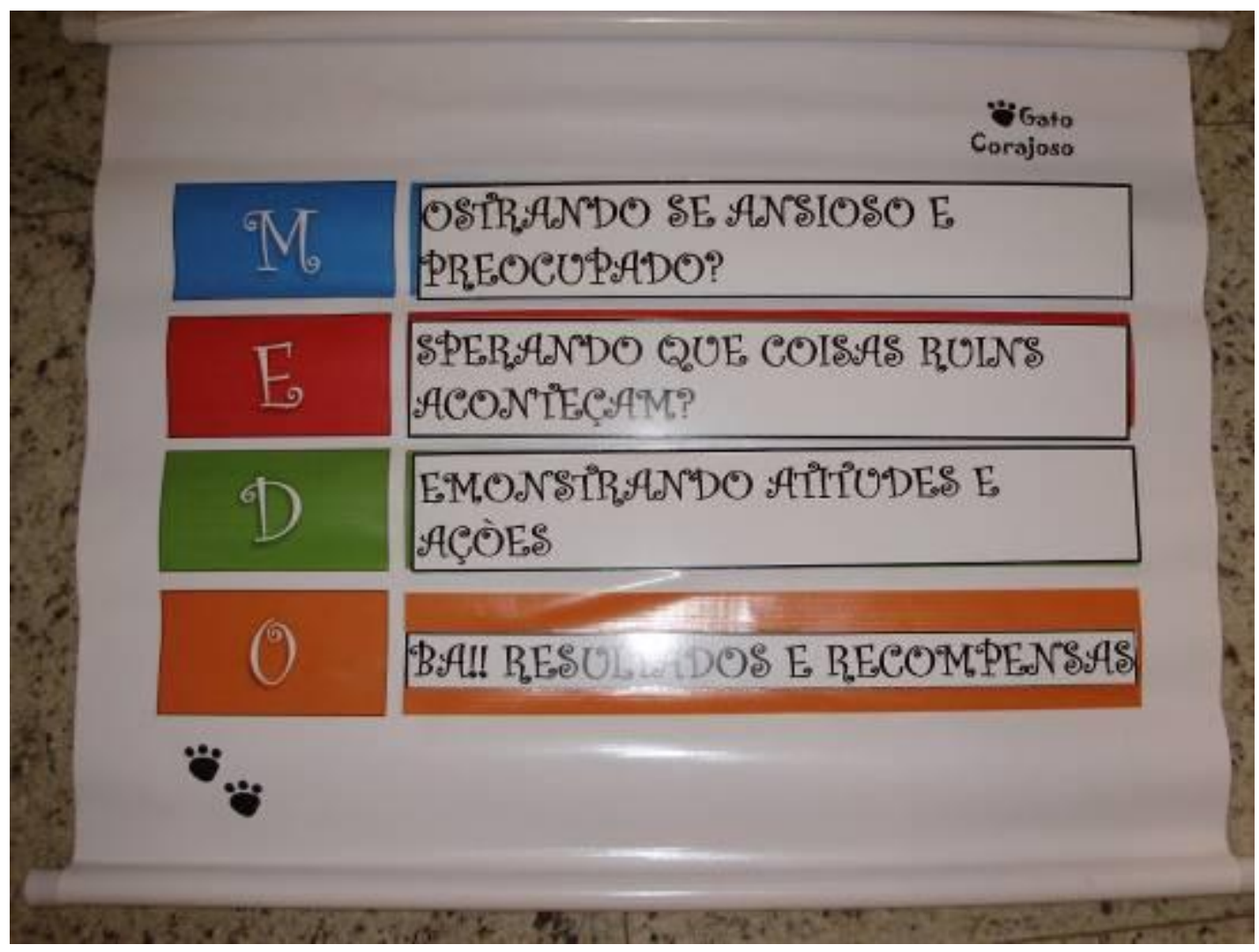




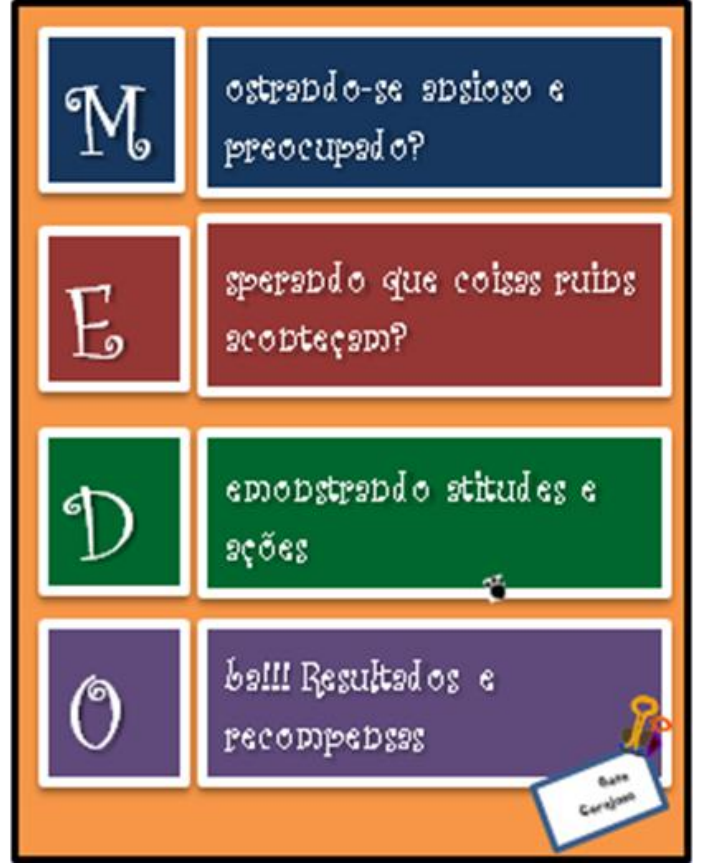




\section{Anexo 13. Círculo mágico}

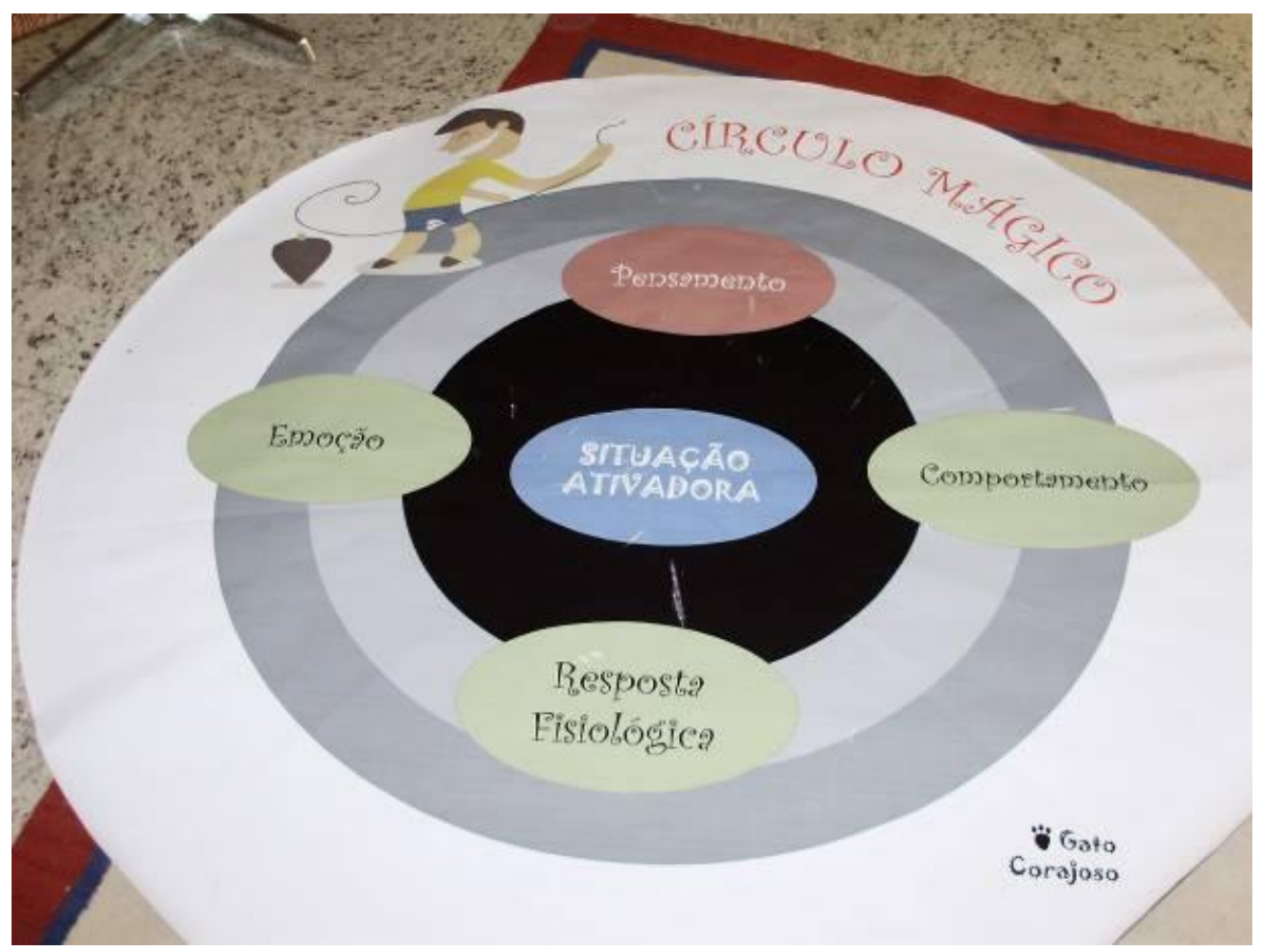


ANEXo 14. Jogo Tô POR UMA

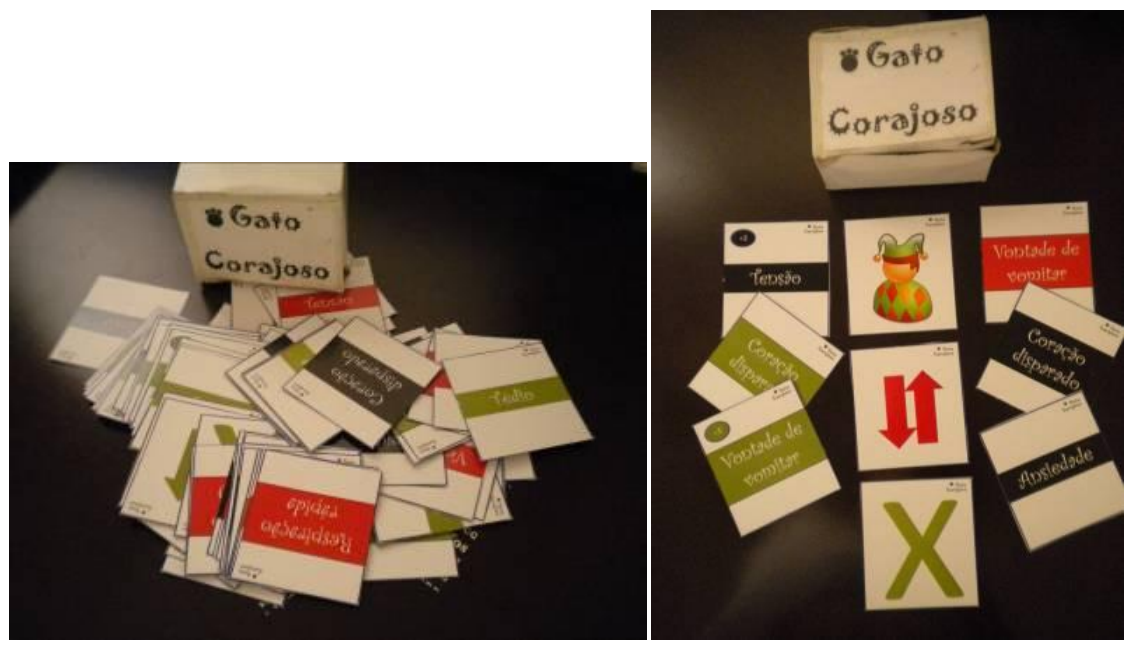




\section{Anexo 15. Agenda}

\section{Exemplo:}

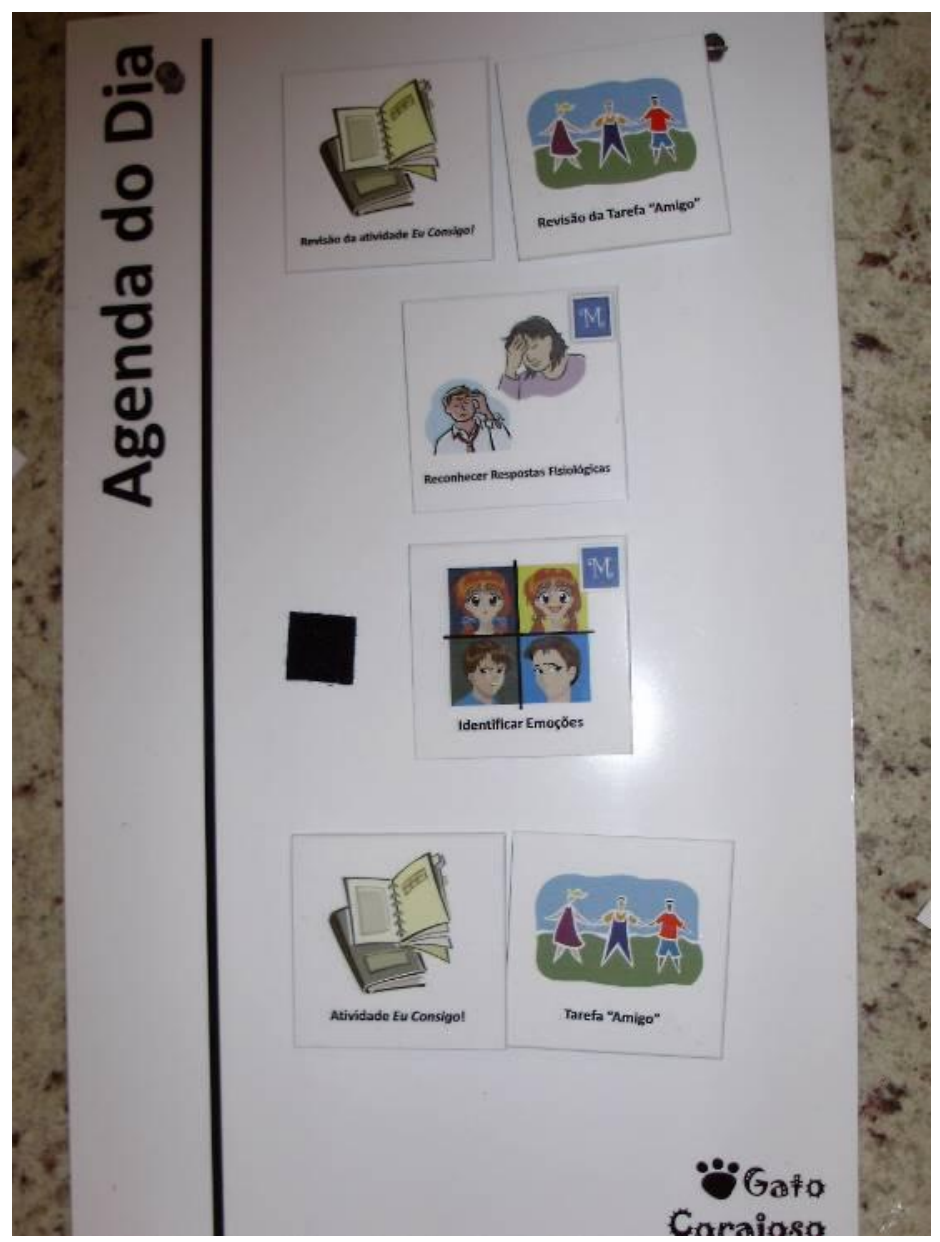


Anexo 16. Banco de pontos e Tarefa Amigo
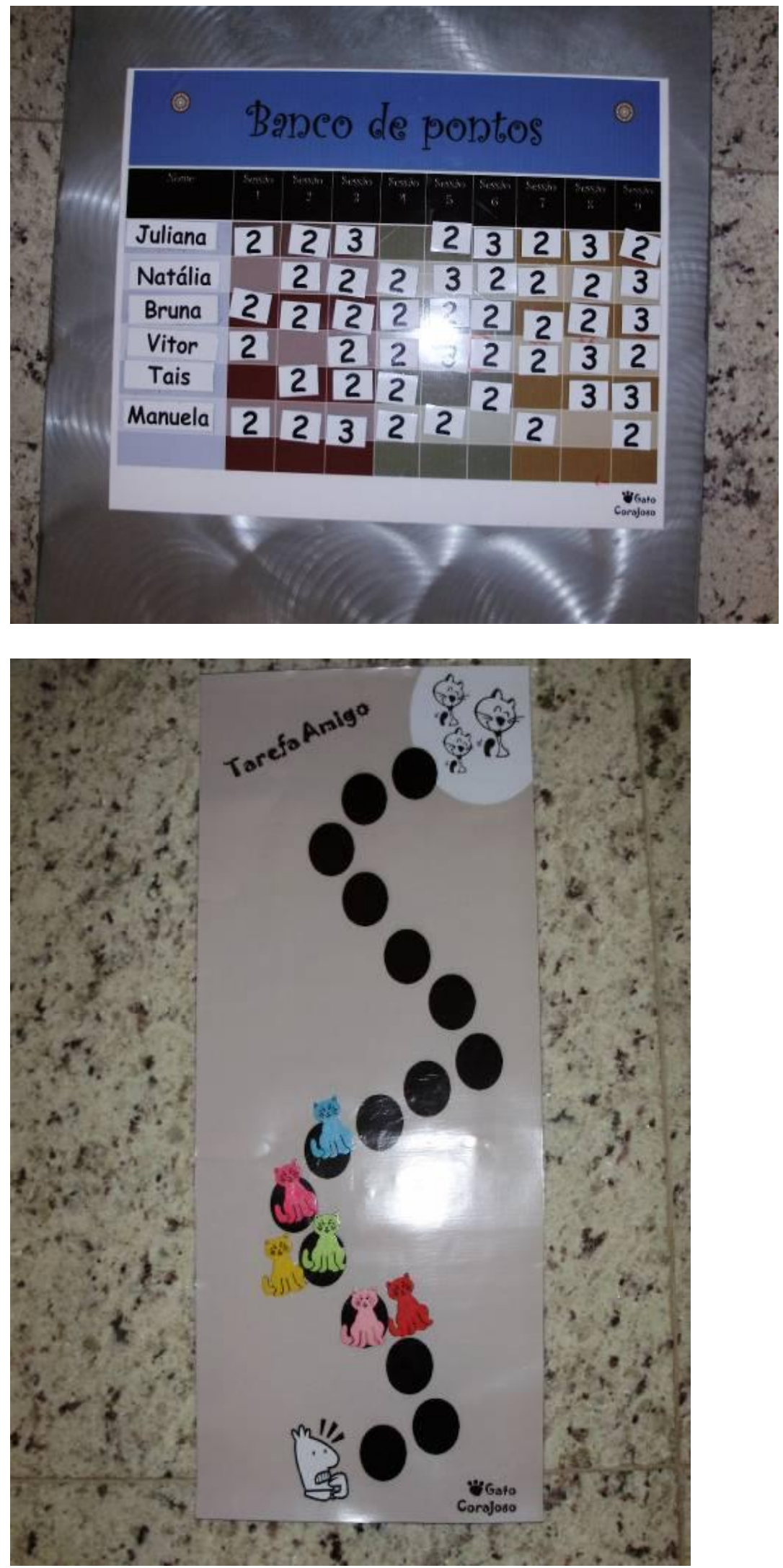


\section{Anexo 17. Logomarca do Protocolo}

\section{$\because$ Gafo \\ Corajoso}




\section{Anexo 18 Camiseta e botton}
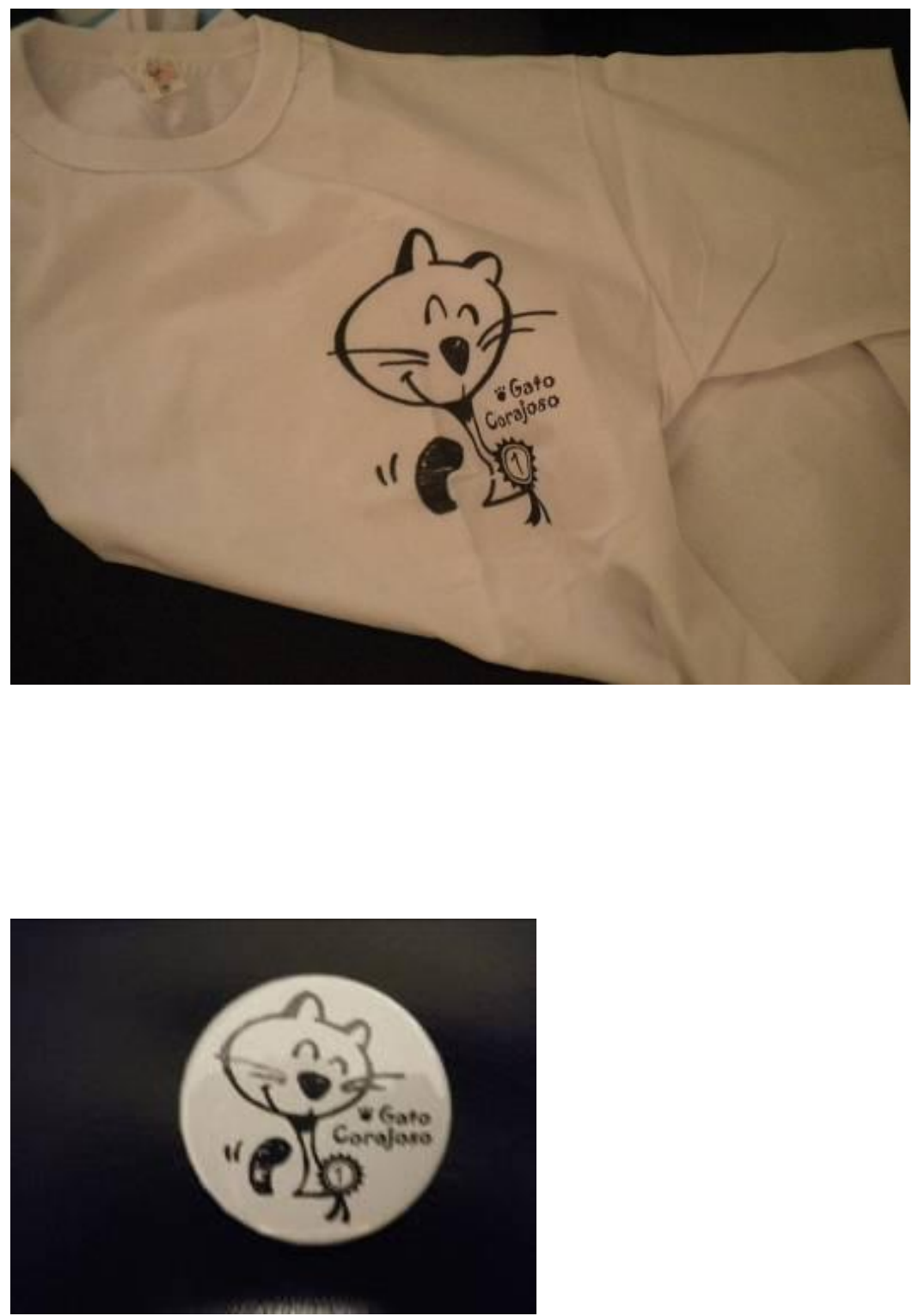


\section{CERTIFICADO \\ $\because$ Gato \\ Corajoso}

Certificamos que:

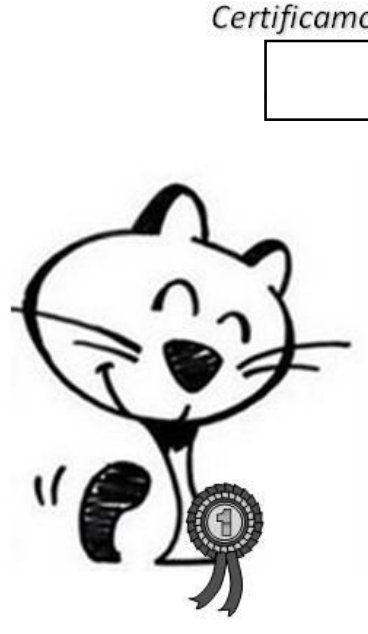

participou do Grupo de Terapia Cognitivo-

Comportamental para crianças ansiosas "Gato

Corajoso", entre os dias 03 de outubro e 05

dezembro, realizando 10 sessões, com duração total de $20 \mathrm{~h}$.

São Paulo, 05 de dezembro de 2009.

Fabiana Gauy

Coordenadora do Projeto 
Anexo 20. Certificado para participantes-Alunos (Exemplo) FRENTE

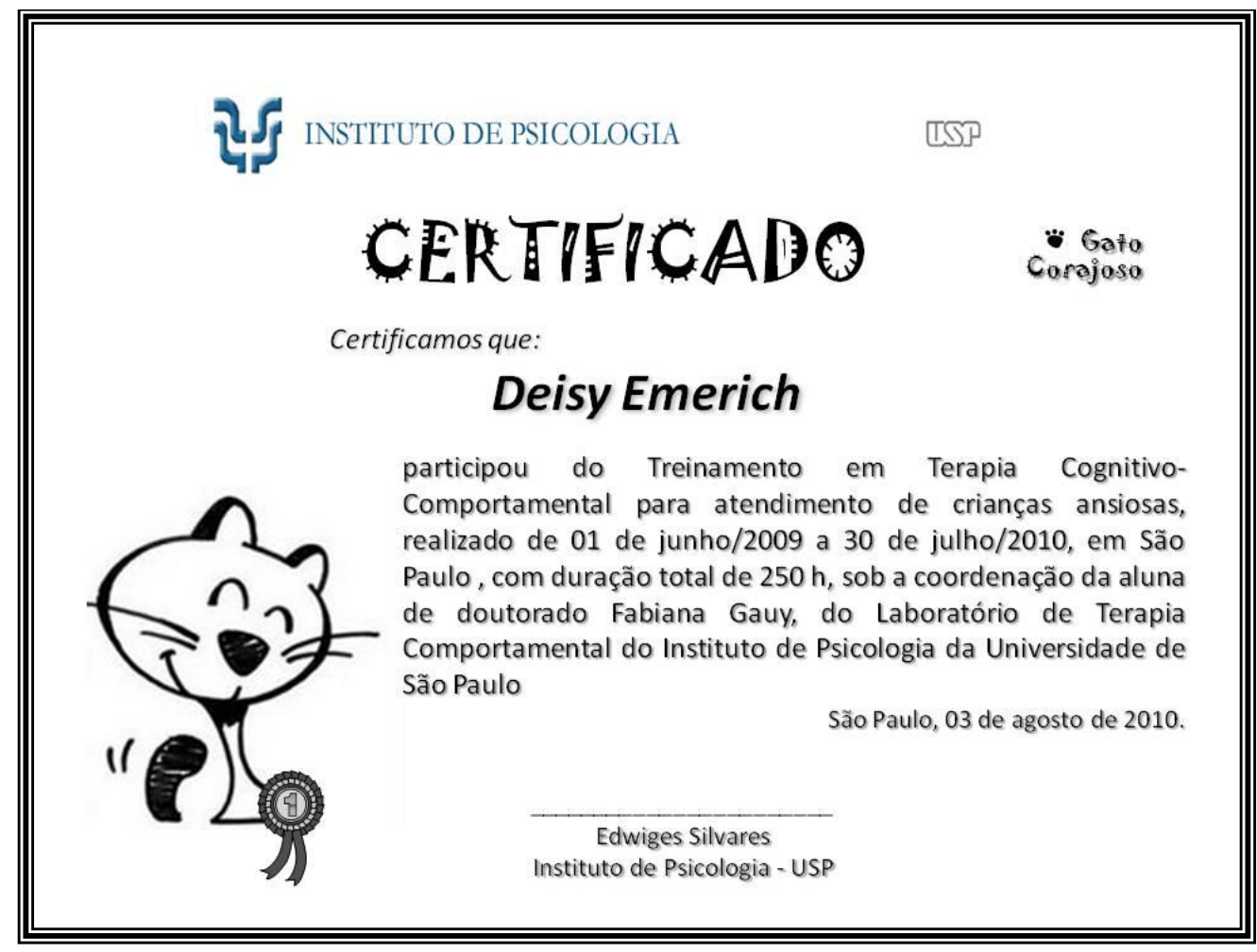

VERSO

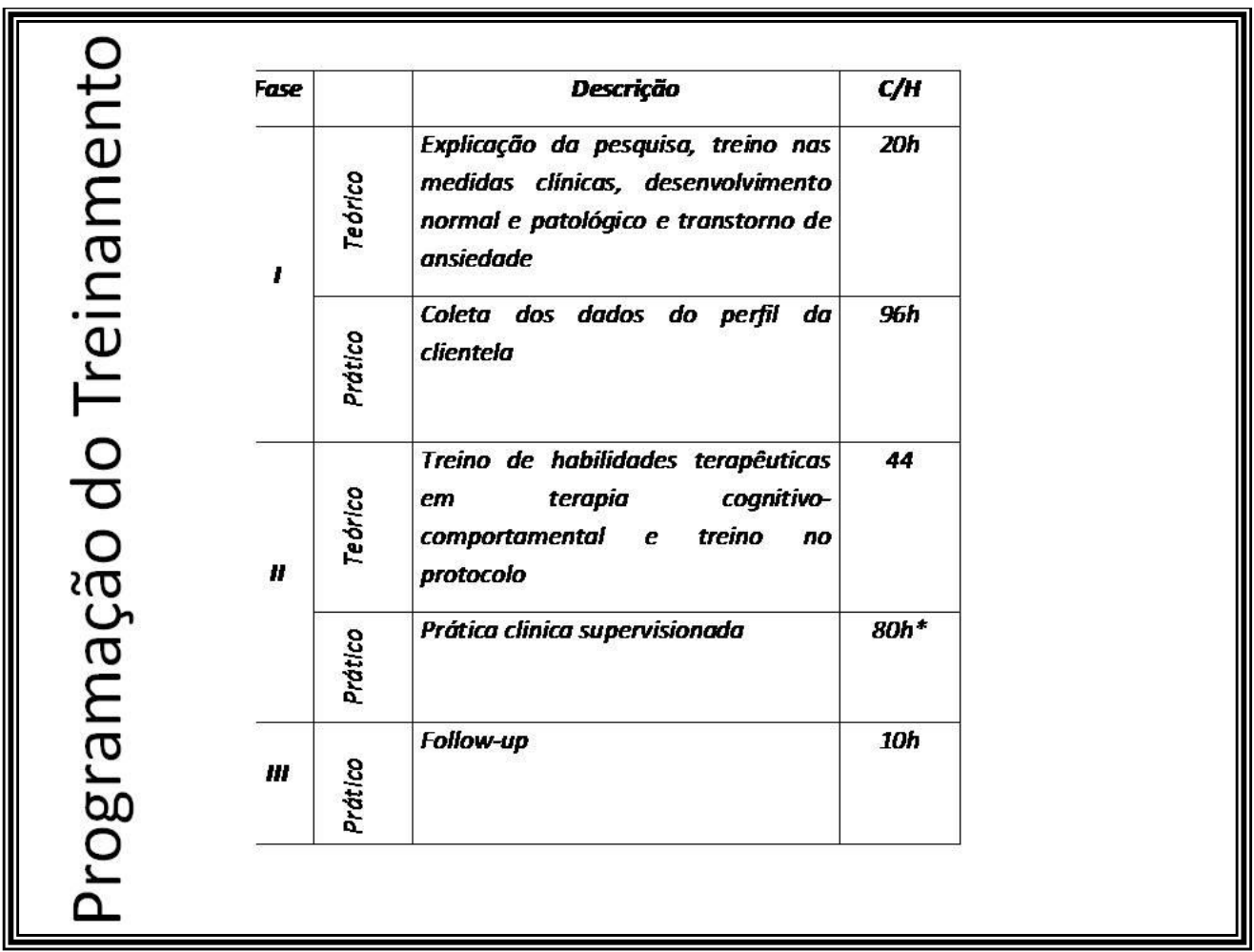


Anexo 21. Manual do treinamento: Etapa II

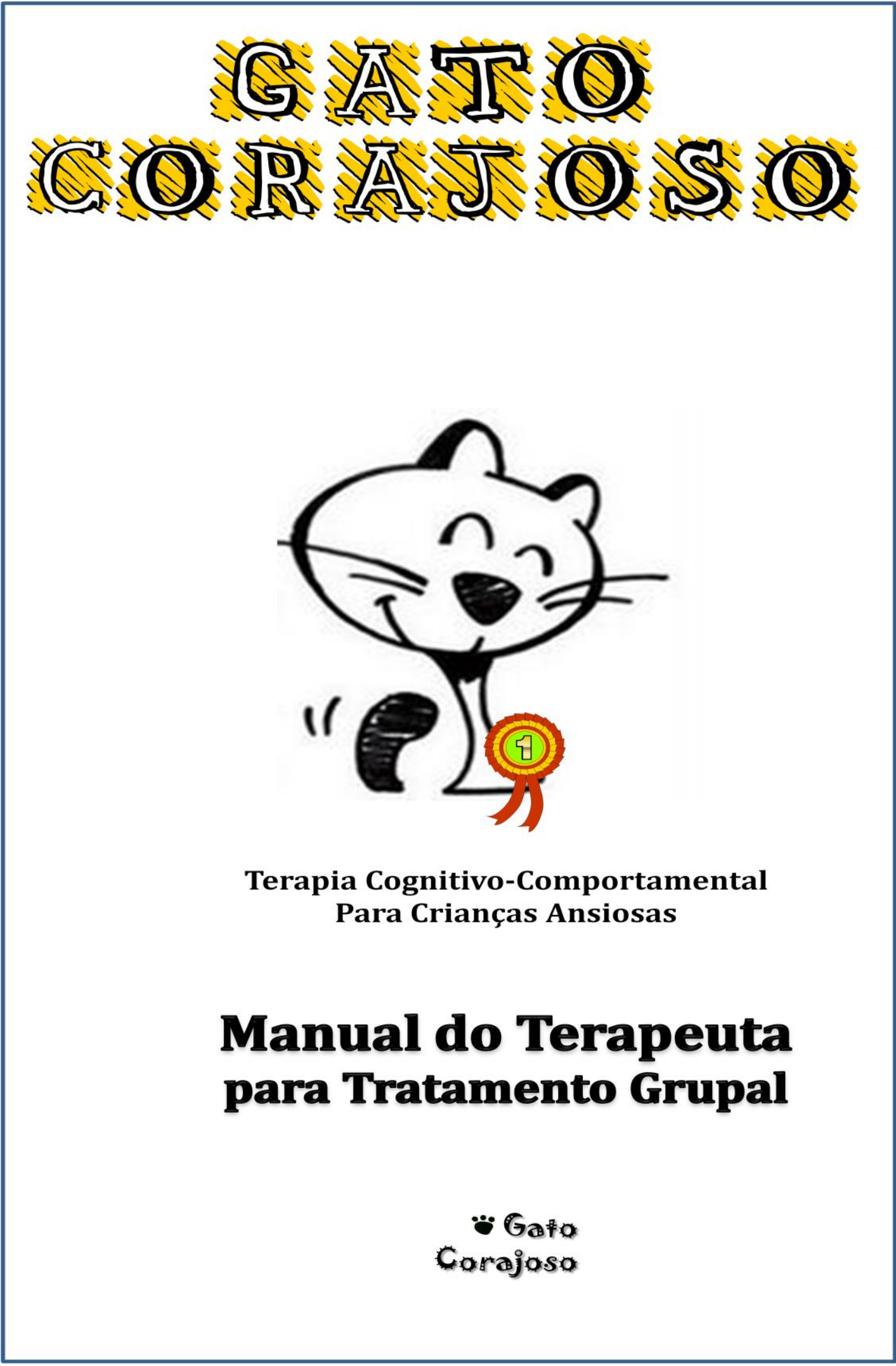


Manual do terapeuta

Adaptado de Therapy Manual de Ellen Flannery-Schroeder e Philip C. Kendal, P.h.D., ABPP, Child and Adolescent Anxiety Disorders Clinic Temple University, por Fabiana Gauy, 2009. APOIO: FAPESP.

Este material é de uso exclusivo para pesquisa de doutorado "Treino de terapeutas iniciantes para atendimento de crianças ansiosas de 9 a 13 anos".

Orientação: Professora Dra. Edwiges Silvares 


\section{INTRODUÇÃO}

O presente manual descreve em 10 sessões de terapia grupal para tratamento de transtornos de ansiedade em crianças e adolescentes.

O programa combina a abordagem cognitivo-comportamental ao integrar elementos da abordagem comportamental (e.g. exposição, relaxamento, e role-plays) com da cognitiva (e.g. reestruturação cognitiva, solução de problemas), com um formato de grupo homogêneo quanto a gênero e idade. Este tratamento grupal assemelha-se com o protocolo para atendimento individual para tratamento de jovens ansiosos descritos em Kendall, Kane, Howard e Siqueland (1989) e avaliado em pesquisa por Kane e Kendall (1989) e por Kendall (1994).

O motivo para usar o formato grupal se deve a três fatos. Primeiro, o uso do formato grupal para crianças ansiosas tem uma justificativa teórica, uma vez que essas crianças apresentam uma dificuldade social marcante, principalmente nos quadros de fobia social e de ansiedade generalizada. 0 tratamento grupal tem sido recomendado para crianças tímidas, socialmente retraídas e isoladas (Yalom, 1975; Toseland, \& Rivas, 1984) e para aquelas que apresentam dificuldade de relacionamento interpessoal (Northen, 1982). Além disso, o tratamento grupal oferece: oportunidades de iniciação e manutenção de relacionamentos, modelagem e modelação, reforço por pares, feedback positivo, aprendizagem indireta e reforço social. Segundo, a eficácia da abordagem grupal tem sido demonstrada como similar ou melhor do que o individual (ver Toseland \& Siporin, 1986, para revisão). Terceiro, há poucos tratamentos que podem disputar a efetividade do custo-benefício do tratamento grupal.

A meta principal do tratamento é oferecer às crianças habilidades necessárias para o enfrentamento bem sucedido de diversas situações provocadoras de ansiedade. $O$ tratamento consiste em ajudar as crianças a reconhecerem sinais gatilhos de ansiedade e a usar estas pistas para manejar a ansiedade mediante estratégias propostas pelo programa de tratamento.

Crianças são também encorajadas a identificar autoinstruções negativas e recebem instruções de como iniciar autoinstruções mais positivas e construtivas. E por fim, o uso de premiação e pontuação por ela mesma é enfatizado. Especificamente, o programa enfatiza enormemente os seguintes elementos de tratamento:

\section{Educação afetiva}

Reconhecimento das reações corporais devido a ansiedade

Identificação e modificação do autorrelato ansioso

Treino do relaxamento

Modelagem e modelação

Role-plays e técnicas de reforçamento contingente

Tarefas de casa (atividades "Como Estou Indo")

Treinamento de aproximação sequenciada de tarefas e de metas

Treinamento de exposição graduada e prática de novas habilidades adquiridas em situações eliciadoras de ansiedade.

Muitas estratégias de intervenções grupais são também enfatizadas, a fim de encorajar responsabilidades, solução de problemas e coesão entre os membros do grupo: 
Participação grupal em uma sequência de tarefas aprendidas pela interação entre os diferentes participantes de acordo com a boa vontade e habilidade social de cada um;

Sessões estruturadas encorajam a expressão de ansiedade em um ambiente tolerante e respeitoso; Uso de tarefas coesão grupal e jogos que fortaleça a relação entre os membros do grupo;

Tarefas de casa designadas para aumentar a coesão grupal (Tarefas "Amigo")

Consistente com o protocolo de atendimento individual (ver Kendall e cols., 1992), o programa de grupo é também dividido em dois segmentos: treino de habilidades específicas e prática das habilidades aprendidas. Além disso, o terapeuta encontra-se separadamente com os pais dos membros do grupo na quarta e na quinta sessão de grupo. Sessões individuais entre terapeuta e membros do grupo podem ser providenciadas para aquelas crianças com dificuldades para acompanhar o grupo ou para aquelas que faltaram alguma sessão.

$\mathrm{O}$ tratamento é dividido em duas partes. A primeira parte da intervenção, que ocorre nas cinco sessões iniciais, trabalha os componentes cognitivos/educativos do tratamento. Durante a intervenção, conceitos e habilidades são apresentados pouco a pouco, aumentando gradativamente a dificuldade. 0 papel do terapeuta é oferecer um modelo de enfrentamento, a partir de role-plays e tarefas específicas (Ollendick \& Cerny, 1981), dos vários conceitos introduzidos no grupo. Gradualmente, as crianças serão encorajadas a começar a participar nestes procedimentos, primeiramente junto com o terapeuta e depois sozinhas. Estratégias cognitivo-comportamentais são apresentadas com um plano de quatro passos para enfrentar a ansiedade. Para facilitar a lembrança dos passos o seguinte acróstico é usado:

Mostrando sentimentos de medo e ansiedade?

Esperando que coisas ruins aconteçam?

Demonstrando atitudes e ações.

Obba! Resultados e recompensas.

Como exposto pelo o acróstico, muitos conceitos importantes são apresentados sequencialmente para a criança durante o seguimento de treinamento do programa. Começando com a percepção de reações físicas diante dos sentimentos e desenvolvendo o reconhecimento de quais reações são específicas da ansiedade. As crianças são treinadas para usar estas reações físicas como pistas para ansiedade.

Em seguida, as crianças são encorajadas a se concentrar em suas autoinstruções e, depois, a fazer modificações em seus autorrelatos de forma apropriada. Isto é apresentado mediante uma sequência de história em quadrinhos com balões de pensamento em branco para as crianças completarem. A ênfase é dada devido à necessidade de criar um plano para o mais efetivo enfrentamento das experiências que causem a ansiedade.

O último conceito introduzido é a autopremiação e autorreforço, mesmo para sucessos parciais. Além disso, as tarefas COMO ESTOU INDO são passadas para criança como atividade de casa para reforçar as informações apresentadas na sessão. As tarefas "Amigo" são usadas para aumentar a coesão do grupo, assim como para aprimorar as habilidades sociais dos membros do grupo. As crianças usam o livro e o caderno de exercício para facilitar o aprendizado (Kendall, 1983).

A segunda parte do tratamento (seguimento prático) consiste em aplicar as recém adquiridas habilidades em uma variedade de exposições graduais a situações eliciadoras de ansiedade. Estas situações são adaptadas para os medos individuais das crianças. É provável que em cada grupo possa haver uma grande variedade de medos e preocupações nas crianças. $O$ terapeuta deve ser sensível as dificuldades 


\section{$\because$ Gafo \\ Corajoso}

individuais de cada criança, assim como, trabalhar em um nível mais global com o grupo. O seguimento prático começa com exposições dentro do grupo, progride para exposições envolvendo o grupo como um todo, para enfim expor individualmente os membros do grupo. A aplicação de estratégias de exposição ao vivo fornece experiências de sucesso que são incompatíveis com as expectativas prévias e oferece evidências (para criança, grupo e outros) de que a mudança está acontecendo.

Finalmente, a última sessão inclui a realização de um comercial filmado sobre o que foi aprendido em relação a como lidar com a ansiedade. O comercial é desenvolvido pelo grupo e promove cooperação, solução de problemas e coesão da equipe. Além disso, o comercial é útil para consolidar a informação aprendida durante o tratamento e reforçar o papel e a participação de cada criança dentro do grupo. Cada membro do grupo receberá uma cópia do comercial para levar para casa.

As seguintes descrições, sessão por sessão, detalham os vários aspectos do tratamento. Em cada caso, em seguida à declaração do objetivo geral da sessão e das metas e atividades específicas. Não pretendendo ser uma transcrição do tratamento, o manual foi projetado para servir como um modelo de orientação para aplicação de estratégias de tratamento.

\section{NOTAS QUE ACOMPANHAM O MANUAL}

Como lidar com as ausências na sessão de grupo? Se a criança faltou a uma sessão de grupo, a criança é agendada para uma sessão individual para cobrir o material perdido ou é solicitada a chegar na próxima sessão cerca de 20' a 30' mais cedo. Se a criança aparenta ter dificuldade de cumprir os horários com o grupo o formato deverá ser revisto. Além disso, se uma criança menos madura cognitivamente tiver dificuldade em processar a informação a uma taxa compatível com a do grupo, uma sessão individual de revisão é agendada.

Os grupos serão mistos quanto ao gênero? Devido a idade das crianças que são alvos do programa de tratamento (idade entre 9 a 13 anos) e a sensibilidade a revelação sobre medos e preocupações são recomendados grupos de um único gênero.

\section{Qual é o tamanho ideal do grupo?}

O tamanho do grupo deve variar entre três e cinco membros. Grupos maiores que cinco, quando possível, iriam requerer a presença de um coterapeuta. Entretanto, os grupos devem permanecer pequenos o suficiente para assegurar que um vínculo básico e sentimento de unidade do grupo sejam facilmente alcançados, pois estes são aspectos essenciais a estratégia de tratamento em grupo.

O que fazer se o grupo é composto por crianças com diferentes idades e habilidades? Encorajar as crianças mais velhas ou mais avançadas a "orientar" aqueles que necessitam ajuda adicional, estimulando e fortalecendo as próprias habilidades e a confiança nas mesmas. 
Objetivo geral: Explicar o tratamento para os pais, incentivar a cooperação dos pais ao tratamento e obter informações adicionais de cada criança, de forma que o terapeuta possa encaminhar melhor as necessidades das crianças.

Material: Contrato de Trabalho

\section{Atividades e Tarefas:}

Fornecer informação adicional sobre o tratamento: 0 terapeuta expõe o programa de tratamento e explica de forma geral onde a criança está no tratamento e quais os próximos passos. As questões dos pais são incentivadas e respondidas.

Dar aos pais uma oportunidade de discutir as suas preocupações com os filhos ou sobre outros fatores que poderiam afetar as dificuldades das crianças e a capacidade de ser beneficiar do tratamento: com questões semiestruturadas, o terapeuta convida os pais a fornecerem informação histórica e/ou atual que eles sentem que será útil para o terapeuta compreender a criança.

Aprender mais sobre as situações nas quais a criança se torna ansiosa e suas reações físicas a preocupações e ansiedade: usando o que foi aprendido nas sessões anteriores o terapeuta discorre de forma geral sobre as suas impressões das situações que são problemáticas para a criança e sobre as típicas respostas somáticas e cognitivas das crianças frente a ansiedade. $\mathrm{O}$ terapeuta convida os pais a compartilhar suas impressões.

Fornecer maneiras específicas para os pais se envolverem no programa: os pais são orientados a contatar o terapeuta se acreditam que tem informações adicionais que pensem ser úteis ou se eles alguma duvida. Dependendo da idade da criança e da qualidade do apoio paterno, o terapeuta pode pedir a ajuda dos pais em outras áreas especificas relacionada a criança no curso do tratamento. Por exemplo, os pais podem ser chamados a ajudar com uma tarefa de casa durante a parte prática do tratamento. 


\section{Sessão 1}

Objetivo geral: Explicitar a informação básica a respeito do programa e construir vínculo entre o grupo e o terapeuta, assim como entre os membros do grupo.

Material:

01 Jogo de Caixa Mágica de Perguntas para crianças

01 Jogo Subida Maluca

Livro “O frio pode ser quente?"

Cópia do Contrato de Trabalho para crianças e pais

Caderno de atividades

Fantoche de Gato (opcional)

Prancheta para cada um (opcional)

Pasta para cada um

Lápis e borracha

Prêmios de participação (lápis e pasta)

Lista de Verificação de Competência para Terapeutas Cognitivo-Comportamentais

Quadro da agenda do dia com os quadradinhos de Conhecer cada um, Contrato de Trabalho e Tarefa Eu Consigo.

\section{Atividades e Tarefas:}

Monte a Agenda do dia passando os cartões para as crianças: Conhecer cada um, Contrato de Trabalho e Tarefa Eu Consigo.

Atividade 1: Abertura do grupo 15 a $20 \mathrm{~min}$

Para construir o vínculo entre os membros do grupo e entre grupo e terapeuta: é essencial que o terapeuta aja com tranquilidade, pois frequentemente crianças ansiosas são evitativas, receosas e cautelosas e tipicamente não familiarizadas com questões que envolvam os próprios pensamentos ou autoinstruções.

$O$ vínculo e a coesão entre os membros do grupo e o terapeuta são críticos para o sucesso da terapia, e tempo suficiente deve ser dedicado ao estabelecimento de relações de confiança entre os membros do grupo e o terapeuta.

Recebam as crianças e as convidem para se sentarem no chão. Tentem fazer o aquecimento perguntando sobre se tiveram alguma dificuldade para chegar, sobre o tempo, etc.

Vá com calma e não se apressem para falar sobre o que as deixam ansiosas ou sobre o motivo que do tratamento. Tenham como objetivo maior que seja divertida a sessão!

Inicie se apresentado e depois solicite uma breve apresentação dos membros do grupo. Exemplo: "Bom dia!!! Hoje nós iremos conversar com vocês sobre um grupo de atendimento psicológico para 9 a 13 anos. Alguns de vocês continuarão neste grupo e outros serão atendidas em outro dia. Nós ficaremos juntos hoje das $10 \mathrm{~h}$ ao $12 \mathrm{~h}$. Durante este período nós queremos nos apresentar e conhecer um pouco de vocês. Depois iremos falar sobre como este grupo de atendimento irá funcionar. Passe no círculo de crianças os quadradinhos para montar a o Quadro da Agenda do Dia.

Caso as crianças estejam tensas os terapeutas podem fazer um tour rápido apresentando no serviço. Mostre onde podem beber água, onde estão os pais, onde é o banheiro. $O$ terapeuta pode usar a brincadeira "Siga o mestre" enquanto passeia pelo serviço.Deve-se incentivar as crianças a fazerem 
perguntas ou pode durante a explicação fazer perguntas para as crianças, proporcionando uma atmosfera na qual as crianças sentem-se livres para exporem suas dúvidas, preocupações e problemas. Este clima de abertura deve ser cultivado ao longo do tratamento.

Atividade 2: Apresentação do participantes 40 a $45 \mathrm{~min}$

Em seguida explique a meta da sessão: informar sobre o atendimento e a apresentação dos participantes: Podemos começar a nos conhecermos? (os terapeutas se apresentam falando o nome, idade, estado civil, onde estuda e onde mora). Agora nós faremos uma brincadeira para sabermos um pouco de vocês.

Inicialmente brinquem de telefone sem fio apenas com o nome. O terapeuta, coterapeuta e observadores devem ficar entre as crianças e mudar de propósito o nome delas para a brincadeira ficar mais divertida. Quem está no final fala o nome que chegou ao ouvido dele e a criança corrige caso esteja errado. Passa para o próximo e assim por diante.

Depois peguem o jogo caixa mágica, tire as cartas da caixa e deixe-as viradas para baixo. Convide as crianças para pegarem uma carta e lerem para o grupo, e quem quiser responde a pergunta, até terminar todas as 11 cartas separadas. Encorajem a participação de todos os membros do grupo.

Durante este período o terapeuta deverá ressaltar as diferenças e as semelhanças entre eles e enfatizar para as crianças que o ponto de vista delas é muito importante. Peça as elas para trocarem algumas informações sobre elas mesmas: histórias ou atividades divertidas, viagem de família, eventos divertidos sobre a escola. Para facilitar isso o terapeuta pode destacar as similaridades entre as histórias das crianças em um esforço para construir a coesão do grupo e ajudar as crianças a se sentirem semelhantes aos outros membros.. Variação: Pode-se usar as figuras com imagens ambíguas para conversar sobre isso). Novamente, recompense a participação, encoraje a verbalização e faça, novamente, questões fáceis de responder

O terapeuta deve acentuar as similaridades entre os membros do grupo mediante do uso do jogo da semelhança e das diferenças e da leitura do livro "O frio pode ser quente?".

Ler o livro: “O frio pode ser quente?". O terapeuta deve conversar que algumas vezes as pessoas vêem coisas de forma diferente (forneça exemplos concretos como "uma parede de tijolos que é muito grande para uma pessoa baixa, pode ser muito baixa para uma pessoa alta", "a comida que é a favorita de uma pessoa, pode causar enjôo em outra"). Demonstre o potencial para diferentes pontos de vista discutindo as comidas mais e menos preferidas. O terapeuta deve mostrar tolerância e respeito pelas diferenças individuais, pois isso dará o clima de abertura/receptividade às opiniões e experiências dos outros. Enfatize que nós estamos interessados no que você vê, sente e pensa sobre várias situações. O ponto de vista de cada criança é valorizado.

Introduza a discussão do contrato: Vocês se lembram do que falamos no início de nosso encontro? Falamos que iríamos nos apresentar e depois que iríamos conversar um pouco sobre como iremos trabalhar juntos. Vocês acham que já nos conhecemos um pouco? Podemos passar para a próxima etapa?

Atividade 3: Explicação do grupo 5 a $10 \mathrm{~min}$

"O grupo terá de 10 encontros e nós trabalharemos com um time. Eu (terapeuta) serei como um treinador de um time e vocês os jogadores. No início de cada encontro vocês saberão o que iremos trabalhar em cada dia. Iremos jogar, brincar e conversar sobre emoções, o que pensamos e o que fazemos. Ao final de cada encontro passaremos um desafio para vocês fazerem em casa. Estes desafios ajudarão. Hoje sabemos que 
quem faz estas atividades em casa se sente melhor mais rápido e ficam bem por mais tempo. Quem fizer estas atividades ganhará 2 pontos e a cada 3 encontros vocês poderão trocar os pontos por prêmios que iremos combinar.

Além dos nossos encontros, conversaremos com os pais em grupo, como hoje, e individualmente com os pais e com vocês quando isso for necessário. Para terminar, é importante vocês não faltarem. Teremos apenas 10 encontros! Caso isso aconteça apesar de tentarem evitar entrem em contato conosco para agendarmos um horário extra. Tentaremos fazer com que os nossos encontros sejam bem divertidos!! Alguma dúvida?".

Atividade 4: Atividade Lúdica e contrato $45 \mathrm{~min}$

\section{JOGO: Escadas e escorredores}

Peguem o jogo Escadas e Escorregadores e pergunte se alguma criança conhece o jogo. Se sim, peça para ela explicar as regras do jogo e corrija se for o caso. Caso ninguém conheça explique as regras do jogo. Joguem o dado para decidirem quem começa.

Após terminarem o jogo, vire o tabuleiro e pergunte para as crianças o que tinha mais escadas ou escorregadores. Trabalhe as distorções, caso haja. Faça uma associação das escadas com algo que os ajudam e dos escorregadores com que os atrapalham. Peça para abrirem de novo o caderno de exercício e solicite que registrem uma escada e um escorregador para eles iniciarem a lista. A ser continuada em casa. Comentem que o atendimento tem como objetivo diminuir os escorregadores e aumentar as escadas.

Peça para eles escolherem um jogo para próxima semana. Revise o que foi trabalho no dia e as informações trocadas por cada criança, esclareça que cada um se conhecer mais é importante para o terapeuta. 0 grupo pode jogar o jogo "Eu me lembro" para preparar-se para finalizar a sessão.

Jogo Eu me Lembro: As crianças tentam lembrar sobre o que cada um falou na sessão e o que fizeram (e.g., nome, preferências, etc).

Seguindo o jogo "Eu me lembro", vem uma discussão sobre sigilo e as exceções a ele. A importância de não revelar informações dos membros do grupo ao outros deve ser enfatizada. Neste momento o terapeuta circula o Contrato para ser lido juntamente com as crianças e explicado para elas. Caso todos entendam e concordem, é solicitado para que assinem ao final da folha. Um contrato fica com a criança e outro com o terapeuta. Apesar deste acordo fazer parte da entrevista inicial é importante enfatizar de novo para que a criança entenda a sua importância.

Comece a fazer uma lista de "Amigos", com o nome e telefone dos membros do grupo para ser distribuído para todos os membros. Peça para que o grupo escolha um jogo que irão jogar na próxima sessão.

Atividade 5: Tarefa de casa $10 \mathrm{~min}$

Explique que as tarefas de casa chamarão "Eu consigo". As crianças são estimuladas a completar as tarefas "Eu consigo" em casa, mais é esclarecido que não haverá penalidades nos casos de esquecimento.

Além da tarefa Escadas e Escorregador, há outra atividade "Eu consigo" do caderno exercício deverão escrever um breve exemplo de uma ocasião em que sentirão realmente felizes, não tristes ou preocupadas. Será solicitada às crianças que elas tentem pensar e concentrar no que deixou elas confortáveis e o que elas sentiram e pensaram na ocasião. Para ajudar as crianças a entender a tarefa o terapeuta oferece um 
exemplo de uma situação em que ele se sentiu realmente bem e descreve a ocasião em termos do que ele sentiu e pensou. Então um membro do grupo pode ser selecionado para dar outro exemplo.

As crianças serão informadas que quer fizer o desafio ganhará 2 pontos por ter completado a tarefa "Eu consigo". Os pontos ganhos podem ser usados para trocar por prêmio a cada 3 encontros, e a criança poderá selecionar as recompensas que deseja ganhar. Opções para recompensas para as duas primeiras oportunidades (depois das sessões 3 e 6) são pequenos brinquedos, passatempo, livros ou jogos.

Atenção: O terapeuta e participantes podem fazer uma lista de recompensa na qual a criança pode escolher o prêmio. As recompensas disponíveis após a sessão 9 são premiações sociais, como festas e passeios em grupo. No caso das crianças possuírem totais diferentes de pontos, serão dadas oportunidades para que as crianças com menos pontos possam fazer mais pontos. Estas oportunidades podem incluir participação verbal, atividades de liderança, ou outra atividade adequada ao nível da criança em particular. O terapeuta assegura que as crianças recebam as recompensas ao mesmo tempo, evitando competição e sentimento ruins.

O terapeuta deve pedir para que cada criança faça um plano que o ajude a fazer a tarefa e a lembrar de trazer o caderno de exercício para próxima sessão. Cada membro do grupo recebe uma pequena recompensa (e.g., lápis colorido) pela participação na primeira sessão.

Atividade 6: Formulário de Feedback $5 \mathrm{~min}$

Entregar para cada um preencher o formulário de Feedback do encontro do dia.

Fiquem atentos se alguém teve dificuldade para ler ou escrever e na interação entre os participantes.

\section{Sessão 2}

Objetivo geral: Fortalecer o vínculo. Ajudar as crianças a identificarem os diferentes tipos de sentimentos e distinguirem os sentimentos de ansiedade e preocupação dos outros sentimentos. Encorajar as crianças a identificarem as pistas fisiológicas (e.g., expressões faciais, postura corporal) para identificarem as emoções. (Passo 1: Mostrando-se ansioso e preocupado?)

\section{Material:}

02 Pontos para cada um que fizer a tarefa (Eu Consigo e Escadas e Escorregadores)

01 Lousa para escrever (ou flip chart) com giz ou pincel atômico

Pincel para quadro branco

Lápis e borracha para cada um

Jogo escolhido na sessão anterior

Caderno de atividades

Cartolina

Revistas

Tesouras sem ponta

01 Pôster Gato Corajoso Passo\#1

Lápis de cor

01 Ampulheta

Banco de pontos com os nomes de cada um 
Painel Tarefa Amigo

Tarefa "Amigo"

Lista de Verificação de Competência para Terapeutas Cognitivo-Comportamentais

Painel com Acróstico MEDO (Passo \#1)

Quadro da agenda do dia com os quadradinhos de Revisão da tarefa Eu Consigo, Reconhecer Respostas

Fisiológicas, Identificar Emoções, Tarefa Eu Consigo e Tarefa Amigo.

\section{Atividades e Tarefas:}

Monte a Agenda do dia passando os cartões para as crianças: Revisão da tarefa Eu Consigo, Reconhecer Respostas Fisiológicas, Identificar Emoções, Tarefa Eu Consigo e Tarefa Amigo.

Atividade 1: Revisão da tarefa .15 a $20 \mathrm{~min}$

Breve revisão dos nomes dos componentes: "Jogo Eu me Lembro" para aquecer o grupo. O terapeuta deve facilitar e encorajar interações verbais entre os membros do grupo.

Recolha a tarefa Escadas e Escorregadores e entregue a Caça-Palavra e o Ligue-Ligue para crianças para introduzir o tema da sessão. Enquanto o terapeuta revisa a tarefa "Eu Consigo" circulando pela sala para ver as resposta de cada criança, o coterapeuta ajuda as crianças com o Caça-Palavra e o Ligue-Ilgue.

Na revisão da tarefa o terapeuta deve discutir o sentimento associado a uma situação agradável/prazerosa. $\mathrm{O}$ terapeuta questiona como a criança se sentiu o que ela pensou e como ela agiu. Após a revisão da tarefa dê os pontos e marque no banco de pontos juntamente com a criança. Caso alguma não tenha feito, explicar porque a tarefa é importante e incentivar que a criança faça a tarefa.

Na sequência explique o que será trabalhado na sessão: (a) conversar sobre as emoções e (b) descobrir as pistas fisiológicas (e.g., expressões faciais, postura corporal) das emoções, passando no círculo de crianças os quadradinhos para montar a o Quadro da Agenda do Dia.

Atividade 2: Atividade Lúdica

$.45 \min$

Jogar a atividade escolhida. Peça para as crianças ficarem atentas ao que sentem durante o jogo e à expressão de emoção dos demais colegas (quando perde, quando ganha, quando espera a vez, etc). (Enquanto o grupo joga o coterapeuta separa os cartões de emoções e respostas fisiológicas).

\section{Atividade 3: Sentimentos e Respostas Fisiológicas...................................45 min}

Mostre o cartaz do Gato Corajoso \#1 e discuta com as crianças as diferentes intensidades de tensão e que emoções estariam associadas a cada figura. Em seguida, liste com o grupo as diferentes emoções que eles conhecem (e.g., surpresa, tristeza, raiva) e escreva no quadro ou em um cartaz, ou peça que cada criança vá até o quadro e anote uma ou mais emoção. O terapeuta deve encorajar as crianças a se lembrarem o máximo de emoções que conseguirem. Veja se todos conhecem as emoções listadas. Depois faça uma nova lista do que elas sentem no corpo quando sentem aquelas emoções (e.g., dor de barriga, coração apertado, taquicardia).

Introduza a ideia de dramatização para as crianças solicitando que façam dois grupos. Cada grupo vai decidir quem irá fazer a dramatização enquanto os demais tentam adivinhar. Aquele que irá fazer a 


\section{Gafo \\ Corajoso}

dramatização pega um dos cartões com emoções. Use a ampulheta para marcar o tempo. Caso o grupo não consiga adivinhar o outro grupo pode tentar. Passe a vez para o próximo grupo.

O terapeuta deve estar alerta para algumas dificuldades que as crianças possam ter para diferenciarem e reconhecer algumas emoções. Se for preciso gaste um tempo maior até que tenha certeza de que as crianças entenderam o conceito. Neste caso, elas podem tentar apenas adivinhar ou dar dicas (e.g., seu time ganhou o campeonato $\rightarrow$ dica para feliz, ou o seu irmão comeu o seu bombom sem pedir $\rightarrow$ dica para raiva). Converse sobre as pistas que cada um teve para adivinhar quando o sentimento dramatizado era ansiedade, medo ou preocupação. E o que cada um sente no corpo quando tem estas emoções. A partir desta discussão introduza o primeiro passo do Acróstico MEDO (M ostrando-se ansioso e preocupado?). Para finalizar mostre o cartaz e cole as letras para completar a frase do acróstico. Atenção: Não é incomum as crianças ansiosas terem dificuldades para diferenciarem ansiedade de raiva e preocupação de depressão. Ademais algumas crianças podem ficar muito ansiosas e não conseguirem dramatizar, não insista!

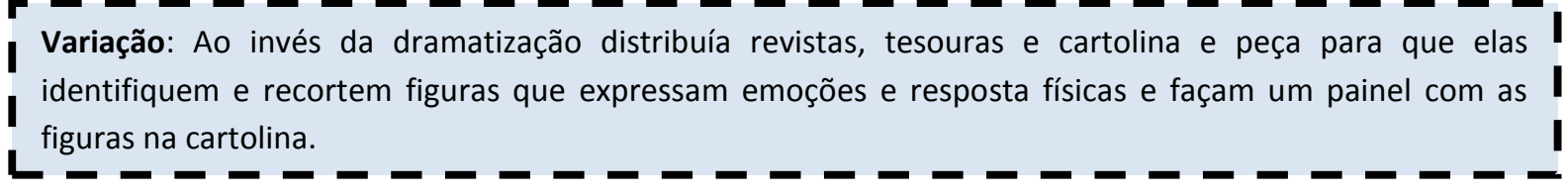

Em seguida peça para fazerem duplas para demonstrarem no desenho do corpo onde e como eles sentem no corpo que estão ansiosos.

Jogo Eu me Lembro: As crianças tentam lembrar sobre o que cada um aprendeu e achou mais importante na sessão.

Atividade 4: Tarefa de casa $10 \mathrm{~min}$

Discuta que anotar as experiências que provoquem e não provoque ansiedade e preocupação ajuda tanto o terapeuta como a criança a perceber as diferença de quando está feliz e relaxada de quando está tornandose ansiosa e preocupada.

Peça que as crianças para próxima semana descrevam duas experiências: o dia que ficaram mais ansiosas na semana e o dia que ficaram relaxadas. E de tentarem adivinhar a emoção de alguém escolhido.

Atenção: $O$ terapeuta deverá enfatizar que a criança não precisará compartilhar a experiência com o grupo caso não queira, mas que será encorajada para comentar as experiências com o grupo ao longo do atendimento.

Pratique na sessão: Inicialmente o terapeuta imagina-se em uma situação que provoque ansiedade nele (a) e então a descreve na forma como deve ser descrita no caderno de exercício. Depois faz o mesmo ao descrever uma situação em que estava feliz e relaxado. O terapeuta, então, pede um voluntário do grupo para fazer o mesmo. Enfatize como a criança sabe que estava ansiosa (pistas) e associe os pensamentos e as emoções.

Tarefa "Amigo": Para facilitar a coesão do grupo, cada membro é associado a um amigo. Caso haja um número ímpar de membros o terapeuta pode ser o amigo de um dos membros. As crianças são instruídas a falar com seus amigos uma vez durante a semana para buscarem a informação solicitada pelo terapeuta. As crianças podem ser instruídas a descobrirem se os seus amigos têm animais de estimação, irmãs ou irmãos, quais são os desenhos favoritos, etc. Estas tarefas no inicio da tarefa consistem de questões fechadas, 
provocadoras de baixa ansiedade, isto é, aquelas que requerem um sim ou um não, ou uma simples palavra como resposta. Ao longo do tratamento estas tarefas vão se tornando gradualmente mais difíceis, exigindo mais argumentação e respostas mais elaboradas e completas (e.g., que coisas deixam você ansioso?). São inicialmente facilitadas mediante o uso de roteiros que conduzem a criança na atividade. Os roteiros podem ser particularmente úteis para crianças evitativas ou socialmente ansiosas. Se um membro do grupo não completa a tarefa durante a semana, nem uma penalidade é sofrida. O membro é encorajado a completar a tarefa (ou outra semelhante) durante a sessão. Os membros do grupo acumulam pontos por completarem as tarefas os quais são acumulados e podem ser trocados por recompensas sociais. Comente que quem fizer a tarefa ganhará um prêmio extra (estrelas) e que será registrado no Painel Tarefa Amigo. Peça para eles escolherem o imã de GATO para marcar no painel

Atividade 5: Formulário de Feedback. $.5 \mathrm{~min}$

Entregar para cada um preencher o formulário de Feedback do encontro do dia. Para o coterapeuta e o observador: avaliar o terapeuta do dia na Escala Cognitiva (Young \& Beck, 1988)

\section{Preparação para sessões com os pais:}

As crianças são lembradas que um dos terapeutas irá encontrar novamente os pais na próxima semana, e que isto não irá interferir no tempo do grupo. O terapeuta reafirma as crianças que não passará aos pais informações pessoais que foram discutidas no grupo, uma vez que ele estará interessado em conversar com ele sobre o que eles estão achando do tratamento e explicar o acróstico do MEDO. As crianças serão informadas que o encontro com os pais tem como objetivo descrever para eles as habilidades que estão sendo ensinadas no grupo e ver se eles têm alguma dúvida ou pergunta sobre o tratamento

\section{Sessão 3}

Objetivos gerais: Revisar diferença entre ansiedade e preocupação das demais emoções. Ensinar a criança sobre as respostas somáticas da ansiedade e auxiliá-la a identificar o que cada um sente (respostas somáticas) quando está ansiosa.

Introduzir a função de pensamentos pessoais e seu impacto nas respostas em situações de ansiedade, ajudar cada criança a começar a reconhecer as autoinstruções (expectativas, questões automáticas e atribuições) em situações de ansiedade e ajudar cada criança a começar a desenvolver e usar autoinstruções que gerem menos ansiedade. (Passo 2 do acróstico - Esperando que coisas ruins aconteçam?)

\section{Material:}

02 Pontos para a tarefa EU CONSIGO para cada um que fizer

Quadro para escrever (ou flip chart)

Pincel atômico para quadro branco

Lápis e borracha para cada um

Caderno de atividades

Termômetro do MEDO

20 Cartões com Balões de pensamentos

Pôster MEDO: com o Passo \# 1 e 2

01 Roteiro para Tarefa Amigo (Roteiro 2) para cada um

Montar o Banco de Pontos com o nome das crianças e os pontos já alcançados 
Painel Tarefa Amigo e imãs

Prêmios para trocar

Lista de Verificação de Competência para Terapeutas Cognitivo-Comportamentais

Quadro da agenda do dia com os quadradinhos de Revisão da tarefa Eu Consigo e da Tarefa Amigo, Identificando Respostas Fisiológicas, Diálogo Interno, Tarefa Eu Consigo e Tarefa Amigo.

Atividades e Tarefas:

Monte a Agenda do dia passando os cartões para as crianças: Revisão da tarefa Eu Consigo e da Tarefa Amigo, Identificando Respostas Fisiológicas, Diálogo Interno, Tarefa Eu Consigo e Tarefa Amigo.

Atividade 1: Revisão da tarefa .15 a $20 \mathrm{~min}$

O terapeuta revisa a tarefa da semana anterior individualmente, enquanto o restante do grupo completa a Lista do Medo. Deixe as caixas de lápis de cor acessível. Na revisão da tarefa Eu Consigo encoraje as crianças para identificarem as diferenças entre a situação em que estavam relaxados daquela que estavam ansiosos (emoção, respostas fisiológicas e pensamentos). Comentem sobre os diferentes graus de ansiedade provocados por uma situação (Mostre o Termômetro do Medo). Estimule as crianças a falarem e identificarem as sensações semelhantes e diferentes entre elas. Distribua os pontos para aqueles que fizeram a tarefa. Registre os pontos do dia no Banco de pontos.

Revisão da tarefa "Amigo": avalie os sucessos e falhas na execução da tarefa. Estimule a discussão das respostas para a questão proposta. Novamente, o terapeuta deve apontar semelhanças entre os membros e modelar o respeito pelas diferenças. Recompense a conclusão das tarefas e ande duas casas no Mapa do Tesouro.

Revise o Passo\#1 (Mostrando-se ansioso e preocupado?) e insira o tema de hoje: identificação dos medos e diálogo interno (Passo \#2), passando os quadradinhos da agenda para cada criança e depois montando o quadro da Agenda do Dia

Atividade 2: Reforço do conteúdo da sessão anterior $.25 \mathrm{~min}$

Utilize as cartas do Jogo Tô Por Uma para revisar a sessão anterior. As regras do jogo são similares ao do CANCAN (Ver no Anexo as regras). Após o jogo peça para as crianças agruparem as cartas com respostas emocionais e fisiológicas e associá-las a pensamentos. Por exemplo: Ninguém gosta de mim (pensamento) $\rightarrow$ Tristeza $\rightarrow$ Dor de cabeça.

Atividade 3: Início da hierarquia da ansiedade

$.50 \mathrm{~min}$

O terapeuta deve compartilhar com as crianças as situações em que ele fica ansioso, o que sentem e pensam (servindo de modelo de enfrentamento). Peça as crianças para identificarem as diferentes respostas somáticas que experimentaram quando estavam com ansiedade. Para facilitar a revelação solicite que as crianças façam duplas e que perguntem um ao outro sobre as respostas somáticas que sentem diante das situações ansiogênicas. Cada membro do grupo recebe uma prancheta com o Formulário 2 para anotar. Peça para que eles escolham duas situações das que foram registradas e peça para que utilizem o Termômetro do MEDO para avaliarem o quanto cada situação leva a ansiedade de 0 a 5 . Entregue para cada um o termômetro do MEDO. Esta situação favorece que cada membro do grupo compreenda mais sobre o que sente no corpo quando está ansioso e a perceberem que os outros também sentem algo similar. Relembre o Passo 1 do acróstico MEDO. 
Pratique usar respostas somáticas como pistas do aumento da ansiedade: discuta com o grupo o fato de que as respostas somáticas deles podem ser sinais úteis de que eles estão ficando ansiosos, e que saber que estão ansiosos pode ajudá-los a usar as habilidades de enfrentamento que eles irão aprender nas sessões seguintes. 0 terapeuta discute com o grupo que notar estas respostas físicas nos outros pode levar a compreensão de que todas as pessoas ficam nervosas. Está percepção ajuda a aliviar as preocupações daquelas crianças que acreditam que são as únicas que ficam nervosas.

Comece a discutir que crianças diferentes têm diferentes tipos de preocupações e medos, apesar de que todos se sentem preocupados ou ansiosos de vez me quando. Em seguida, é feito uma atividade na qual cada criança revela seus medos em "balões" anônimos. Coloque os cartões balões no meio da roda para que eles possam escrever quantos quiserem. Depois leia os balões em voz alta pelo terapeuta. 0 terapeuta deve estar atento a necessidade de aceitar cada conjunto particular de preocupação de uma criança, desta forma modelando a aceitação, respeito e tolerância dos membros do grupo frente aos diferentes tipos de medo. O terapeuta sugere que as crianças podem se ajudar, uma vez que uma atividade/situação em que uma criança poderia evitar por medo (e.g., andar de elevador), a outra criança pode se sentir confortável. Isto prepara para o estágio da parte prática do tratamento, no qual as crianças serão incentivadas a orientar as outras em áreas em que são especialmente fortes. Eles também são incentivados a usarem semelhanças entre os membros para facilitar o sentimento de adequado e aceito, bem como aumentar a união do grupo.

O coterapeuta compila uma lista de todos os medos revelados (e outros originados da experiência do terapeuta com outras crianças ansiosas), e distribui uma cópia da lista na sessão 4, de tal forma que cada criança possa iniciar a construção de sua própria lista de hierarquia de situações de ansiedade. Esta lista é recolhida e atualizada pelo terapeuta quando necessário. Para facilitar a seleção para exposição ao vivo que ocorrerá na parte pratica do tratamento. Se as crianças tem medo em comum as exposições irão incluir o enfrentamento conjunto do medo (e.g., medo de separação podem ser manejado pelo grupo com a experiência de viajar para um lugar desconhecido com poucas coordenadas).

Desenvolver a coesão do grupo: Para potencializar os efeitos de união do grupo na revelação de medos, o terapeuta conduz o grupo em uma atividade de construção de coesão. Por exemplo: o grupo brinca com um jogo no qual o objetivo não pode ser alcançado sem a cooperação e participação de todos os membros do grupo, ou o grupo pode agendar uma festa ou viagem juntos para um local combinado.

Atividade 4:Avaliando diálogos internos $.30 \mathrm{~min}$

Nesta semana vamos conversa sobre tipos de pensamentos que a pessoas têm em diferentes situações. Por exemplo, se eu ganhar um ratinho numa rifa, provavelmente pensarei "Estou tão animado que mal posso esperar para brincar com isso". Estes pensamentos estão "conversando comigo", portanto, algumas vezes, eu os chamo de "diálogo interno".

Cartoons com balões de pensamento vazios são mostrados para o grupo. Junto com o terapeuta, o grupo dá exemplos de possíveis pensamentos para diferentes situações dos cartoon. Eles devem mostrar cenas simples onde os pensamentos dos personagens sejam óbvios, e devem incluir alguns diferentes tipos de sentimentos. Os exemplos devem incluir uma criança abrindo um presente de aniversário ou uma criança que derrubou o sorvete. 
O terapeuta então apresenta uma situação que não é estressante, mas ambígua, ou seja, os pensamentos associados com a experiência podem variar de pensamentos de enfrentamento a pensamentos ansiosos, e o terapeuta trabalha para ilustrar que dependendo de qual pensamento a pessoa tem, seu comportamento vai variar. Balões de pensamento e diferentes cartoons são utilizados. O grupo é estimulado a desenvolver dois conjuntos de possíveis pensamentos para cada balão de pensamento e discutir a mudança no comportamento por causa dos diferentes pensamentos. O terapeuta repete esta sequência usando situações cada vez mais geradoras de ansiedade. O terapeuta deve concentrar o foco em autoinstruções de ansiedade, não de raiva ou depressão, e deve esclarecer a situação se as crianças começarem a confundir esses pensamentos. Apresente o segundo passo do acróstico Esperando que o pior aconteça?

Retome as situações de ansiedade ou a lista de medo e tente junto com as crianças a identificar os possíveis pensamentos associados a estas situações revisando o tema da sessão.

Atividade 5: Discussão dos Prêmios e Pontos

$10 \mathrm{~min}$

Apresente os Prêmios e os pontos que cada um valerá para troca (e.g., bombom 3 pontos, caneta colorida 6 pontos, etc). Peça para que eles preencham no caderno a folha de Prêmios de acordo com o que for discutido e decidido pelo grupo. Negocie para que eles pensem que na próxima será a troca dos pontos por prêmios. Incentive que a criança não troque todos os pontos de uma vez, e que guarde alguns pelo menos para a próxima sessão para que consiga trocar por um prêmio melhor.

Jogo Eu me Lembro: As crianças tentam lembrar sobre o que cada um aprendeu e achou mais importante na sessão.

Atividade 6: Tarefa de casa

$15 \mathrm{~min}$

É pedido às crianças que escrevam, ou registrem de alguma forma, as duas experiências de maior ansiedade que tiverem na semana seguinte. Elas são instruídas a prestar atenção especialmente nos pensamentos, assim como nas respostas somáticas durante cada experiência.

Tarefa "Amigo": Cada membro do grupo recebe o novo amigo para entrar em contato ao longo da semana. Cada membro terá então dois amigos - para ligar e outros dois que ligação para ele. A questão a ser perguntada deve ter resposta fechada (i.e., sim ou não). Peça para elas anotarem o nome das crianças e a pergunta a ser realizada. Ela pode fazer uma única pergunta para as duas crianças ou uma pergunta diferente para cada uma. As crianças são solicitadas a registrar a resposta dos amigos para apresentar na sessão seguinte. Estas tarefas são elaboradas para aumentar a habilidade social da criança, reduzir a ansiedade social por meio da repetição e facilitar a união do grupo pela disseminação de informação e fatos sobre cada um dos participantes. Como deve ser ressaltado durante o tratamento o terapeuta nota semelhanças entre os membros do grupo.

Atividade 7: Formulário de Feedback. $.5 \min$

Entregar para cada um preencher o formulário de Feedback do encontro do dia. Para o coterapeuta e o observador: avaliar o terapeuta do dia na Escala Cognitiva (Young \& Beck, 1988)

Preparação para sessão: O terapeuta deve preparar o CD de relaxamento para cada membro do grupo. 


\section{Sessão 2 para Pais}

\section{ENCONTRO COM OS PAIS}

Objetivos gerais: Avaliar o acompanhamento dos filhos, fazer um levantamento das situações de baixa, média e alta ansiedade para os filhos e para eles, e ensinar para os pais os quatro passos do acróstico e o relaxamento.

\section{Material:}

Cadernos de exercícios

Termômetro do Medo

\section{Atividades e Tarefas:}

Solicitar informação geral do andamento do filho(a)

Dar aos pais uma oportunidade de discutir as suas preocupações com os filhos ou sobre outros fatores que poderiam afetar as dificuldades das crianças e a capacidade de ser beneficiar do tratamento: com questões semiestruturadas, o terapeuta convida os pais a fornecerem informação histórica e/ou atual que eles sentem que será útil para o terapeuta compreender a criança.

Fazer um levantamento de situações de baixa, média e alta ansiedade para os filhos e para eles.

Ensinar como usar o acróstico e o relaxamento para ajudar o filho(a) e a si mesmo(a) diante das situações desencadeadora de ansiedade

Fornecer maneiras específicas para os pais se envolverem no programa: os pais são orientados a contatar o terapeuta se acreditam que tem informações adicionais que pensem ser úteis ou se eles alguma duvida. Dependendo da idade da criança e da qualidade do apoio paterno, o terapeuta pode pedir a ajuda dos pais em outras áreas especificas relacionada a criança no curso do tratamento. Por exemplo, os pais podem ser chamados a ajudar com uma tarefa de casa durante a parte prática do tratamento.

Entregar para eles um caderno de exercícios para utilizarem o acróstico (2 situações na semana), $C D$ de relaxamento e o registro do relaxamento diário para ser entregue na próxima semana. 


\section{Sessão 4}

Objetivos gerais: Começar a criar uma hierarquia de situação de ansiedade para cada membro do grupo. Introduzir o treino de relaxamento e seu uso no controle da tensão associada a ansiedade. Revisar a percepção de pistas somáticas que mostrem que a criança está tensa e ansiosa. Demonstrar para crianças a relação entre as pistas somáticas e exercícios de relaxamento. Introduzir o Passo \#3: Demonstrando atitudes e ações. E ajudar cada criança a começar a desenvolver e usar autoinstruções que gerem menos ansiedade.

\section{Material:}

02 Pontos para a tarefa

01 Cópia da lista com os medos registrados na Lista de Medos, nos balões da sessão anterior para cada um e da listas de situações temidas feitas pelos pais de cada criança

$01 \mathrm{CD}$ de relaxamento para cada criança

Termômetro do Medo

01 Roteiro para falar ao telefone com o Amigo (pg.) para cada um

Colchonetes

Livro Três Ursos (Wright, 2005)

Pôster Círculo Mágico

Instruções para o relaxamento

Caderno de atividades

Tarefa "AMIGO"

Painel com acróstico (Passo \#1, 2,e 3)

Banco de pontos com os pontos e nomes no devido lugar

Painel Tarefa Amigo

Lista de Verificação de Competência para Terapeutas Cognitivo-Comportamentais

Quadro da agenda do dia com os quadradinhos de Revisão da Tarefa Eu Consigo e Tarefa Amigo, Reconhecendo respostas fisiológicas, Relaxamento, Demonstrando atitudes e ações, Tarefa Eu Consigo e Tarefa Amigo.

Conhecimento das sessões com os pais: Conte para as crianças que você encontrou com os pais deles conforme comunicado e planejado. Assegure a eles que você pode dizer que os pais realmente se preocupam com eles e ficarão orgulhosos com as habilidades que eles estão começando a aprender. E que foi ensinado para eles os 4 passos da estratégia medo que ele já conhecem dois passos e conhecerão hoje o terceiro passo. Comente que também foi ensinado para os pais o relaxamento que eles irão aprender hoje. Incentive as questões das crianças sobre o encontro com os pais.

\section{Atividades e Tarefas:}

Monte a Agenda do dia passando os cartões para as crianças: revisão da tarefa Eu Consigo e Tarefa Amigo, Reconhecendo respostas fisiológicas, Relaxamento, Demonstrando atitudes e ações, Tarefa Eu Consigo e Tarefa Amigo.

Atividade 1: Revisão da tarefa. .15 a $20 \mathrm{~min}$

O terapeuta revisa as tarefas de casa individualmente. Os demais membros do grupo preenchem o folheto: Esperando Coisas Ruins?, no qual várias situações de ansiedade são descritas e é solicitado as crianças 
diferenciem os pensamentos de ansiedade ou catastrófico e de enfrentamento. Esta tarefa posteriormente será revisada em grupo, após a revisão das tarefas de casa e tarefa "Amigo".

Enquanto o terapeuta revisa as tarefas ele discute com cada criança as experiências de ansiedade descritas no caderno. A discussão se concentra também em como a criança percebeu que estava ansiosa e qual foi o seu diálogo interno ansioso, usando uma versão modificada de procedimento de atendimento chamada coluna tripla: três colunas intituladas situação, reações corporais e pensamentos são desenhadas no caderno da criança com espaço a esquerda para uma 4a e 5a coluna. O terapeuta explica que as colunas vazias são para as duas habilidades restantes a serem aprendidas, das quais uma será discutida nesta sessão.

\begin{tabular}{|l|l|l|l|l|}
\hline Situação & $\begin{array}{l}\text { Reações } \\
\text { Corporais }\end{array}$ & Pensamentos & & \\
\hline & & & & \\
\hline
\end{tabular}

Revisão da tarefa "Amigo": De novo, discuta os problemas vividos e envolva o grupo na estratégia de solução de problemas. Recompense as crianças andando casas no Mapa do Tesouro por completarem as tarefas de casa e as tarefas "Amigo". Novamente, o terapeuta deve apontar semelhanças entre os membros e modelar o respeito pelas diferenças.

\section{Atividade 2: Reforço do conteúdo da sessão anterior}

$.40 \mathrm{~min}$

O terapeuta explica que o objetivo do programa não é eliminar totalmente o sentimento de ansiedade (já que todo mundo experimenta esta sensação de vez em quando), mas equipara as crianças com habilidades/ferramentas que podem usar quando estiverem nervosas.

Em seguida leia o livro: Três Ursos (Wright, 2005). Mostre que como no livro ficamos preocupado mesmo sem precisar. Depois de ler a estória use o pôster círculo mágico, onde as crianças são incentivadas a identificarem a situação ativadora problema do Urso Marrom, e para criarem diferentes respostas fisiológicas e emoções que ele pode ter sentido, e os possíveis pensamentos e o comportamento. Depois passe para alguma situação que eles registraram na tarefa Eu consigo. Veja quem gostaria de compartilhar com o grupo. Use o círculo mágico até que todas tenham entendido a reconhecer e discriminar as situações, respostas físicas/emocionais, pensamento e comportamento associadas a ansiedade.

Usando um super-herói da vida real ou um que o grupo crie (e.g., Gato Corajoso ou mascote do grupo), o terapeuta e as crianças podem criar juntos uma estória sobre como este personagem se sentiu ansioso, mas enfrentou a sua preocupação e superou o desafio. A escolha do super-herói/mascote envolve a discussão sobre as escolhas potencias e as características que as torna apropriadas ou não. A estória é criada usando o procedimento de múltiplos narradores, onde o terapeuta cria uma situação e cada criança continua a estória até a sua conclusão. Este procedimento incentiva a participação de todos os membros do grupo e permite que cada um sinta que contribuiu de uma maneira importante.

Atividade 3: Relaxamento

$.20 \mathrm{~min}$

Introduza a ideia de que algumas reações somáticas associada a ansiedade envolve tensão muscular. Sugira que quando uma pessoa fica ansiosa algumas partes do corpo ficam tensas, e que algumas respostas somáticas associadas a ansiedade são resultados desta tensão muscular. 
Peça aos membros do grupo para pensarem em uma situação na qual eles estavam realmente calmos e felizes. Peça a eles que se imaginem na cena e concentrem-se em como o seu corpo se sente. Discuta com o grupo a diferença ente como o corpo deles sente quando estão tensos de quando estão relaxados.

Reforce esta ideia pedindo aos membros do grupo a deixar o pulso firme apertando as mãos enquanto o terapeuta conta até 5 e para se concentrarem em como se sentem. Então diga as crianças para relaxarem os punhos, e por cinco segundos concentre-se na sensação de relaxamento e de calor em suas mãos. 0 terapeuta usa seu discernimento para escolher a criança que fará a atividade primeiro - usando o membro do grupo que irá modelar uma abordagem efetiva para o aprendizado do relaxamento.

Introduza o exercício da Boneca de Pano e do Robô. Peça as crianças para discutirem o movimento do robô e da boneca de pano. $O$ terapeuta modela a forma como os robôs se movem enquanto caminham e pede aos membros do grupo para fazerem o mesmo. $O$ terapeuta explica que quando as pessoas estão tensas elas se sentem duras e desconfortáveis devido a rigidez muscular. Discuta como o corpo gasta energia excessiva quando está tenso. Explique que este trabalho extra faz com que o corpo fique cansado mais facilmente. $O$ terapeuta então imita o jeito de andar de uma boneca de pano, o qual se assemelha ao caminhar de uma pessoa com os músculos completamente relaxados. As crianças são incentivadas a fazerem o mesmo. Segue-se então um breve jogo no qual o terapeuta ou algum membro do grupo ordena para que o grupo alterne entre o jeito de andar da boneca de pano e do robô.

Discuta a ideia de que quando alguém se sente ansioso e preocupado é comum que algumas partes do seu corpo fiquem tensa ou muito tensa. Se ele relaxar estas partes tensas estará dando o primeiro passo para enfrentar a ansiedade. Peça as crianças para que discutam experiências anteriores de relaxamento com o grupo.

\section{Introdução dos procedimentos de relaxamento:}

Explique a respiração diafragmática pedindo para que eles levem o ar para barriga estufando-a, e soltando o ar pela boca devagar. Peça para puxarem o ar, conte 1,2, 3, segure o ar 1, 2, 3 e solte o ar 1, 2, 3, 4, e 5. Em seguida peça para que se deitem no chão

Apague as luzes da sala e peça as crianças para que fiquem em uma posição confortável. Explique que você irá fazer um exercício para ajudá-los a aprender a relaxar, e peça para que eles fechem os olhos. A primeira habilidade de treinamento de relaxamento é a respiração profunda. Solicite para que as crianças usem a respiração expandindo o abdômen, e então soltem o ar vagarosamente, prestando atenção em como os seus corpos se sentem enquanto o ar sai. Este procedimento é repetido 3 vezes. Peça as crianças para concentrarem em como os seus corpos sentem depois de algumas respirações notando as sensações de relaxamento e sugerindo para criança que este é um jeito rápido de relaxar quando eles percebem que estão ficando ansiosos. Sugira que esta técnica pode ser mais útil como a primeira estratégia de enfrentamento das situações de ansiedade.

Novamente, peça as crianças para deixar os pulsos rígidos contando até 5 , e então relaxar contando até 5 , atentando-se para sensação de relaxamento e calor nas suas mãos. Seguindo em direção aos braços e continuando em direção aos seus corpos.

Continue o exercício de relaxamento concentrando-se nos diversos grupos musculares (e.g., mãos, barriga, ombros, faces, pernas) nos quais as crianças relataram a experiência de tensão. Os exercícios de relaxamento Olledick e Cerny (1981), são recomendados: 


\section{Exemplo de Instrução para o Relaxamento}

Quando você se sentir tenso, ansioso, nervoso ou com medo você pode usar o relaxamento para ficar mais tranquilo. Primeiro eu gostaria que você respirasse bem devagar levando o ar até a sua barriga e soltando o ar devagar pela sua boca sem soprar. Deixe o ar sair suavemente pela sua boca. Puxe o ar até eu contar 3, segure o ar e solte até eu contar 5. Vamos lá: Puxe o ar 1, 2, 3. Segure 1, 2, 3. Agora solte o ar devagar 1, 2, 3, 4, 5. Respire de novo pelo nariz 1, 2, 3, segure 1, 2, 3, e solte devagar 1, 2, 3, 4, 5. Mais uma vez, puxe o ar 1, 2, 3, segure 1,2,3 e solte $1,2,3,4,5$. Observe as suas mãos. Aperte agora a sua mão direita como se estivesse espremendo um limão com ela, 1, 2, 3, 4, 5. Relaxe a sua mão 1, 2, 3, 4, 5. Respire 1,2,3, e relaxe 1,2,3,4,5. A outra mão agora. Aperte 1,2,3,4,5. Relaxe 1,2,3,4,5. Levante os ombros no sentido das orelhas, $1,2,3,4,5$. Relaxe os ombros $1,2,3,4,5$. Respire $1,2,3$, e relaxe 1,2,3,4,5. Leve os braços para cima da sua cabeça com se você quisesse encostar na parede,1,2,3,4,5. Relaxe 1,2,3,4,5. Braços para frente do corpo, como se você fosse uma múmia, 1,2,3,4,5. Relaxe 1,2,3,4,5. Movimente a cabeça para um lado, 1,2,3,4,5. Para o outro lado, 1, 2, 3, 4, 5. Relaxe 1, 2, 3, 4, 5. Respire 1,2,3, e relaxe 1,2,3,4,5. Movimente a cabeça para frente, 1,2,3,4,5. Relaxe 1,2,3,4,5. Movimente para trás, 1, 2, 3, 4, 5. Relaxe, 1, 2, 3, 4, 5. Respire 1,2,3,4.,5 e relaxe 1,2,3,4,5. Estique os braços para frente como se você fosse uma múmia e contraia os braços, 1,2, 3, 4,5; . Relaxe 1, 2, 3, 4, 5. Respire 1,2,3, e relaxe 1,2,3,4,5. Contraia a barriga, $1,2,3,4,5$. Relaxe 1,2,3,4,5. Aperte os joelhos com se apertasse algo no meio deles, $1,2,3,4,5$. Relaxe, 1, 2, 3, 4, 5. Respire 1,2,3, e relaxe 1,2,3,4,5. Contraia as pernas e os dedos dos pés, $1,2,3,4,5$. Relaxe 1,2,3,4,5. Isso! Respire e relaxe. Observe o seu corpo. Eu vou contar de 5 a 1 e pouco a pouco vá mexendo o seu corpo. Cinco, movimente as pernas, Ok. Quatro, movimente os braços, ok. Três, movimente devagar o rosto para um lado, para o outro, ok. Dois, dê um longa espreguiçada levando os braços para cima da cabeça, ok. Um, abra os seus olhos. Muito bem! Espero que você tenha conseguido relaxar!

O exercício não deve durar mais do que 15', porque é improvável que as crianças consigam manter a atenção por mais tempo. Informe ao grupo que cada criança receberá uma gravação de relaxamento ao final da sessão para que possa praticar em casa. Explique ao grupo que estes procedimentos exigem prática e que eles podem necessitar completar os exercícios em algumas ocasiões separadas antes que comecem a se sentir relaxados ao seguirem os procedimentos.

Reforce e desenvolva a percepção do grupo de como e por que o relaxamento pode ser benéfico: o terapeuta explica que os exercícios de treinamento do relaxamento são feitos para ajudar as crianças a entender se o que eles se sentem é estar tenso ou relaxado e ajudar as crianças a aprender a relaxar mais rapidamente. Explique que nas situações de ansiedade da vida real eles normalmente não terão a chance de fazerem o exercício de relaxamento, mas provavelmente poderão respirar algumas vezes e concentrarse no relaxamento dos grupos musculares que costuma sentir tensos quando estão ansiosos.

Atividade 4: Enfrentamento as reações corporais, emoções e diálogos internos internos $.20 \mathrm{~min}$

O terapeuta resume as duas estratégias de enfrentamento previamente ensinadas, lembrando ao grupo que eles agora percebem que os seus corpos respondem com certas reações quando eles ficam ansiosos, e eles também produzem diálogos internos ou autoinstruções de ansiedade. Use a experiência de alguns cadernos como exemplo. 
Sugira ao grupo que eles podem aprender os passos para mudar as suas respostas em situações de ansiedade. Reconhecer as respostas corporais e identificar as autoinstruções de ansiedade usando os primeiros dois passos para aprender como agir em situações ainda que se sintam ansiosas. O terapeuta sugere ao grupo que quando estiverem em uma situação de ansiedade ou preocupação é mais fácil lidar com a ansiedade se sabem quais passos seguir. Monte no painel com a ajuda das crianças os dois primeiros passos. Em seguida coloque o terceiro passo: Demonstrando atitudes e ações. Converse que o relaxamento ajuda no Passo \#3. Resuma:

\section{Primeiro passo:}

\section{Meu corpo está me dizendo que estou ansioso e com medo?}

Relaxe! Acalme-se Use as suas estratégias de relaxamento, como a respiração diafragmática ou concentrarse para relaxar os músculos tensos.

\section{Segundo Passo:}

\section{O que está no meu balão de pensamento? $O$ que eu espero que aconteça ?}

Eu tenho razão para pensar que isto irá acontecer? Isso já aconteceu antes? O que mais eu posso pensar nesta situação? (Desenvolver auto-instruções de enfrentamento e aplicá-las para ajudar a conceituação de situações com não amendrotadora).

O terapeuta introduz que além do relaxamento tentar avaliar de forma diferente também ajuda e faz parte do Passo \#3. De que forma o Urso Marrom poderia mudar os pensamentos dele?

Passe para cada um uma lista com todos os medos registrados na Lista de Medos, nos balões da sessão anterior para cada um e da listas de situações temidas feitas pelos pais de cada criança. Peça para que eles avaliem cada uma com o Termômetro do MEDO. Peça que escrevam na folha de Situações de baixa ansiedade aquelas que levam ansiedade 0 a 1 e pratique a habilidade:

\section{Pratique a habilidade}

O terapeuta modela, usando auto-instruções de enfrentamento, um personagem em uma situação de baixa ansiedade, descrevendo quais são seus pensamentos, questionando se são pensamento realistas ou não perguntando questões como "isso é provável de acontecer? Isso já aconteceu antes?", e decidindo que talvez ele esteja se preocupando demais com esses eventos.

O terapeuta e o grupo dramatizam diferentes situações, numa ordem crescente de ansiedade. Os membros do grupo são selecionados para atuar em papéis que vivem circunstâncias geradoras de ansiedade. As dramatizações devem ressaltar os pensamentos dos personagens e suas tentativas de avaliar a legitimidade dos seus pensamentos. Os membros do grupo ajudam os personagens a considerar alternativas de pensamentos sobre a situação de ansiedade e devem incentivar a mudança de pensamento do personagem, de ansiosos para de enfrentamento.

Jogo Eu me Lembro: As crianças tentam lembrar sobre o que cada um aprendeu e achou mais importante na sessão.

Atividade 5: Tarefa de casa $15 \mathrm{~min}$

O terapeuta explica de novo sobre a necessidade de praticar o relaxamento descrevendo a capacidade de relaxar como uma habilidade a ser aprendida e não algo que pode ser feito automaticamente. É solicitado 
as crianças que pratiquem os procedimentos de relaxamento usando suas gravações no mínimo 3 vezes durante as semanas seguintes. As crianças são estimuladas a encontrar um local confortável para praticar, longe de barulhos ou outras formas de distração. O objetivo é praticar ao menos 3 vezes e registrar a experiência no caderno. Alem disso, é solicitado as crianças que escrevam sobre duas situações de ansiedade e registrem os pensamentos e pistas somáticas que eles identificaram.

Tarefa "Amigo": A atividade é perguntar ao amigo duas questões que serão elaboradas pela própria criança. O terapeuta orienta aos membros do grupo a registrarem questões e respostas, e inicia uma breve discussão sobre possíveis assuntos para a tarefa. Os participantes são incentivados ao oferecer suas ideias voluntariamente.

Atividade 6 Formulário de Feedback. $.5 \mathrm{~min}$

Entregar para cada um preencher o formulário de Feedback do encontro do dia. Para o coterapeuta e o observador: avaliar o terapeuta do dia na Escala Cognitiva (Young \& Beck, 1988)

Preparação para próxima sessão: Lembrar as crianças que a semana que vem será agendado um horário para cada criança e os respectivos pais serem atendidos para uma nova avaliação e para prepará-los para a nova etapa do atendimento. Explique para eles que vocês irão discutir sobre a lista de medos de cada um e que a partir das sexta sessão vocês irão trabalhar bastante as ferramentas que eles aprenderam. E que na sessão que vem eles irão aprender a última ferramenta.

\section{Sessão 5}

Objetivos gerais: Desenvolver habilidade de enfrentamento e manejo da ansiedade e introduzir o conceito de autopremiação baseada no desempenho. Revisar o treino de relaxamento e os outros passos do plano de enfrentamento da ansiedade

\section{Material:}

02 Pontos para a tarefa Eu Consigo para cada um que fizer

01 Cópia das folhas Situação de Ansiedade já apresentados na sessão anterior para cada um

01 Cópia das Situações de Média Ansiedade e Alta Ansiedade para cada um classificar

Termômetro do Medo

Jogo Guerra do Stress (Separe algumas cartas para usar no jogo)

Lista para discussão de como eles podem se autorreforçarem (VIDE CADERNO DE EXERCÍCIOS)

Tiras de quadrinhos

Caderno de atividades

Painel com acróstico (Passo \#1, 2,3 e 4)

Banco de pontos com os pontos e nomes no devido lugar

Painel da Tarefa Amigo

Lista de Verificação de Competência para Terapeutas Cognitivo-Comportamentais

Quadro da agenda do dia com os quadradinhos de Revisão da Tarefa Eu Consigo e Tarefa Amigo, Demonstrando atitudes e ações, Oba! Resultados e recompensas, Tarefa Eu Consigo e Tarefa Amigo.

\section{Atividades e Tarefas:}


Monte a Agenda do dia passando os cartões para cada um: Revisão da Tarefa Eu Consigo e da Tarefa Amigo, Demonstrando atitudes e ações, Oba! Resultados e Recompensas, Tarefa Eu Consigo e Tarefa Amigo.

Atividade 1: Revisão da tarefa $.15 \mathrm{~min}$

Inicie uma discussão sobre as experiências de ansiedade das crianças. Peça a cada criança para relatar uma de suas experiências registradas com um desenvolvimento de plano de ação ao enfrentar uma situação de ansiedade, reforçando até mesmo tentativas parciais de enfrentamento. Peça aos membros do grupo para sugerir outras alternativas de ações ou atitudes que poderia ser consideradas.

Revisão da tarefa "Amigo": De novo, discuta os problemas vividos e envolva o grupo na estratégia de solução de problemas. Pergunte aos membros do grupo se eles conseguiram fazer as perguntas sem usar o roteiro. Valorize as tentativas independentemente dos resultados. Discuta com o grupo que eles podem reduzir o uso do roteiro da tarefa ate que eles não precisem mais. Recompense as crianças andando casas no Mapa do Tesouro por completarem as tarefas de casa e as tarefas “Amigo". Novamente, o terapeuta deve apontar semelhanças entre os membros e modelar o respeito pelas diferenças.

Atividade 2: Revisão da sessão anterior

$.40 \mathrm{~min}$

Revise o treino de relaxamento: reserve 15' para um exercício de relaxamento, usando parte do tempo para revisar os grupos musculares. Discuta com o grupo sobre suas experiências de usar o relaxamento como uma primeira resposta em situações de ansiedade, amplie a ideia de um rápido exercício de relaxamento tal como algumas respirações diafragmáticas e relaxamento de músculos que tendem a ficar tensos.

Jogue o Jogo Guerra do Stress. E depois usando o Círculo Mágico retome os passos do acróstico com os temas das cartas do Jogo e com as situações da semana. Na parte do comportamento aborde a mudanças de atitudes e no pensamento as novas perspectivas. Lembre-os do livro O quente pode ser frio. Demonstre que quando a atitude e os pensamentos mudam a emoção também muda.

\section{Desenvolva um plano para enfrentar a ansiedade}

Este plano será especifico para cada tipo de situação e para as preferências das crianças por estratégias que serão úteis a elas. Peça que membros do grupo posicionem a frase (Demonstrando atitudes e ações) na frente da letra $D$ do pôster Medo. Em seguida, descreva para o grupo como desenvolver um plano para mudar alguma coisa usando os dois cartazes com as seguintes questões:

(a) Questão 1. O que eu posso fazer para tornar esta situação menos assustadora? (explore as alternativas para mudar a situação. Faça uma lista de todas as alternativas possíveis, mesmo aquelas que obviamente não são as melhores); e

(b) Questão 2. Quais seriam as melhores coisas a fazer (determine qual é a alternativa preferível e executável).

O terapeuta mostra outra situação de solução de problemas simples e concreta, e o grupo é incentivado a sugerir alternativas e decidir o que fazer. Para facilitar este processo, as alternativas podem ser listadas em um grande quadro. O terapeuta ressalta o número de alternativas para mostrar para as crianças de que em uma situação de ansiedade elas têm varias opções (i.e., escolhas de comportamento). O grupo então decide coletivamente qual é a melhor alternativa. Ao longo do exercício o terapeuta também explica ao grupo que esta habilidade requer prática e que não deve esperar ótimos desempenhos imediatamente. 


\section{$\because$ Gafo \\ Corajoso}

Atividade 3: Solução de problemas

$25 \mathrm{~min}$

Inicialmente retome a lista de situações de baixa ansiedade do grupo. 0 terapeuta escolhe uma das situações para modelar os quatro passos usando o painel e o circulo mágico e convida o grupo para seguilo. Eventualmente o grupo é solicitado para participar de dramatização usando a sala como cenário, mas o terapeuta deve estar preparado com situações relevantes caso o grupo não contribua com ideias.

Em seguida faça outra lista de situações que geram maior ansiedade. As novas habilidades são aplicadas a situações de ansiedade mais elevadas. Usando o modelo do terapeuta, seguido por dramatizações, para ilustrar a habilidade. Explique ao grupo que pode haver situações onde há algumas ações que são alternativas preferenciais (e.g., receber injeção de um médico) é explicado que nestas situações a pessoa pode precisar modificar a sua atitude.

Para revisar os conceitos de atitudes e pensamentos de ansiedade em comparação com os de enfrentamento, o grupo pode debater entre eles sobre pensamentos ansiosos e outros sugerindo pensamento de enfrentamento para várias situações de ansiedade. Os grupos devem se alternar de forma equivalente ao longo do debate para que as crianças adquiram prática para os dois tipos de argumentação. O terapeuta monitora os pensamentos fazendo correções e esclarecendo conceitos quando necessário.

\section{Atividade 4: Prática de autoavaliações e recompensas em caso de sucesso.....25 min}

Introduza a ideia de autoavaliação descrevendo como as crianças podem decidir se estão ou não satisfeita com os seus esforços. Sugira que as pessoas costumam se autoavaliarem, dando a si mesmos prêmios ou punições pelos próprios comportamentos, embora elas possam não saber disso. Forneça exemplos concretos de ambas as avaliações, de acordo com as experiências individuais dos participantes (e.g., para um pequeno jogador: imagine que você fez um ponto que ajudou o seu time a ganhar um ponto, você teve sucesso no que você tentou fazer? Como você se sentiu? O que você faria a seguir? No que você pensaria?). Ressalte de que não seria razoável esperar fazer um ponto em todos os jogos, e que não fazer um ponto sempre não é justificativa para se punir. Ressalte que um resultado exitoso não é pré-requisito para recompensa. Por exemplo: uma criança que treina duro para se preparar e se esforça bastante para o jogo e perde, pode ser mais merecedora de recompensa pelo esforço realizado do que aquela que faz o ponto, mas não se preparou.

Apresente dois cenários: um no qual uma criança enfrenta com sucesso um problema simples e se autoavalia positivamente; e outro no qual a criança deverá enfrentar uma situação de maior dificuldade, onde suas ações podem ter pequeno impacto na solução de problema, mas onde ela pode se sentir bem ou mal sobre os seus pensamentos a respeito da situação. Discuta a diferença para ajudar o grupo a aprender que é possível eles se autoavaliarem positivamente mesmo em situações com resultado desfavorável além do seu controle.

Discuta novamente os diversos tipos de recompensas - um tapinha nas costa, sentir-se bem por dentro, um sorriso, ou uma atividade especial. Peça para que eles escrevam na Lista de autorreforçadores no caderno de exercício.

Apresente aos participantes tiras de quadrinhos com balões de pensamentos em branco que mostram os personagens realizando alguma atividade, fazendo autoavaliação e recompensando a eles mesmos. Peça as crianças para preencherem os balões de pensamentos. As dificuldades das situações retratadas devem aumentar gradualmente. 
O terapeuta fornece um modelo de enfrentamento, descrevendo ao menos um cenário no qual ele teve êxito ao enfrentar uma situação de ansiedade, se autoavaliou positivamente e escolheu uma recompensa apropriada. Exemplos de recompensas podem incluir dizer a si mesmo que o trabalho foi bem feito, escrever sobre a conquista em um diário ou cartão de créditos, contar a um amigo, ou gastar mais tempo no seu passatempo preferido. Os participantes são incentivados em pensar em situações similares envolvendo ansiedade, que eles enfrentaram com sucesso, se o grupo for receptivo os cenários podem ser dramatizados. $O$ terapeuta pode usar se necessário os cartões cenários para que as crianças discutam e escolha algum para dramatizar.

Todos os participantes são estimulados a participarem da discussão sobre as possíveis recompensas. 0 terapeuta então descreve no mínimo um cenário no qual o personagem faz alguma coisa certa, mas gostaria de fazer outras coisas melhores, demonstrando autorrecompensa por sucesso parcial (perfeição não é necessária para recompensa). 0 grupo é convidado para discutir ou dramatizar situações semelhantes nas quais o resultado não é um completo sucesso. A discussão deve incluir o valor das tentativas de enfrentamento. $O$ terapeuta então descreve um cenário no qual o personagem enfrenta bem os seus sentimentos de ansiedade, mas o resultado é negativo apesar dos seus esforços. Demonstrando a autorrecompensa pelo seu êxito no uso do plano de 4 passo, mesmo no caso de resultados negativo.

O terapeuta resume as duas estratégias de enfrentamento previamente ensinadas, lembrando ao grupo que eles agora percebem que os seus corpos respondem com certas reações quando eles ficam ansiosos, e eles também produzem diálogos internos ou autoinstruções de ansiedade. Use a experiência de alguns cadernos como exemplo.

Jogo Eu me Lembro: As crianças tentam lembrar sobre o que cada um aprendeu e achou mais importante na sessão.

Atividade 6: Tarefa de casa $10 \mathrm{~min}$

Peça para cada participante para registrar duas situações de ansiedade que viveram e para darem especial atenção nas suas experiências de autoavaliação e premiação. Especificamente peça as crianças para se concentrarem se eles se autoavaliaram no sucesso parcial ou apenas no sucesso total, seus sentimentos a seguir, e que recompensas foram escolhidas.

Tarefa "Amigo": entregue às crianças uma questão semiestruturada para perguntarem ao seu amigo. Eles são orientados a registrarem as respostas do amigo. É solicitado que façam uma segunda questão de prosseguimento e que registre. $O$ terapeuta irá modelar o uso do plano de 4 passos da tarefa amigo. As crianças que estão tendo dificuldades em completar as Tarefas "Amigo" são encorajadas a pedir ajuda àquelas que não estão com dificuldades. Os participantes que completam estas tarefas com facilidade são estimulados a compartilhar as estratégias de enfrentamento e a se envolverem na solução de problemas para ajudar aquelas com dificuldades. Se necessário, as tarefas podem ser dramatizadas para prática entre as sessões.

Atividade 7: Formulário de Feedback. $5 \min$

Entregar para cada um preencher o formulário de Feedback do encontro do dia. Para o coterapeuta e o observador: avaliar o terapeuta do dia na Escala Cognitiva (Young \& Beck, 1988).

Preparação para próxima sessão: Preparar cartões vale-prêmios para troca de pontos. 


\section{Objetivo geral:}

Completar a avaliação intermediária do tratamento. Revisar com eles o uso que eles fizeram do acróstico e do relaxamento e as possíveis dificuldades. Além disso, revisar e resumir as habilidades dos filhos apresentadas durante a primeira metade do tratamento e trabalhar com os pais no projeto de experiências ao vivo dos filhos, moldadas de acordo com as necessidades individuais.

\section{Material:}

Lista de medo de cada criança

Imã do Acróstico

\section{Atividades e Tarefas:}

O terapeuta deve completar a avaliação considerando que as avaliações de acompanhamento são realizadas individualmente com os pais e as crianças.

Responder as questões a cerca do tratamento e obter informações com os pais para desenvolver melhores estratégias de enfrentamento.

Descreva o progresso geral das crianças para cada pai e criança, revisando os pontos fortes e fracos da criança. Apresente a lista de medos e discuta com os pais e as crianças.

Pergunte aos pais sobre questões adicionais e preocupações que possam ter. Estimule os pais a procurarem o terapeuta com questões, comentários ou novidades que eles possam ter no futuro. Ressalte a importância da comunicação entre terapeutas e pais, e enfatize o papel desta informação no sucesso do tratamento com as suas crianças.

Discuta com os pais a mudança nas atividades da primeira para a segunda metade do tratamento. Descreva a natureza e o propósito das exposições ao vivo e obtenha informações relevantes dos pais que poderão ser úteis na escolha do conteúdo e das situações de ansiedade durante a segunda metade do tratamento. Revise com os pais o acróstico MEDO e o plano de 4 passos. Estimule a criança a ajudar a descrever os passos para os pais. Ao final entregue o imã com o acróstico.

ATENÇÃO: Crie situações na sessão para usar o acróstico em tempo real. Fazer um relato escrito desta avaliação e entregar para supervisora. 


\section{Sessão 6}

Objetivo Geral: Descrever as alterações no tipo de atividades, devido à mudança de tratamento para prática, realizar um evento do grupo para comemorar a nova etapa e as habilidades aprendidas até agora, e para aumentar a coesão e a filiação grupal. Praticar o plano de enfrentamento de 4 passos em condições de baixa ansiedade, tanto imaginárias quanto ao vivo. (Nota: as práticas ao vivo nesta sessão envolvem todo o grupo).

\section{Material:}

02 Pontos para a tarefa CEI para cada um que fizer a tarefa

Imãs para tarefa Amigo

Pôster MEDO completo

Prêmios para trocar

Prêmios sociais para tarefa amigo

Formulário de Feedback

Preparação para confraternização (jogo, lanche, etc)

Caderno de exercícios (pg.)

Formulário de Feedback

Lista de Verificação de Competência para Terapeutas Cognitivo-Comportamentais

\section{Atividades e Tarefas:}

Monte a Agenda do dia passando os cartões para cada um: Revisão da Tarefa Eu Consigo e da Tarefa Amigo, Mostrando-se preocupado?, Esperando que coisas ruins aconteçam?, Demonstrando atitudes e ações, Oba! Resultados e Recompensas, Tarefa Eu Consigo e Tarefa Amigo.

\section{Preparação Pré-sessão}

Os terapeutas devem selecionar várias situações que são susceptíveis de provocar leve ansiedade nos membros do grupo e que podem ser utilizadas para prática imaginária e ao vivo.

As exposições ao vivo começam com o grupo como um todo enfrentando situações provocadoras de ansiedade (tanto na sessão como em situações reais) e, em seguida, os progressos das exposições ao vivo envolvem situações individuais (tanto no consultório quanto em situações reais). Exposições de grupo ao vivo são baseadas em receios comuns aos membros, sempre que possível. Já as exposições individuais são adaptadas a cada membro do grupo, considerando os medos únicos e específicos.

Atividade 1: Revisão da tarefa

15 a $20 \mathrm{~min}$

Cada membro do grupo é convidado a apresentar a sua experiência ansiosa da semana e a detalhar em descrição a utilização dos 4 passos. O terapeuta toma o cuidado de reforçar todas as tentativas de enfrentamento e oferece sugestões e / ou correções nas estratégias de resolução de problemas aos membros do grupo.

Revisão das tarefas "Amigo": inclui discutir os sucessos/dificuldades na realização da tarefa. Discuta com o grupo se o grau de ansiedade sentida na realização da tarefa foi reduzida. Salientar que esta exposição repetida é responsável pela redução na ansiedade. Generalizar este conceito para outras situações ou tarefas temidas. 
O grupo está em uma nova etapa na qual passa a praticar as novas competências aprendidas nas sessões anteriores. Em vez de aprender sobre sentimentos, pensamentos e estratégias, o foco será praticar aquilo que foi aprendido. Em princípio, as sessões práticas de envolver todo o grupo na prática do plano de enfrentamento de 4 passos em situações de moderada ansiedade. Nas sessões seguintes, os participantes praticam individualmente, a partir do plano de 4 passos, situações que lhes causam ansiedade. As exposições começam como imaginárias e prosseguem como situações reais. Elas também são graduadas no nível de ansiedade que elas provocam.

\section{Hora de praticar}

Grupo evento social: Envolva o grupo em uma agradável atividade social - um parque, um jantar, excursão, jogos - qualquer atividade considerada prazerosa por todos. Incentive a discussão da formação da Amizade dentro do grupo. Reforce o trabalho em equipe realizado pelos participantes. Mais importante ainda, é ver que cada membro do grupo está se divertindo.

\section{Atividade 3: Conceito de exposições imaginárias e ao vivo}

$40 \mathrm{~min}$

Descreva o conceito de exposições imaginárias e ao vivo em termos que as crianças vão compreender. Discuta como grupo que medos e ansiedade são normalmente dominados através de exposições repetidas. Utilize exemplos (e.g., tarefas amigo, primeiro dia de escola, aprender a andar de bicicleta) para ilustrar que o medo pode ser superado pelo enfrentamento da situação temida. Ressalte a importância de permanecer na situação tempo suficiente, de tal maneira que o medo comece a regredir.

Além de enfrentar o medo por um tempo adequado, eles também devem enfrentar aquela situação repetidamente. Compare isso com os comportamentos de evitação, que parecem ajudar inicialmente, mas que pioram as coisas (isto é, produzem mais medo) no longo prazo. Repetidas exposições são um pouco desagradáveis no curto prazo, mas extremamente benéficas (ou seja, reduzem / eliminam os medos), no longo prazo. Para ter certeza de que os membros do grupo compreenderam os conceitos de duração, repetição, e evitação, use uma linguagem simples e ilustrações vívidas.

\section{Hora de praticar}

Exposição Imaginária (baixa ansiedade): O terapeuta prepara situações de baixa ansiedade, em que vários membros do grupo identificaram como problemáticas. $O$ terapeuta descreve uma cena que provoque ansiedade e simula estar na situação, modelando em voz alta os pensamentos ao longo da situação - utilizando o plano de 4 passos e o acróstico MEDO para ajudar a lembrar de todos os passos. Em seguida, o terapeuta pede ao grupo para pensar em um cenário um pouco diferente, mas semelhante, incentivando cada membro a contribuir com o plano de 4 passos a ser realizado. O terapeuta indica o uso dos 4 passos, conforme necessário.

Exposição ao Vivo no Consultório (baixa ansiedade): O grupo é convidado a praticar suas novas habilidades, em situação real praticada no procedimento de dramatização. Cada membro do grupo participa da exposição, recebendo do grupo, ou, se necessário, do terapeuta, uma parte da tarefa a ser completada. Por exemplo, a tarefa pode ser pegar uma chave com uma pessoa desconhecida, em um local desconhecido. Um membro do grupo pede direções, outro leva o grupo para o quarto onde a chave vai ser buscada, outro membro pergunta pela chave e outro leva o grupo para a porta que a chave destranca e abre-o. O terapeuta deve se assegurar de que cada parte da missão é relevante para as necessidades de cada criança (e g., uma criança socialmente ansiosa é incumbida da tarefa de pedir a chave; uma criança com ansiedade de separação recebe a tarefa de encontrar o caminho). Como este é o primeiro esforço para a prática do exercício no consultório, o grupo é encorajado a usar os seus cartões MEDO, conforme necessário. 0 terapeuta acompanha o grupo na realização do exercício. Se a tarefa do grupo interrompe-se em qualquer ponto, incentive a solução de problemas e recorde ao grupo a se auto-recompensar pelos êxitos parciais alcançados. 
Com a participação do grupo, o terapeuta escolhe uma ou duas situações que são suscetíveis de provocar ansiedade moderada em cada membro do grupo e que podem ser utilizados para prática ao vivo na próxima sessão. Estas exposições não irão ocorrer no consultório, mas em situações reais. Explique ao grupo que eles estarão praticando em uma situação mais difícil e incentive uma perspectiva positiva, de aventura a ser realizada.

Se houver tempo, faça exercícios de relaxamento com o grupo para fechar a sessão, com um lembrete para continuarem em casa a prática com suas gravações de relaxamento.

Atividade 5: Discussão dos Prêmios e Pontos $10 \mathrm{~min}$

Apresente os Prêmios e os pontos que cada um valerá para troca. Peça para que eles preencham no caderno a folha de Prêmios de acordo com o que for discutido e decidido pelo grupo. Negocie para que eles pensem que na próxima será a troca dos pontos por prêmios sociais. Incentive que a criança não troque todos os pontos de uma vez, e que guarde alguns pelo menos para a próxima sessão para que consiga trocar por um prêmio melhor. Dê prêmios extras pela participação na tarefa Amigo. Converse sobre os reforçadores naturais associados ao prêmio (e.g. trocar os pontos por adesivos $\rightarrow$ reforço arbitrário; conseguir enfrentar os medos $\rightarrow$ reforço natural).

Troca dos prêmios escolhidos. Lembre-os que a próxima troca na sessão 9 será de prêmios sociais.

Jogo Eu me Lembro: As crianças tentam lembrar sobre o que cada um aprendeu e achou mais importante na sessão.

Atividade 6: Tarefa de casa.

$.15 \mathrm{~min}$

Peça aos membros do grupo para registrar uma experiência de ansiedade semelhante à praticada durante a sessão - incluindo cada passo do plano utilizando o acróstico para lembrarem-se dos 4 passos. Os membros do grupo também são convidados a desenhar e trazer para a próxima sessão uma imagem de um personagem de desenho favorito ou figura imaginária figura que possa ajudar as crianças a enfrentar as situações quando estão se sentindo ansiosas.

Tarefa Amigo: Instrua cada membro do grupo a fornecer informações sobre si mesmo para os seus amigos. Assim, eles não irão fazer perguntas aos seus amigos, mas sim fornecer informações aos seus amigos. 0 terapeuta deve propositadamente deixar a descrição da tarefa um pouco ambígua para aumentar o nível de ansiedade que os membros do grupo irão experimentar. Peça para que eles comecem a discutir sobre o encerramento da Projeto e expliquem que filmaremos um mensagem final (individual ou grupal) deles na última sessão (pode ser em dupla, individual ou incluir o grupo todo).

Atividade 7: Formulário de Feedback $.5 \mathrm{~min}$

Entregar para cada um preencher o formulário de Feedback do encontro do dia. Para o coterapeuta e o observador: avaliar o terapeuta do dia na Escala Cognitiva (Young \& Beck, 1988) 


\section{Sessão 7}

Objetivo Geral: Praticar a aplicação das habilidades de enfrentamento em situações ao vivo que provoque de baixo a moderado níveis de ansiedade em cada participante. (Obs.: as situações ao vivo nesta sessão envolvem os participantes individualmente. Os demais membros atuam como observadores ou participantes dependendo da natureza dos medos individuais de cada criança. Cada criança participa de uma situação ao vivo que é moldada para o enfrentamento da ansiedade e medo particular). Compare a autopontuação de desempenho com as pontuações de desempenho com a dos observadores usando gravações em vídeo como ajuda.

\section{Material:}

02 Pontos para a tarefa CEI para cada um que fizer a tarefa

Imãs para tarefa Amigo

Pôster MEDO completo

Estrelas adesivas

Filmadora

Livro Leonardo

Preparação para exposição

Caderno de exercícios (pg.)

Formulário de Feedback

Lista de Verificação de Competência para Terapeutas Cognitivo-Comportamentais

\section{Atividades e Tarefas:}

Monte a Agenda do dia passando os cartões para cada um: Revisão da Tarefa Eu Consigo e da Tarefa Amigo, Mostrando-se preocupado?, Esperando que coisas ruins aconteçam?, Demonstrando atitudes e ações, Oba! Resultados e Recompensas, Tarefa Eu Consigo e Tarefa Amigo.

Atividade 1: Revisão da tarefa $15 \mathrm{~min}$

Peça a um membro do grupo que conduza a revisão das tarefas de casa. Discuta no mínimo uma situação de experiência de ansiedade registrada por cada criança em seu caderno e o personagem escolhido para ajudar no enfrentamento. Assegure que a discussão concentre-se ao máximo no plano elaborado para enfrentar a situação, a autoavaliação e recompensa. Ressalte para o grupo que uma pessoa pode ter medo de mais de uma coisa em uma mesma situação e pode precisar de usar um plano de enfrentamento para cada uma.

Revisão das tarefas "Amigo": Discuta as experiências do grupo em aprender mais sobre seus amigos. O terapeuta debate como a revelação de informações por uma pessoa faz com que a outra pessoa fale mais de si mesma. Inicie uma discussão sobre como este processo ocorre na formação de amizades. As crianças devem demonstrar para o grupo as informações que eles passaram aos seus amigos. O terapeuta pode usar esse tempo para refinar as habilidades sociais da criança, dando sugestões e parabenizando pelas interações bem feitas. Os participantes devem se envolver na discussão e podem fornecer informação sobre como outras reações e comportamentos afetam a eles. Esta informação pode ser útil para aqueles participantes que continuem a ter dificuldades com essas tarefas. Recompense as crianças pela cooperação e congratule o condutor da revisão da tarefa de casa pelo seu trabalho.

Atividade 2: Enfrentamento ao vivo (moderada ansiedade). $.90 \mathrm{~min}$ 


\section{$\because$ Gafo \\ Corajoso}

Ler com o grupo o livro: Leonardo e discutir com o grupo sobre o assunto do livro.

Descreva a mudança de formato a partir da exposição ao vivo (de situações grupais para situações individuais). Lembre ao grupo que agora eles irão agir sozinhos em situações de ansiedade, contudo eles ainda podem contar com o grupo para conselhos, apoio e incentivo.

Pratique as habilidades de enfrentamento em situações que causem de baixo a moderado níveis de ansiedade para cada participante usando dramatização. Lembre as crianças de usarem a imagem ou o personagem que escolheram para ajudar no enfrentamento. $O$ terapeuta prepara um conjunto de objetos para criar uma cena e pede para cada membro do grupo que dramatize sua própria situação. Quando personagens adicionais forem necessários os demais membros podem atuar como figurantes para criar um cenário realista. $\mathrm{O}$ terapeuta fornece indicações quando necessário para incentivar o uso dos 4 passos. Este procedimento assegura uma dupla exposição para cada participante. Pois eles irão participar das próprias situações de ansiedade e das situações dos seus colegas. Nota: Alguns minutos devem ser usados para o treino de relaxamento se o terapeuta perceber que algum participante está tendo dificuldade para controlar o seu nível de ansiedade diante a dramatização.

Pratique o plano de enfrentamento de 4 passos em situações ao vivo no consultório que devem induzir níveis moderados de ansiedade em cada criança: o nível de dificuldade das situações ao vivo deve ser mensurados com o nível da respectiva criança participante. Assim, crianças mais avançadas praticam situações de alto grau de ansiedade. Enquanto crianças menos avançadas praticam situação de moderada ansiedade. As situações são escolhidas considerando a hierarquia de medo de cada criança. Os participantes praticam suas situações de ansiedade sequencialmente.

Faça um exercício de treino de relaxamento na situação da forma que for possível, concentrando-se nas áreas de tensão que os participantes costumam sentir. Breves exercícios de relaxamento podem ser usados a qualquer momento durante a sessão, caso algum participante tenha dificuldades com sua ansiedade. 0 terapeuta apresenta um modelo de enfrentamento, ressaltando os aspectos da situação que podem ser difíceis para cada criança, personalizando partes do plano para lidar com as dificuldades e preocupações específicas de cada criança. Os participantes devem ser encorajados a fornecer ajuda ao terapeuta durante o processo.

Cada participante é estimulado a discutir suas próprias respostas somáticas e pensamentos, e, junto com o grupo, fazer modificações em suas autoinstruções. $O$ terapeuta deve cuidar para que esse procedimento ocorra de forma organizada.

O grupo então desenvolve estratégias reais para enfrentamento de situações a aplica essas estratégias. 0 terapeuta assegura o envolvimento de cada membro do grupo (i.e., tenha um papel integral) na tarefa, abstendo-se de atribuir as partes aos participantes. Esta tarefa é deixada para o grupo. Apenas se necessário o terapeuta deve intervir. Após completar o manejo das estratégias, ajude os participantes a avaliar seus desempenhos e determinar a recompensa apropriada. Esteja certo de ajudar cada participante a identificar o sucesso em qualquer parte do plano de 4 passos e não focarem somente no resultado final quando eles avaliarem o próprio trabalho. 


\section{Hora de praticar}

O terapeuta apresenta um modelo de enfrentamento verbalizando os seus pensamentos e sentimentos sobre os aspectos particulares da situação que sabidamente são os mais difíceis para criança, cuidadosamente desenvolvendo estratégias e modificando auto-instruções de ansiedade. Avalie no Termômetro do Medo o quanto estão ansiosos. Os participantes não envolvidos na situação são convidados para contribuir com idéias e estratégias. A criança que está fazendo a exposição é estimulada a discutir suas reações somáticas e seus pensamentos, e a fazer modificações nas autoinstruções de ansiedade. A criança é estimulada a respirar algumas vezes e a tentar relaxar.

Cada criança pode desenvolver estratégias reais de enfrentamento e utilizá-las. O desempenho é gravado em vídeo pelo terapeuta. A criança participante e os demais membros do grupo avaliam o desempenho, o quão bem a criança se saiu no enfrentamento da situação, imediatamente após o termino da exposição. Peça então para que a criança avalie no Termômetro do Medo o quanto a criança está ansiosa no momento. Apresente o vídeo para o grupo que reavaliam o desempenho da criança exposta. O terapeuta ressalta algumas diferenças de pontuação da criança participante e as diferenças de pontuação dadas pelo grupo em relação a pontuação dada pela própria criança. Passem para a próxima criança. OBS.: proponha exposição que a criança consiga enfrentar. Fale para ela que ela pode pedir ajuda para qualquer terapeuta ou colega. Fique atento para facilitar o enfrentamento. Incentive, torça e nos 4 passos oriente o que é melhor fazer a partir do levantamento das possíveis dificuldades. Ajude as crianças a avaliarem esta situação com um desafio a ser enfrentado e não um problema a ser temido.

Tem sido demonstrado que a reavaliação do próprio desempenho após assistido em vídeo leva a pontuações mais altas. Estimule cada criança participante a recompensar a si mesmo de forma adequada. Este processo é repetido com todos os membros do grupo.

Jogo Eu me Lembro: As crianças tentam lembrar sobre o que cada um aprendeu e achou mais importante na sessão.

Atividade 3: Tarefa de casa.

$15 \mathrm{~min}$

Cada participante é solicitado a registrar duas experiências de ansiedade anotando as suas ações para cada etapa do plano de enfrentamento de 4 passos. Peça para que eles coloquem o imã com o acróstico em um lugar bem visível para lembrá-los. Caso achem melhor podem fazer um cartão para andar na carteira. Sugira que eles usem figuras de revistas ou desenhos que se relacionem ao nome do grupo, ao acróstico MEDO e a um símbolo de "SEM MEDO", e forneça a eles os recursos necessários. É explicado ao grupo que a 4 sessões restantes, e deve ser estimulado uma discussão dos sentimentos em relação ao grupo e ao tratamento.

Tarefa Amigo: Os participantes devem discutir com o amigo do grupo sobre o que acharam do tratamento: as partes favoritas, as menos favoritas e os sentimentos a respeito da conclusão do tratamento.

Atividade 4: Formulário de Feedback. $.5 \mathrm{~min}$

Entregar para cada um preencher o formulário de Feedback do encontro do dia. Para o coterapeuta e o observador: avaliar o terapeuta do dia na Escala Cognitiva (Young \& Beck, 1988) 


\section{Sessão 4 com os pais}

\section{Objetivo geral:}

Avaliar com os pais as dificuldades que estão tendo com o uso do acróstico e do relaxamento, e a evolução dos filhos; incentivá-los a ajudar os filhos e eles mesmos no enfrentamento dos medos; e preparar para o término do programa.

Material: Caderno de exercício e Plano de Ação

\section{Atividades e Tarefas:}

- O terapeuta deve avaliar as possíveis dificuldades dos pais no uso do acróstico e do relaxamento. Trabalhar solução de problemas.

- Avaliar as tarefas dos pais no caderno de exercício.

- Responder as questões a cerca do tratamento e obter informações como os pais para desenvolver melhores estratégias de enfrentamento:

- Descreva o progresso geral das crianças nesta nova etapa de exposição e avaliar se o enfrentamento em cada aumentou. Avalie as mudanças na escola e em casa.

- Pergunte aos pais sobre questões adicionais e preocupações que possam ter. Tente usar o acróstico e o plano de ação para ajudá-lo a lidar com os problemas. Estimule os pais a procurarem o terapeuta com questões, comentários ou novidades que eles possam ter no futuro. Ressalte a importância da comunicação entre terapeutas e pais, e enfatize o papel desta informação no sucesso do tratamento com as suas crianças.

- Refazer o relaxamento.

\section{Sessão 8}

Objetivo Geral: Iniciar a prática de aplicação das habilidades de enfrentamento da ansiedade em situações ao vivo que produzam altos níveis de ansiedade em cada criança (Nota: as exposições ao vivo desta sessão envolvem os participantes individualmente).

\section{Material:}

02 Pontos para a tarefa CEI para cada um que fizer a tarefa Imãs para tarefa Amigo Pôster MEDO completo Preparação para exposição Caderno de exercícios (pg.)

Formulário de Feedback Lista de Verificação de Competência para Terapeutas Cognitivo-Comportamentais 


\section{Atividades e Tarefas:}

Monte a Agenda do dia passando os cartões para cada um: Revisão da Tarefa Eu Consigo e da Tarefa Amigo, Mostrando-se preocupado?, Esperando que coisas ruins aconteçam?, Demonstrando atitudes e ações, Oba! Resultados e Recompensas, Tarefa Eu Consigo e Tarefa Amigo.

Atividade 1: Revisão da tarefa

$20 \mathrm{~min}$

Peça a um membro do grupo que conduza a revisão das tarefas de casa. Discuta no mínimo uma situação de experiência de ansiedade registrada por cada criança em seu caderno e o personagem escolhido para ajudar no enfrentamento. Assegure que a discussão concentre-se ao máximo no plano elaborado para enfrentar a situação, a autoavaliação e recompensa. Ressalte para o grupo que uma pessoa pode ter medo de mais de uma coisa em uma mesma situação e pode precisar de usar um plano de enfrentamento para cada uma.

Revisão das tarefas "Amigo": Discuta a natureza do contato entre os amigos. O terapeuta pergunta sobre o uso dos passos MEDO nas situações em que os participantes não sabiam o que dizer aos amigos. $O$ uso dos passos MEDO é parabenizado. O terapeuta pergunta sobre os contatos e os assuntos conversados. Ele encoraja a manutenção dos relacionamentos após o término do tratamento. Recompense os participantes por sua cooperação e participação.

Atividade 2: Enfrentamento ao vivo (alta ansiedade) $.80 \mathrm{~min}$

Pratique por exposição imaginária, dramatização e/ou verbalmente o plano de enfrentamento de 4 passos em situações ao vivo que tendem a gerar altos níveis de ansiedade em cada criança: Novamente, prepare situações de elevada ansiedade, especificamente moldadas para os medos de cada criança, para serem realizadas em locais onde os membros do grupo devem experimentar alto nível de estresse. Cada criança participa das situações de ansiedade individualmente; entretanto, se o tempo não for bastante, as crianças podem participar de suas situações ao mesmo tempo.

\section{Hora de praticar}

Prepare situações de elevada ansiedade, especificamente moldadas para os medos de cada criança, para serem realizadas em locais onde os membros do grupo devem experimentar alto nível de estresse. Cada criança participa das situações de ansiedade individualmente; novamente, se o tempo não for bastante, as crianças podem participar de suas situações ao mesmo tempo. Faça um exercício de treino de relaxamento na situação, conforme for apropriado. A criança que está praticando na situação é estimulada a discutir suas reações somáticas e pensamentos, e a fazer modificações em suas auto-instruções de ansiedade. Os participantes podem ajudar se for absolutamente necessário; ainda, a criança participante é encorajada a usar o plano de 4 passos de forma independente. A criança deve desenvolver estratégias reais para enfrentar a situação e utilizá-las. Incentive cada criança a avaliar seu desempenho e recompensar a si mesma de forma adequada. Este processo é repetido com todos os participantes.

Planeje a gravação do comercial de TV: o grupo é lembrado sobre o vídeo divertido para ajudar a contar a outras crianças sobre como manejar ansiedade. O terapeuta assegura que os participantes trabalhem juntos responsavelmente, de tal forma que cada membro tem participação no planejamento do comercial. 
Jogo Eu me Lembro: As crianças tentam lembrar sobre o que cada um aprendeu e achou mais importante na sessão.

Atividade 3: Tarefa de casa

$.15 \mathrm{~min}$

Cada participante é solicitado a registrar duas experiências de ansiedade, anotando suas atividades para cada etapa do plano de enfrentamento de 4 passos. Os participantes e o terapeuta determinam o que cada criança deve preparar em casa para a gravação do comercial durante a sessão seguinte, como cenários e figurinos. Os membros do grupo recebem os recursos necessários e são lembrados de que a última sessão envolverá a gravação de um comercial real de televisão. Lembre ao grupo que restam duas sessões e discuta os sentimentos de todos a respeito do término do grupo. Incentive a manutenção das amizades formadas durante o tratamento.

Tarefa Amigo: Cada participante deve entrar em contato com seu amigo e é incentivado a desenvolver seu próprio plano do que dizer.

Atividade 4: Formulário de Feedback $.5 \mathrm{~min}$

Entregar para cada um preencher o formulário de Feedback do encontro do dia. Para o coterapeuta e o observador: avaliar o terapeuta do dia na Escala Cognitiva (Young \& Beck, 1988)

\section{Sessão 9}

Objetivo Geral: Continuar a prática de aplicação das habilidades de enfrentamento da ansiedade em situações ao vivo que produzam altos níveis de ansiedade em cada criança (Nota: as exposições ao vivo desta sessão envolvem os participantes individualmente).

\section{Material:}

02 Pontos para a tarefa CEI para cada um que fizer a tarefa Imãs para tarefa Amigo

Pôster MEDO completo

Preparação para exposição

Prêmios sociais para trocar

Vale-prêmios

Caderno de exercícios (pg.)

Formulário de Feedback

Lista de Verificação de Competência para Terapeutas Cognitivo-Comportamentais

Os terapeutas devem pensar como agradecer cada criança e o colega pelo andamento do grupo.

\section{Atividades e Tarefas:}

Monte a Agenda do dia passando os cartões para cada um: Revisão da Tarefa Eu Consigo e da Tarefa Amigo, Mostrando-se preocupado?, Esperando que coisas ruins aconteçam?, Demonstrando atitudes e ações, Oba! Resultados e Recompensas, Tarefa Eu Consigo e Tarefa Amigo. 
Como na sessão anterior o grupo é orientado para conduzir a revisão das tarefas de casa. Assim, eles são responsáveis por escolher um líder e por detalhar o uso do plano de 4 passos de maneira organizada e eficiente. O terapeuta deve auxiliar caso seja necessário.

Revisão das tarefas "Amigo": Discuta a natureza do contato entre os amigos e os assuntos conversados no intervalo da sessão. O terapeuta pergunta sobre o uso dos passos MEDO nas situações em que os participantes não sabiam o que dizer aos amigos. O uso dos passos MEDO é parabenizado. Encoraje a manutenção dos relacionamentos após o término do tratamento. Comente que a semana que vem será a última sessão do grupo. Lembre que em janeiro e março eles voltaram para uma avaliação, mas não será mais em grupo. Incentive que eles mantenham contato por telefone, ORKUT, MSN. E que um pode ajudar o outro mesmo não estando juntos no grupo. Converse sobre o término do programa. Recompense os participantes por sua cooperação e participação.

Atividade 2: Enfrentamento ao vivo (alta ansiedade)

$70 \mathrm{~min}$

Pratique por exposição imaginária, dramatização e/ou verbalmente o plano de enfrentamento de 4 passos em situações ao vivo que tendem a gerar altos níveis de ansiedade em cada criança: Novamente, prepare situações de elevada ansiedade, especificamente moldadas para os medos de cada criança, para serem realizadas em locais onde os membros do grupo devem experimentar alto nível de estresse. Cada criança participa das situações de ansiedade individualmente; entretanto, se o tempo não for bastante, as crianças podem participar de suas situações ao mesmo tempo.

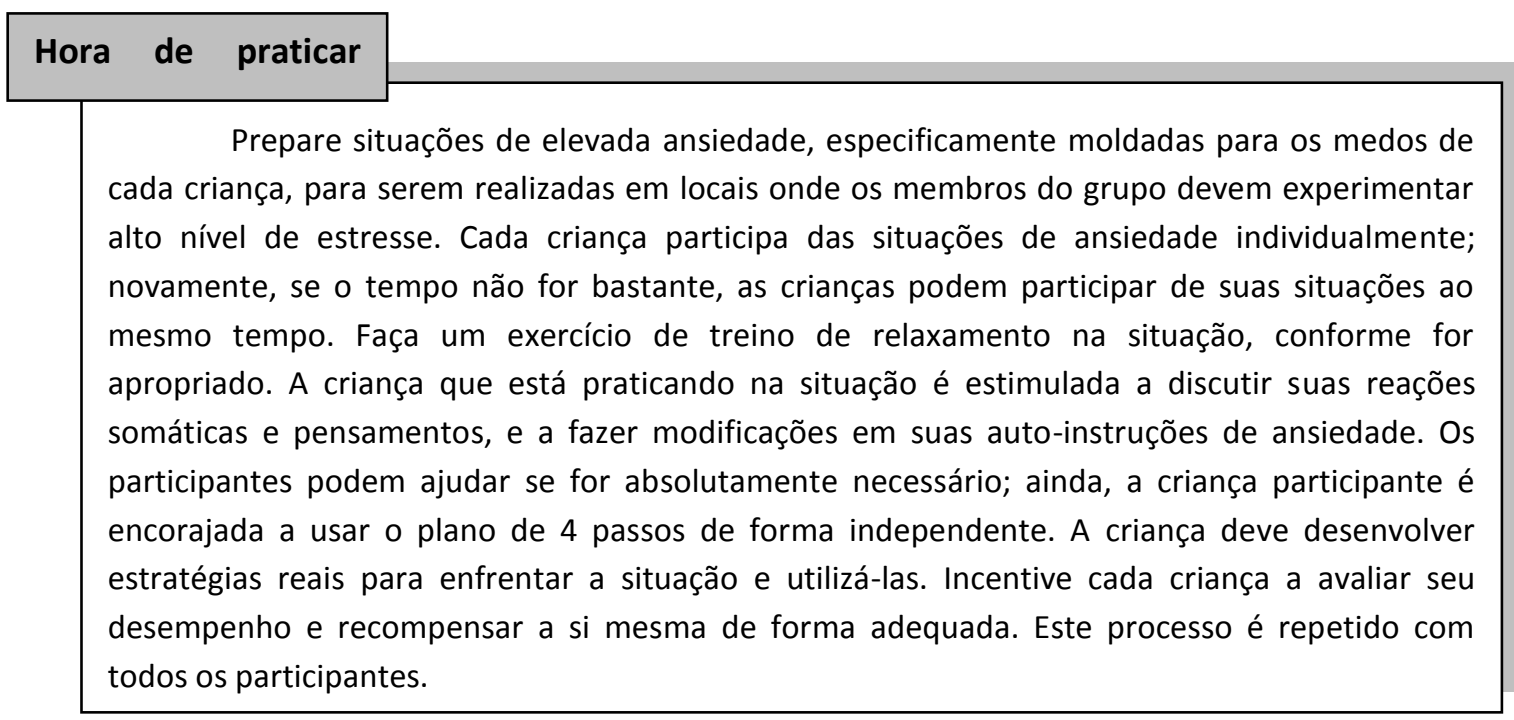

Atividade 3: Preparação do Comercial e da confraternização final. $.15 \mathrm{~min}$

O terapeuta combina com as crianças o que eles farão no comercial de TV, e incentiva as crianças dividirem papeis e tarefas. Lembre-os que a melhor forma de aprender é ensinar e o comercial terá este objetivo: deles ensinarem para outras crianças como elas podem enfrentar os medos como eles fizeram no grupo. 0 terapeuta assegura que os participantes trabalhem juntos responsavelmente, de tal forma que cada membro tem participação no planejamento do comercial. O mesmo é feito em relação a confraternização . Antecipe as possíveis dificuldades e como resolve-las. 
Os participantes e o terapeuta determinam o que cada criança deve preparar em casa para a gravação do comercial durante a sessão seguinte, como cenários e figurinos. Os membros do grupo recebem os recursos necessários e são lembrados de que a última sessão envolverá a gravação de um comercial real de televisão. Lembre ao grupo que resta apenas uma sessão e discuta os sentimentos de todos a respeito do término do grupo. Incentive a manutenção das amizades formadas durante o tratamento.

Jogo Eu me Lembro: As crianças tentam lembrar sobre o que cada um aprendeu e achou mais importante na sessão.

Atividade 4: Tarefa de casa.

$.10 \mathrm{~min}$

Cada participante é solicitado a registrar duas experiências de ansiedade, anotando suas atividades para cada etapa do plano de enfrentamento de 4 passos. Peça para que cada um escreva com as próprias palavras o que sentia e pensava antes do grupo começar e o que aprendeu no grupo, e que faça um agradecimento a cada um e a si mesmo pelo o que foi aprendido. Lembre as crianças que o objetivo do programa não era ficar livre da ansiedade, mas aprender a conviver com ela. E que cada um está mais preparado para enfrentar os seus medos desde que continuem a treinar os 4 passos.

Tarefa Amigo: Cada participante deverá entrar em contato com cada amigo e terapeuta para agradecer e explicar de que forma aquela pessoa o ajudou no grupo, e é incentivado a desenvolver seu próprio plano do que dizer. Cada terapeuta oferece um modelo agradecendo o esforço específico de cada criança e cada colega conforme preparado previamente. NOTA: lembre o grupo que os ganhos do time representam o esforço de cada e a confiança inspirada pelo grupo.

Atividade 5: Formulário de Feedback.

$.5 \mathrm{~min}$

Entregar para cada um preencher o formulário de Feedback do encontro do dia. Para o coterapeuta e o observador: avaliar o terapeuta do dia na Escala Cognitiva (Young \& Beck, 1988)

\section{Sessão 10}

Objetivo Geral: Revisar e resumir o programa de treinamento, e começar a trazer o encerramento para os relacionamentos terapêuticos.

\section{Material:}

02 Pontos para a tarefa CEI para cada um que fizer a tarefa

01 Estrela para tarefa Amigo para cada um que fizer a tarefa Pôster MEDO completo

Quadro da Tarefa Amigo

Caderno de exercícios (pg.)

Preparar o material para o encerramento

Quebra-cabeça com a foto do "Time"

Material para o comercial

Filmadora

Notebook

Data-show 


\section{Atividades e Tarefas:}

Atividade 1: Revisão da tarefa $15 \min$

O grupo é orientado para conduzir a revisão das tarefas de casa. Assim, eles são responsáveis por escolher um líder e por detalhar o uso do plano de 4 passos de maneira organizada e eficiente. A discussão deve enfatizar cada sucesso que tenha sido obtido. Recompense os participantes por sua cooperação e participação.

Atividade 2: Gravação do comercial $50 \mathrm{~min}$

Converse com o grupo para os acertos finais para filmagem, e adicione os materiais que os participantes prepararam em casa àqueles já prontos. Tente realizar um ensaio e faça mais de um, se necessário. Grave um breve comercial e reveja junto com o grupo. Pergunte aos participantes se eles gostariam de compartilhar o vídeo com seus pais, e convide-os a assistir junto com o grupo se for o caso.

Atividade 3: Evento social do grupo

$25 \mathrm{~min}$

Reserve tempo suficiente na sessão para envolver todos em um evento social do grupo, como uma festa, um jantar ou um passeio no campo. Durante o evento, incentive a discussão sobre os relacionamentos formados durante o tratamento e estimule sua manutenção. Agradeça aos participantes por todo seu esforço e promova uma discussão sobre os ganhos obtidos no tratamento - tanto os objetivos individuais e do grupo que foram atingidos.

Agende um encontro com os pais de cada criança durante as próximas duas semanas, e lembre-os de que eles precisarão comparecer: a sessão final é um encontro de avaliação, uma oportunidade para o terapeuta revisar o progresso de cada criança com seus pais e ela própria, e uma chance para o terapeuta despedir-se individualmente de cada criança. Peça aos pais para trazerem o número de telefone, o endereço e outros dados de contato atualizados, para eles mesmos e para contato durante o seguimento. Explique cuidadosamente para cada criança o que irá acontecer na sessão de avaliação e planeje a inclusão de um breve ritual de despedida envolvendo o terapeuta e a criança. 


\section{Objetivo Geral:}

Completar a avaliação final do tratamento, revisar e resumir o programa de tratamento, fazer planos com os pais para ajudar a criança a manter os ganhos e a generalizar a novas habilidades adquiridas tanto de enfrentamento da ansiedade como de relacionamento entre pares.

\section{Material:}

CBCL, MASC, CDI, SNAP, Inventário de satisfação do consumidor e certificado

\section{Atividades e Tarefas:}

É necessário que outra pessoa ajude o terapeuta nesta sessão de avaliação. A avaliação do tratamento com os membros do grupo deverá ser conduzida individualmente com cada participante. A avaliação no programa de tratamento consiste em:

(a) Descrever os progressos das crianças junto com os pais, revisando as facilidades e dificuldades das crianças no programa.

(b) Revisar para os pais o acróstico MEDO e o plano de 4 passos e encorajar a criança a ajudar a descrevê-lo para os pais. Encorajá-los a incentivarem a criança a usar o plano de enfrentamento quando começarem a se sentirem ansiosos.

(c) Pergunte aos pais se gostaria de fazer alguma pergunta adicional. Quando eles parecerem confortáveis, solicite que deixem a sala por alguns minutos ficando apenas a criança com o terapeuta.

(d) Aplicar na mãe: o $\mathrm{CBCL}$ - peça para ela considerar com a criança está na ultima semana e o Inventário de satisfação do consumidor (Marinho, 1997). Aplicar na criança: MASC, SNAP e CDI.

(e) Compartilhe com a criança um pequeno "ritual de despedida". Isto pode incluir a entrega de um certificado ou outra forma de comemoração pelo término do programa de tratamento. Durante este momento, compartilhe coisas que marcaram durante o tratamento e solicite que a criança faça o mesmo. Incentive a criança a continuar praticando as novas habilidades para aumentar a confiança no sucesso obtido por elas. Diga a criança que o terapeuta irá ligar daqui 3 semanas para ver como estão as coisas e perguntará se ele gostaria de uma ligação de ajuste ou uma sessão. É entregue para criança o telefone de contato para falar com o terapeuta caso seja necessário algum ajuste antes das três semanas. 


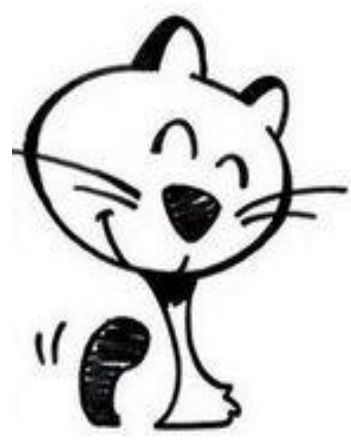

Caderpo de

Atividades 


\section{Este caderno é seu!}

Escreva o seu nome, idade, data de nascimento, endereço e telefone nos espaços abaixo:

Nome:

Idade: Data de Nascimento:

Telefones:

Endereço:

\section{Terapeutas:}

1. Nome: Telefone:

2. Nome: Telefone:

3. Nome: Telefone:

Agora aqui anote o nome, idade, data de nascimento e telefone nos "Amigos do Grupo" nos espaços abaixo:

Nome: Aniversário:

Telefones: E-mail:

Nome: Aniversário:

Telefones: E-mail:

Nome: Aniversário:

Telefones: E-mail:

Nome: Aniversário:

Telefones: E-mail:

Nome: Aniversário:

Telefones: E-mail:

Nome: Aniversário:

Telefones: E-mail: 


\section{Contrato de trabalho: Criança}

\section{Objetivos:}

1. Ajudar você e o grupo a reconhecer as emoções, as respostas fisiológicas e os pensamentos que levam a ansiedade.

2. Ensinar e treinar você e o grupo a enfrentar os problemas que são consequências da ansiedade, a partir de uma intervenção psicológica na abordagem cognitivo-comportamental

3. Criação de um ambiente amigável de discussão, de ajuda e de troca de experiências sobre as dificuldades de cada um.

Local das sessões:

Número de sessões com você e o grupo: vocês serão atendidos em 10 sessões semanais, e 3 sessões de seguimento (um mês depois; três meses; e seis meses).

Número de sessões com os pais: além de vocês iremos conversar só com seus pais em 4 sessões, a 1a no sábado dia ________ $/ 201$, das $10 \mathrm{~h}$ às $11 \mathrm{~h}$, e outras vezes no mesmo dia e horário que você virá nas sessões 3a 7 , 7 a e 9 a sessão. Conversaremos com você e seus pais juntos antes da 6ạ sessão e depois da 10a sessão. Atenção: Caso seja necessário, sessões individuais com você, pais ou ambos podem ser agendadas.

Dia e horário das sessões: o seu atendimento será na segunda das 8h15 às 10h15.

Início e término das sessões semanais: nosso grupo irá iniciar no dia e terminará no dia

Faltas: Este tratamento precisa que você venha a todas as sessões programadas, afinal são apenas 10 encontros!! Quando você falta isto irá te atrapalhar. Além disso, seremos um time. Em um time todo "jogador" é essencial, assim a sua falta também irá atrapalhar o andamento do grupo. Caso haja uma necessidade de faltar, avise-nos o quanto antes, por telefone, para que seja possível marcar uma reposição em outro horário. Se você faltar mais de duas vezes infelizmente terá que deixar o grupo.

Banco de pontos: Você será desafiado a fazer algumas atividades fora do grupo que se chamam: "EU CONSIGO". Estas atividades ajudarão você a enfrentar os medos, preocupações e ansiedade mais rápido e por mais tempo. Esta é uma forma de você utilizar outros lugares para treinar o que foi trabalhado na sessão. As atividades serão passadas sempre no final de cada sessão e antes de cada uma iremos conversar sobre o que você fez. Cada atividade realizada valerá 2 pontos, que podem ser trocados por prêmios, que iremos combinar, a cada três sessões. Cada prêmio terá um valor e exigirá que a você alcance um número de pontos para obtê-la. Você também poderá ganhar pontos extras pelo ser esforço e participação.

Sigilo: como seremos um time, é importante confiarmos um no outro. Para isso é essencial que você não comente para ninguém o que os outros falaram ou fizeram no grupo. $\boldsymbol{O}$ que acontece no grupo fica no grupo. Lógico que você pode comentar o que você fez ou falou.

Brasília, 4 de outubro de 2010.

Assinatura do participante: 


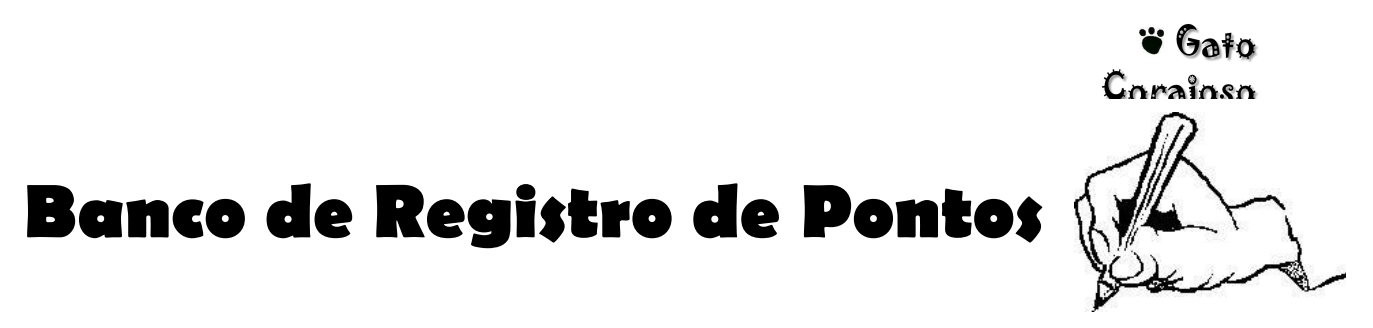
Eu Consigo

\begin{tabular}{|c|c|c|}
\hline Sessc̃o 1 & Sessc̃॰ 2 & Sessã๑ 3 \\
\hline TROCA* & รessũo 4 & Sessc̃o 5 \\
\hline Sessc̆o 6 & TROCA & Sessä० 7 \\
\hline Sessc̆๑ 8 & รessc̄๑ 9 & TROCA \\
\hline
\end{tabular}




\section{Prêmios}

\section{Recompensas}

Pontes

\begin{tabular}{l|l}
\hline 1. & \\
\hline 2. & \\
\hline 3. & \\
\hline $4 \cdot$ & \\
\hline 5. & \\
\hline 6. & \\
\hline $7 \cdot$ & \\
\hline 8. & \\
\hline 9. & \\
\hline 10. & \\
\hline $11 \cdot$ & \\
\hline 12. & \\
\hline $13 \cdot$ & \\
\hline
\end{tabular}




\section{Prêmios Sociais}

\section{Recompensas}

Pontos

\begin{tabular}{l|l}
\hline 1. & \\
\hline 2. & \\
\hline 3. & \\
\hline $4 \cdot$ & \\
\hline 5. & \\
\hline $6 \bullet$ & \\
\hline $7 \cdot$ & \\
\hline 8. & \\
\hline 9. & \\
\hline 10. & \\
\hline $11 \bullet$ & \\
\hline 120 & \\
\hline $13 \cdot$ & \\
\hline
\end{tabular}




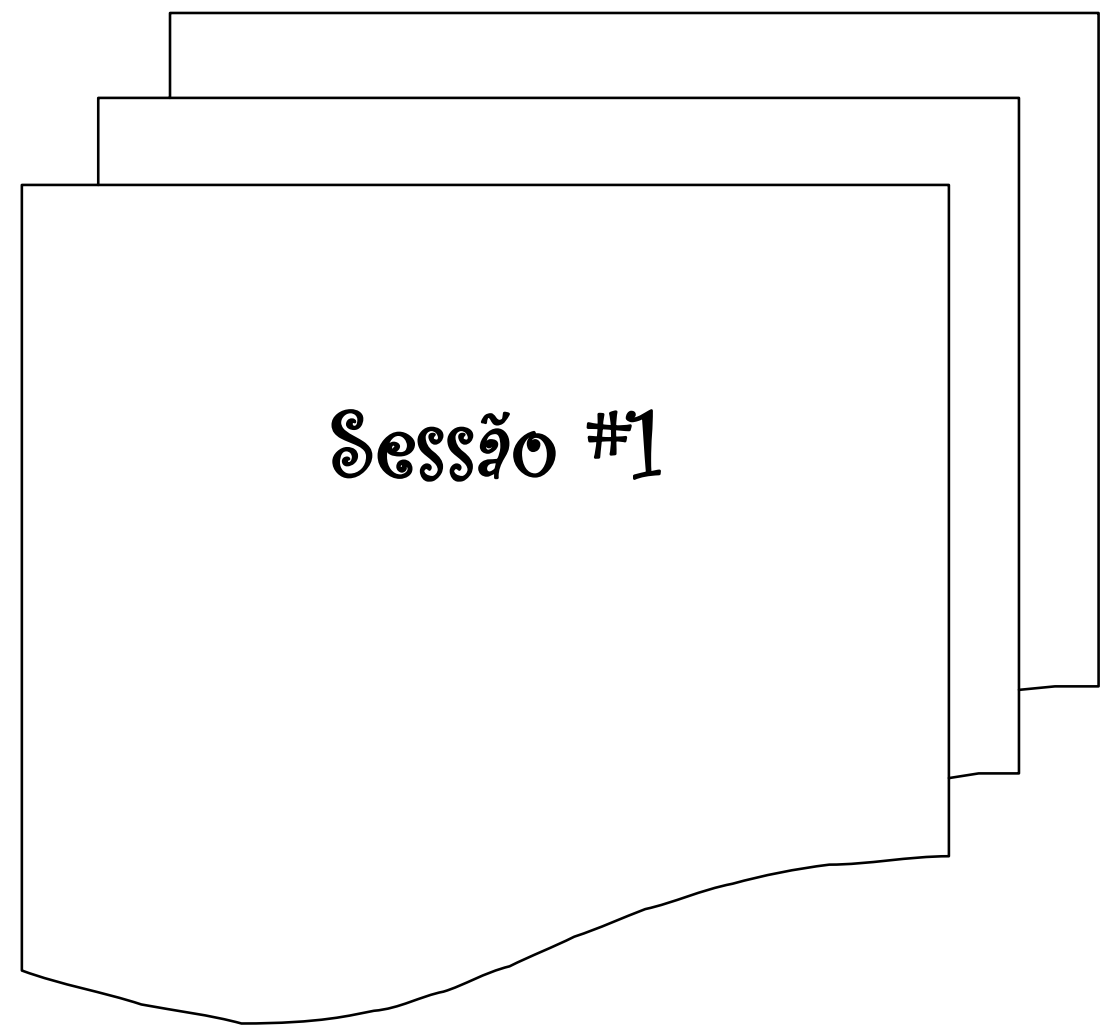




\section{Eu Consigo: હessão \#1}

Escorregadores

\section{Escadas}




\section{Eथ Consigo: હessão \#1}

Descreva um momento desta semana quando você se sentiu realmente bem. Quando você não estava chateada(o) ou preocupada(o). Lembre-se de descrever a situação na qual você estava, o que você pensou e o que você sentiu. 


\section{Formulário de Feedback*}

*Adaptado de Friedberg e cols, 2004 por Fabiana Gauy

1) O quanto o grupo me ajudou hoje?

Muito

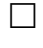

7
6

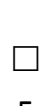

5
Um pouco

$\square$

4

Um pouco

Muito

6

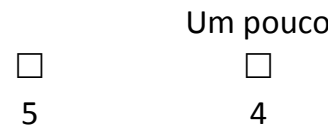

2) O quanto me diverti hoje?
7

6
Nada

$\square$

3

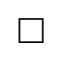

1

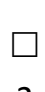

2

3) Hoje, Eu aprendi:

4) O quanto eu posso usar o que aprendi Na escola

Muito

$\square$

7

Em casa

Muito

7

Com meus amigos

Muito

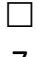

7

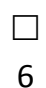

6
Um pouco

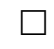

4
Nada

1

$\begin{array}{cc} & \text { Nada } \\ \square & \square \\ 2 & 1\end{array}$




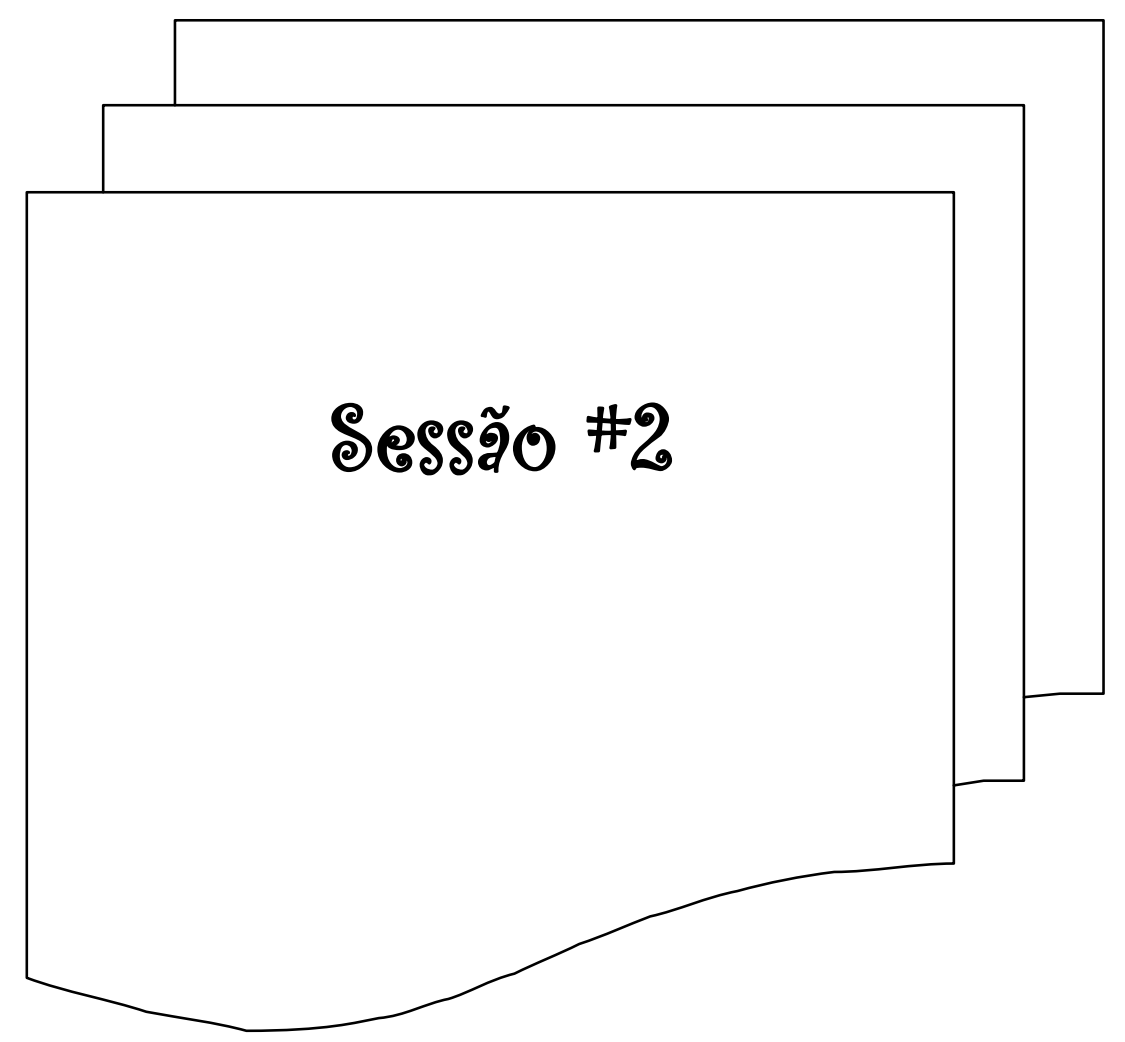




\section{caça-palaUras}

Nome:

Data:

$\begin{array}{llllllllllllllll}N & C & A & L & M & N & R & A & F & \text { I } & N & O & P & Q & R & A\end{array}$

$\begin{array}{llllllllllllllll}O & F & E & E & R & U & T & N & E & D & O & D & R & A & R & M\end{array}$

$\begin{array}{llllllllllllllll}J & R & A & I & V & A & D & S & E & R & T & \text { I } & D & R & F & O\end{array}$

$\begin{array}{llllllllllllllll}O & D & R & E & V & T & A & \text { I } & M & E & D & O & T & U & \text { I } & R\end{array}$

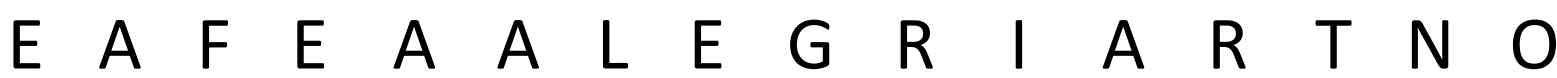

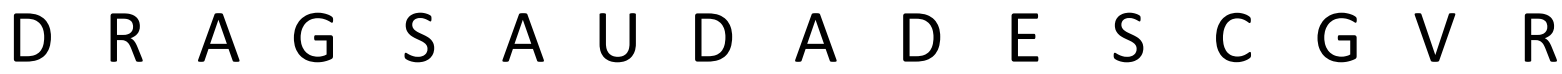

$\begin{array}{llllllllllllllll}V & E & R & G & O & N & H & A & F & T & E & D & I & O & E & G\end{array}$

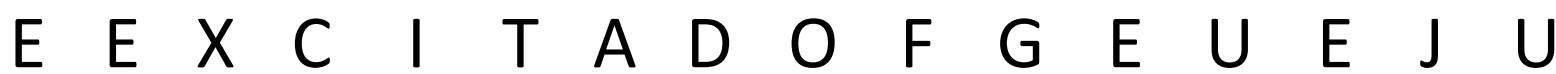

$\begin{array}{llllllllllllllll}R & E & R & D & E & V & B & E & B & N & M & \text { I } & M & R & A & L\end{array}$

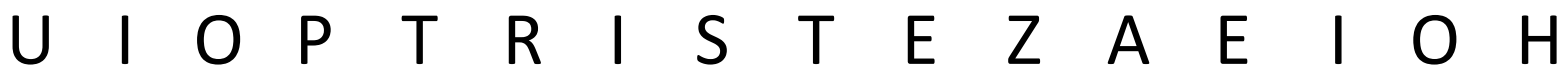

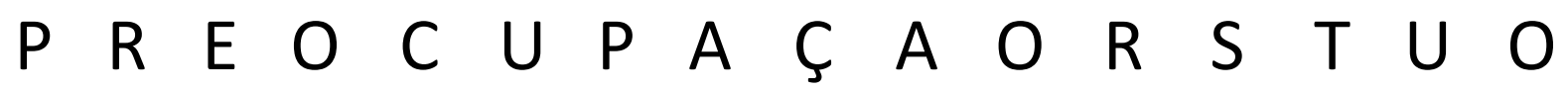

Encontre as seguintes palavras:

Alegria

Tristeza

Ciúmes

Orgulho

Excitado

Amor

Medo

Nojo

Tédio

Saudades

Raiva

Vergonha

Ansiedade

Preocupação Ódio

Inveja 


\section{Ligue-Ligue}

Nome:

Data:

Quando as pessoas sentem certas emoções como alegria ou tristeza, elas sentem algumas mudanças no corpo. Por exemplo, quando as pessoas estão tristes, geralmente elas choram. Você pode também apontar uma pessoa que está envergonhada porque ela ficou ruborizada. Tente associar os sentimentos abaixo com as reações corporais que você acha que pode acontecer quando alguém está se sentindo daquele jeito. Lembre-se de que um sentimento pode ter mais de uma reação corporal.

\section{REACOES CORPORAIS}

EMOGAO

Triste

Surpreso

Feliz

Irritado

Nervoso

Amedrontado

Nojo

Preocupado

Orgulhoso

Ansioso
Tensão

Mãos frias

Face ruborizada

Tremor

Mãos molhadas

Dor de barriga

Desconforto na barriga

Mal estar físico

Dor de cabeça

Vômito

Olhos arregalados

Coração disparado

Dificuldade para relaxar

Inquietação 
Dupla:

Onde e como vocês sentem as emoções no coppo?

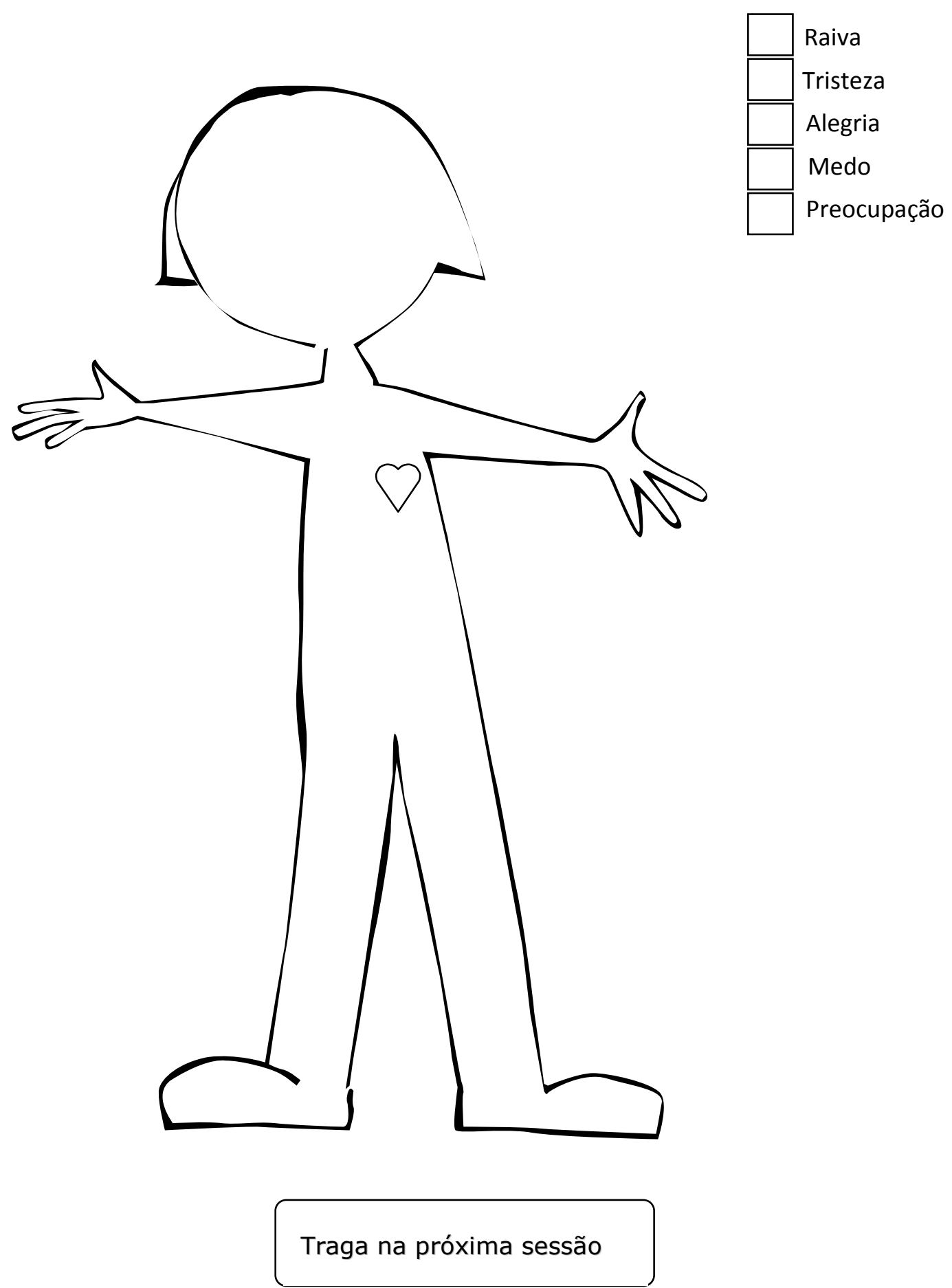




\section{Eu Consigo: હessão \#2}

Escreva sobre duas situações que aconteceram com você esta semana. Uma situação deve ser um momento no qual você se sentiu relaxado, e outra que você se sentiu ansioso, com medo ou preocupado. Lembre-se de descrever as situações, em que você estava pensando e o que você estava sentindo.

Fiđue atebto pa diferebça das duas situações!

\section{Situação \# 1 (relaxado):}

O que pensou::

O que sentiu:

\section{Situação \# 2 (ansioso):}

O que pensou:

O que sentiu:

\section{Tarefa Detetive dos sentimentos}

Observe alguém nesta semana. Pode ser alguém da sua família, ou um amigo. Como pode você dizer o que esta pessoa está sentindo se ela não falar a você?

Nome da outra pessoa:

Situação:

Os sentimentos da outra pessoa:

O que você viu que foi uma pista/dica do que a outra pessoa estava sentindo? 


\section{Formulário de Feedback*}

*Adaptado de Friedberg e cols, 2004 por Fabiana Gauy

1) O quanto o grupo me ajudou hoje?

Muito

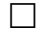

7
6

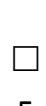

5
Um pouco

$\square$

4

Um pouco

Muito

6

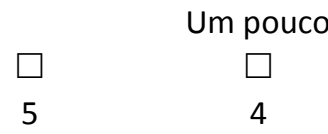

2) O quanto me diverti hoje?
7

6
Nada

$\square$

3

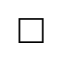

1

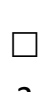

2

3) Hoje, Eu aprendi:

4) O quanto eu posso usar o que aprendi Na escola

Muito

7

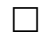

6

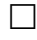

5
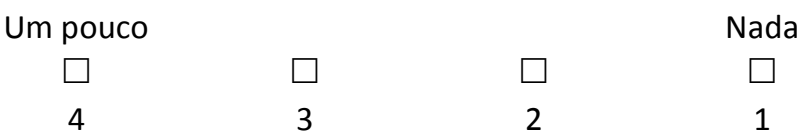

Em casa

Muito

7

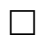

6

3

Nada

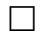

1

Com meus amigos

Muito

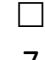

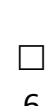

6

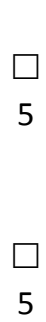

5
Um pouco

4

Um pouco

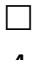

3

2

1

Nada

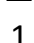

1

Nada

5) Caso você tenha alguma reclamações, sugestões ou comentários escreva aqui: 
๑อรSลั゚\#3

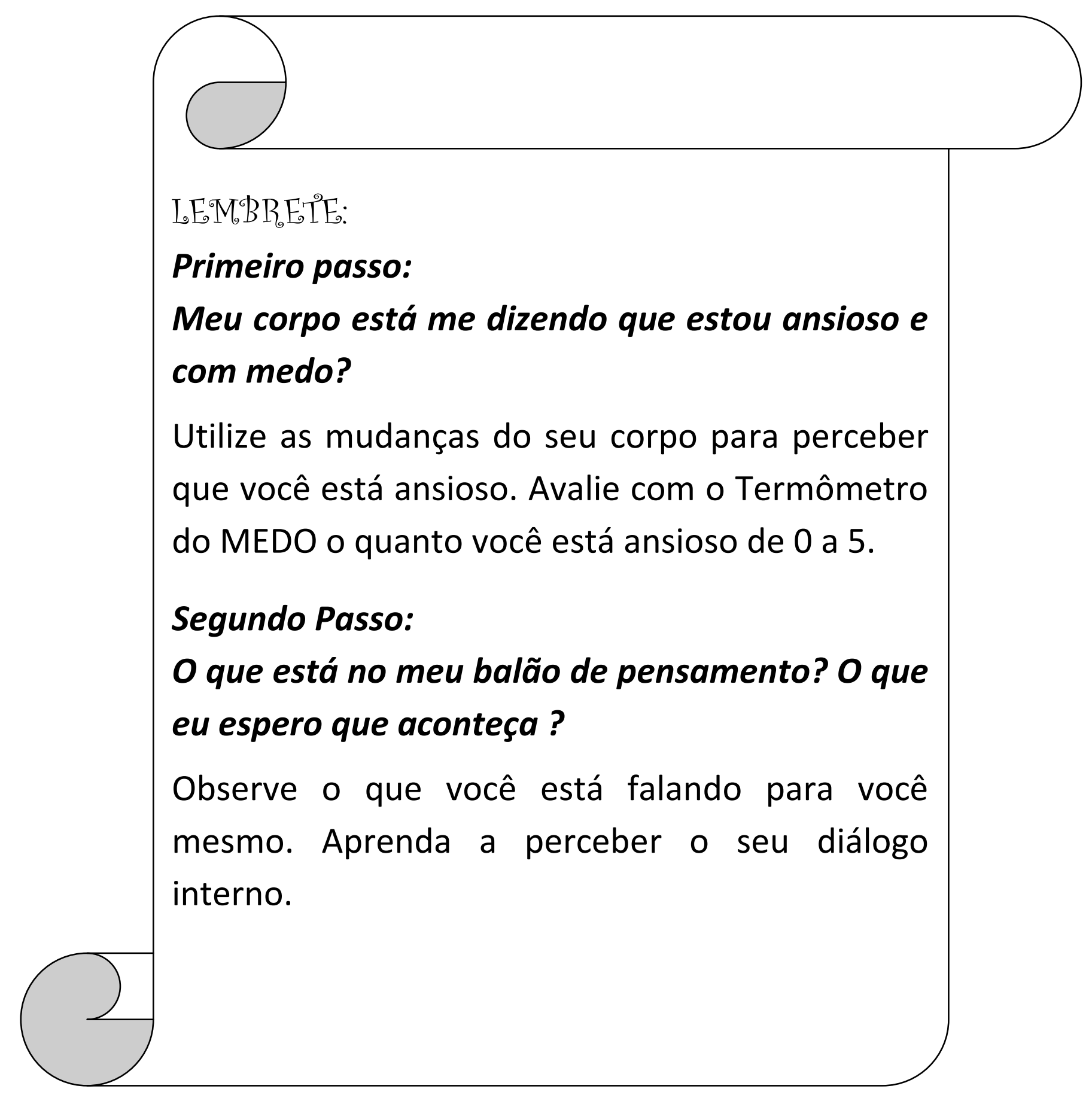




\section{Lista do Medo}

\section{Nome:}

Abaixo há uma lista de diversas situações (ou objetos) que muitas crianças têm medo. Marque um $\mathrm{X}$ na coluna ao lado da situação ou objeto, e avalie o quanto ela deixa você com medo utilizando o termômetro do medo de 1 a 5 .

\begin{tabular}{|l|l|l|}
\hline \multicolumn{1}{|c|}{ Situação ou objeto } & $\begin{array}{c}\text { Marque com x } \\
\text { se tiver medo }\end{array}$ & $\begin{array}{c}\text { Termômetro do } \\
\text { medo } \\
\text { (1-5) }\end{array}$ \\
\hline Estar longe dos familiares & & \\
\hline Sair mal na prova & & \\
\hline Brigar com os pais & & \\
\hline Andar de elevador & & \\
\hline Fazer prova & & \\
\hline Ir a uma loja sozinho(a) & & \\
\hline Fazer um pedido para o garçom & & \\
\hline Conhecer pessoas novas & & \\
\hline Encontrar um amigo dos pais & & \\
\hline Levar uma bronca da professora & & \\
\hline Ser suspenso da escola & & \\
\hline Ir para escola & & \\
\hline Dar a resposta errada & & \\
\hline Cometer um erro & & \\
\hline Ter que falar em público & & \\
\hline Ficar doente & & \\
\hline Morrer & & \\
\hline Uns dos pais adoecerem & & \\
\hline Um dos pais morrerem & & \\
\hline Ir a aniversários & & \\
\hline Dormir na casa de amigos(as) & & \\
\hline Andar de avião & & \\
\hline Andar de metrô ou ônibus & & \\
\hline Ficar perdido & & \\
\hline Sua festa de aniversário & & \\
\hline Ir ao médico ou dentista & & \\
\hline Ver sangue & & \\
\hline Nadar ou água & & \\
\hline Cachorro ou gato & & \\
\hline Cobras & & \\
\hline Trovão e relâmpago & & \\
\hline Ficar no escuro & & \\
\hline Ficar sozinho em casa & & \\
\hline Ser o centro das atenções & & \\
\hline Dormir na cama sozinho & & \\
\hline Imprevistos & & \\
\hline & & \\
\hline
\end{tabular}




\begin{tabular}{|c|c|c|}
\hline Situação ou objeto & $\begin{array}{l}\text { Marque com } x \\
\text { se tiver medo }\end{array}$ & $\begin{array}{c}\text { Avalie o medo } \\
\text { (1-3) }\end{array}$ \\
\hline \multicolumn{3}{|l|}{$\begin{array}{l}\text { Combinar com alguém de encontrar e a pessoa se } \\
\text { atrasar e não avisar, ou não atender o telefone }\end{array}$} \\
\hline \multicolumn{3}{|l|}{ Ser esquecido pelos pais em algum lugar } \\
\hline \multicolumn{3}{|l|}{ Ser alvo de provocações na escola pelos colegas } \\
\hline \multicolumn{3}{|l|}{ Deixar o lanche cair } \\
\hline \multicolumn{3}{|l|}{ Ir para casa de uma amigo } \\
\hline \multicolumn{3}{|l|}{ Dormir na casa de alguém } \\
\hline \multicolumn{3}{|l|}{$\begin{array}{l}\text { Estórias folclóricas ou Lendas urbanas (exemplo: } \\
\text { chupa-cabra, curupira, loira do banheiro) }\end{array}$} \\
\hline & & \\
\hline & & \\
\hline & & \\
\hline & & \\
\hline & & \\
\hline & & \\
\hline & & \\
\hline & & \\
\hline & & \\
\hline & & \\
\hline & & \\
\hline
\end{tabular}




\section{Eur Consigo: હesรão \#3}

Durante esta semana descreva duas situações nas quais você se sentiu com medo ou nervoso. Então, dê a essa situação uma nota, usando sua escala. Preste atenção também aos seus pensamentos.

Situação \# 1

Reação do meu corpo/Sentimentos

Termômetro do Medo:

Pensamento

Situação

Reação do meu corpo/Sentimentos

Termômetro do Medo:

Pensamento 


\section{Formulário de Feedback*}

*Adaptado de Friedberg e cols, 2004 por Fabiana Gauy

1) O quanto o grupo me ajudou hoje?

$\begin{array}{ccc}\text { Muito } & \\ \square & \square & \square \\ 7 & 6 & 5\end{array}$

Um pouco
$\square$
4

Muito

7

6

$\square$

Um pouco

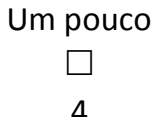

4

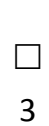

3
Nada

1

Nada

$\square$

1

3) Hoje, Eu aprendi:

4) O quanto eu posso usar o que aprendi Na escola

Muito

$\square$

7

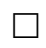

5

Um pouco

$\begin{array}{ll}\square & \square \\ 4 & 3\end{array}$

Um pouco

Muito

7

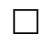

5

Com meus amigos

Muito

$\square$
7

6

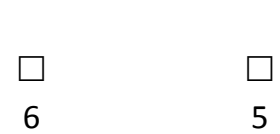

Um pouco

$\begin{array}{ll}\square & \square \\ 4 & 3\end{array}$

Nada

$\square$

1

Nada

1

Nada

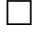

1

5) Caso você tenha alguma reclamações, sugestões ou comentários escreva aqui: 


\section{๑อรSล̃o \#4}

LEMMBRETE:

Primeiro passo:

Meu corpo está me dizendo que estou ansioso e com medo?

Relaxe! Acalme-se ! Use as suas estratégias de relaxamento, como a respiração diafragmática ou concentrar-se para relaxar os músculos tensos.

\section{Segundo Passo:}

0 que está no meu balão de pensamento? $O$ que eu espero que aconteça?

Eu tenho razão para pensar que isto irá acontecer? Isso já aconteceu antes? O que mais eu posso pensar nesta situação? (Desenvolver auto-instruções de enfrentamento e aplicá-las para ajudar a conceituação de situações com não amendrotadoras) 


\section{Esperando Coisas Ruins?}

Lembra que conversamos os balões de pensamentos? Nos seus "balões de pensamentos" estão o que você pensa e o que você diz para você mesmo dentro da sua cabeça. Chamamos esta conversa de diálogo interno. Você já deve ter percebido que o que você pensa ou diz para você mesmo ninguém escuta, mas o que talvez você ainda não saiba é que os seus pensamentos e diálogos internos afetam como você age. Vamos dar um exemplo: se você está preocupado(a) ou ansioso(a) com o teste de matemática e com isso ficar pensando que não irá conseguir, provavelmente você ficará ansioso(a) e talvez desista de estudar diante da primeira dificuldade. Chamamos isso de pensamento catastrófico ou ansioso. Agora se você pensar que pode enfrentar a situação e conseguir mudar os seus pensamentos, uma vez que você não tem dados suficientes de saber que não irá conseguir antes de tentar, a chance de você conseguir se concentrar nos estudos e sair melhor na prova aumenta. Chamamos isso de pensamentos de enfrentamento.

Abaixo há uma lista de pensamentos. Veja se você consegue reconhecer quais são pensamentos catastróficos e quais são pensamentos de enfrentamento. Marque um x no pensamento.

\begin{tabular}{|c|c|c|}
\hline & $\begin{array}{l}\text { Pensamento } \\
\text { catastrófico }\end{array}$ & $\begin{array}{l}\text { Pensamento de } \\
\text { enfrentamento }\end{array}$ \\
\hline \multicolumn{3}{|l|}{ Situação 1: Você irá encontrar uma pessoa que nunca viu antes } \\
\hline \multicolumn{3}{|l|}{ "Eu seu que está pessoa vai achar que eu sou bobo(a)" } \\
\hline \multicolumn{3}{|l|}{ "Se eu disser 'oi!', a pessoa irá pensar que eu só gentil" } \\
\hline \multicolumn{3}{|l|}{ "Eu não sou gosto de conhecer pessoa novas" } \\
\hline \multicolumn{3}{|c|}{$\begin{array}{l}\text { Situação 2: Você chama seu amigo da escola para vocês brincarem lá fora, mas ele diz que não pode } \\
\text { sair, nem brincar hoje }\end{array}$} \\
\hline \multicolumn{3}{|l|}{ "Talvez o meu amigo ainda não tenha terminado a tarefa ainda" } \\
\hline \multicolumn{3}{|l|}{ "Acho que ele não gosta de mim" } \\
\hline \multicolumn{3}{|l|}{$\begin{array}{l}\text { "Ele talvez esteja com algum problema, posso deixar para brincar } \\
\text { outro dia e perguntar para ele se posso ajudá-lo em algo" }\end{array}$} \\
\hline \multicolumn{3}{|l|}{ Situação 3: Você terá que fazer uma apresentação na escola } \\
\hline \multicolumn{3}{|l|}{ "Se eu errar o melhor é continuar apresentando" } \\
\hline \multicolumn{3}{|l|}{ "Se eu errar as pessoas irão rir de mim" } \\
\hline \multicolumn{3}{|l|}{ "Dará tudo certo hoje! Eu já passei por isso antes" } \\
\hline \multicolumn{3}{|l|}{ Situação 4: Você está sozinho sem os seus pais e ouve um barulho } \\
\hline \multicolumn{3}{|l|}{ "Meu Deus! É um ladrão" } \\
\hline \multicolumn{3}{|l|}{$\begin{array}{l}\text { "Eu penso que é melhor ligar para um amigo porque eu estou } \\
\text { nervoso" }\end{array}$} \\
\hline "Eu nunca mais vou ficar sozinho de novo!!" & & \\
\hline
\end{tabular}




\section{Eu Consigo: હessão \#4}

Durante esta semana descreva duas situações nas quais você se sentiu com ansiedade, medo, preocupado ou nervoso. Então, dê a essa situação uma nota, usando o termômetro. Preste atenção também aos seus pensamentos.

Situação

Reação do meu corpo/Sentimentos

Termômetro do Medo:

Pensamento

Situação

\#

Reação do meu corpo/Sentimentos

Termômetro do Medo:

Pensamento

Traga na próxima sessão 


\section{Registro do Relaxamento}

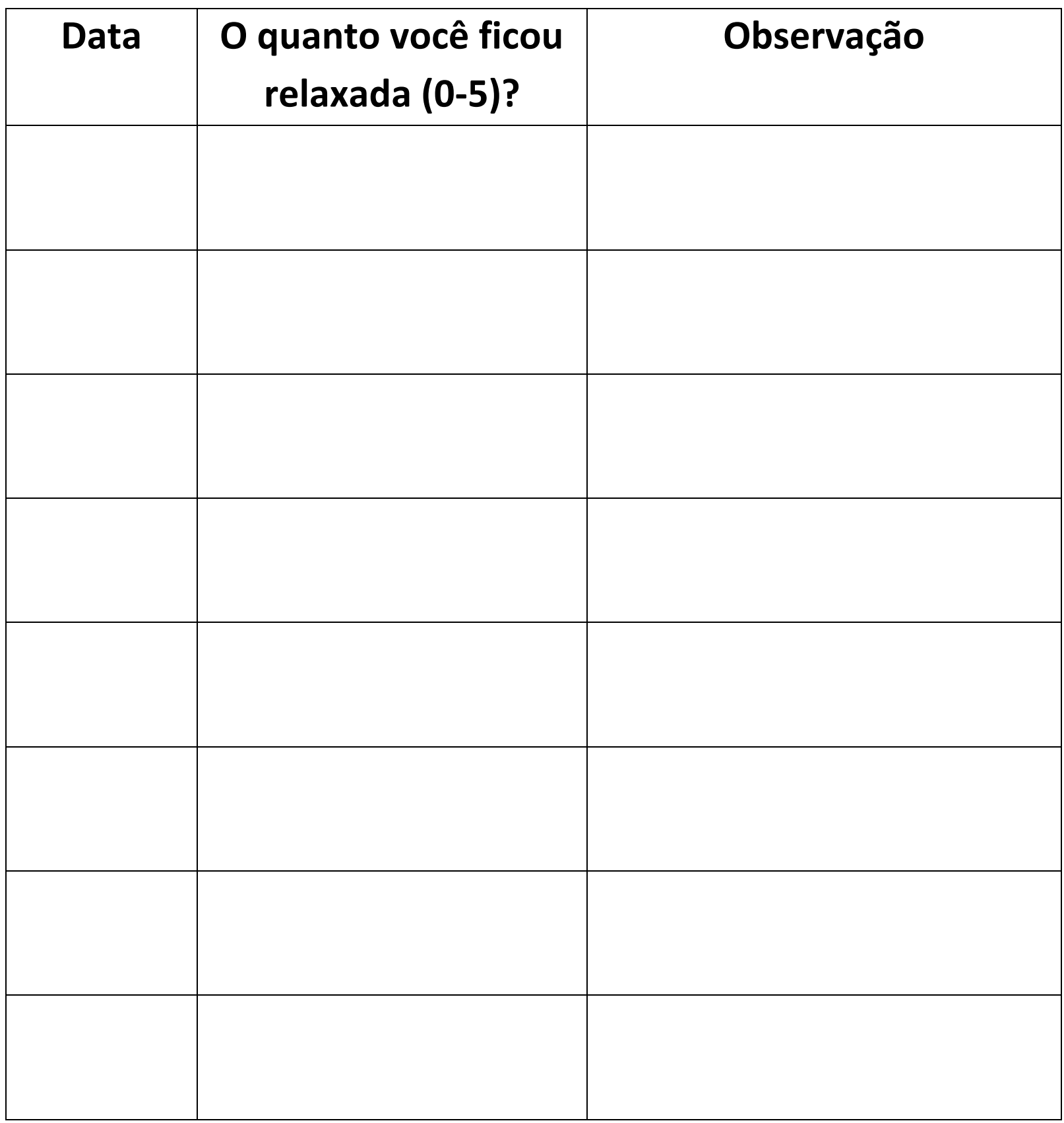

Traga na próxima sessão 


\section{Liste situações de baixa ansiedade (grau 1)}

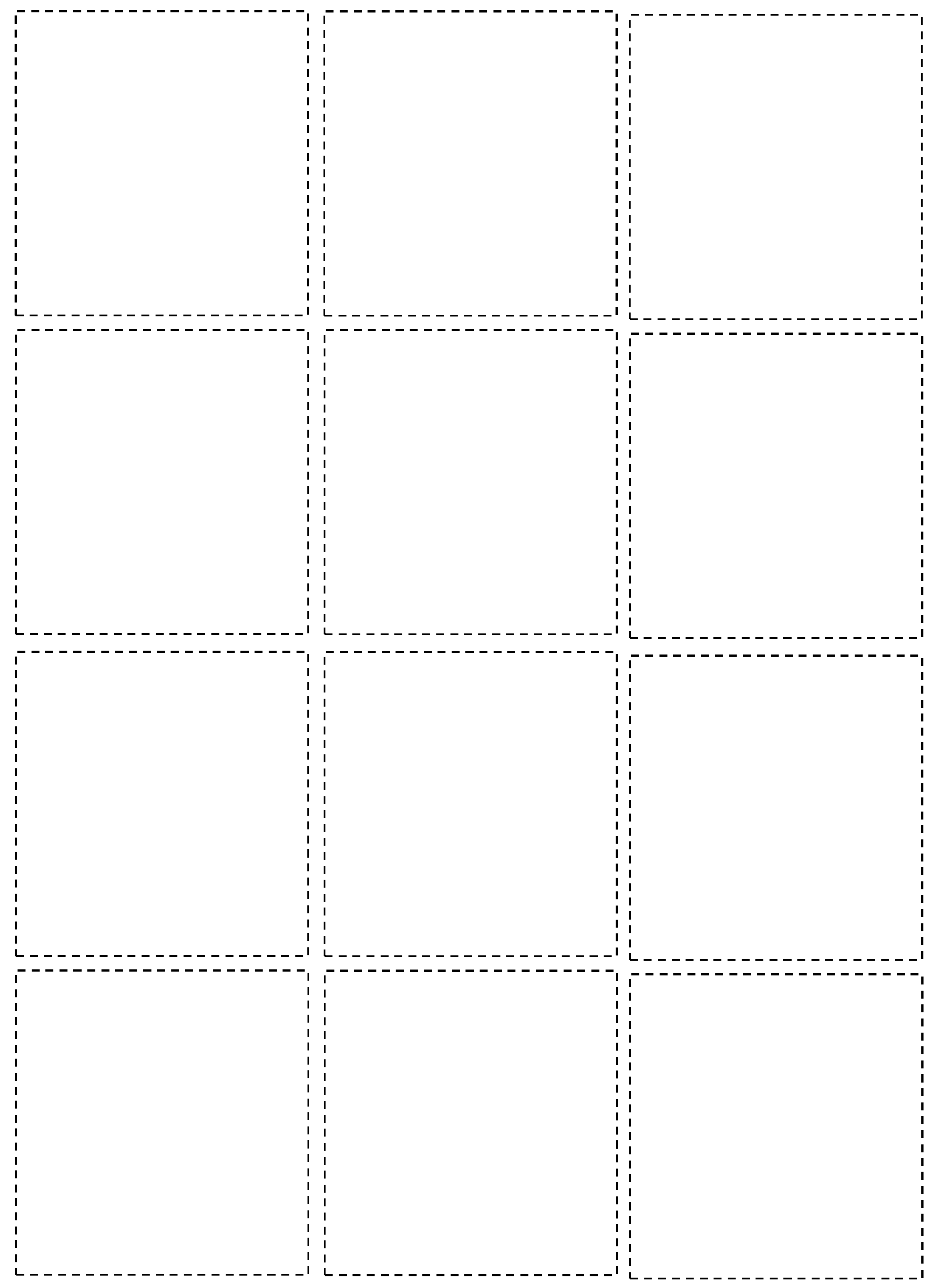




\section{Formulário de Feedback*}

*Adaptado de Friedberg e cols, 2004 por Fabiana Gauy

1) O quanto o grupo me ajudou hoje?

Muito

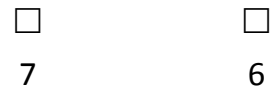

Um pouco

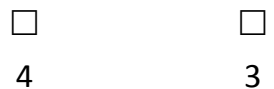

2) O quanto me diverti hoje?

Muito

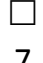

6

Um pouco

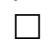

4
3

2
Nada

1

$\begin{array}{cc} & \text { Nada } \\ \square & \square \\ 2 & 1\end{array}$

Nada

$\square$

1

$\begin{array}{cc} & \text { Nada } \\ \square & \square \\ 2 & 1\end{array}$

3) Hoje, Eu aprendi:

4) O quanto eu posso usar o que aprendi Na escola

Muito

$\square$

7

Em casa

Muito

$\square$

7

Com meus amigos

Muito

$\square$

7
6

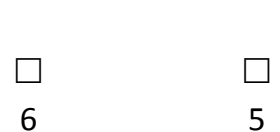

5

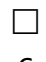

6

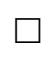

5

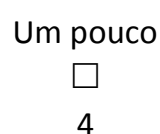

Um pouco

$\square$

Um pouco

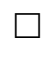

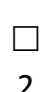

2

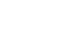




\section{Eu Consigo: હessão \#5}

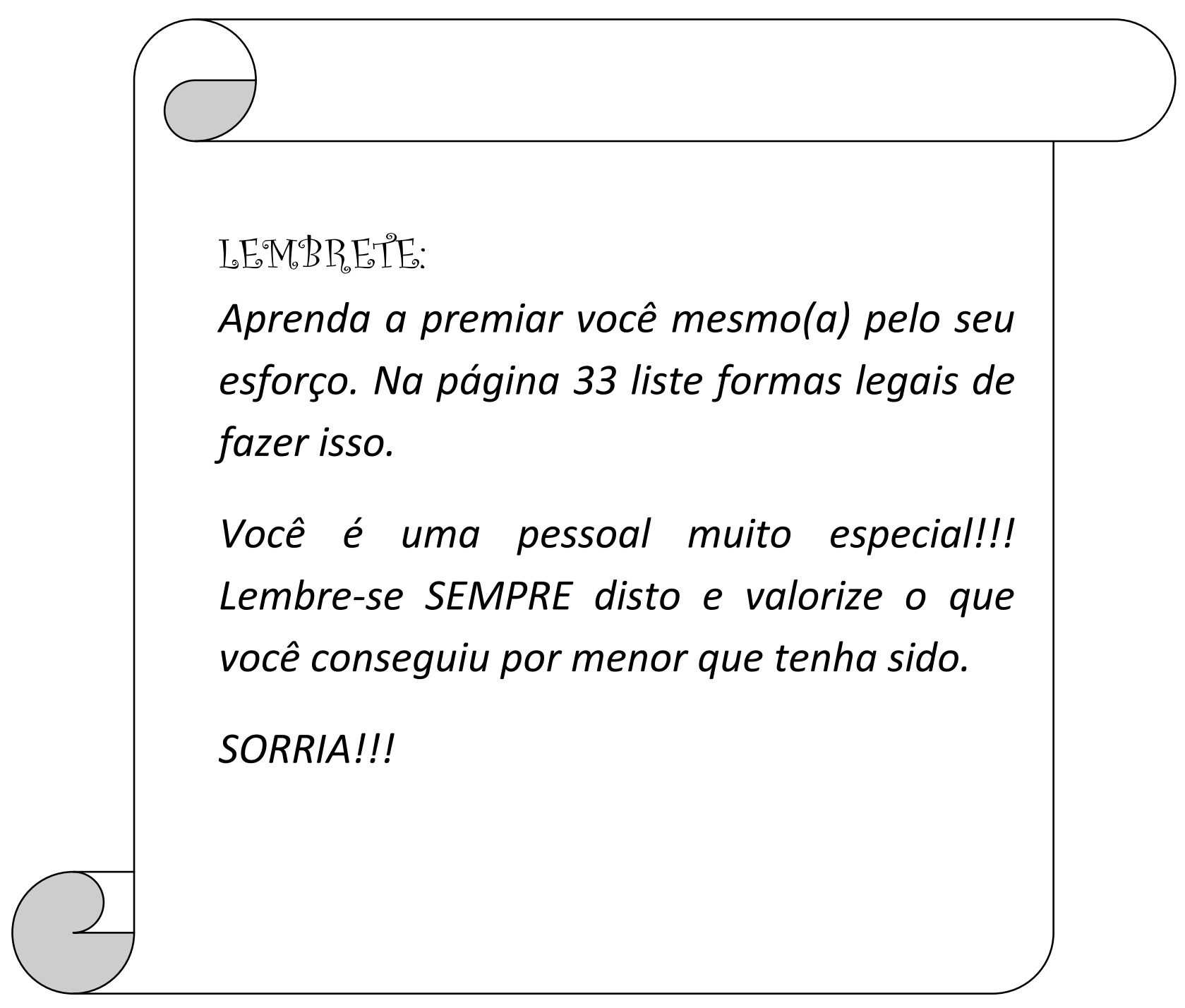


Você perdeu seus sapatos em algum lugar da casa, Você tem que encontrá-los ou chegará atrasada na escola

Questão 1: O que eu posso fazer para tornar esta situação menos assustadora?

(explore as alternativas para mudar a situação. Faça uma lista de todas as alternativas possíveis, Mesmo aquelas que obviamente não são as melhores).

Questão 2: Quais seriam as melhores coisas a fazer? (determine qual é a alternativa preferível e executável).

\section{Passo 3: Situação 2}

Você estava brincando com o seu jogo ou brinquedo preferido, mas sem querer você o estraga.

Questão 1: O que eu posso fazer para tornar esta situação menos assustadora?

(explore as alternativas para mudar a situação. Faça uma lista de todas as alternativas possíveis, mesmo aquelas que obviamente não são as melhores).

Questão 2: Quais seriam as melhores coisas a fazer (determine qual é a alternativa preferível e executável). 


\section{Eथ Consigo: હeรsão \#5}

Pratique os três passos: Mostrando-se ansioso e preocupado?, Esperando que o pior aconteça?, Demonstrando atitudes e ações.Durante esta semana descreva duas situações nas quais você se sentiu com medo ou nervoso. Preste atenção também aos seus pensamentos.

*Situação \# 1

Reação do meu corpo/Sentimentos

Termômetro do Medo:

Pensamento

Lidando com os pensamentos

Ações e atitudes que podem ajudar

Resultados e Recompensas

*Situação \# 2

Reação do meu corpo/Sentimentos

Termômetro do Medo:

Pensamento

Lidando com os pensamentos

Ações e atitudes que podem ajudar

Resultados e Recompensas 


\section{Liste situações de média ansiedade (grau 2)}

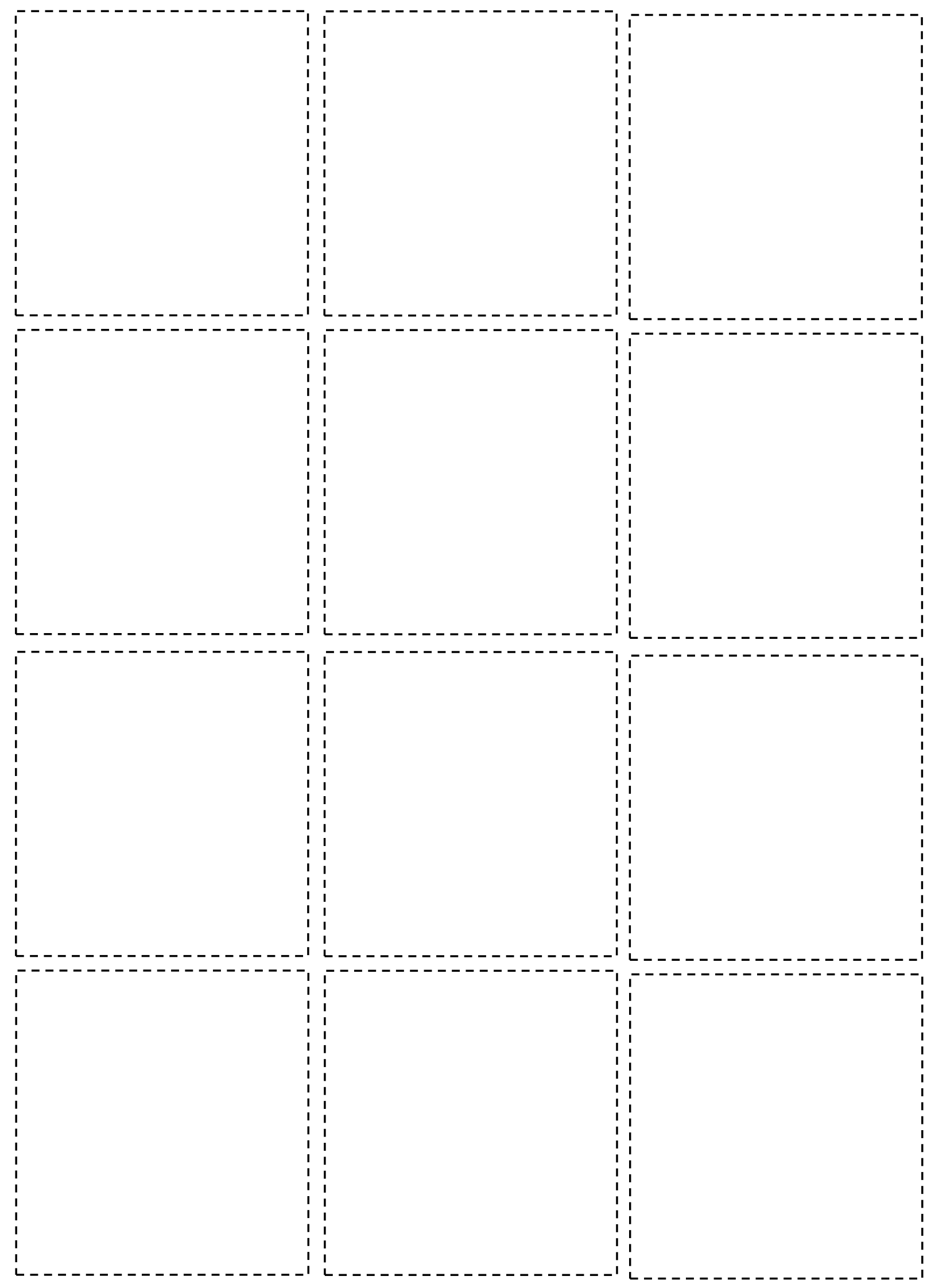


Lista de Tipos de Recompensas Que Eu Posso Me Dar:

1.

2.

3.

4.

5.

6.

7.

8.

9.

10.

11.

12.

13.

14

15. 


\section{Formulário de Feedback*}

*Adaptado de Friedberg e cols, 2004 por Fabiana Gauy

1) O quanto o grupo me ajudou hoje?

Muito

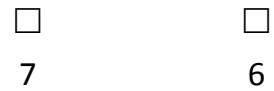

Um pouco

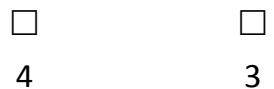

3

2) O quanto me diverti hoje?

Muito

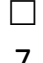

6

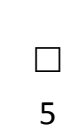

5
Um pouco

$\square$

4

3
Nada

1

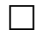

2

\begin{tabular}{cc}
\multicolumn{1}{c}{} & Nada \\
$\square$ & $\square$ \\
2 & 1
\end{tabular}

Nada

$\square$

1

2

3) Hoje, Eu aprendi:

4) O quanto eu posso usar o que aprendi Na escola

Muito

$\square$

7

5

Em casa

Muito

$\square$
7

Com meus amigos

Muito

$\square$

7
6

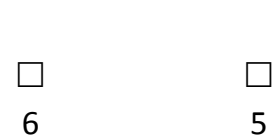

5

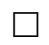

5

$\square$

Nada

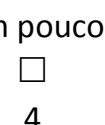

$\square$

3

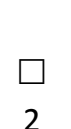

2 $\square$

1
Um pouco

$\square$
4

Um pouco

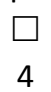

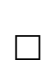

3
Nada

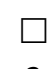

2

1
Nada

1

5) Caso você tenha alguma reclamações, sugestões ou comentários escreva aqui: 
SอรSลัO \#G

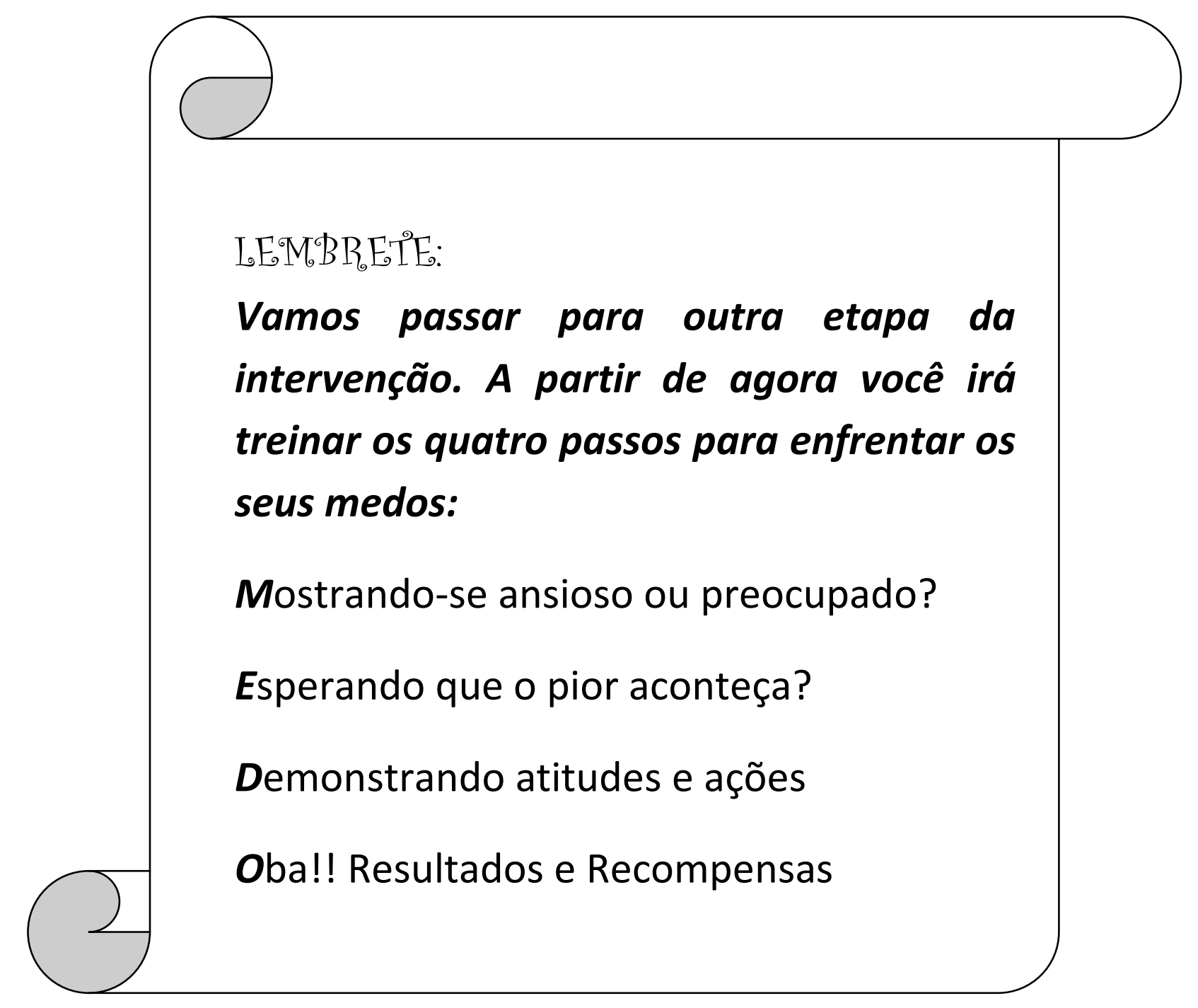




\section{PLAANO DE AÇ $\tilde{A} O$}

Objetivos

Datar_ا____

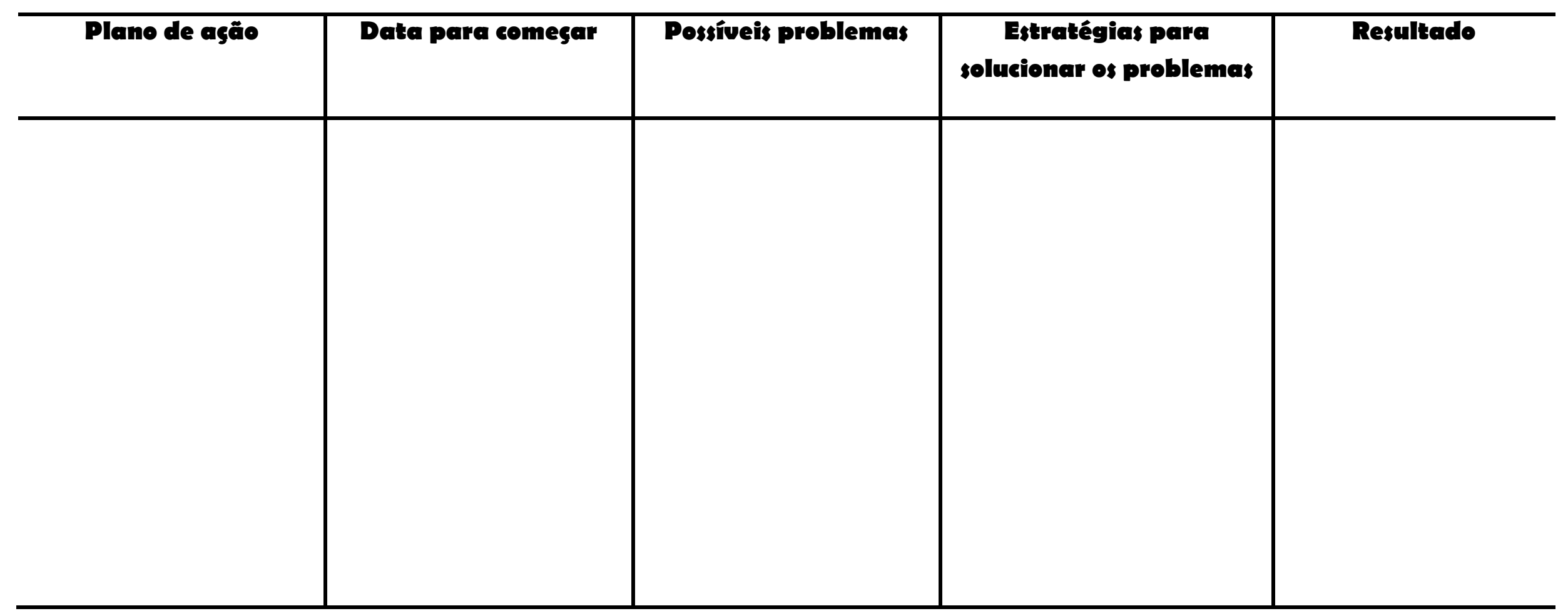




\section{$\because$ Gafo \\ Corajoso \\ Hora de praticar: Sîtuações fáceis!!!}

Você se lembra do plano MEDO?

Primeiro, uma rápida revisão. Escreva abaixo o plano MEDO. Se puder, escreva sem olhar no painel:

M

$\mathrm{E}$

D

O

Vamos hoje começar a praticar o enfrentamento de situações fáceis. O quanto você acha ficou preocupado(a)/ansioso(a)agora? Circule usando o TERMÔMETRO do MEDO

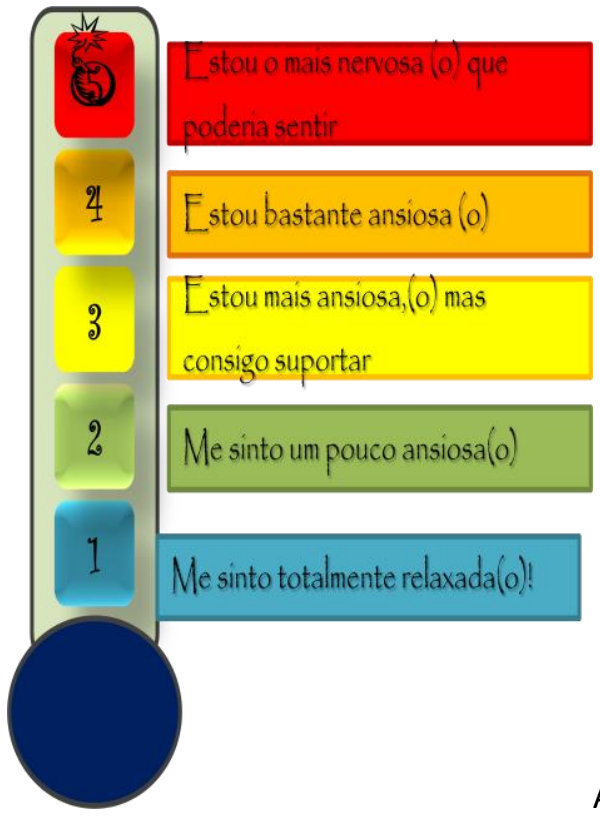

Anote aqui:

Como já conversamos em uma situação podem existir várias que te deixam preocupado. Pense em todas que conseguir se lembrar e avalie como poderia enfrentá-las:

Possíveis problemas

Estratégias 
Depois de avaliar o que o deixaria nervoso(a) ou ansioso(a) e pensar nas estratégias, avalie novamente o quanto você está preocupado(a)/ansioso(a)agora? Circule usando o TERMÔMETRO do MEDO

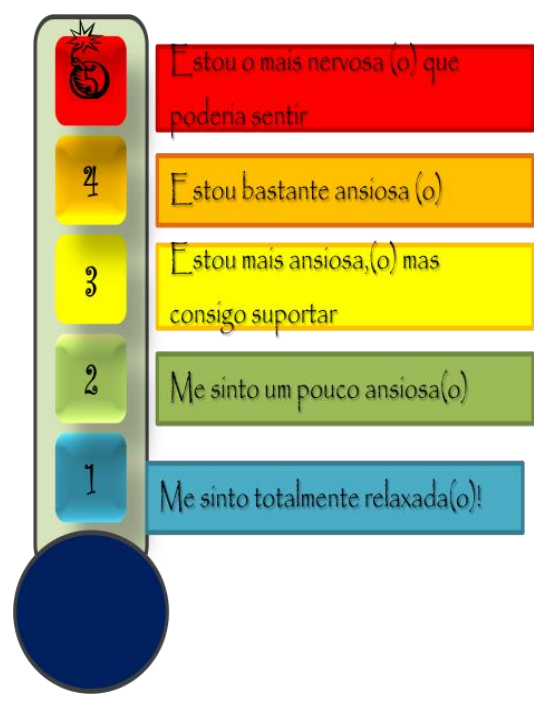

Anote aqui: 


\section{Eu Consigo: હessão \#6}

Pratique os três passos: Mostrando-se ansioso e preocupado?, Esperando que o pior aconteça?, Demonstrando atitudes e ações.Durante esta semana descreva duas situações nas quais você se sentiu com medo ou nervoso. Preste atenção também aos seus pensamentos.

*Situação \# 1

Reação do meu corpo/Sentimentos

Termômetro do Medo:

Pensamento

Lidando com os pensamentos

Ações e atitudes que podem ajudar

Resultados e Recompensas

*Situação \# 2

Reação do meu corpo/Sentimentos

Termômetro do Medo:

Pensamento

Lidando com os pensamentos

Ações e atitudes que podem ajudar

Resultados e Recompensas 


\section{Registro do Relaxamento}

\begin{tabular}{|l|l|l|}
\hline Data & $\begin{array}{c}\text { O quanto você ficou } \\
\text { relaxada (0-5)? }\end{array}$ & Observação \\
\hline & & \\
\hline & & \\
\hline & & \\
\hline & & \\
\hline & & \\
\hline & & \\
\hline & & \\
\hline
\end{tabular}

Traga na próxima sessão 


\section{Liste situações de média ansiedade (grau 3)}

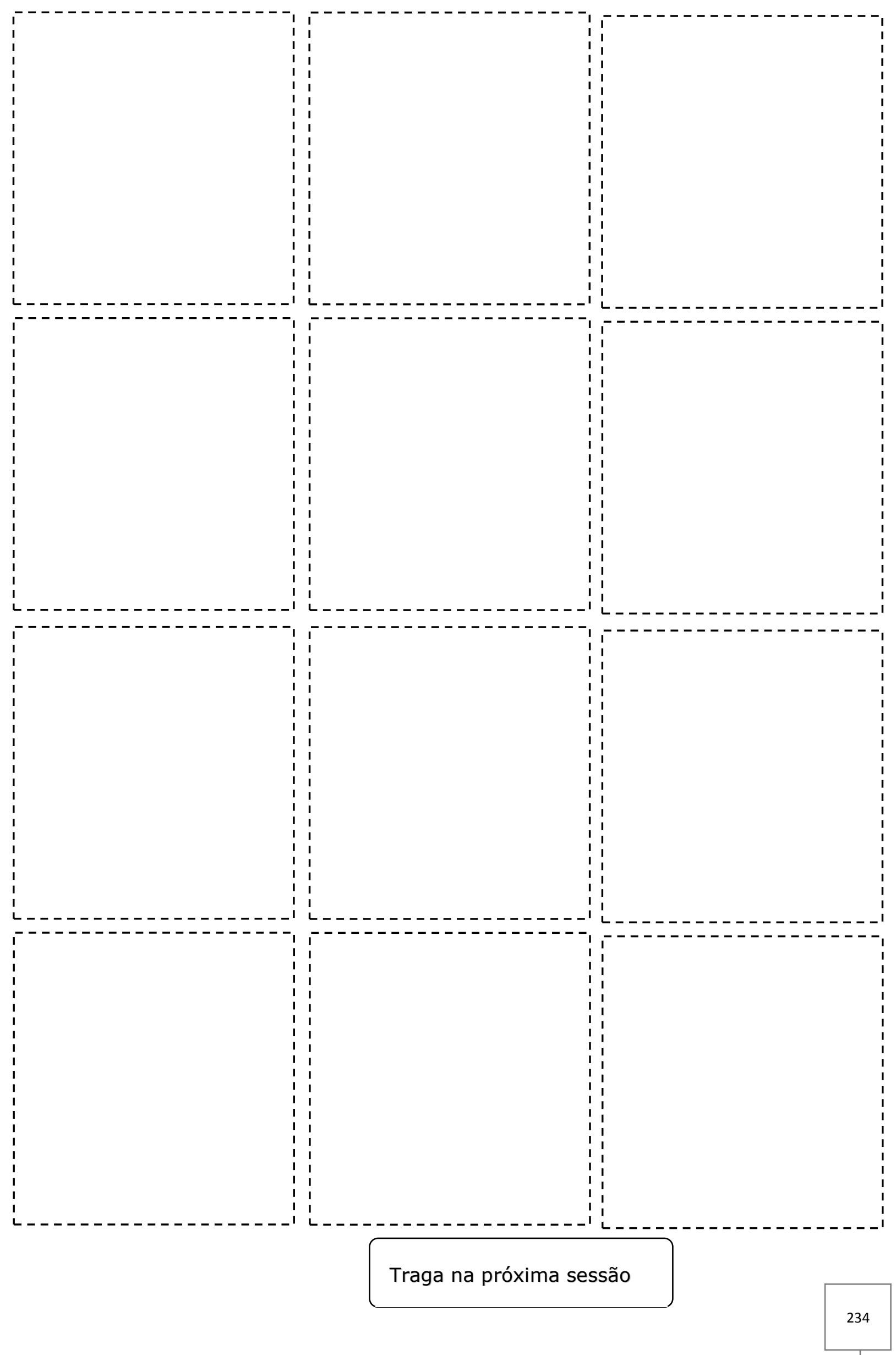


Liste situações de alta ansiedade (grau 4 e 5)

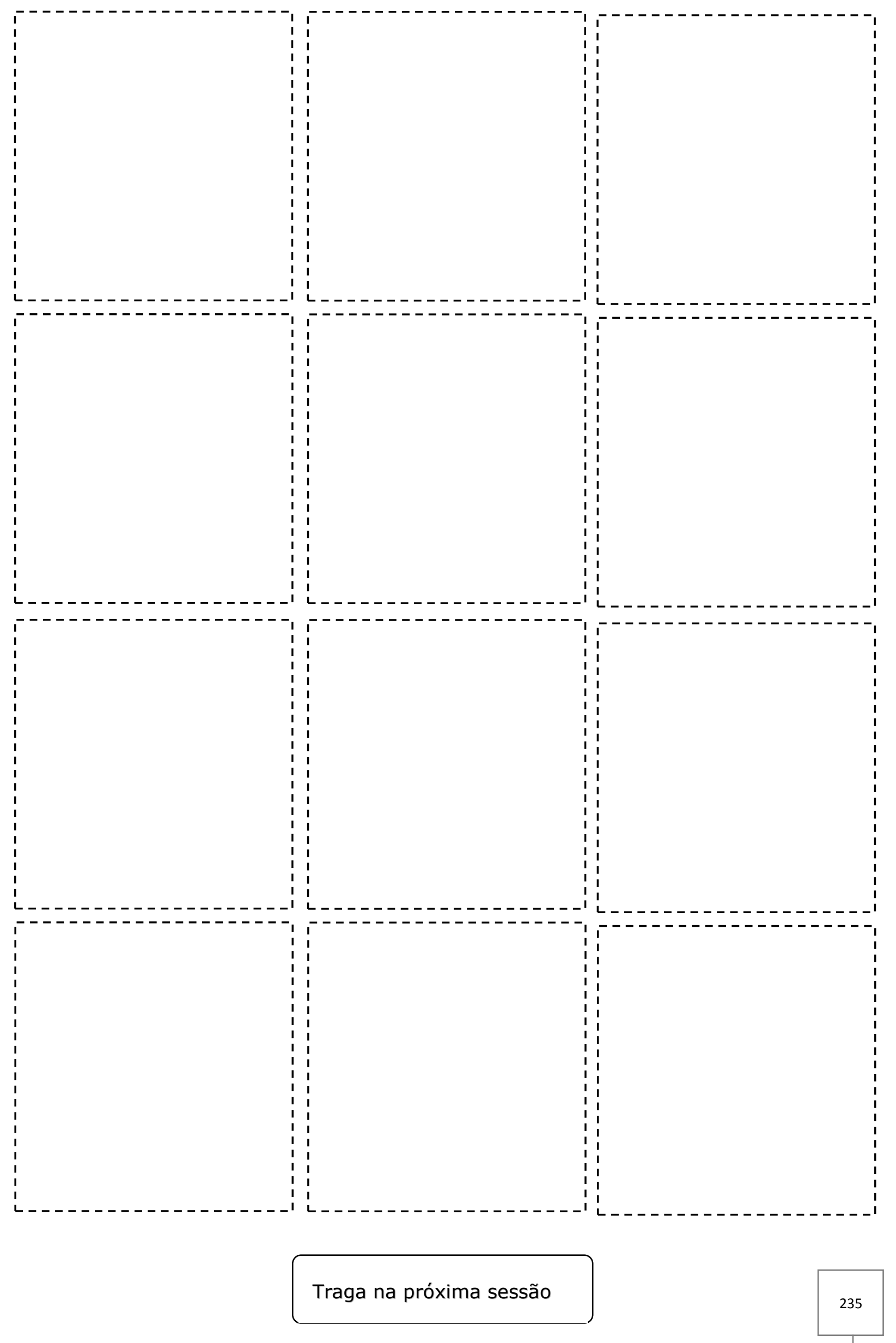




\section{Formulário de Feedback*}

*Adaptado de Friedberg e cols, 2004 por Fabiana Gauy

1) O quanto o grupo me ajudou hoje?

Muito

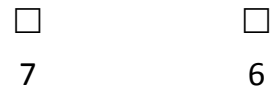

Um pouco

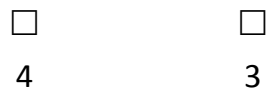

2) O quanto me diverti hoje?

Muito

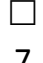

6

Um pouco

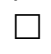

4
3

2
Nada

1

$\begin{array}{cc} & \text { Nada } \\ \square & \square \\ 2 & 1\end{array}$

Nada

$\square$

1

$\begin{array}{cc} & \text { Nada } \\ \square & \square \\ 2 & 1\end{array}$

3) Hoje, Eu aprendi:

4) O quanto eu posso usar o que aprendi Na escola

Muito

$\square$

7

Em casa

Muito

$\square$

7

Com meus amigos

Muito

$\square$

7
6

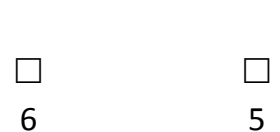

5

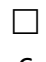

6

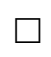

5

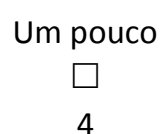

Um pouco

$\square$

Um pouco

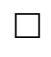

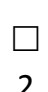

2

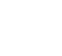


$\because$ Gafo
Corajoso

๔eรSล̃o \#6

Vamos treinar os quatro passos para enfrentar os seus medos:

Mostrando-se ansioso ou preocupado?

Esperando que o pior aconteça?

Demonstrando atitudes e ações

Oba!! Resultados e Recompensas 


\section{Eeu Consigo: હesรão \#6}

Pratique uma situação usando "os passos"

* Situação \# 1

PASSO \# 1 "Mostrando Sentimentos"

Reações do meu corpo/sentimento

PASSO \#2 “Esperando coisas ruins acontecerem"

Pensamento ansiosos

Lidando com os pensamentos

PASSO \#3 "Demonstrando ações e atitudes"

Ações e Atitudes que podem ajudar

PASSO \# 3 Demonstrando atitudes e ações

PASSO \#4"Oba! Resultados e Recompensas”

Resultados e Recompensas

*Situação \# 2

PASSO \# 1 "Mostrando Sentimentos"

Reações do meu corpo/sentimento

PASSO \#2 "Esperando coisas ruins acontecerem"

Pensamento ansiosos

Lidando com os pensamentos

PASSO \#3 "Demonstrando ações e atitudes"

Ações e Atitudes que podem ajudar

PASSO \# 3 Demonstrando atitudes e ações

PASSO \#4"Oba! Resultados e Recompensas"

Resultados e Recompensas 


\section{Registro do Relaxamento}

\begin{tabular}{|l|l|l|}
\hline Data & $\begin{array}{c}\text { O quanto você ficou } \\
\text { relaxada (0-5)? }\end{array}$ & Observação \\
\hline & & \\
\hline & & \\
\hline & & \\
\hline & & \\
\hline & & \\
\hline & & \\
\hline & & \\
\hline
\end{tabular}




\section{Formulário de Feedback*}

*Adaptado de Friedberg e cols, 2004 por Fabiana Gauy

1) O quanto o grupo me ajudou hoje?

Muito

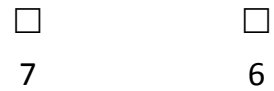

Um pouco

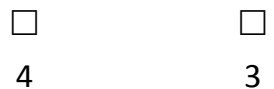

3

2) O quanto me diverti hoje?

Muito

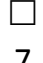

6

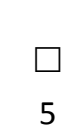

5
Um pouco

$\square$

4

3
Nada

1

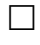

2

\begin{tabular}{cc}
\multicolumn{1}{c}{} & Nada \\
$\square$ & $\square$ \\
2 & 1
\end{tabular}

Nada

$\square$

1

2

3) Hoje, Eu aprendi:

4) O quanto eu posso usar o que aprendi Na escola

Muito

$\square$

7

5

Em casa

Muito

$\square$
7

Com meus amigos

Muito

$\square$

7
6

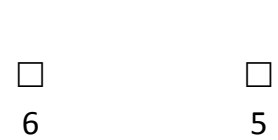

5

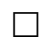

5

$\begin{array}{cc} & \text { Um pouco } \\ \square & \square \\ 5 & 4\end{array}$

Um pouco

$\square$

Um pouco

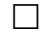

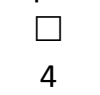

Nada

$\square$

1

Nada

$\square$

Nada

$\square$

1

5) Caso você tenha alguma reclamações, sugestões ou comentários escreva aqui: 
SอรSล̃o \#8

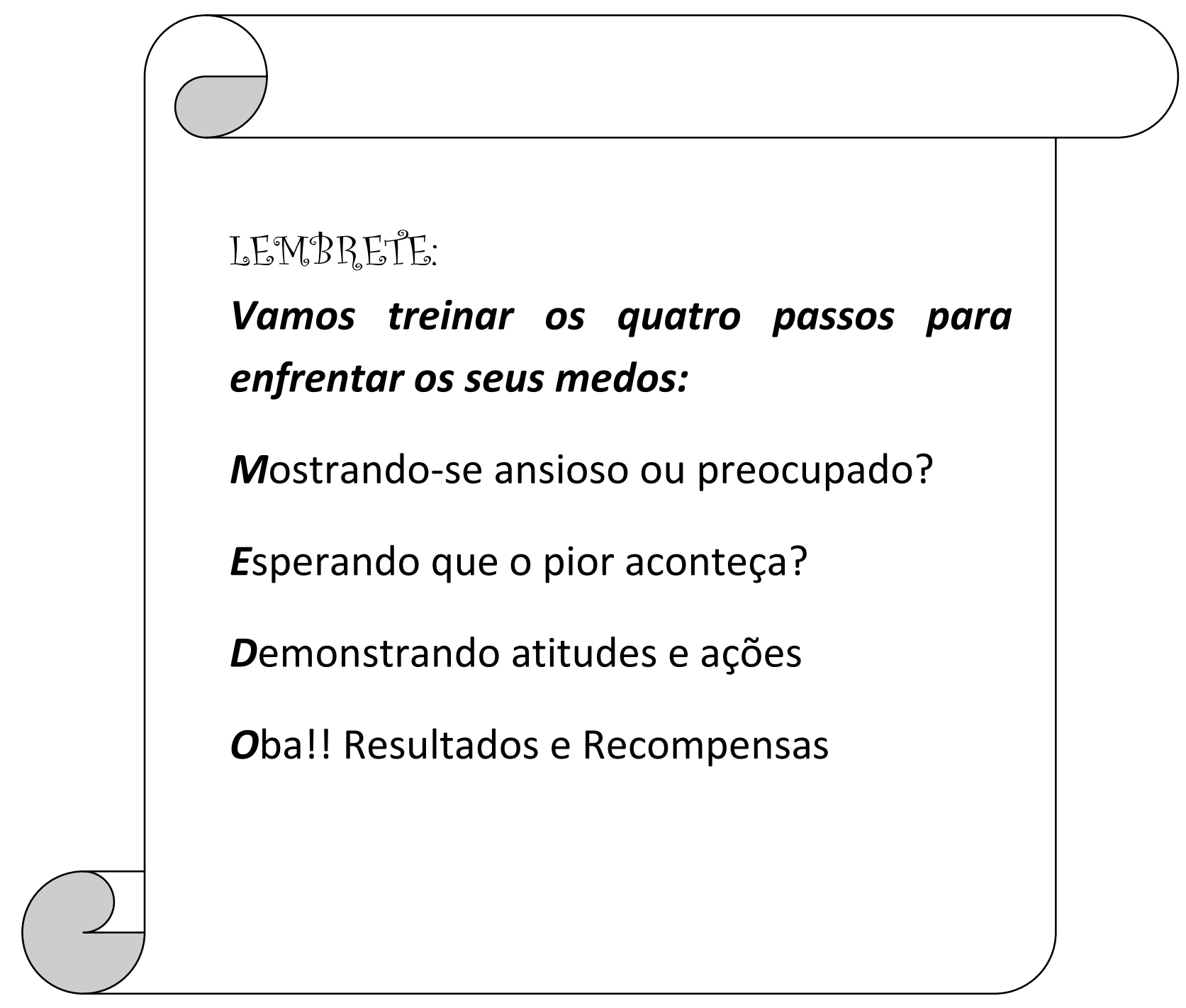




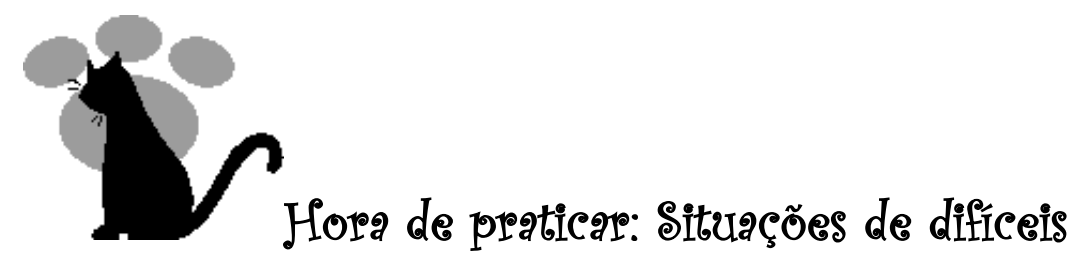

Situação:

Descreva como você está se sentindo e o que você está pensando:

Avalie o quanto você está ansioso neste momento:

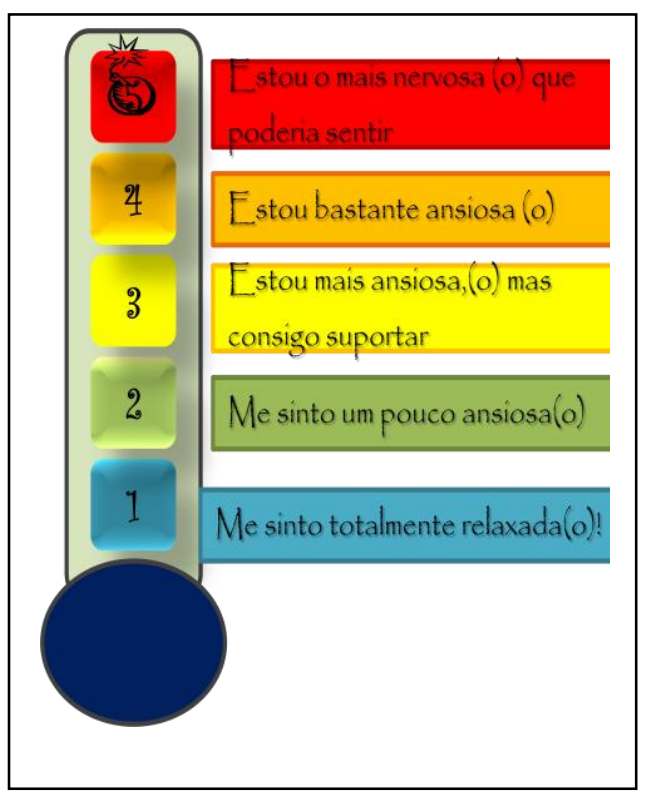

Avalie aqui:

Agora imagine que alguém nesta situação poderia se dar muito mal. Qual é a pior coisa que poderia acontecer? Descreva abaixo: 
Que sugestões você daria para esta pessoa que poderiam ajudá-la nesta situação:

Agora descreva o que você aprendeu que te ajudar a enfrentar as suas dificuldades

Avalie o quanto você ficaria ansioso se tivesse que enfrentar esta situação:

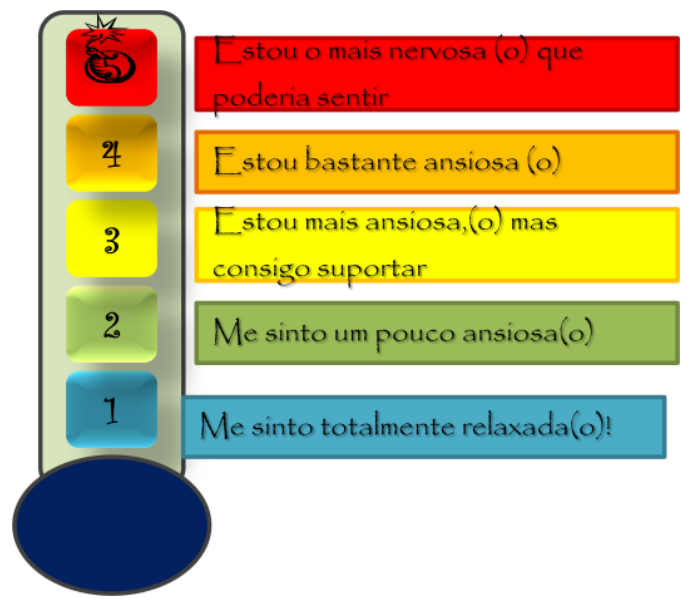

Avalie aqui:

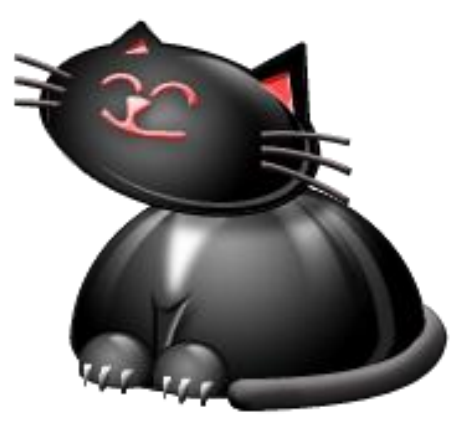




\section{Eथ Consigo: હessão \#8}

Situação \# 1

PASSO \# 1 "Mostrando Sentimentos"

Reações do meu corpo/sentimento

PASSO \#2 "Esperando coisas ruins acontecerem"

Pensamento ansiosos

Lidando com os pensamentos

PASSO \#3 "Demonstrando ações e atitudes"

Ações e Atitudes que podem ajudar

PASSO \# 3 Demonstrando atitudes e ações

PASSO \#4"Oba! Resultados e Recompensas"

Resultados e Recompensas

*Situação \# 2

PASSO \# 1 "Mostrando Sentimentos"

Reações do meu corpo/sentimento

PASSO \#2 "Esperando coisas ruins acontecerem"

Pensamento ansiosos

Lidando com os pensamentos

PASSO \#3 "Demonstrando ações e atitudes"

Ações e Atitudes que podem ajudar

PASSO \# 3 Demonstrando atitudes e ações

PASSO \#4 “Oba! Resultados e Recompensas"

Resultados e Recompensas 
Registro do Relaxamento

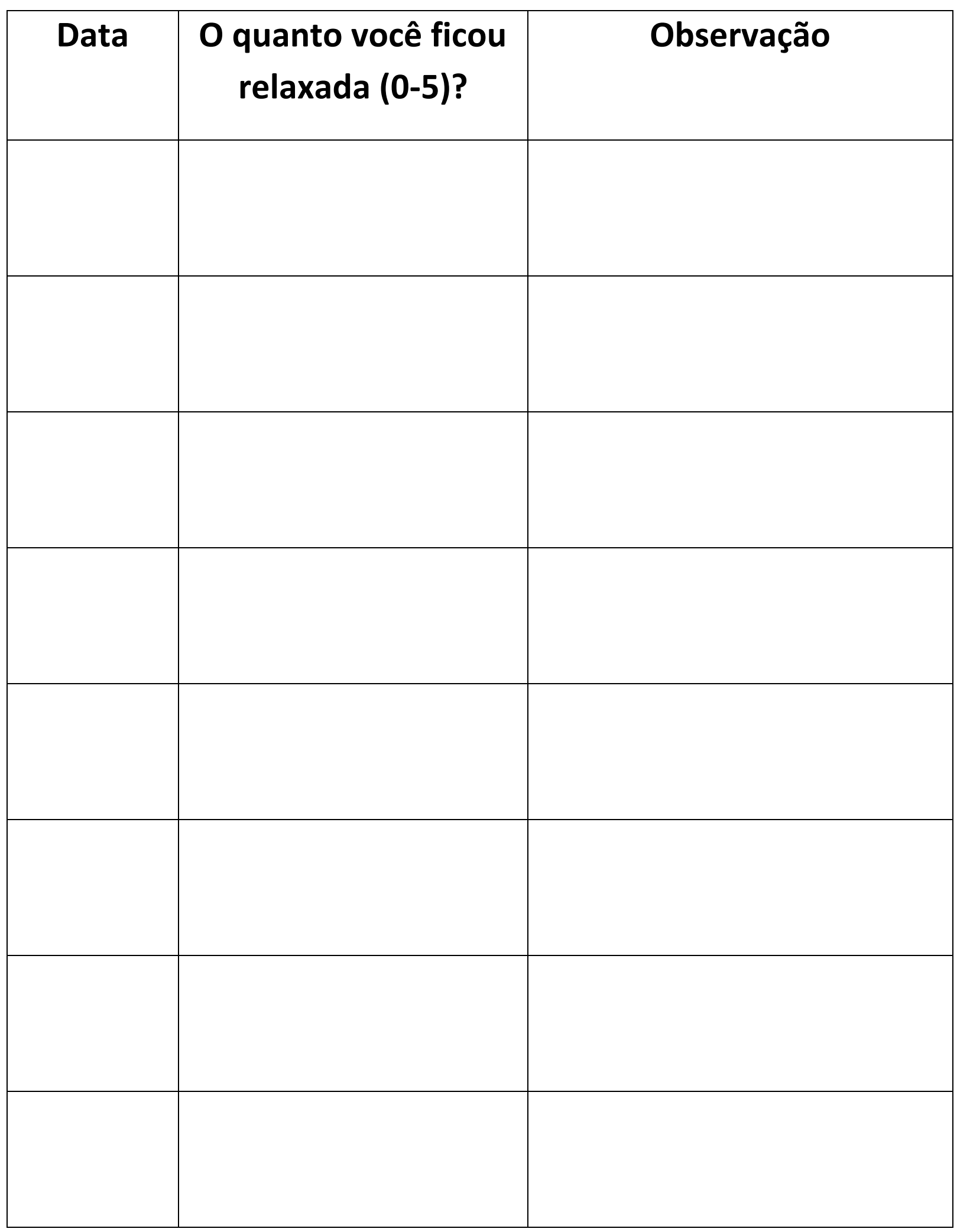




\section{Formulário de Feedback*}

*Adaptado de Friedberg e cols, 2004 por Fabiana Gauy

1) O quanto o grupo me ajudou hoje?

Muito

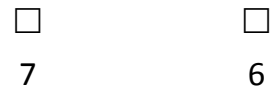

Um pouco

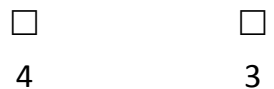

2) O quanto me diverti hoje?

Muito

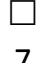

6

Um pouco

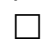

4
3

2
Nada

1

$\begin{array}{cc} & \text { Nada } \\ \square & \square \\ 2 & 1\end{array}$

Nada

$\square$

1

$\begin{array}{cc} & \text { Nada } \\ \square & \square \\ 2 & 1\end{array}$

3) Hoje, Eu aprendi:

4) O quanto eu posso usar o que aprendi Na escola

Muito

$\square$

7

Em casa

Muito

$\square$

7

Com meus amigos

Muito

$\square$

7
6

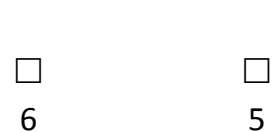

5

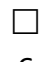

6

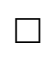

5

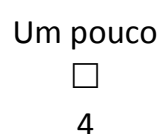

Um pouco

$\square$

Um pouco

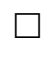

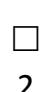

2

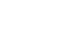


〔อรSล̃o \#ด

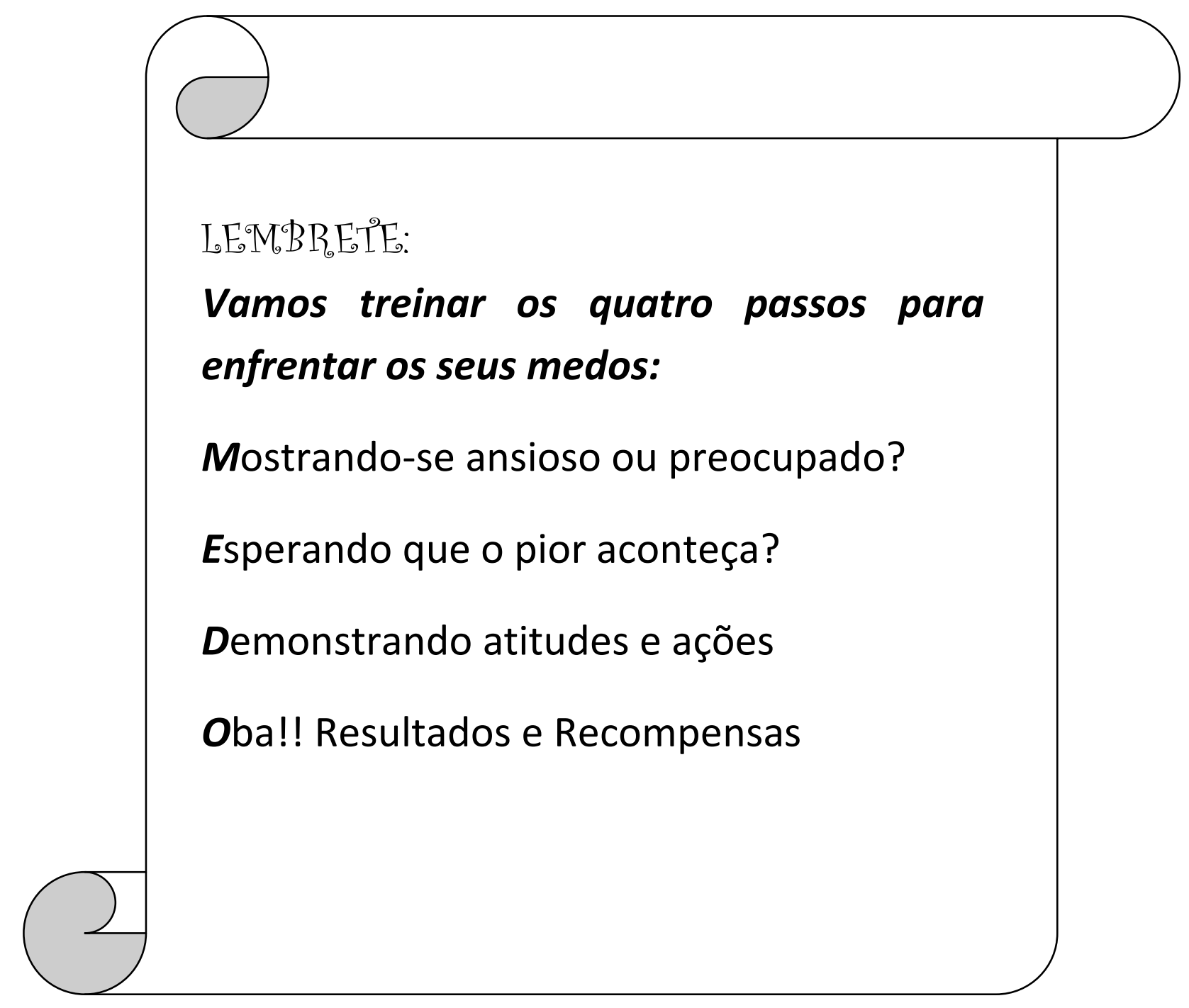




\section{Eथ Consigo: હessão \#9}

Pratique uma situação usando "os passos"

*Situação \# 1

PASSO \# 1 "Mostrando Sentimentos"

Reações do meu corpo/sentimento

PASSO \#2 "Esperando coisas ruins acontecerem"

Pensamento ansiosos

Lidando com os pensamentos

PASSO \#3 “Demonstrando ações e atitudes"

Ações e Atitudes que podem ajudar

PASSO \# 3 Demonstrando atitudes e ações

PASSO \#4"Oba! Resultados e Recompensas"

Resultados e Recompensas

*Situação \# 2

PASSO \# 1 "Mostrando Sentimentos"

Reações do meu corpo/sentimento

PASSO \#2 "Esperando coisas ruins acontecerem"

Pensamento ansiosos

Lidando com os pensamentos

PASSO \#3 "Demonstrando ações e atitudes"

Ações e Atitudes que podem ajudar

PASSO \# 3 Demonstrando atitudes e ações

PASSO \#4"Oba! Resultados e Recompensas"

Resultados e Recompensas 


\section{Registro do Relaxamento}

\begin{tabular}{|l|l|l|}
\hline Data & $\begin{array}{c}\text { O quanto você ficou } \\
\text { relaxada (0-5)? }\end{array}$ & Observação \\
\hline & & \\
\hline & & \\
\hline & & \\
\hline & & \\
\hline & & \\
\hline & & \\
\hline & & \\
\hline & & \\
\hline
\end{tabular}




\title{
Anexo 22. Aprovação do Comitê de Ética de SP
}

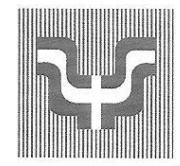

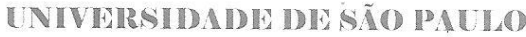 \\ INGTITUTO DI: PSICOILOCHL

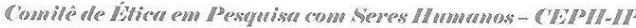

Of.035/08-CEPH-IP-20/06/2008

Senhora Professora,

O Comitê de Ética em Pesquisa com Seres Humanos do IPUSP (CEPH-IP), aprovou o projeto intitulado "Treino de Terapeutas-Estagiários no Atendimento de Crianças Ansiosas" a ser desenvolvido pela doutoranda Fabiana Vieira Gauy sob a orientação de V.Sa, no Programa de Pós-Graduação em Psicologia Clínica do Instituto de Psicologia da Universidade de São Paulo.

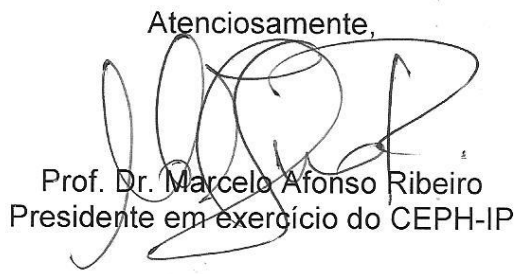

Ilma. Sra.

Profa. Titular Edwiges Ferreira de Mattos Silvares

Departamento de Psicologia Clínica

Instituto de Psicologia da Universidade de São Paulo 


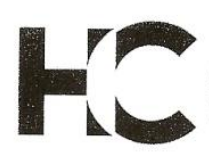

\section{APROVAÇĀO}

A Comissão de Ética para Análise de Projetos de Pesquisa CAPPesq da Diretoria Clínica do Hospital das Clínicas e da Faculdade de Medicina da Universidade de São Paulo, em sessão de 20/05/2009, APROVOU O Protocolo de Pesquisa no 0460/09, intitulado: 'TREINO DE TERAPEUTAS-ESTAGIÁRIOS NO ATENDIMENTO DE CRIANÇAS ANSIOSAS" apresentado pelo Departamento de PSIQUIATRIA.

Cabe ao pesquisador elaborar e apresentar à CAPPesq, os relatórios parciais e final sobre a pesquisa (Resolução do Conselho Nacional de Saúde n 196, de 10/10/1996, inciso IX.2, letra "c").

Pesquisador (a) Responsável: DR. FRANCISCO LOTUFO NETO

Pesquisador (a) Executante: FABIANA VIEIRA GAUY

Orientador (a): DRA. EDWIGES FERREIRA DE MATTOS SILVARES

CAPPesq, 20 de Maio de 2009

Recebido: 26105109 , as $10 \mathrm{~V}$ - $<$

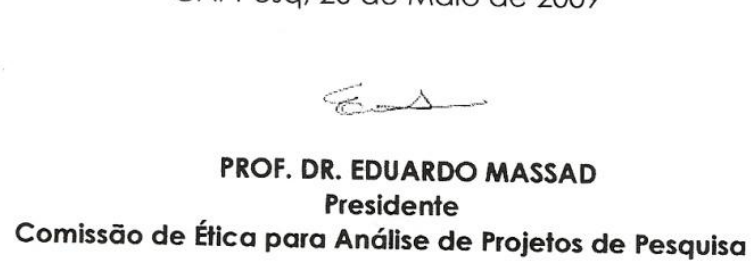

Departamento de Psanuatria da FMUSP

\footnotetext{
Comissão de Ética para Análise de Projetos de Pesquisa do HCFMUSP e da FMUSP Diretoria Clínica do Hospital das Clinicas da Faculdade de Medicina da Universidade de São Paulo Rua Ovidio Pires de Campos, 225, 5ªndar - CEP 05403010 - Săo Paulo - SP Fone: 01130696442 Fax: 01130696492 e-mail: cappesq@hcnet.usp.br / secretariacappesq2@hcnet.usp.br 


\section{Anexo 23. Aprovação do Comitê de Ética do DF}

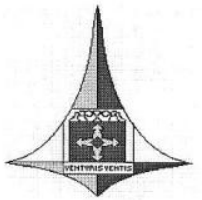

GOVERNO DO DISTRITO FEDERAL

SECRETARIA DE ESTADO DE SAÚDE

COMITÊ DE ÉTICA EM PESQUISA

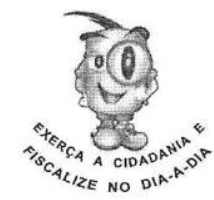

PARECER № $342 / 2010$

PROTOCOLO №DO PROJETO: $322 / 10$ - Treino de terapeutas-estágiários no atendimento de crianças ansiosas.

Área Temática Especial: Grupo III (não pertencente à área temática especial), Ciências da Saúde.

Validade do Parecer: 18/10/2012.

Tendo como base a Resolução 196/96 CNS/MS, que dispõe sobre as diretrizes e normas regulamentadoras em pesquisa envolvendo seres humanos, assim como as suas resoluções complementares, o Comitê de Ética em Pesquisa da Secretaria de Estado de Saúde do Distrito Federal, após apreciação ética, manifesta-se pela APROVAÇÃO DO PROJETO.

Esclarecemos que o pesquisador deverá observar as responsabilidades que Ihe são atribuídas na Resolução 196/96 CNS/MS, inciso IX.1 e IX.2, em relação ao desenvolvimento do projeto. Ressaltamos a necessidade de encaminhar o relatório parcial e final, além de notificações de eventos adversos quando pertinentes.

Brasília, 18 de outubro de 2010

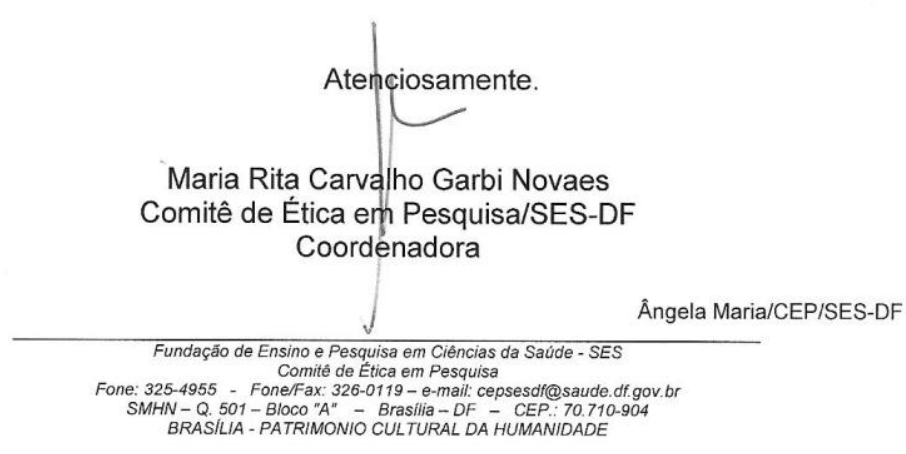

